\title{
Cationic Antimicrobial Peptides: Thermodynamic Characterization of Peptide-Lipid Interactions and Biological Efficacy of Surface-Tethered Peptides
}

Dissertation zur Erlangung des akademischen Grades des

Doktors der Naturwissenschaften (Dr. rer. nat.)

eingereicht im Fachbereich Biologie, Chemie, Pharmazie

der Freien Universität Berlin

vorgelegt von

Mojtaba Bagheri

aus Marvdasht (Iran)

Juni 2010 
Hereby, I declare that I have prepared this work independently under supervision of Dr. Margitta Dathe in the time period from October 2006 until April 2010 at Leibniz-Institut für Molekulare Pharmakologie (FMP) in Berlin. To best of my knowledge, this thesis contains no previously published materials by another person.

1. Gutachterin: $\quad$ Prof. Beate Koksch, Freie Universität Berlin

2. Gutachter: $\quad$ Prof. Michael Bienert, Leibniz-Institut für Molekulare Pharmakologie

Disputation am 09 September 2010 
To my parents 


\section{Acknowledgments}

I would like to show my appreciation to Prof. Dr. Michael Bienert (FMP), the head of Department of Chemical Biology of FMP, and my PhD supervisors Dr. Margitta Dathe (FMP) and Prof. Dr. Beate Koksch (Freie Universität Berlin) for giving me the opportunity to work in the interesting field of antimicrobial peptides and their support during my doctoral thesis research.

I would especially like to thank Dr. Michael Beyermann (FMP), and Prof. Dr. Sandro Keller (University of Kaiserslautern) for their informative discussions and suggestions.

Furthermore, Mrs. Annerose Klose, Mrs. Angelika Ehrlich, Mrs. Dagmar Krause, and Mr. Bernhard Schmikale are thanked for their assistance in the field of peptide synthesis, HPLC and mass measurements. I would also like to acknowledge Mr. Rudolf Dölling (Biosyntan $\mathrm{GmbH})$ for the synthesis of c- $(1 \mathrm{MeW}) \mathrm{F}(1 \mathrm{MeW})$, c- $(5 \mathrm{MeoW}) \mathrm{F}(5 \mathrm{MeoW})$, and c$(5 \mathrm{fW}) \mathrm{F}(5 \mathrm{fW})$.

I would also like to thank Mrs. Heike Nikolenko and Christof Junkes for their support in maintaining cell cultures. I am very grateful for the generous technical support of Nadin Jahnke, Gerdi Kemmer, and Katharina Grimm (all FMP) with ITC and CD expriments.

Special thanks to Ewan St. John Smith (Max Delbrück Center for Molecular Medicine) and Gesa Schäfer (FMP) for the time they spent on correcting my thesis as well as for their fruitful suggestions.

Finally, I would like to thank my parents for their understanding and patience and their spiritual support in my life. 


\section{Content}

ABBREVIATIONS AND SYMBOLS ................................................................................

Abbreviations

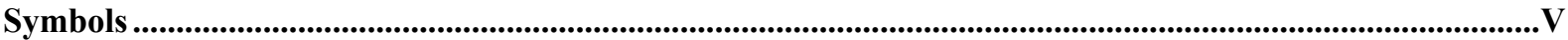

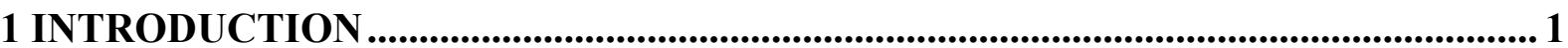

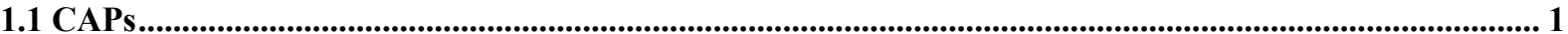

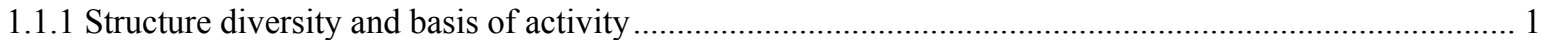

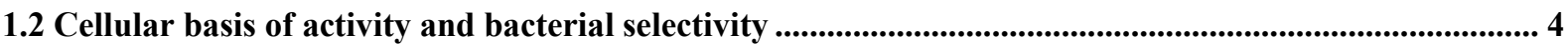

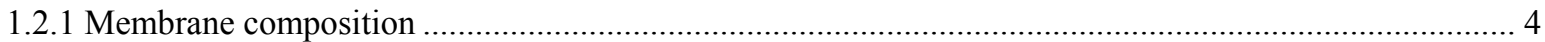

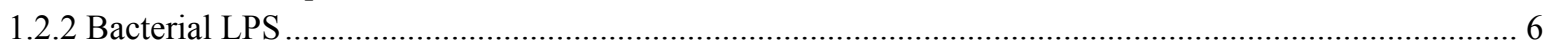

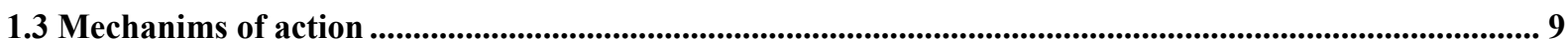

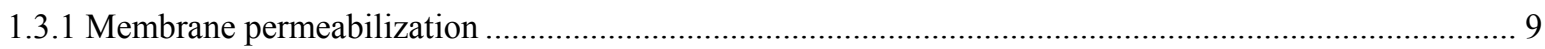

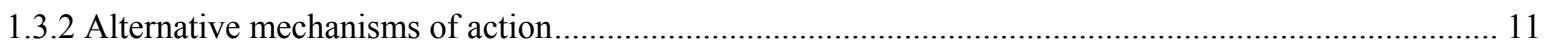

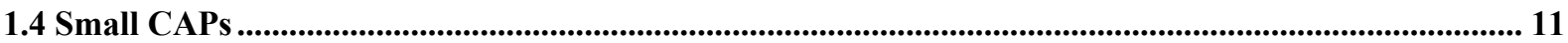

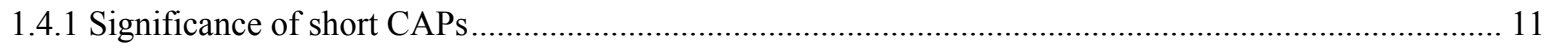

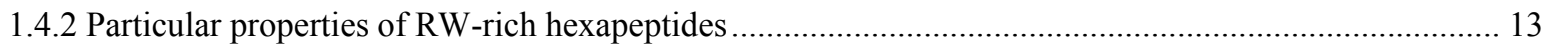

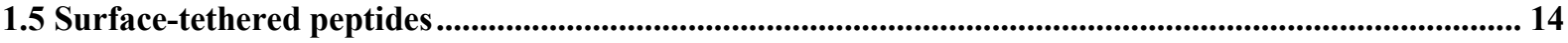

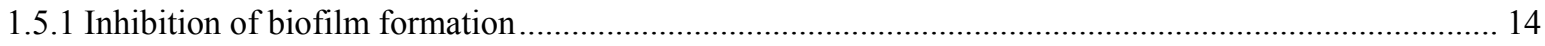

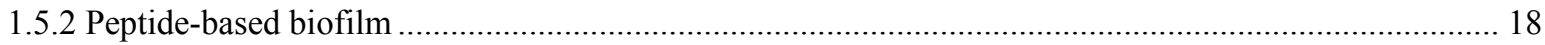

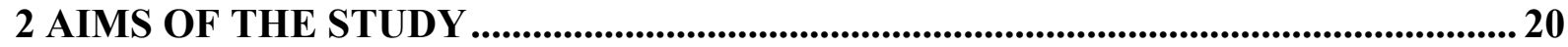

2.1 Structural basis of anti-E. coli activity of cyclic RW-rich hexapeptides ..................................................... 20

2.2 Preparation and perspectives of surface-tethered peptides.............................................................................. 21

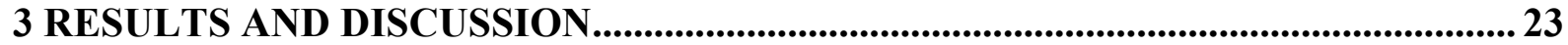

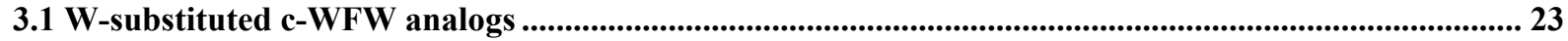

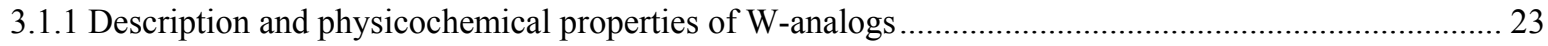

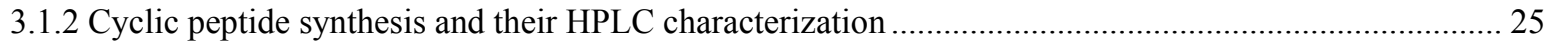

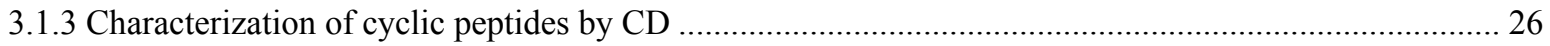

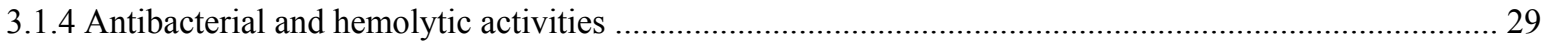

3.1.5 Cyclic peptide binding to lipid bilayers determined by ITC ..................................................... 31

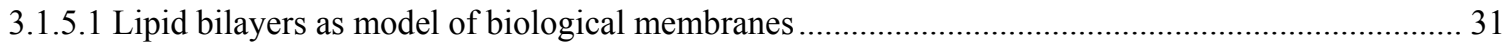

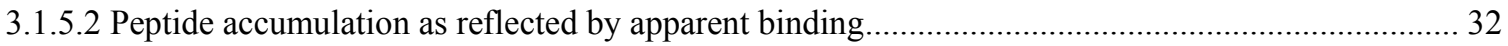

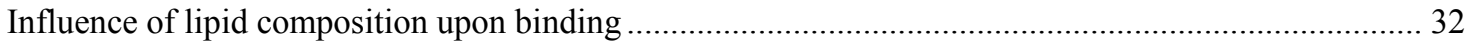

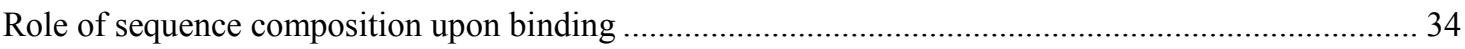

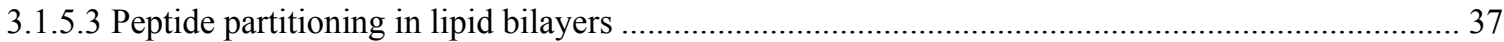

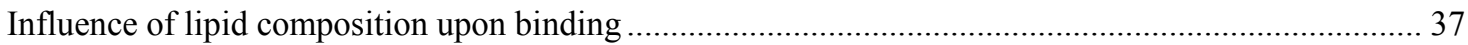

Role of sequence composition upon binding ................................................................................... 38

3.1.5.4 Effect of ionic strength upon c-WFW binding to r-LPS and s-LPS lipid systems ....................... 42 
3.1.5.5 Heat capacity change on membrane partitioning of c-WFW ................................................ 44

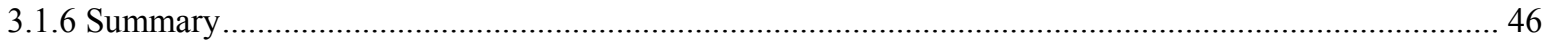

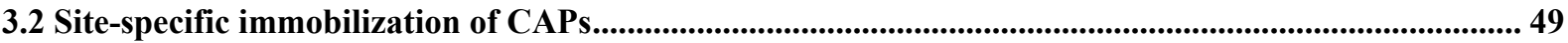

3.2.1 Physical and chemical properties of PEGylated resins as model solid surfaces ..................................50

3.2.2. Activity of surface tethered membrane-active CAPs - role of tethered peptide site ............................. 51

3.2.2.1 Characterization of KLAL and MK5E peptides by HPLC and CD.......................................... 51

3.2.2.2 Preparation and characterization of tethered KLAL and MK5E peptides .................................. 53

3.2.2.3 Biological activities of free and tethered KLAL and MK5E peptides.......................................... 55

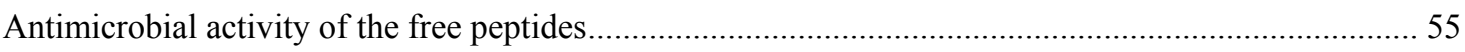

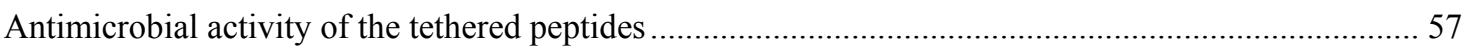

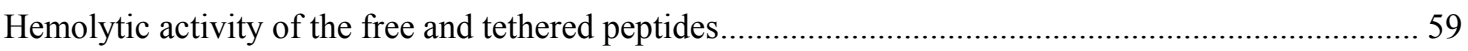

3.2.2.4 Bilayer permeabilizing activities of free and tethered KLAL and MK5E peptides........................ 59

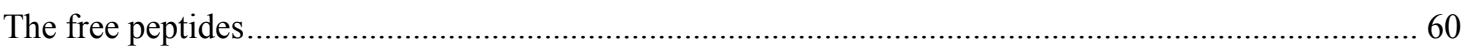

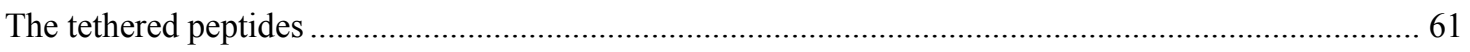

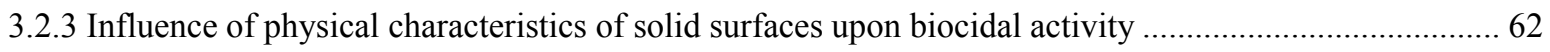

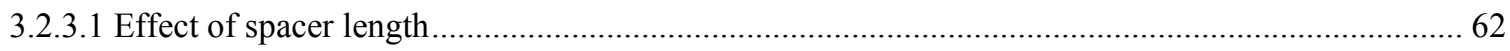

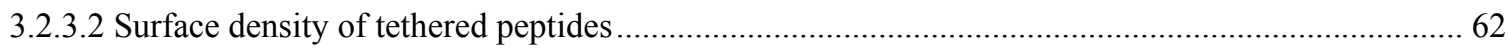

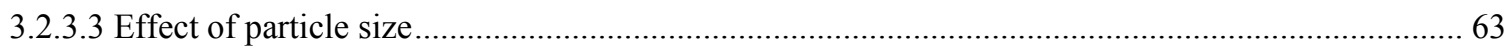

3.2.4 Peptide-tethering as a strategy to investigate the mode of action of CAPs.......................................6 65

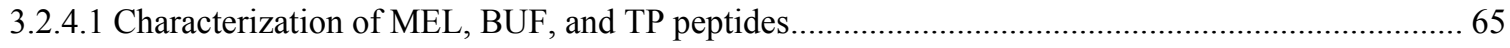

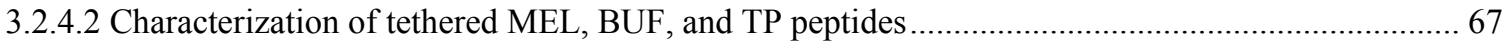

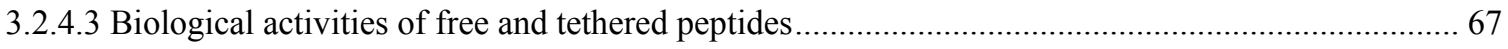

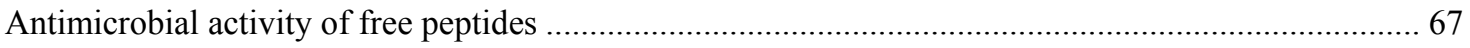

Inner and outer membrane-permeabilizing activities of MEL, BUF, and TP peptides ........................ 69

Antimicrobial activity of tethered peptides............................................................................ 70

3.2.4.4 Bilayer permeabilizing activities of free and tethered MEL, BUF, and TP peptides .................... 71

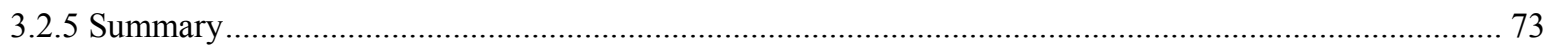

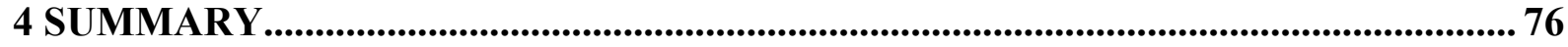

4.1 W-substituted c-WFW analogs .......................................................................................................................... 76

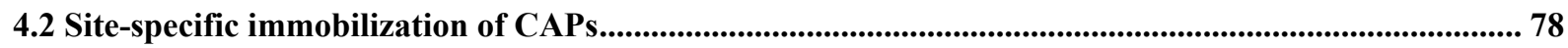

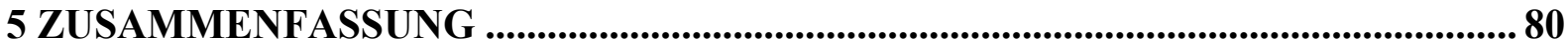

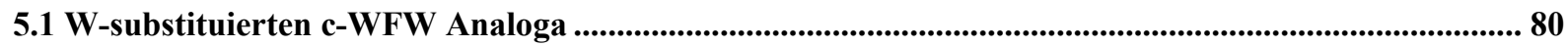

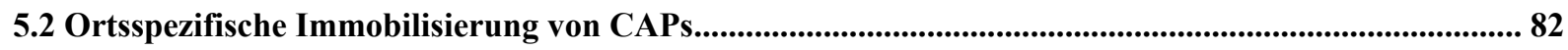

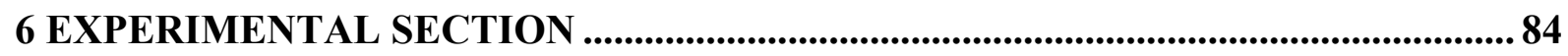

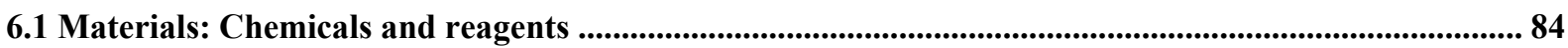

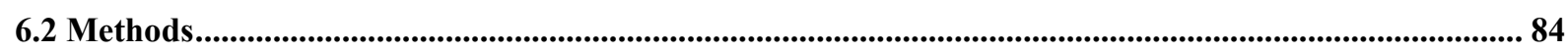

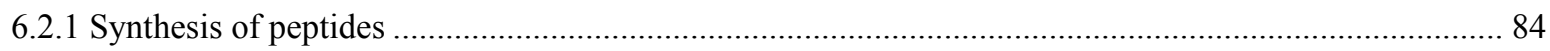

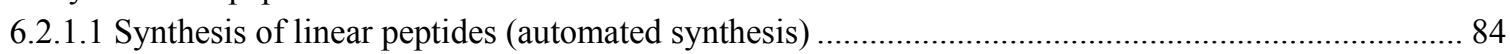

6.2.1.2 Synthesis of cyclic peptides (manuel synthesis) ..................................................................... 85

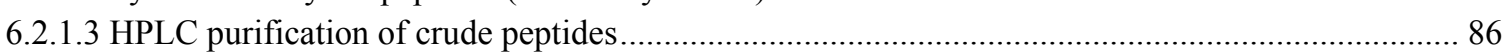

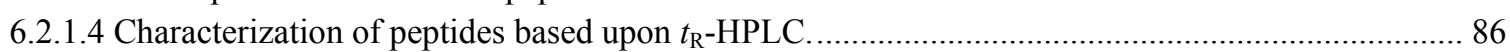

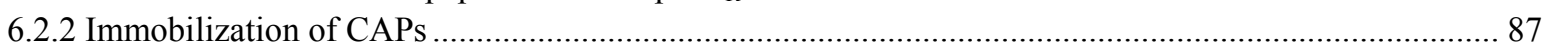




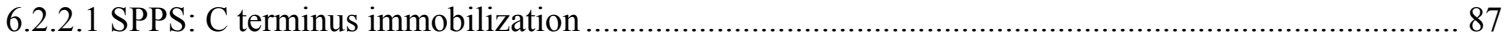

6.2.2.2 Thioalkylation: $\mathrm{N}$ terminus and side chain immobilization of KLAL ....................................... 87

6.2.2.3 Oxime-forming ligation: $\mathrm{N}$ terminus and side chain immobilization of MK5E, MEL, BUF, and TP

6.2.2.4 Characterization of tethered peptides using UV-absorption of the Fmoc-chromophore

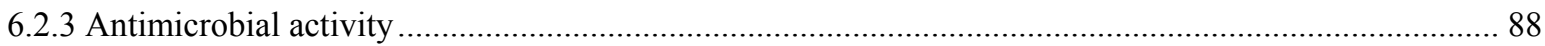

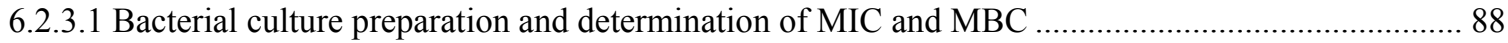

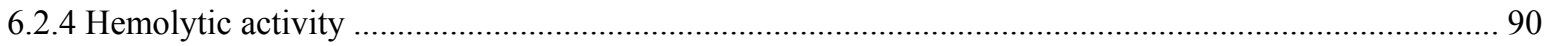

6.2.5 Inner and outer membrane permeabilizing activities of MEL, BUF and TP and their AOA-modified

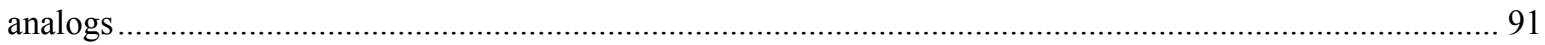

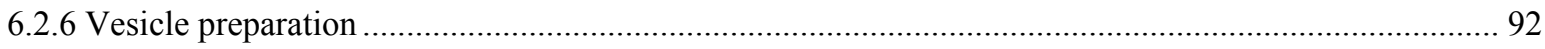

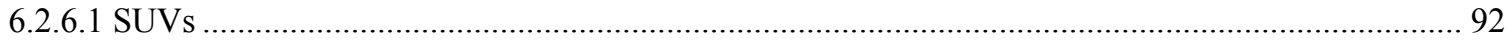

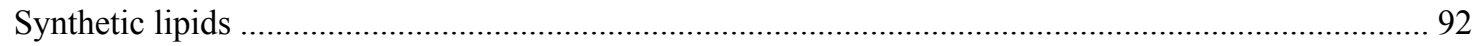

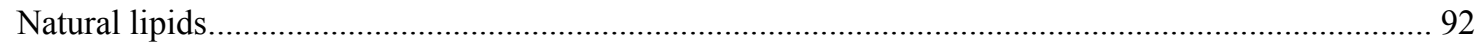

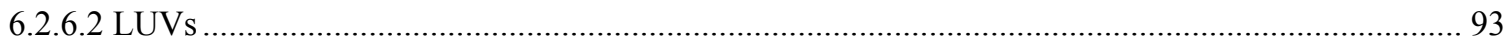

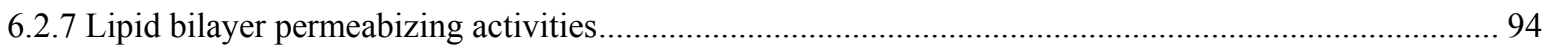

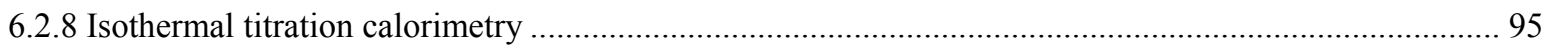

6.2.8.1 Theory and description of surface partitioning equilibrium model ............................................ 96

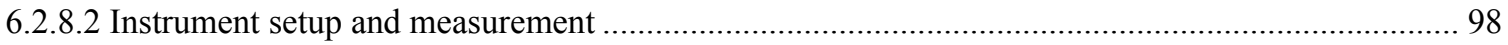

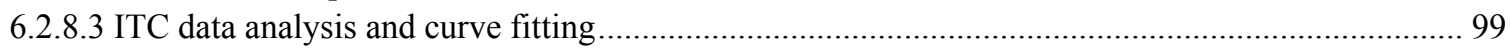

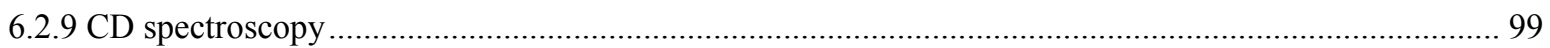

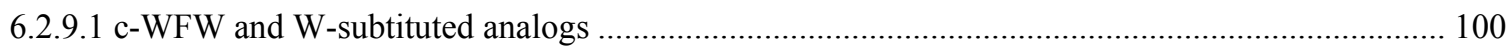

6.2.9.2 Model KLAL peptide, MK5E, and the PEGylated analogs...................................................... 100

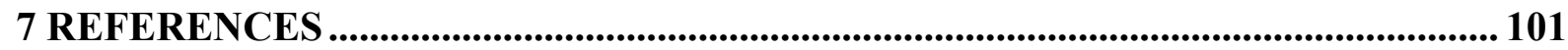

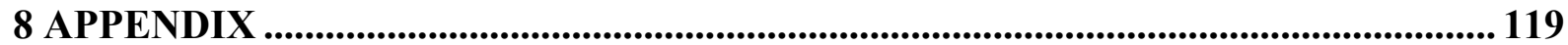

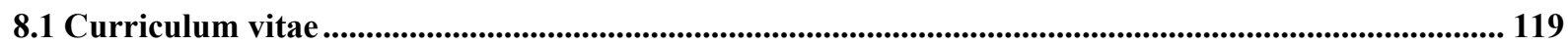

8.2 Publications and scientific conference contributions .................................................................................... 119

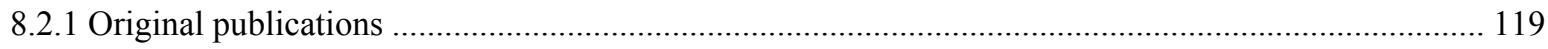

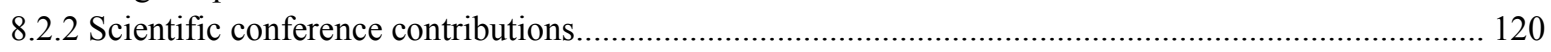




\section{Abbreviations and Symbols}

\section{Abbreviations}

\begin{tabular}{|c|c|}
\hline $1 \mathrm{MeW}$ & 1-Methyl-L-tryptophan \\
\hline 1-PrOH & 1-Propanol \\
\hline $5 \mathrm{fW}$ & 5-Fluoro-L-tryptophan \\
\hline $5 \mathrm{MeoW}$ & 5-Methoxy-L-tryptophan \\
\hline $5 \mathrm{MeW}$ & 5-Methyl-DL-tryptophan \\
\hline $\mathrm{ACN}$ & Acetonitrile \\
\hline $\mathrm{Ac}_{2} \mathrm{O}$ & Acetic anhydride \\
\hline Ac-RW & Ac-RRWWRF-NH ${ }_{2}$ \\
\hline $\mathrm{AOA}$ & Aminooxy acetic acid \\
\hline Arg, R & Arginine \\
\hline Asn, $\mathrm{N}$ & Asparagine \\
\hline Asp, $\mathrm{P}$ & Aspartic acid \\
\hline b3-hW & L- $\beta$-Homotryptophan \\
\hline Bal & $\beta$-(Benzothien-3-yl)-L-alanine \\
\hline Boc & tert-Butyloxycarbonyl \\
\hline $\mathrm{BrAcOH}$ & Bromoacetic acid \\
\hline BSA & Bovine serum albumin \\
\hline BUF & Buforin 2 \\
\hline CAP & Cationic antimicrobial peptide \\
\hline CL & Cardiolipin \\
\hline $\mathrm{CD}$ & Circular dichroism \\
\hline ClTrt-Cl & (2'-Chloro)-chlorotrityl polystyrene \\
\hline $\mathrm{c}-\mathrm{RW}$ & cyclo-RRWWRF \\
\hline c-WFW & cyclo-RRRWFW \\
\hline Cys, C & Cysteine \\
\hline DCM & Dichloromethane \\
\hline Dde & 4,4-Dimethyl-2,6-dioxocyclohex-1-ylidene ethyl \\
\hline Dht & $(\gamma \mathrm{S} / \gamma \mathrm{R})$-Dihydrotryptophan \\
\hline DLS & Dynamic light scattering \\
\hline
\end{tabular}


DIC

DIEA

DMF

DPPC

DPPE

DPPG

DVB

$\mathrm{EC}_{25}$

$\mathrm{EC}_{50}$

EDC

EDT

Fmoc

Fmoc-Cl

Gal

GalNAc

Glc

GlcN

GlcNAc

Gln, Q

Glu, E

Gly, G

$\mathrm{GnHCl}$

HAPyU

HBTU

Hep

His, $\mathrm{H}$

HMPA

$\mathrm{HOBt}$

HOEGMA

Igl

ITC
$N^{\prime}, N^{\prime}$-Diisopropylcarbodiimide

$N^{\prime}, N^{\prime}$-diisopropylethylamine

Dimethylformamide

1,2-Dipalmitoyl-sn-glycero-3-phospho-choline

1,2-Dipalmitoyl-sn-glycero-3-phosphoethanolamine

1,2-Dipalmitoyl-sn-glycero-3-[phospho-rac-(1-glycerol)]

Divinylbenzene

Quarter maximal effective concentration

Half maximal effective concentration

1-Ethyl-3-(3-dimethylaminopropyl)carbodiimide

1,2-Ethandithiol

9-Fluorenylmethoxycarbonyl

Chloroformic acid 9-fluorenylmethyl ester

Galactose

N-Acetyl-galactosamine

Glucose

Glucosamine

N-Acetyl-glucosamine

Glutamine

Glutamic acid

Glycine

Guanidinium hydrochlorid

1-(1-Pyrrolidinyl-1 $H$-1,2,3-triazolo [4,5-b] pyridine-1-ylmethylene) pyrrolidinium hexafluorophosphate $N$-oxide

2-(1H-benzotriazole-1-yl)-1,1,3,3-tetramethylaminium hexafluorophosphate

L-Glycerol-D-manno-heptose

Histidine

4-(Hydroxymethyl)phenoxyacetic acid

Hydroxybenzotriazole

Hydroxyl-terminated oligo(ethyleneglycol) methacrylate

$(\alpha S)-(2-I n d a n y l) g l y c i n e$

Isothermal titration calorimetry 
Kdo

LA

LB

LC/ESI-TOF MS

LPS

LUV

Lys, K

MALDI-MS

MBC

MBHA

$\mathrm{MEO}_{2} \mathrm{MA}$

MEL

MG 1

MG 2

MIC

Nal

$\mathrm{NCF}$

NHS

NMI

NMR

O.D.

ONPG

PAA

Pbf

PEG 2

PEG

Phe, F

PMPI

POPC

POPE

POPG
3-deoxy-D-manno-oct-2-ulosonic acid

Lipid A

Luria broth

liquid chromatography/electrospray ionization time-of-flight mass spectrometry

Lipopolysaccharide

Large unilamellar vesicles

Lysine

Matrix-assisted laser desorption/ionization mass spectrometry

Minimal bacteriocidal concentration

4-Methylbenzhydrylamine hydrochloride

Poly(2-(2-methoxyethoxy)ethyl methacrylate

Melittin

Magainin 1

Magainin 2

Minimal inhibitory concentration

$\beta$-(2-naphthyl)alanine

Nitrocefin

$N$-hydroxysuccinimide

$N$-Methylimidazole

Nuclear magnetic resonance

Optical density

$o$-nitrophenyl- $\beta$-D-galactopyranoside

Polyacrylic acid

2,2,4,6,7-pentamethyldihydrobenzofuran-5-sulfonyl

8-amino-3,6-dioxaoctanoic acid

Polyethylene glycol

Phenylalanine

$N$-(p-maleimidophenyl)isocyanate

1-Palmitoyl-2-oleoyl-sn-glycero-3-phospho-choline

1-palmitoyl-2-oleoyl-sn-glycero-3-phosphoethanolamine

1-Palmitoyl-2-oleoyl-2-oleoyl-sn-glycero-3-[phospho-rac-(1-glycerol)] 


\begin{tabular}{|c|c|}
\hline POPI & 1-palmitoyl-2-oleoyl-sn-glycero-3-phosphoinositol \\
\hline POPS & 1-Palmitoyl-2-oleoyl-sn-glycerol-3-phosphatidylserine \\
\hline Pro, $\mathrm{P}$ & Proline \\
\hline PVP & Polyvinylpyrrolidone \\
\hline $\mathrm{RBC}$ & Red blood cell \\
\hline r-LPS & Rd-lipopolysaccharide \\
\hline RP-HPLC & Reversed-phase high performance liquid chromatography \\
\hline RW & RRWWRF \\
\hline SAR & Structure-activity relationship \\
\hline SDS & Sodium lauryl sulfate \\
\hline Ser, $\mathrm{S}$ & Serine \\
\hline s-LPS & Smooth-lipopolysaccharide \\
\hline SM & Sphingomyelin \\
\hline SPPS & Solid-phase peptide synthesis \\
\hline SUV & Small unilamellar vesicles \\
\hline TBP & Tributyl phosphine \\
\hline$t$-Bu & tert-butyl \\
\hline TFA & Trifluoroacetic acid \\
\hline TFE & 2,2,2-trifluoroethanol \\
\hline Thr, T & Threonine \\
\hline TIPS & Triisopropylsilane \\
\hline $\mathrm{TP}$ & Tritrpticin \\
\hline$t_{\mathrm{R}}$ & Retention time \\
\hline TRIS & Tris(hydroxymethyl) aminomethane \\
\hline Trt & Trityl \\
\hline Tyr, Y & Tyrosine \\
\hline UV-VIS & Ultraviolet-Visible \\
\hline
\end{tabular}




\section{Symbols}

\begin{tabular}{|c|c|}
\hline$A_{\mathrm{L}}$ & Membrane area occupied by one lipid headgroup \\
\hline$A_{\mathrm{P}}$ & Membrane area occupied by the peptide \\
\hline$c_{\mathrm{L}}$ & Total lipid concentration \\
\hline$c_{\mathrm{P}, \mathrm{b}}$ & Concentration of membrane surface-bound peptide \\
\hline$c_{\mathrm{P}, \mathrm{f}}$ & Bulk concentration of peptide \\
\hline$c_{\mathrm{P}, \mathrm{i}}$ & Interfacial concentration of peptide \\
\hline$\Delta C_{\mathrm{p}}^{\circ}$ & Molar heat capacity changes \\
\hline$\Delta G^{\circ}$ & Standard Gibbs free energy of membrane partitioning \\
\hline$\Delta H^{\circ}$ & Standard molar enthalpy of membrane partitioning \\
\hline$\Delta S^{\circ}$ & Standard molar entropy of membrane partitioning \\
\hline$\varepsilon_{0}$ & Electric permittivity of free space \\
\hline$\varepsilon_{\mathrm{r}}$ & Dielectric constant of water \\
\hline$F_{0}$ & Faraday constant \\
\hline$\gamma$ & Lipid accessibility factor \\
\hline$K_{0}$ & Intrinsic partition coefficient \\
\hline$K_{\text {app. }}$ & Apparent binding constant \\
\hline$\lambda$ & Wavelength \\
\hline$\Theta_{\mathrm{mr}}$ & Mean residue molar ellipticity \\
\hline$R$ & Gas constant \\
\hline$R_{\mathrm{b}}$ & molar ratio of bound peptide over accessible lipid \\
\hline$\sigma$ & Membrane surface charge density \\
\hline$V_{\text {cell }}$ & Volume of the calorimeter cell \\
\hline$\Delta \varphi$ & Membrane surface potential \\
\hline$z_{\mathrm{P}}$ & Effective charge number of peptide \\
\hline
\end{tabular}




\section{Introduction}

\subsection{CAPs}

CAPs have been found in almost all species of eukaryotic organisms and are recognized as the evolutionarily conserved components of their innate immune system that defend the host against microbes through membrane or metabolic disruption [1]. A distinguishable advantage of CAPs over conventional antibiotics is that they do not provoke immune responses [2]. Regardless of their origin and biological efficacy, CAPs share common features. They are short peptides (usually between 3-50 amino acid residues), which include a large content of basic amino acids and a global distribution of hydrophobic and hydrophilic residues. Due to the high frequency of amino acid residues, such as $\mathrm{R}$ and $\mathrm{K}$ in their sequences, they carry an overall positive charge in the physiological $\mathrm{pH}$ range, which is of great importance for their interactions with the negative charges of bacterial cell membranes [1]. CAPs adapt an amphipathic conformation at polar-nonpolar interfaces with a hydrophobic domain consisting of nonpolar amino acid residues on one side and polar or charged residues on the opposite (Fig. 1). Because of these physicochemical characteristics, CAPs have a tendency to accumulate on the negatively charged microbial surfaces and membranes. Each CAP has a unique pattern of activity against a variety of Gram-positive and Gram-negative bacteria, yeasts, fungi and viruses [4]. While the antimicrobial peptide cecropin A is only active against Gram-positive bacteria [5], MG 2 and dermaseptin show activity against both types of bacteria as well as fungi [6,7], and the membrane-lytic peptide MEL attacks both prokaryotic and mammalian cells [8].

\subsubsection{Structure diversity and basis of activity}

In spite of their common mechanism of action, CAPs show remarkable structural diversity. The relationship between their structure and the spectrum of antimicrobial activity is a complex subject, because even CAPs of the same structure may have different effects upon microorganisms and mammalian cells $[9,10]$. Due to the high structural diversity of the large number of peptides discovered so far, it is difficult to classify CAPs into generally accepted groups. Nevertheless, CAPs can be roughly classified based upon their secondary structure into four major categories: $\alpha$-helical, $\beta$-sheet, loop, and extended peptides [11] (Fig. 2). CAPs with $\alpha$-helical and $\beta$-sheet secondary structures are among the most ubiquitous 
peptides in nature. Besides this classification, there are a few groups of CAPs, which are classified based on frequent occurrence of one or more amino acid residues, e.g., Bac5 [13] and PR-39 [14] are PR-rich antimicrobial peptides; indolicidin has a high content of $\mathrm{W}$ residues, and histatin 5 [15] contains numbers of $\mathrm{H}$ residues.
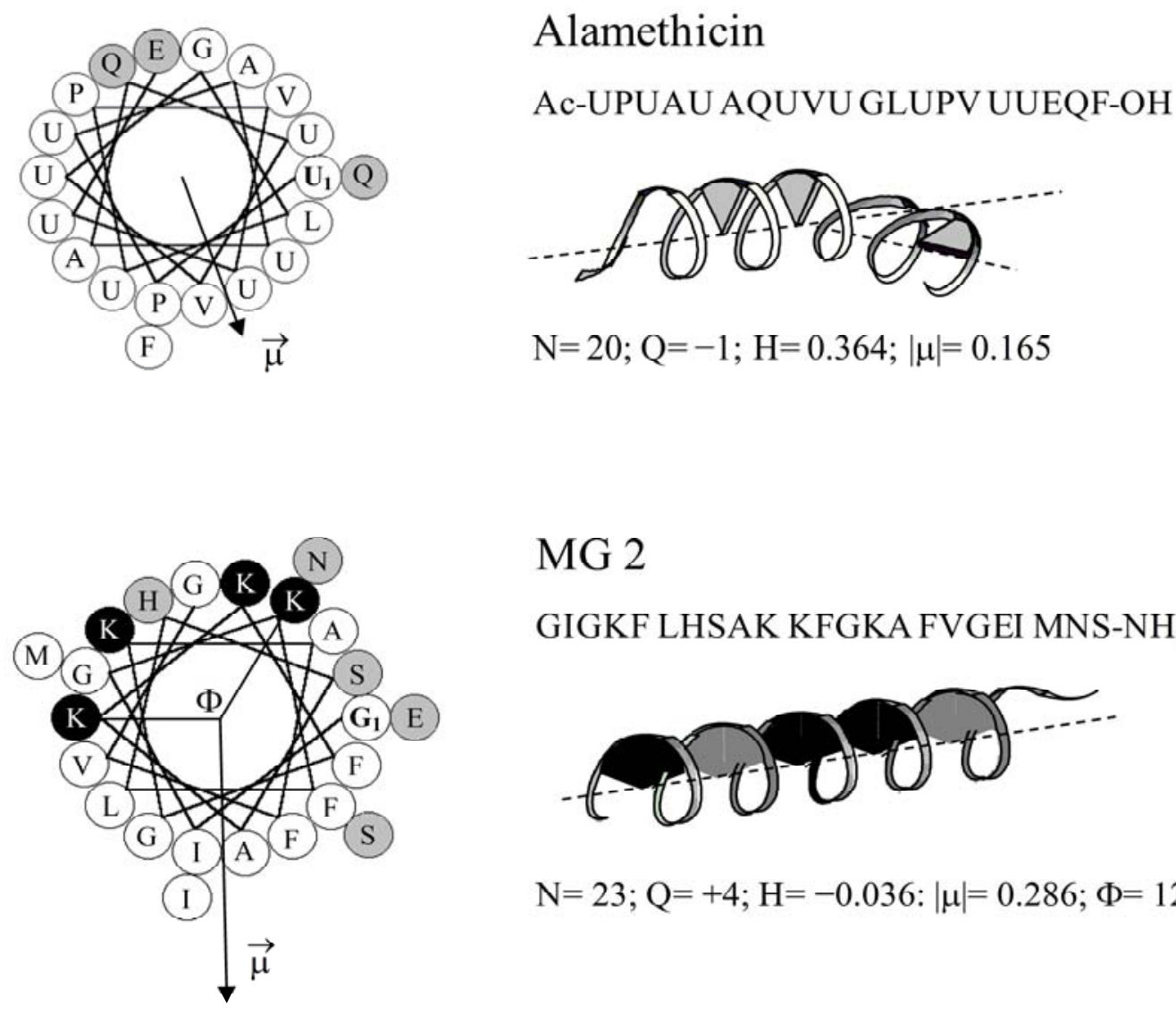

\section{MG 2}

GIGKF LHSAK KFGKA FVGEI MNS-NH

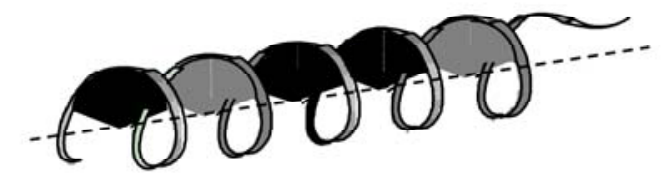

$\mathrm{N}=23 ; \mathrm{Q}=+4 ; \mathrm{H}=-0.036:|\mu|=0.286 ; \Phi=120^{\circ}$

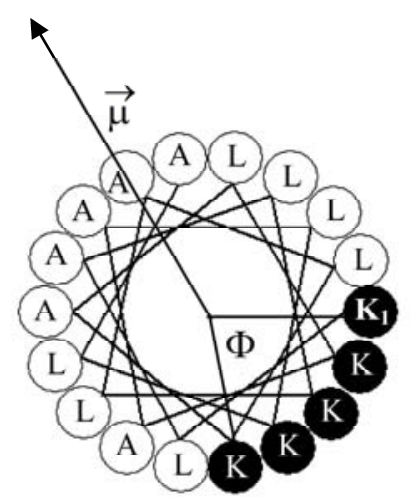

\section{KLAL}

KLALK LALKA LKAAL KLA-NH ${ }_{2}$

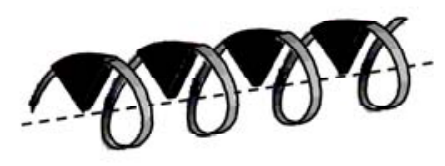

$\mathrm{N}=18 ; \mathrm{Q}=+6 ; \mathrm{H}=-0.019 ;|\mu|=0.334 ; \Phi=80^{\circ}$

Fig. 1. Helical wheel projection of the amphipathic $\alpha$-helix in alamethicin, MG 2, and model KLAL peptide. The positively charged residues are presented in black, the hyrdrophilic residues in gray, and the hydrophobic residues in white colors. Q, $\mathrm{H}, \mu$, and $\Theta$ represent the total positive charge of the peptide, peptide hydrophobicity, the hydrophobic moment, and the angle subtended by cationic residues, respectively. Adapted from ref. [3]. 


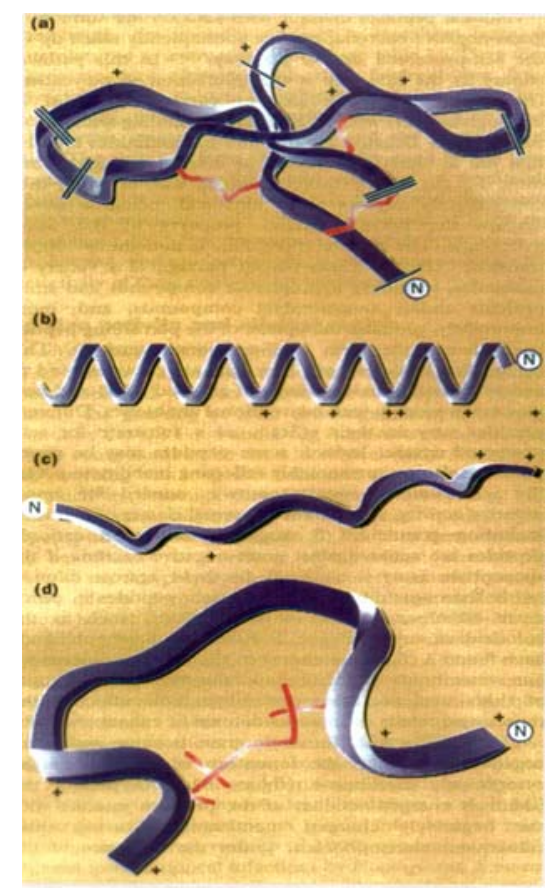

Fig. 2. Schematic description of the models representing the structure of CAPs. The strutures from top to bottom are: (a) $\beta$-sheet structure; e.g., human $\beta$-defensin 1 , which forms a triple- $\beta$-sheet structure stabilized by three disulfide bonds. The N-terminal region of $\beta$-defensin 1 also contributes to an $\alpha$-helix segment. (b) $\alpha$-helix structure, e.g., MG 2, (c) extended structure, e.g., indolicidin, which does not contain structural elements of $\alpha$ helices or $\beta$-sheets. Instead, it has a stretched spiral structure; (d) loop, which is restrained by disulfide bridge, e.g., tachyplesin. It adopts a $\beta$-hairpin fold. Taken from ref. [12].

The knowledge and understanding of activity-modulating structural parameters responsible for the antibacterial activity and specificity of CAPs may provide insight into both the relationship between structure and activity as well as the mechanism of action. Because of their wide dissemination, $\alpha$-helical peptides are the best-studied CAPs. Dathe et al. demonstrated that the physicochemical parameters of CAPs, such as (i) the helicity and amphipathicity, (ii) the hydrophobicity, (iii) the hydrophobic moment, (iv) the magnitude of the charge, and (v) the angle subtended by the charged helix face are effective modulators for biological activity and membrane selectivity of the peptides (Fig. 1) [16]. Using an approach of minimal peptide sequence modification, Wieprecht and Dathe et al. studied the influence of these structural parametes upon membrane activity for MG 2-analog peptides [17-20]. They showed that an enhanced hydrophobic moment or increased hydrophobicity resulted in more potent antimicrobial peptides. In contrast, the disturbance of the amphipathic helix due to double D-amino acid substitution, particularly in the stable helix region of the peptides, led to less membrane activity. In addition, an enlarged cationic domain increased lipid affinity and 
permeabilizing activity of the peptides. The reinforcement of the electrostatic interactions between positively charged peptides and negatively charged membrane components had a higher influence upon the bactericidal acivity than on the hemolytic effect.

\subsection{Cellular basis of activity and bacterial selectivity}

\subsubsection{Membrane composition}

The majority of CAPs work differently compared to conventional antibiotics, which generally block an enzymatic activity essential for a microorganism's reproduction through a specific interaction with a protein or a protein-nucleic acid complex [21]. Because CAPs often act via permeabilization of the bacterial cell membranes; one should consider the differences in structure of the outer layer of bacterial species, their cell profiles, and the variable composition of lipids in the plasma membrane in order to understand the basis of their different spectra of activity.

Bacterial cell membranes are usually rich in anionic lipids [1]. A schematic representation of the cell wall of Gram-positive and Gram-negative bacteria is shown in Fig. 3. The cell enevelope of Gram-negative bacteria consists of an outer and an inner (cytoplasmic) membrane. The outer membrane is highly asymmetric, with the outer leaflet covered by highly negatively charged LPS (>90\%) and the inner leaflet mainly composed of POPE. A thin layer of peptidoglycan, which constitutes the largest part of the preplasmic space, covers the distance between the outer and cytoplasmic membranes. The cytoplasmic membrane, which is considered as the target for CAPs, is composed of: POPE, negatively charged POPG phospholipid and cardiolipin. In contrast, Gram-positive bacteria have no outer membrane, but a thick peptidoglycan layer which protects the cytoplasmic membrane. The main difference arises from the ratio of POPE and POPG phospholipids in the cytoplasmic membrane of Gram-positive and Gram-negative bacteria (Table 1). Whereas the content of negatively charged lipids is higher in Gram-positive bacteria (approximately $60-90 \%$ of the total phospholipids), a much higher proportion of POPE is found in the inner membrane of Gram-negative strains (Table 1) [22]. The difference in the molar ratio of POPG and POPE may be important for the lateral organization, lipid packing and/or mobility, which can be modified in the interaction with other moieties in particular with CAPs. 


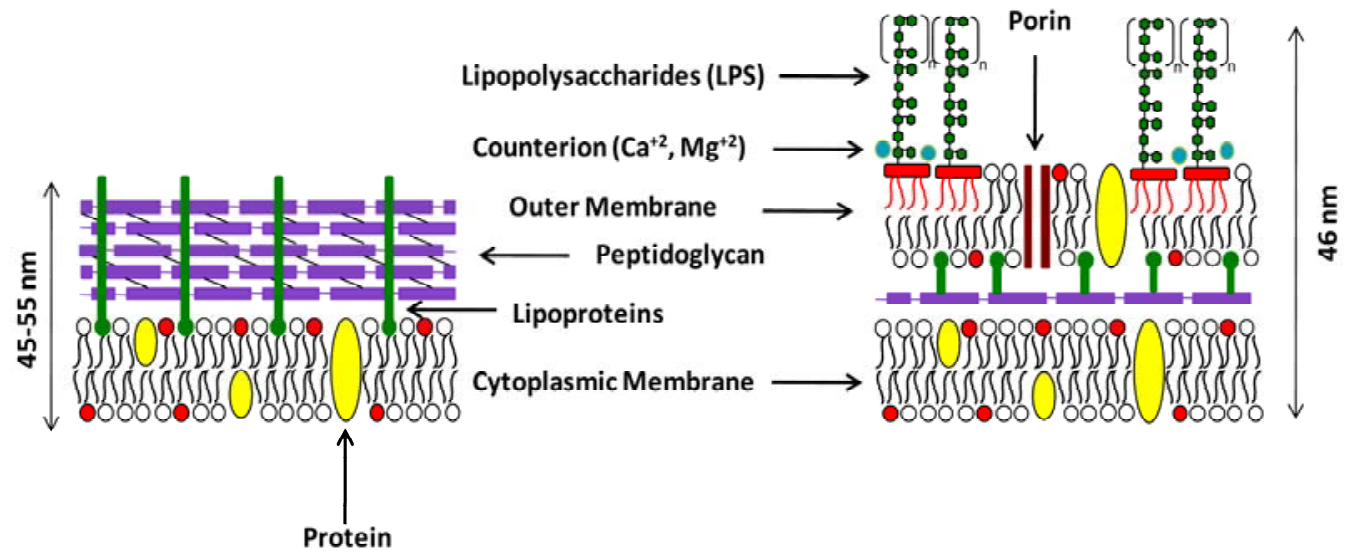

Fig. 3. Schematic representation of the cell wall structure of Gram-positive and Gram-negative bacteria.

Table 1. Phospholipid composition of the plasma membranes of selected microorganisms. Adapted from ref. $[22,23]$.

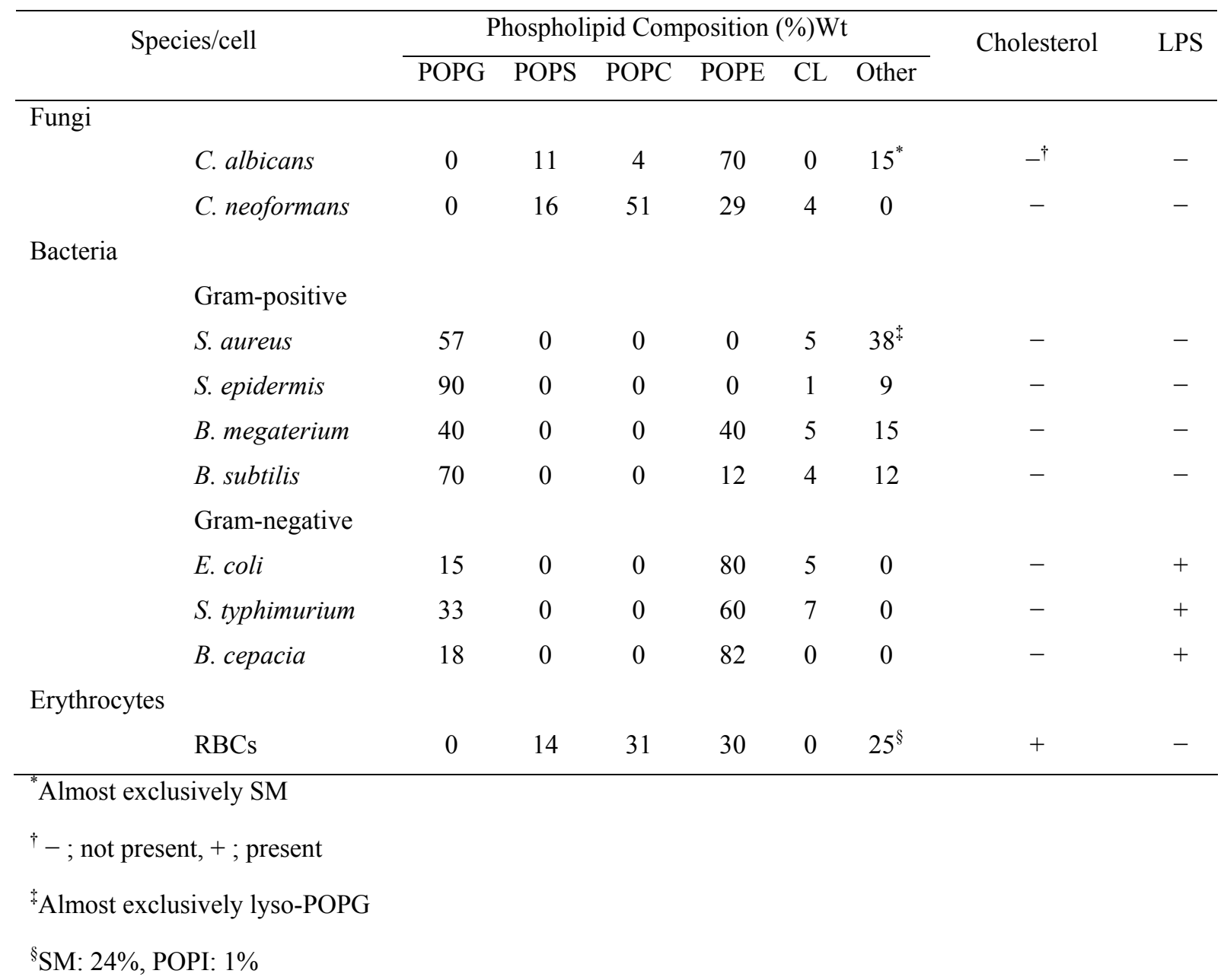


The bacterial negatively charged outer surface provides the basis for accumulation of cationic peptides, which is driven by electrostatic interactions. Compared to bacterial membranes, the outer layer of the mammalian cell membrane contains exclusively zwitterionic POPC, POPE, and neutral SM, and the inner layer contains POPE and POPS [24]. In addition, the plasma membrane of mammalian cells is characterized by the presence of cholesterol in both layers. This endows the membrane with different mechanical properties responsible for reduced binding of amphipathic molecules, such as CAPs to these membranes (Fig. 4) [25].

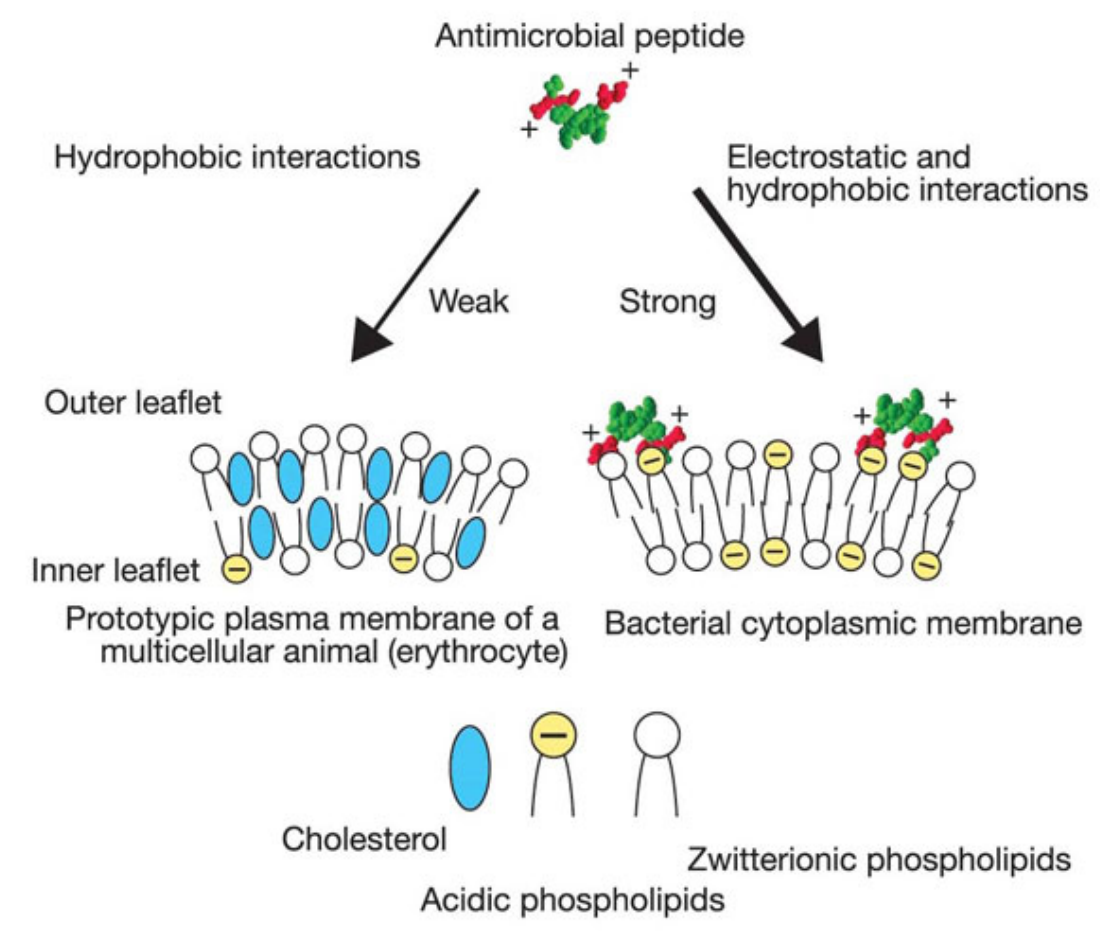

Fig. 4. Schematic description of the molecular basis of cell selectivity of CAPs. Taken from ref. [1]

\subsubsection{Bacterial LPS}

LPS is quite different from the membrane phospholipids and plays an important role as an efficient barrier to certain hydrophobic antibiotics [26]. As a result of destroying Gramnegative bacteria, LPS can be released from the cell wall into the blood stream and induce septic shock [27]. Thus, the interaction of peptides with LPS for both the antibacterial, as well as the anti-inflammatory, effects of the peptides is of crucial importance. LPS is an amphiphilic heteropolymer and consists of a conserved fatty acyl chain backbone known as 
LA and a large polysaccharide chain [28]. LA is the toxic moiety of LPS. The backbone of LA consists of a diglucosaminecarbohydrate backbone in a beta-(1' $\rightarrow 6)$-linkage, which is phosphorylated at positions 1 and 4' (Fig. 5) [28]. A total of four 3-hydroxy-fatty acyl chains, generally having a length of 12 to 14 carbon atoms and known as "fatty acids primary", are attached directly to the carbohydrate backbone by either ester- or amide-linkages (Fig. 5). The primary 3-hydroxy fatty acids can be further esterified by a total of 4-7 fatty acids. These fatty acid chains are so-called "fatty acids secondary", which are not directly bound to LA.

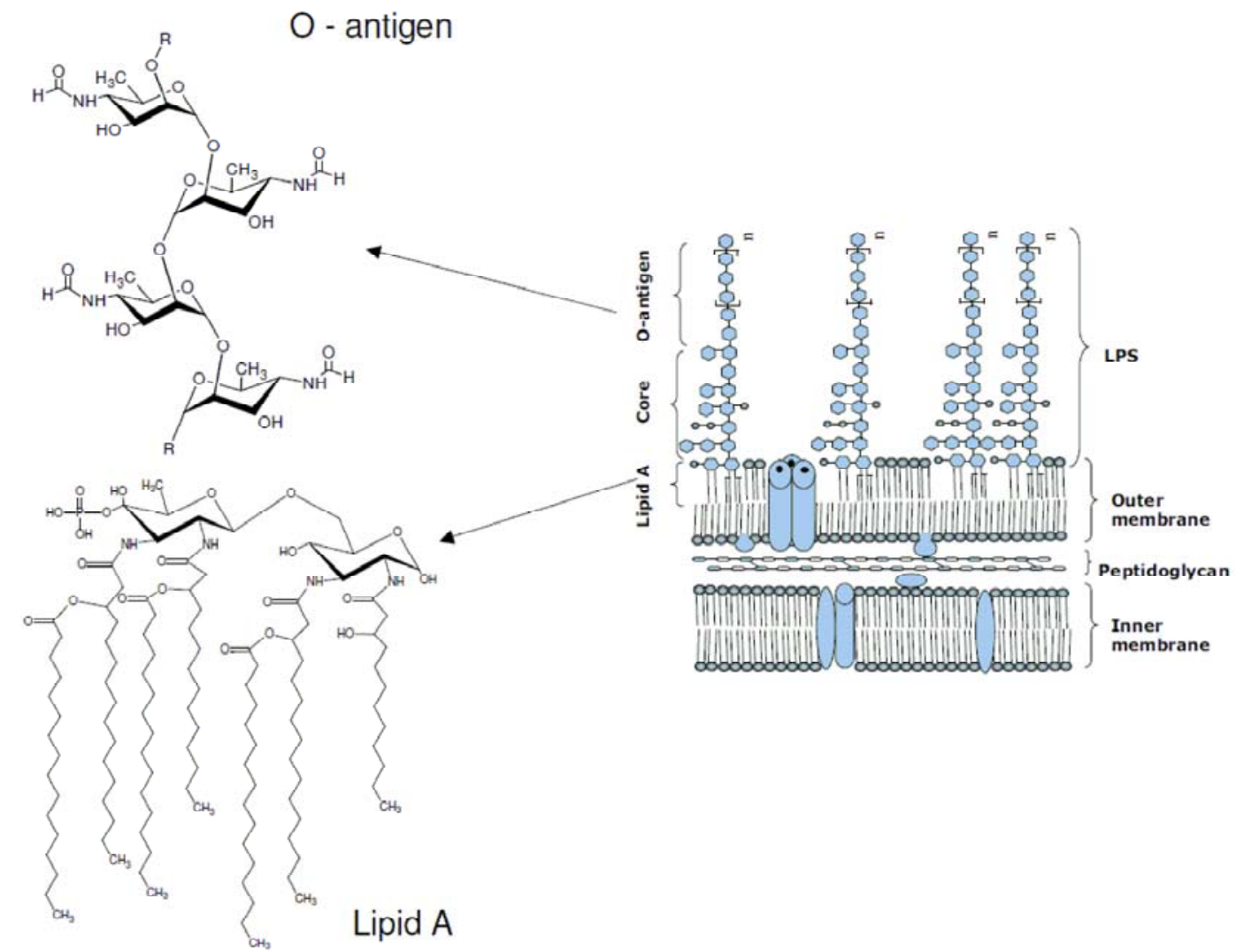

Fig. 5. Schematic structure of LPS from Brucella spp. Taken from ref. [29].

The polysaccharide structure of LPS consits of an oligosaccharide core with a limited number of sugars, and highly variable polysaccharide chains composed of one or more oligosaccharide repeating units, the so-called O-antigen (Fig. 5). The O-antigen has several biological activities; it serves as a receptor for bacteriophages, modulates the activation of the alternative complement pathway, and inhibits the attachment of membrane attack molecules to the bacterial outer membrane [26,30]. When an LPS contains the O-antigen chain, it is described as s-form LPS (smooth) because the bacterial colonies have a smooth morphology 
(Fig. 6). However, not all Gram-negative bacteria possess an O-antigen. Such bacteria are termed rough (r) because they form rigid, incomplete colonies on solid agar and autoagglutinate in saline. Several rough (r)-mutants were shown to have truncated polysaccharide cores due to defects in genes that code for glycosyl or phosphoryl transferases. Depending upon the length of the core region of the polysaccharides, they are described as Re-, Rd-, Rc-, Rb-, and Ra-LPS (Fig. 6) [28]. The rough mutant containing the complete core is termed Ra-LPS. LPS which lack the terminal sugar are known as Rb-LPS, and Re-LPS is the shortest LPS mutant which occurs in nature. Re-LPS contains only two singly-negatively charged Kdo.

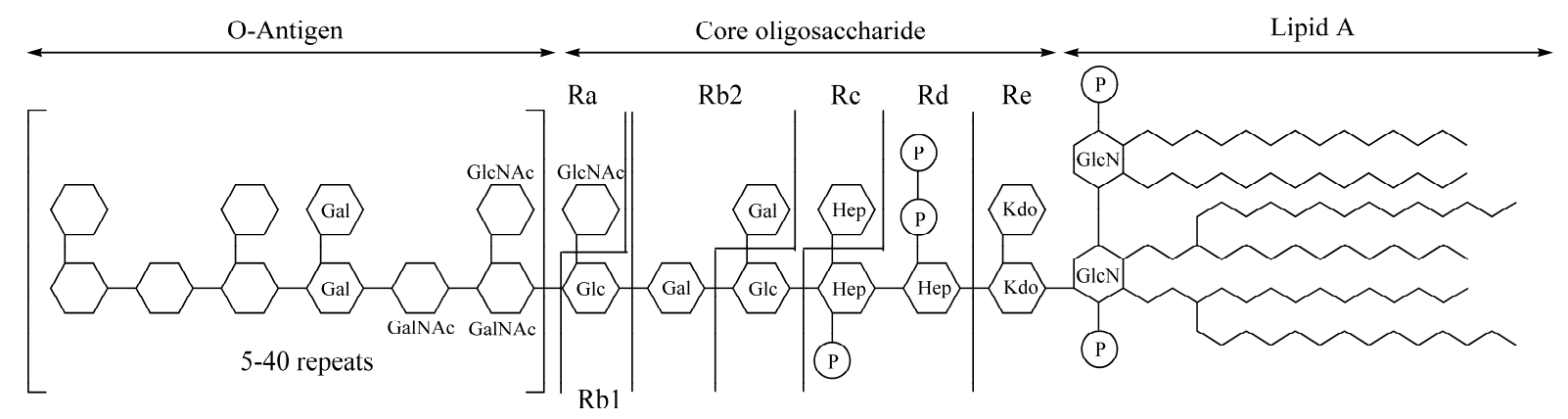

Fig. 6. General structure of $\boldsymbol{E}$. coli LPS. The diversity of sugar moieties in the core region and the composition of LA are conserved in different $E$. coli strains. However; the O-antigen region varies strongly among different E. coli strains. Charged residues are located preferentially in the core oligosaccharide region. Ra-Re denote the different rough chemotypes of LPS. Native, complete LPS is called smooth LPS (s-LPS). Adapted from ref. [28].

LPS possess binding sites for calcium and magnesium ions are responsible for the structural stability of the outer membrane of Gram-negative bacteria [31]. The susceptibility of Gram-negative bacteria to CAPs has been proposed to be associated with factors that facilitate the transport of the peptide across the outer membrane, such as the magnitude and the location of the LPS charge, the concentration of LPS in the membrane and the absence of O-antigen chains. CAPs are either trapped in the outer barrier [32] or increase their permeability by causing disordering of the LPS organization [12]. A mechanism of "selfpromoted uptake" has been proposed for the transport of CAPs across the complex outer membrane, thus facilitating peptide accessibility to the inner target membrane [12]. 


\subsection{Mechanims of action}

\subsubsection{Membrane permeabilization}

Most of the soluble CAPs penetrate into the cell membrane and enhance the permeability. Electrostatic interactions cause the accumulation of the cationic peptides at the negatively charged bacterial membrane, and hydrophobic interactions drive their insertion into the lipid bilayer [33]. Additionally, counter ion exchange initiating a "self-promoted uptake" across the outer LPS-rich membrane modulates the peptide accessibility to the inner target membrane of Gram-negative bacteria [12]. Several models have been proposed to explain the modes of action of CAPs, which are presented in Fig. 7. However, the evidence for the anticipated modes of action is based on experiments carried out on model lipid systems [34]. Peptides bind to the membrane by assuming an amphipathic helix with the polar domain exposed to the membrane surface and the hydrophobic helix face buried in the lipid acyl chain region. Changes in the lipid bilayer structure and reorientation of the bound peptides lead to membrane permeabilization.

\section{(A) barrel-stave model (transmembrane helix bundles)}

This model describes a pore as an aggregated set of membrane-bound CAPs. The axes of the $\alpha$-helical sequences are oriented perpendicular to the membrane surface (Fig. 7A). The peptide sequences should be long enough to span a $30 \AA$ thick lipid membrane, and thus this model is not appropriate for short CAPs. A typical example for this model is alamethicin, which forms stable ion channels [35]. The pore formation is initiated with alamethicin $\mathrm{N}$ terminus insertion into the membrane interior where the peptide hydrophobic region binds to the hydrophobic chains of lipids and the peptide hydrophilic region forms a central lumen. The channel diameters range from 0.2 and $2 \mathrm{~nm}$ [36] and the number of helices which form the alamethicin pore varies between 3-11 [37,38].

\section{(B) toroidal model (wormhole)}

The toroidal pore model is comparable to the barrel-stave model; however, the pores are instable and poorly reproducible (Fig. 7B) [33]. In this model, the peptides associate with the polar lipid headgroups and penetrate into the membrane. The bound peptides cause lipid chain disorder and induce an enhanced lipid surface expansion and curvature modulation, which lead to an unfavorable strain between the outer and inner lipid layers. At high peptide concentration, the peptides are lined perpendicular to the membrane surface. Then, both 
peptides and lipids form a transmembrane pore which connects the inner and outer lipid layers [39]. The membrane activity of MG 2 is associated with this type of pore [40-42]. The pore diameter reaches $3 \mathrm{~nm}$, about twice as large as the alamethicin channel [43].

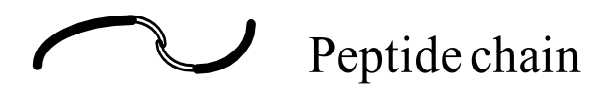

\section{Binding}

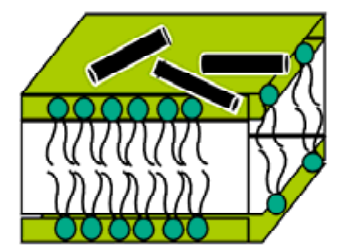

Surface state

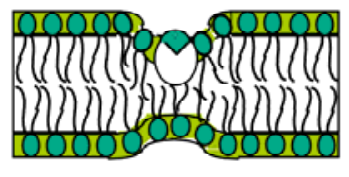

Local thinning

\section{Permeabilization}

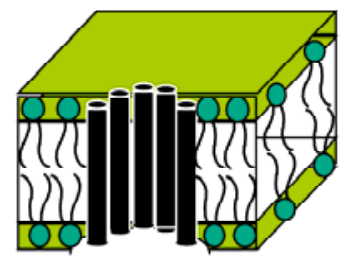

A

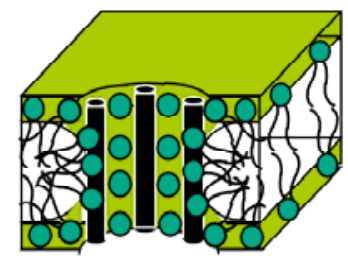

$\mathrm{B}$

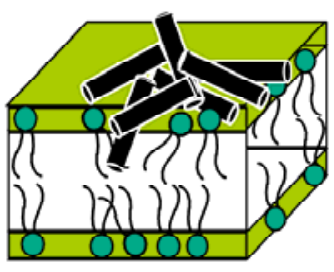

$\mathrm{C}$

Fig. 7. The classical models for the mode of membrane permeabilization of CAPs. The black cylinders represent the peptides. (A) barrel-stave model (e.g., alamethicin), (B) toroidal pore model (e.g., MG 2), and (C) Carpet-like model (e.g., model KLAL peptide). Taken from ref. [3].

\section{(C) carpet-like model}

This model reflects the mode of action of short amphiphilic CAPs, which are not able to span the membrane. Based on this model, membrane permeabiliziaton happens through the following steps. (i) The peptides electrostatically accumulate at the membrane surface. (ii) After reaching a threeshold concentration, the peptides orientate parallel to the membrane surface where their hydrophobic surface points towards the hydrophobic interior of the lipid bilayer, and their hydrophilic surface is in contact with the phospholipid headgroups. (iii) The peptides self-associate on the bilayer, leading to high surface tension, destruction of membrane integrity, and consequently membrane collapse (Fig. 7C) [33]. In this scenario no 
local CAPs bundles will be formed. Model KLAL peptides have been suggested to permeabilize the lipid bilayer according to this mode of action [44].

\subsubsection{Alternative mechanisms of action}

In spite of the membrane-permeabilizing activities, a different view on the mechanism of action of CAPs involves their penetration across the membranes of pathogens without pore formation [4]. This process is followed by inhibition of intracellular processes, such as protein synthesis [45], DNA replication [46], or by targeting mitochondria and causing efflux of ATP [5]. Support for these mechanisms of action comes from investigations of BUF [46], histatins [47], the P-rich antimicrobial peptide indolicidin [48], and others [4].

Besides these modes of antimicrobial activity, lipid segregation induced by CAPs is another alternative model which leads to the formation of domains in bacterial membranes. This model was proposed to explain the membrane permeabilizing action of cyclic RW-rich hexapeptides [49] (Fig. 8).

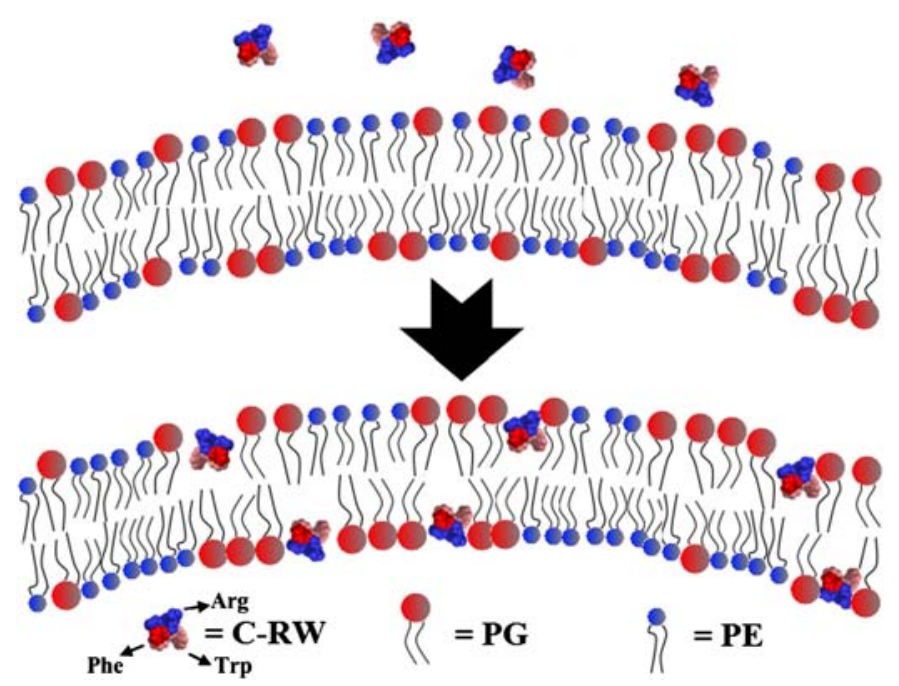

Fig. 8. Schematic description of c-RW-induced demixing in a mixed POPG/POPE bilayer. POPG and POPE headgroups are represented by red and blue balls, respectively. c-RW segregates POPG from POPE creating defects between the formed domains. Taken from ref. [49].

\subsection{Small CAPs}

\subsubsection{Significance of short CAPs}

Over the last few decades, thousands of CAPs of various length, amino acid composition and conformation have been described [50]. Most of them belong to the class of 
$\alpha$-helical peptides. However, unresolved problems of toxicity against eukaryotic cells, the limited stability against proteolytic digestion in vivo and high production costs prevent using such CAPs orally and systemically. There is therefore a requirement for the development of new classes of CAPs with improved activity profiles [2].

Small CAPs rich in particular amino acid residues, such as $\mathrm{R}, \mathrm{W}$, and $\mathrm{P}$ have gained high interest as lead compounds [51-55]. They are usually found as small antimicrobial motifs of much larger natural compounds [56]. The mechanisms of interaction of small and conformationally constrained peptides with cellular membranes, as well as the key factors that provide bacterial specificity for these peptides, are much less well understood [57]. Thus, among others, small RW-rich peptides with improved toxicity against bacteria are interesting candidates to study the structural motifs and forces responsible for selectivity and may pave the way to develop new therapeutics with potent activity against multi-resistant bacteria.

The role of $\mathrm{R}$ and $\mathrm{W}$ residues for biological and bilayer permeabilizing activities has been described for several sequences. Examples are: the hexapeptide lactoferricin [58], indolicidin [59], TP [60], Pac-525 [61], the short bovine bactenecins analogs [54], and synthetic linear RW-rich hexapeptides indentified from combinatorial library studies [62]. On the level of the lipid membrane, the $\mathrm{W}$ residue has a high propensity to insert into the membrane and partition near the membrane-water interface [63], while positively charged $\mathrm{R}$ residues, with hydrogen bonding properties, provide the basis for peptide interaction with the anionic components of bacterial membranes. The electric dipole moment and hydrogen bonding ability of $\mathrm{W}$ with both anionic components of lipid membrane, e.g., phosphate groups and water molecules in the membrane interface, as well as intramolecular cation- $\pi$ electron interactions between $\mathrm{R}$ and $\mathrm{W}$ have been suggested to be responsible for favoured partitioning and the interfacial location of the peptides [64]. These unique properties make peptides, even if shortened to three amino acid residues, highly active [52].

Furthermore, cationic and bulky hydrophobic amino acids proved to be the best mimics of the amphipathic topology of the active-site $\beta$-strands of LPS-binding proteins [65]. $\mathrm{W}$, as a component in many LPS-binding motifs, also points to a significant role of peptidesugar interactions for selective toxicity against Gram-negative bacteria. Studies with lactoferricin-derived peptides and LPS mutant E. coli strains underlined the importance of an appropriate location of $\mathrm{R}$ and $\mathrm{W}$ residues for antimicrobial activity [66]. It has been suggested that the peptides first interact with the negative charges present in the inner core. LPS- 
disorganization finally results in facilitated approach of $\mathrm{W}$ residues to the LA as the preferred hydrophobic binding site [66].

\subsubsection{Particular properties of $\mathrm{RW}$-rich hexapeptides}

RW-rich hexapeptides derived by structural modifications of the synthetic hexapeptide Ac-RW (Fig. 9) [53] create one group of small CAPs. The parent sequence, Ac-RW, was identified by screening of a synthetic combinatorial library [62]. The peptide adopts an amphipathic structure in a membrane-mimetic environment [67].

A

$\mathrm{B}$
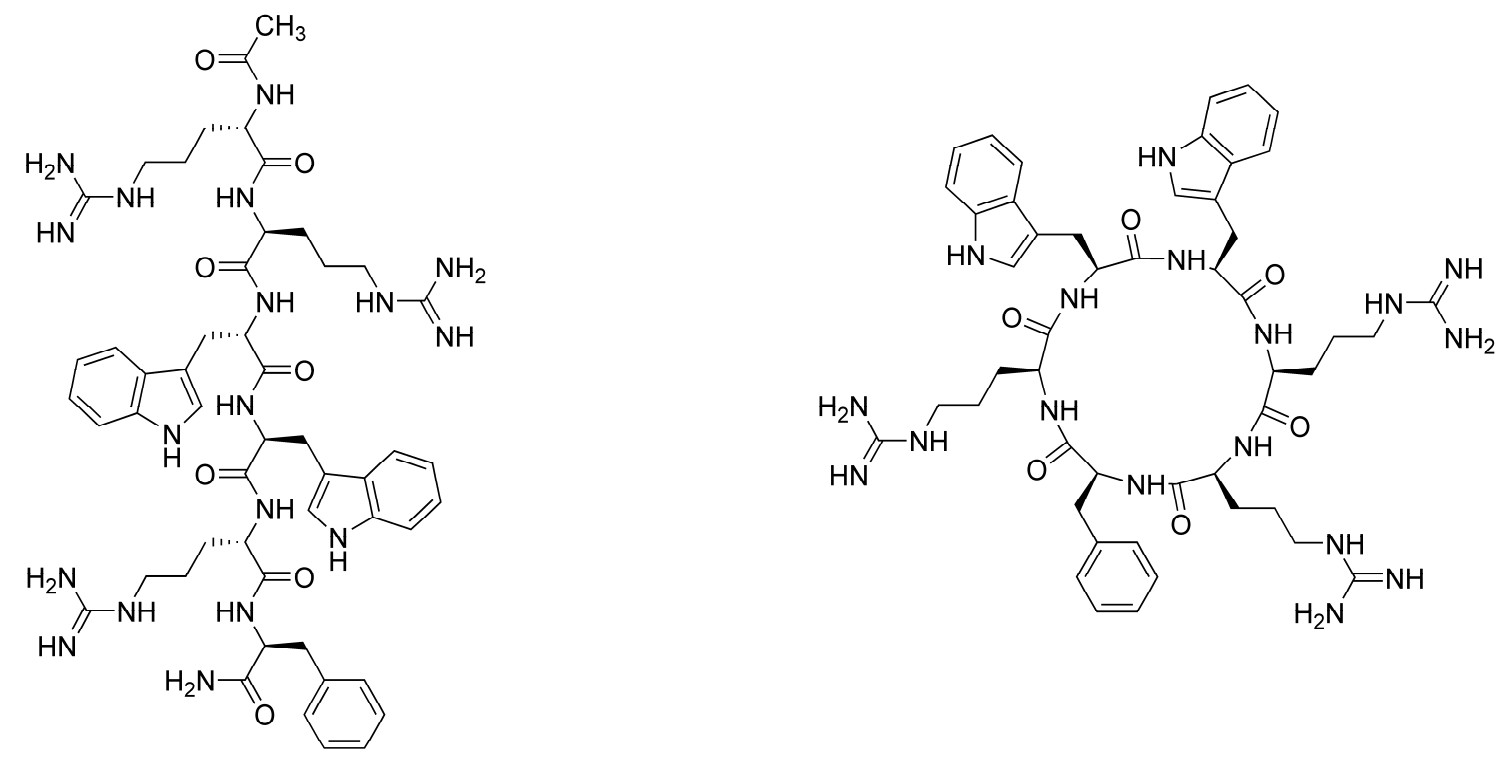

Fig. 9. Chemical structures of (A) Ac-RW, and (B) c-RW peptides.

Recently, it has been shown that head-to-tail cyclization of Ac-RW (Fig. 9) distinctly enhances the peptide's activity against Gram-negative E. coli [53]. However, in contrast to its high antimicrobial activity, the cyclic peptide only weakly permeabilizes lipid bilayers $[53,68]$. Single amino acid substitutions or replacement of L-amino acid residues by Denantiomers were demonstrated to enhance or abolish the antimicrobial activity $[53,68,69]$. The peptides are able to permeabilize the outer and inner membranes of E. coli [70], but, interestingly, their activity decreases against wall-deficient L-forms of E. coli. Moreover, studies with mutant E. coli strains demonstrated that the activity of sequences with three adjacent aromatic residues, for instance, c-WFW, is reduced upon removal of the O-antigen 
and shortening of the core region of the outer-membrane LPS [70]. This points to a particular role of LPS in peptide activity and selectivity against $E$. coli.

Using solution NMR spectroscopy, it was shown that the c-RW consists of two $\beta$-turn motifs [71]. On interaction with detergents and lipids, c-RW develops pronounced amphipathicity compared to its rather flexible structure in water [73]. Molecular dynamic simulations led to the suggestion that the peptide backbone lies parallel to the lipid bilayer surface, the positively charged $\mathrm{R}$ residues interact with the phosphate groups of the lipids, and insertion of the aromatic residues into the acyl chain region reduces the permeability barrier of a DPPC bilayer to water [74]. Furthermore, the peptide induces lipid demixing and formation of peptide-rich domains in DPPG/DPPE bilayers (Fig. 8) [49].

The observation that many cyclic hexapeptides are similar in conformation, but differ in the sequence [73] and their antimicrobial activities raises the question of whether specific amino acid residues are responsible for the cyclization-induced pronounced activity and selectivity of the RW-rich hexapeptides against Gram-negative bacteria. Studies using trimesic acid as a template mimicking the peptide backbone have demonstrated an essential role of the guanidino moiety for bacterial selectivity [74]. However, it seems that not only charge-driven peptide accumulation at negatively charged E. coli membranes, but also the exact nature of the interaction of W residues with LPS domains is important to be understood. Only a few studies have investigated the influence of the aromatic $\mathrm{W}$ residues on the bacterial selectivity of the peptides. So far, c-RW analogs with a lipophilic Nal or a bulky non-aromatic amino acid residue, i.e., bicyclo[1.1.1]pentane, instead of $\mathrm{W}$ were demonstrated to increase the bactericidal activity of the peptides, whereas introduction of $\mathrm{Y}$ or $\mathrm{F}$ residues abolished the activity $[53,68,69]$.

\subsection{Surface-tethered peptides}

\subsubsection{Inhibition of biofilm formation}

Biofilm is community of microorganisms growing on a surface and are usually encased in an extracellular polysaccharide matrix that they themselves secrete [75]. It can develop on any surface that is exposed to sufficient moisture, such as medical devices, surgery equipment, implants, food packaging and purification systems (Fig. 10). The formation of a pathogenic biofilm starts with the adhesion of bacteria or fungi to surfaces by 
non-specific long- and short-range forces [77]. The most common invading pathogens that cause implant-associated infections include Gram-negative E. coli and Pseudomonas species, Gram-positive Staphylococci and Candida species [78]. Biofilm is rarely resolved by host defense mechanisms [75]. In addition, antibiotic therapy typically reverses the symptoms caused by planktonic cells released from the biofilm, but fails to destroy the biofilm itself [79]. The factors considered to be responsible for biofilm resistance include: inability of antimicrobial penetration in all areas of the biofilm, reduced growth rate in biofilm, and possible expression of resistance genes [80]. Due to their intrinsic resistance to conventional antibiotic therapy, biofilm formation leads to a significant increase in costs for removing them. Industrial companies spend billions of dollars a year to control them. To combat this threat, research must focus on antimicrobial coatings in order to reduce the initiation of microorganism aggregation on such materials and thus prevent biofilm formation.

Various approaches have been designed in ordrer to develop such biomedical surfaces including: (i) surfaces covered with bacteria-repellent or anti-adhesive agents using highly hydrated and close-packed, chain-like molecules, such as PEG [81] or bearing negative charges [82]; (ii) polymer matrices with incorporated antibiotics (non-covalently), which are released into the surrounding medium in a controlled manner [83,84]: and (iii) antimicrobial polymers, which are either prepared by polymerization of constitutive monomers with therapeutic moieties [85-87] or covalently bound to antimicrobial agents [88-93] (Fig. 11). However, these strategies suffer from several disadvantages, such as limited affinity of biomaterials for antibiotics, modification of the mechanical properties of the materials, and a limited spectrum of therapeutics and active monomers with polymerization-compatible chemistry. The major obstacle is their hemolytic activity [90,94,95], particularly the toxicity of surfaces modified with quaternary ammonium, pyridinium and related compounds $[88,96,97]$ to human cells [98].

The production of surfaces covalently covered with antibiotics is another important approach to overcome the problem of biofilm formation. Examples of these surfaces are ampicillin and penicillin attached to expanded poly(tetrafluoroethylene) $[99,100]$. 


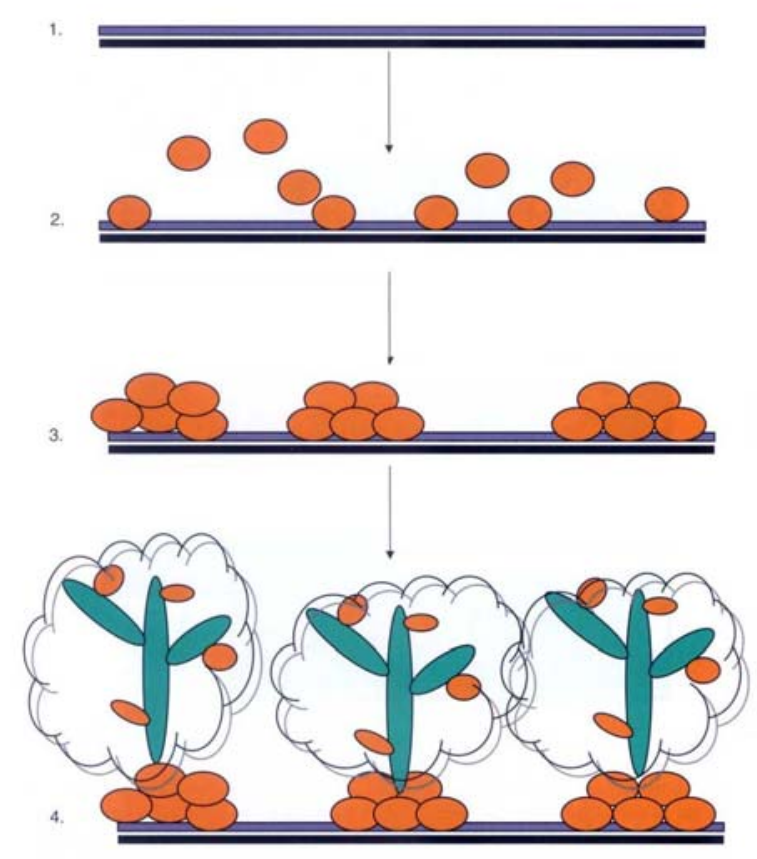

Fig. 10. Candida albicans biofilm development on inert surfaces. (1) Inert surface coated with a conditioning film (blue) consisting largely of host proteins. (2) Early attachment and colonization by C. albicans yeast-phase cells (orange). (3) Microcolony yeast basal layer formation, involving stacking of yeasts in the formation of the microcolonies. (4) Expansion of the biofilm architecture through the development of a hyphal/pseudohyphal

layer (turquoise) that protrudes from the inner yeast layer to the outer reaches of the biofilm. Hyphal layer development occurs simultaneously with the development of the thick layer of matrix material that has engulfed both the hyphal and yeast biofilm layers. Taken from ref. [76].

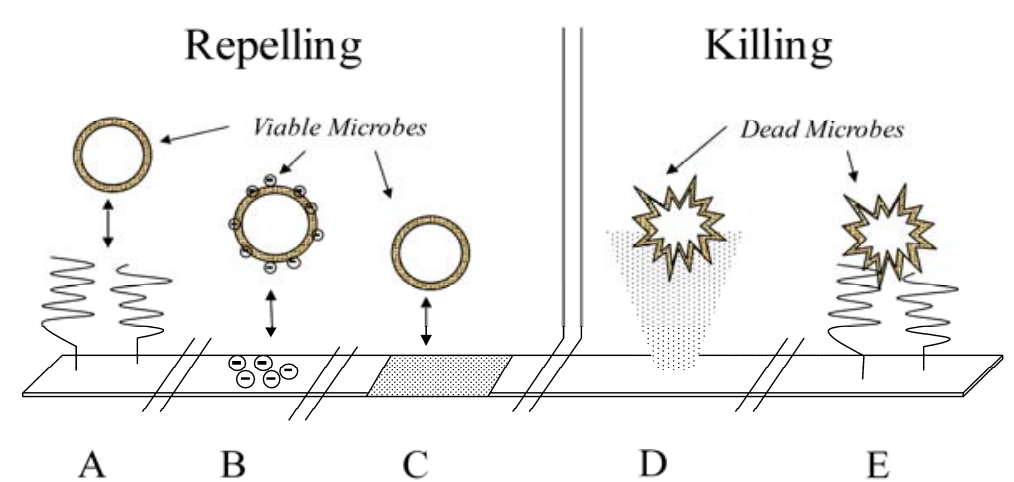

Fig. 11. Different types of antimicrobial coatings. A) Surfaces covered with ultrahydrophilic molecules, e.g., PEG; B) anionic antimicrobial surfaces, e.g., PAA; C) ultrahydrophobic surfaces, such as lotus-effect surfaces; D) antibacterial coating release, e.g., $\mathrm{Ag}^{+}$, triclosan, $\mathrm{Cl}_{2}$; E) contact killing non-leaching antimicrobial surfaces, e.g., PVP, $\mathrm{TiO}_{2}$. 


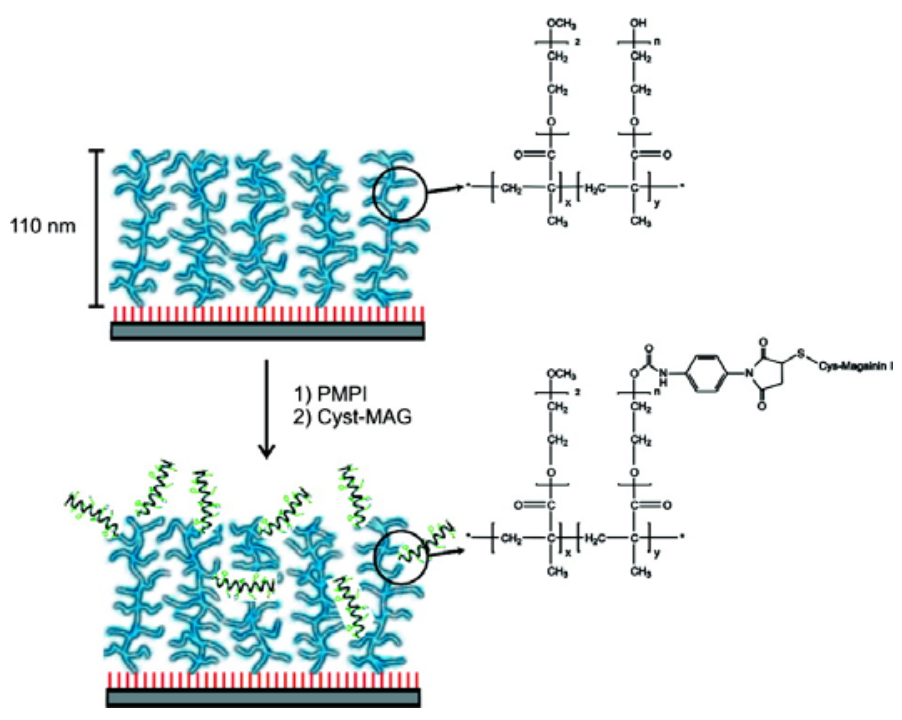

Fig. 12. Oriented grafting of MG 1-Cys derivative on poly(MOE ${ }_{2} \mathrm{MA-co-HOEGMA)} \mathrm{brushes} \mathrm{via} \mathrm{a}$ PMPI heterolinker. Taken from ref. [102].

However, the growing emergence of bacterial resistance towards classical antibiotics is a major drawback to their applicability for the production of antibiotic surfaces. Because of the bacterial membrane-permeabilizing activities, as well as the low hemolytic activities of surface-tethered peptides, CAPs have gained high interest as a potential strategy to tackle the formation of biofilm. Recent examples are: magainin derivatives immobilized on resin beads [101]; poly( $\mathrm{MEO}_{2} \mathrm{MA}-\mathrm{co}-\mathrm{HOEGMA}$ ) brushes [102] (Fig. 12) and gold surfaces [103]; immobilized cecropin-MEL hybrid peptide on a variety of different types of substrates such as amidated polymer brushes, hydrogel and beads [104]; nisin-tethered on block copolymers made of ethylene oxide and propylene oxide monomers [105]; cellulose membranes covered with short bactenecins analogs (Bac2A) [106]; a synthetic $\alpha$-helical CAP, namely E14LKK immobilized with poly(ethylene) [107]; resin beads covered with a $\beta$-sheet CAP [108]; silicaand titania-cationic decapeptide (KSL) nanoparticles [109]; titanium surfaces coated with vancomycin [110], human host defense peptide LL-37 [111] or antimicrobial peptoids [112]; and TP derivatized amphiphilic block copolymers [113]. Inhibition of a biofilm culture of Pseudomonas aeruginosa, or other oral pathogens, by the human host defense peptide LL-37 or a peptide mimictic based on the structure of MG 2 are examples of this application [114,115]. The enzymatic degradation of a tethered peptide is significantly slower than the corresponding soluble peptide [101] and thus the antimicrobial activity mainly originates from immobilized, as opposed to leached peptides [103,104]. Moreover, the activity of these 
antimicrobial coatings may remain conserved even after heating up to $200{ }^{\circ} \mathrm{C}$ and over a broad $\mathrm{pH}$ range [116].

\subsubsection{Peptide-based biofilm}

Recent strategies for the immobilization of CAPs on solid surfaces used either: (i) covalent linkage via SPPS [101,106,108,116], thioalkylation [102,104,111], EDC/NHS activation on $\mathrm{COOH}$-enriched surfaces [103,107], disulfide exchange reaction on polymers using thiolated-peptides [105], or (ii) non-covalent methods using highly specific interactions, such as the biotin-streptavidin system [106]. CAPs may be tethered randomly on the solid surfaces or specifically at the $\mathrm{C}$ terminus, $\mathrm{N}$ terminus or side-chains of the peptides via the $\varepsilon$ amino group of selected $\mathrm{K}$ residues present within the peptide sequences. However, due to the random immobilization process there is no control over the orientation of the tethered peptides.

The pioneer studies by Haynie et al. demonstrated the relationship between peptide structure and activity of soluble and resin-tethered peptides [101]. It was shown that Cterminal immobilization distinctly reduced the activity of potent antimicrobial sequences and that the relationship between the antimicrobial activity and structural properties, such as amphipathicity, was retained. Furthermore, the structure-related activity profile of the investigated peptides did not change with immobilization [101]. Studies with a $\beta$-sheet antimicrobial peptide attached to PEG-modified beads or directly to the hydrophobic MBHA resin demonstrated that peptide immobilization via a long spacer stays bactericidal even after extensive washing [108]. These reports let to the expectation that the activity of immobilized peptides strongly depends upon the length and kind of spacer between the active sequences and the solid matrices. However, the flexibility of the peptides, the peptide density on the surface and the position of immobilization will also influence activity.

The biocidal activity of immobilized peptides may be position-dependent. This means that the tethered peptides should be tethered on surfaces at a position, which allows effective interaction between the critical domains of the CAP and the bacterial cell membrane. Support comes from tethered MG 1 [103], a cecropin-MEL hybrid peptide [104], and an $\alpha$-helical peptide E14LKK [107]. Randomly immobilized MG 1 on gold surfaces [103], as well as the peptide $\mathrm{C}$ terminally tethered on $\mathrm{MEO}_{2} \mathrm{MA}-\mathrm{co}$-HOEGMA brushes, showed good activity against Gram-positive bacteria [102]: the tethered peptide reduced surface adhesion of 
bacteria by more than $50 \%$. In contrast, the antimicrobial activities of a tethered cecropinMEL hybrid peptide [104] and an $\alpha$-helical peptide E14LKK [107] are orientation-dependent with randomly immobilized peptides being almost inactive. The highest specific biological activities were achieved with the cecropin-MEL hybrid peptide and E14LKK when they were tethered at the $\mathrm{C}$ terminus and $\mathrm{N}$ terminus, respectively [104,107]. The screening of antimicrobial activities of a library of tethered peptides derived from Bac2A analogs against $P$. aeruginosa demonstrated that the antimicrobial activity of the immobilized peptides is influenced by the positioning of hydrophobic and cationic amino acid residues within a sequence in respect to the site of linkage to the solid surface [106]. For optimal activity, the hydrophobic and cationic amino acids must occupy places far away and very close to the linkage site, respectively.

Systematic studies with respect to the influence of the position of peptide coupling, the distance between the active compounds and the solid surface, as well as peptide density in relation to an optimized activity, have not been conducted so far. However, because of the different mode of action of antimicrobial peptides such studies are essential for the selection of peptides suitable for the generation of antibiotic surfaces.

Moreover, chemical immobilization renders CAPs less flexible and the range of peptide penetration into the bacterial cell wall is reduced compared to soluble peptides. Due to the limited ability of tethered peptides to penetrate the bacterial cytoplasmic membrane, it may allow us to elucidate the membrane selectivity of the peptides. A comparison of activities of soluble CAPs and surface-tethered compounds on both biological and model membranes level is expected to provide information about the mode of membrane interaction and permeabilization. Previous studies with colloidal gold particles coated with gentamicin-BSA conjugates demonstrated that the covalent immobilization of the aminoglycoside antibiotic could be used as a strategy to investigate the sites of antibiotic action [117]. 


\section{Aims of the study}

\subsection{Structural basis of anti-E. coli activity of cyclic RW- rich hexapeptides}

The activity of cyclic RW-rich hexapeptides against Gram-negative E.coli is determined by the peptide sequence and modulated by LPS in the outer cell wall. In spite of the amount of experimental data, important issues concerning the particular physicochemical aspects of $\mathrm{W}$ residues within the RW-rich cycles for the interactions with E. coli membranes are not yet understood. The aim of the first part of the study was to answer the following questions:

1. Which structural motifs of the cyclic RW-rich peptides are important for recognition of and interaction with bacterial and model membranes?

2. Are there selective interactions between the aromatic side chain of $\mathrm{W}$ residues and distinct regions of the Gram-negative bacterial outer membrane LPS, which could explain the high cyclization-induced anti-E. coli activity?

To answer the questions, a set of cyclic hexapeptide analogs of c-WFW carrying substitutions of $\mathrm{W}$ by unnatural aromatic amino acids were synthesized manually. The substituents differ in terms of hydrophobicity, dipole moment and quadrupole moment (aromaticity), ability to form hydrogen bonds, and amphipathicity. They include Dht, Igl, 5MeoW, 5fW, 5MeW, $1 \mathrm{MeW}$, and Bal (Fig. 13). In addition, the $\beta$-amino acid b3-hW was included to increase the size of the backbone cycle. The activities of the peptides were

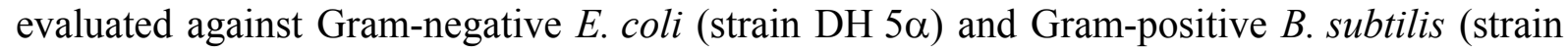
DSM 347) bacteria as well as RBCs. To correlate the biological activity profile with the driving forces of peptide-membrane interactions, peptides binding to different membrane model systems were studied by way of ITC. Binding parameters were derived by applying a surface partition equilibrium model combined with the Gouy-Chapman theory to account for electrostatic effects at the membrane surface. The phospholipid bilayers used in this study were composed of POPC or POPC/POPG $(3 / 1[\mathrm{~mol} / \mathrm{mol}])$ to model the electrostatic properties of erythrocyte and bacterial target membranes, respectively. Furthermore, POPC bilayers doped with LA, r-LPS, or s-LPS (Fig. 16) were used to assess the contribution of different regions of outer-membrane LPS to the peptide activity against E. coli. 


\subsection{Preparation and perspectives of surface-tethered peptides}

It is expected that the antimicrobial activity of tethered peptides is influenced by both the peptide sequence and the solid surface. The aim of second part of the study was to know:

1. How does immobilization influence the biological and membrane permeabilizing activities of membrane active peptides?

1.1. How do the physical parameters of the solid material, such as: (i) the spacer length between the solid surface and the active sequences, (ii) the capacity of the functional groups on the surface, and (iii) the surface area of solid matrix affect the activities of the immobilized peptides?

1.2. How does immobilization at different positions of the peptide, $\mathrm{C}$ terminus, $\mathrm{N}$ terminus, and side chains, influence the activity spectrum?

2. What will be the effect of immobilization upon the mode of peptide action?

2.1. Could peptide tethering be used as a strategy to get insight into the mode of action of CAPs?

For this task, CAPs of different sources, structures, and modes of action were tethered on PEGylated resin beads as a model of solid surfaces. The synthesis resins included: TentaGel $\mathrm{S} \mathrm{NH}_{2}, \quad$ TentaGel $\mathrm{M} \mathrm{NH}_{2}, \quad$ TentaGel MB NH $\mathrm{N}_{2}, \quad$ HypoGel $400 \mathrm{NH}_{2}$, and HypoGel $200 \mathrm{NH}_{2}$ with various size, capacity and PEG spacer length (Table 9). The immobilized peptides included: (i) $\alpha$-helical membrane-active peptides, such as a synthetic model (KLAL) peptide and MK5E (a peptide derived from natural MG2), which act according to the carpet-like and toroidal pore mode respectively [44,118]; (ii) MEL, a membrane-active peptide with the ability to form discrete ion channels [8]; (iii) BUF, a highly cationic peptide without membrane-permeabilizing activity, which targets intracellular moieties [46]; and (iv) TP, an RW-rich peptide with a typical turn-turn structure which has ambiguous modes of action ranging from membrane lysis to interaction with intracellular targets $[119,120]$. Standard SPPS, thioalkylation, and oxime-forming ligation strategies were used to immobilize the peptides at the $\mathrm{C}$ and $\mathrm{N}$ termini and via different side-chain positions. In order to demonstrate the suitability of the peptides for preparation of bioactive surfaces, 
antimicrobial and hemolytic activities of tethered peptides were evaluated against E. coli and B. subtilis, as well as RBCs, and compared to that of soluble peptides. Model membranes such as POPC, POPC/POPG (3/1 [mol/mol]), POPC/POPG (1/3 [mol/mol]), loaded with calcein were prepared to assess the lipid bilayer-permeabilizing activities of soluble and tethered peptides. These results were correlated to their biological activities in order to study the influence of tethering upon the peptides mode of action. 


\section{Results and discussion}

\subsection{W-substituted c-WFW analogs}

In order to investigate the influence of the physicochemical properties of $\mathrm{W}$ residues upon the bacterial selectivity of c-WFW and to analyze the interaction with lipid bilayers mimicking the inner and outer membranes of bacteria, $\mathrm{W}$ residues were replaced in the sequence with unnatural amino acids, such as Dht, $\mathrm{Igl}, 1 \mathrm{MeW}, \mathrm{Bal}, 5 \mathrm{MeW}, 5 \mathrm{MeoW}, 5 \mathrm{fW}$ and b3-hW (Fig. 13). Each modification endows the cyclic peptide with a unique property (Table 2). The biological activities of the peptides were correlated with their affinity for lipid bilayers doped with LPS mutants in order to indentify structural motifs of the peptides and interaction partners on cellular level, which are responsible for the recognition of $E$. coli.

\subsubsection{Description and physicochemical properties of $\mathrm{W}$-analogs}

The aromatic side chain $\mathrm{W}$ is regarded as a highly hydrophobic residue based on the Liu-Deber hydrophobicity scale [121], characterized by a dipole moment of $\sim 2.1 \mathrm{D}$ in magnitude, which is directed from N-1 in the five-membered ring to C-5 in the six-membered ring of indole [122] and able to form hydrogen bonds.
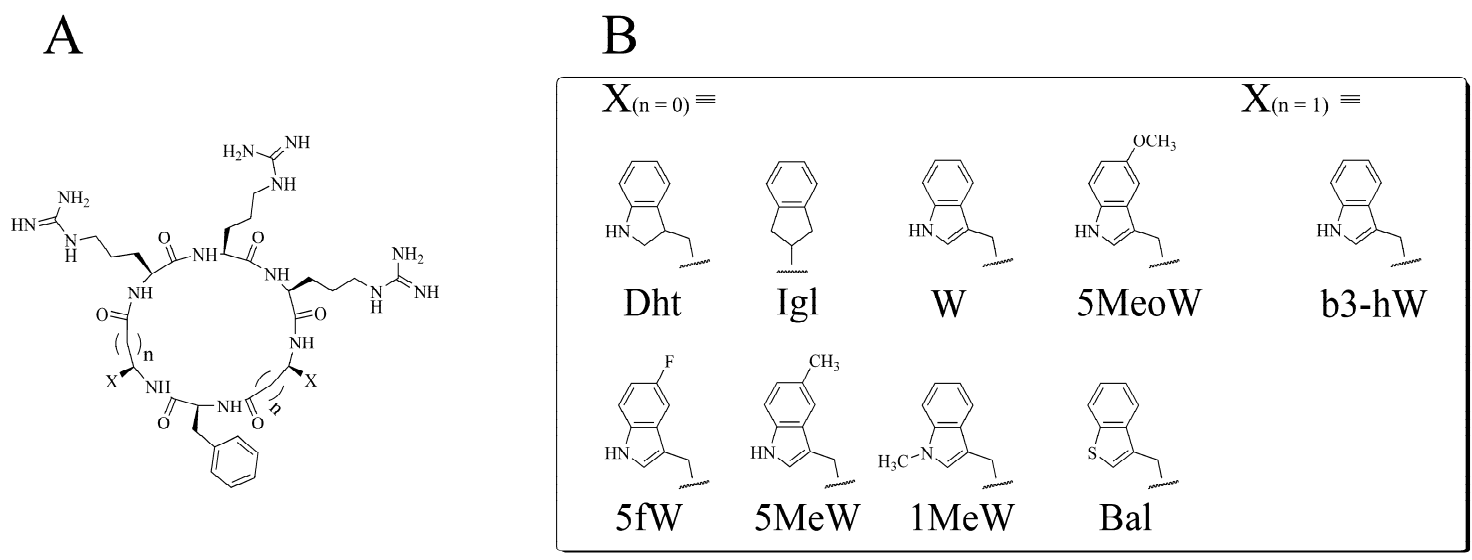

Fig. 13. A) Schematic structure of cyclic peptide with the positions for the desired modifications, and (B) chemical structure of the amino acids analogs of $W$ used in this study.

Dht is the product of the reduction of $\mathrm{W}$, is no longer planar in character and introduces steric, as well as charge distribution changes. With a changed distribution of 
electrons, it has neither the aromaticity nor the dipole moment of $\mathrm{W}$, but hydrogen bonding ability is conserved. As the aromaticity of $\mathrm{W}$ has been proposed as the reason for its waterlipid interfacial preference [63], Dht does not seem to position at this region. Igl also bears a fused-ring aromatic side chain, which is; however, closer to the backbone compared to Dht and incapable of hydrogen bonding. Similar to Dht, Igl is not expected to lie at the lipid-water interfacial region; however, it is more hydrophobic than Dht (Fig. 14, Table 3). The hydrogen bonding ability of $\mathrm{W}$ is blocked in the case of $1 \mathrm{MeW}$ by the more hydrophobic and bulky methyl group. However, $1 \mathrm{MeW}$ has the amphipaticity of $\mathrm{W}$ and a dipole moment $(\sim 2.2 \mathrm{D})$ with similar direction and magnitude [122]. Bal has the same size as the indole ring, but because of the lower electronegativity of the sulfur atom in the five-membered ring, its dipole moment is reduced compared to $\mathrm{W}$ (Table 2). It has no considerable amphipathic structure and does not have the hydrogen bonding characteristics of $\mathrm{W}$ [123]. Both $1 \mathrm{MeW}$ and Bal residues are more hydrophobic than $\mathrm{W}$. This appeared in the higher $t_{R}$-values of c$(1 \mathrm{MeW}) \mathrm{F}(1 \mathrm{MeW})$ and c-(Bal)F(Bal) compared to c-WFW (Fig. 14, Tables 3).

Table 2. Changes in the physicochemical characteristics of $W$ analogs.

\begin{tabular}{|c|c|c|c|c|c|c|}
\hline \multirow[b]{2}{*}{ Degree of change } & \multicolumn{6}{|c|}{ Physicochemical characteristics of W-analogs* } \\
\hline & \multicolumn{2}{|c|}{ Hydrogen bonding } & \multirow{2}{*}{$\begin{array}{c}\text { Dipole moment } \\
5 \mathrm{MeoW}\end{array}$} & \multirow{2}{*}{$\begin{array}{c}\text { Quadrupole moment } \\
5 \mathrm{MeoW}\end{array}$} & \multicolumn{2}{|c|}{ Amphipathicity } \\
\hline & $5 \mathrm{MeoW}$ & $5 \mathrm{fW}$ & & & & \\
\hline \multirow[t]{2}{*}{$>\mathrm{W}$} & & & $5 \mathrm{fW}$ & & & \\
\hline & Dht & b3-hW & b3-hW & b3-hW & $5 \mathrm{fW}$ & $5 \mathrm{MeoW}$ \\
\hline \multirow[t]{4}{*}{$=\mathrm{W}$} & \multirow{3}{*}{\multicolumn{2}{|c|}{$5 \mathrm{MeW}$}} & $5 \mathrm{MeW}$ & $5 \mathrm{MeW}$ & b3-hW & $5 \mathrm{MeW}$ \\
\hline & & & $1 \mathrm{MeW}$ & $1 \mathrm{MeW}$ & $1 \mathrm{MeW}$ & Dht \\
\hline & & & & Bal & & \\
\hline & & & Dht & Dht & & Igl \\
\hline \multirow[t]{2}{*}{$<\mathrm{W}$} & & & Igl & Igl & \multirow{2}{*}{\multicolumn{2}{|c|}{ Bal }} \\
\hline & & & Bal & $5 \mathrm{fW}$ & & \\
\hline
\end{tabular}

${ }^{*}$ The classification is based on the chemical structures of the residues. Their influence on peptide hydrophobicity and amphipathicity as reflected in the RP-HPLC retention behavior is shown in Table 3. 
Unlike 1Metrp, 5Metrp is potentially able to form hydrogen bonding with water or anionic phosphate and carboxylate groups of lipid membranes. However, the quadrupole moment (aromaticity) and the dipole moment of 5MeW are similar to that of $\mathrm{W}$ and $1 \mathrm{MeW}$ in magnitude and direction $[122,124]$. In contrast, the methoxy group and fluorine atom with their electron-withdrawing effect at C-5 will enhance the dipole moment of indole. However, the density of negative charges above and below the plane of the indole ring is weaker in the case of $5 \mathrm{fW}$, which will lead to a lower quadrupole moment compared to W. On the other hand, the methoxy group will push electrons into the indole ring plane resulting in strengthening the $\pi$-electron system and quadrupole moment compared to $\mathrm{W}$ [124]. Substitution of the hydrogen at C-5 by the methoxy group and fluorine atom will also enhance the hydrogen bonding character of the $-\mathrm{NH}-$ moiety. In addition, the methoxy group and fluorine atom can form hydrogen bonds with water molecules at the lipid bilayer interface. Incorporation of $\mathrm{b} 3-\mathrm{hW}$ with the same side chain as $\mathrm{W}$ enhances the size and likely the flexibility of the backbone ring (Fig. 13). Therefore, the lipid-bound peptide might adopt conformations different from the parent cyclic peptide (c-WFW) with a different degree of amphipathicity.

\subsubsection{Cyclic peptide synthesis and their HPLC characterization}

The sequences synthesized for this study (Table 3) are based on the previously described hexapeptide c-WFW with three adjacent aromatic and charged residues $[53,68]$. Key features, such as the number and distribution of the three $\mathrm{R}$ and non-charged residues were maintained.

The hydrophobicity/amphipathcity of c-WFW is characterized by $t_{\mathrm{R}}=18.83 \mathrm{~min}$ in RP-HPLC (Fig. 14, Table 3). Because of the protonation of $-\mathrm{NH}-$ at physiological $\mathrm{pH}$, the peptide with two Dht residues is much more hydrophilic than c-WFW. Also, c-(Igl)F(Igl) is highly hydrophilic and characterized by $t_{\mathrm{R}}=15.91 \mathrm{~min}$ in RP-HPLC. c-(b3-hW)F(b3-hW) is slightly more hydrophobic than c-WFW as the result of two extra methylene groups. The Balcontaining peptide is the most hydrophobic one in this series. Introduction of $5 \mathrm{MeoW}, 5 \mathrm{fW}$, $1 \mathrm{Metrp}$, and $5 \mathrm{MeW}$ only slightly enhances the hydrophocitiy compared to the parent peptide $\left(19.08 \mathrm{~min}<t_{\mathrm{R}}<20.41 \mathrm{~min}\right)$. 
Table 3. Amino acid sequences, calculated and observed molecular masses, and $t_{\mathrm{R}}$ in RP-HPLC of cWFW, W-substituted analogs, and the linear Ac-WFW.

\begin{tabular}{|c|c|c|c|c|}
\hline \multirow[b]{2}{*}{ Peptide denotation ${ }^{*}$} & \multirow[b]{2}{*}{ Amino acid sequence } & \multicolumn{2}{|c|}{ Molecular mass (Da.) } & \multirow[b]{2}{*}{$\begin{array}{c}t_{R} \\
(\mathrm{~min})\end{array}$} \\
\hline & & calculated & observed & \\
\hline $\mathrm{c}-(\mathrm{Dht}) \mathrm{F}(\mathrm{Dht})^{\dagger}$ & cyclo-RRR(Dht)F(Dht) & 992.2 & 992.5 & 9.92 \\
\hline c-(Igl)F(Igl) & cyclo-RRR(Igl)F(Igl) & 961.8 & 962.5 & 15.91 \\
\hline c-WFW & cyclo-RRRWFW & 988.2 & 988.5 & 18.83 \\
\hline c- $(5 \mathrm{MeoW}) \mathrm{F}(5 \mathrm{MeoW})$ & cyclo-RRR(5MeoW)F(5MeoW) & 1048.2 & 1049.1 & 19.08 \\
\hline c-(5fW)F(5fW) & cyclo-RRR(5fW)F(5fW) & 1024.2 & 1025.3 & 19.92 \\
\hline $\mathrm{c}-(\mathrm{b} 3-\mathrm{hW}) \mathrm{F}(\mathrm{b} 3-\mathrm{hW})$ & cyclo-RRR(b3-hW)F(b3-hW) & 1016.2 & 1016.6 & 20.06 \\
\hline $\mathrm{c}-(5 \mathrm{MeW}) \mathrm{F}(5 \mathrm{MeW})^{\dagger}$ & cyclo-RRR(5MeW)F(5MeW) & 1016.2 & 1016.6 & 20.37 \\
\hline $\mathrm{c}-(1 \mathrm{MeW}) \mathrm{F}(1 \mathrm{MeW})$ & cyclo-RRR(1MeW)F(1MeW) & 1016.2 & 1016.8 & 20.41 \\
\hline c-(Bal)F(Bal) & cyclo-RRR(Bal)F(Bal) & 1022.2 & 1022.4 & 22.03 \\
\hline Ac-WFW & Ac-RRWFWR-NH ${ }_{2}$ & 1047.2 & 1047.5 & 16.58 \\
\hline
\end{tabular}

${ }^{*}$ The purities of the products were more than $95 \%$ (Fig. 14).

${ }^{\dagger}$ These unnatural amino acids are not enantiomerically pure. See section for Abbreviations.

\subsubsection{Characterization of cyclic peptides by CD}

To get structural information on representative cyclic peptides in comparison to the linear Ac-WFW, CD spectra of the peptides containing N-1 and C-5 substituted W analogs, c(b3-hW)F(b3-hW), and $\mathrm{c}-(\mathrm{Bal}) \mathrm{F}(\mathrm{Bal})$, as well as the parent peptide, were recorded in phosphate buffer, a mixture of buffer and TFE and in the SDS micelle- and POPG liposomebound state (Fig. 15). While studies in buffer provide information on the structural flexibility of peptides in aqueous solution, TFE represents a solvent which induces intramoleular and intermolecular hydrogen bonding and thus favours helix formation of linear peptides [125]. TFE solvent conditions were taken to monitor the ability / propensity of peptides to adapt a secondary structure [17]. The anisotropic nature of SDS micelles and POPG bilayers represent more suitable models of cell membranes and the high negative charge provides the basis for high peptide binding [126,127].

The spectra of c-WFW dissolved in buffer shows a negative band and a shoulder at 200 and $220 \mathrm{~nm}$, respectively (Fig. 15). The ellipticities at $200 \mathrm{~nm}$ and below originate from the peptide bonds and thus changes in this spectral region reflect the properties of the backbone. Less negative and positive ellipticities below $200 \mathrm{~nm}$ are associated with 
constrained structures. In the wavelength region of $220-230 \mathrm{~nm}$, contribitions of the peptide bond and the aromatic side chains superimpose. In the presence of TFE only minor spectral changes were observed for c-WFW, thus confirming a rather limited conformational flexibility of the cycle. Furthermore, interaction with SDS and POPG had minor influences upon the conformation.
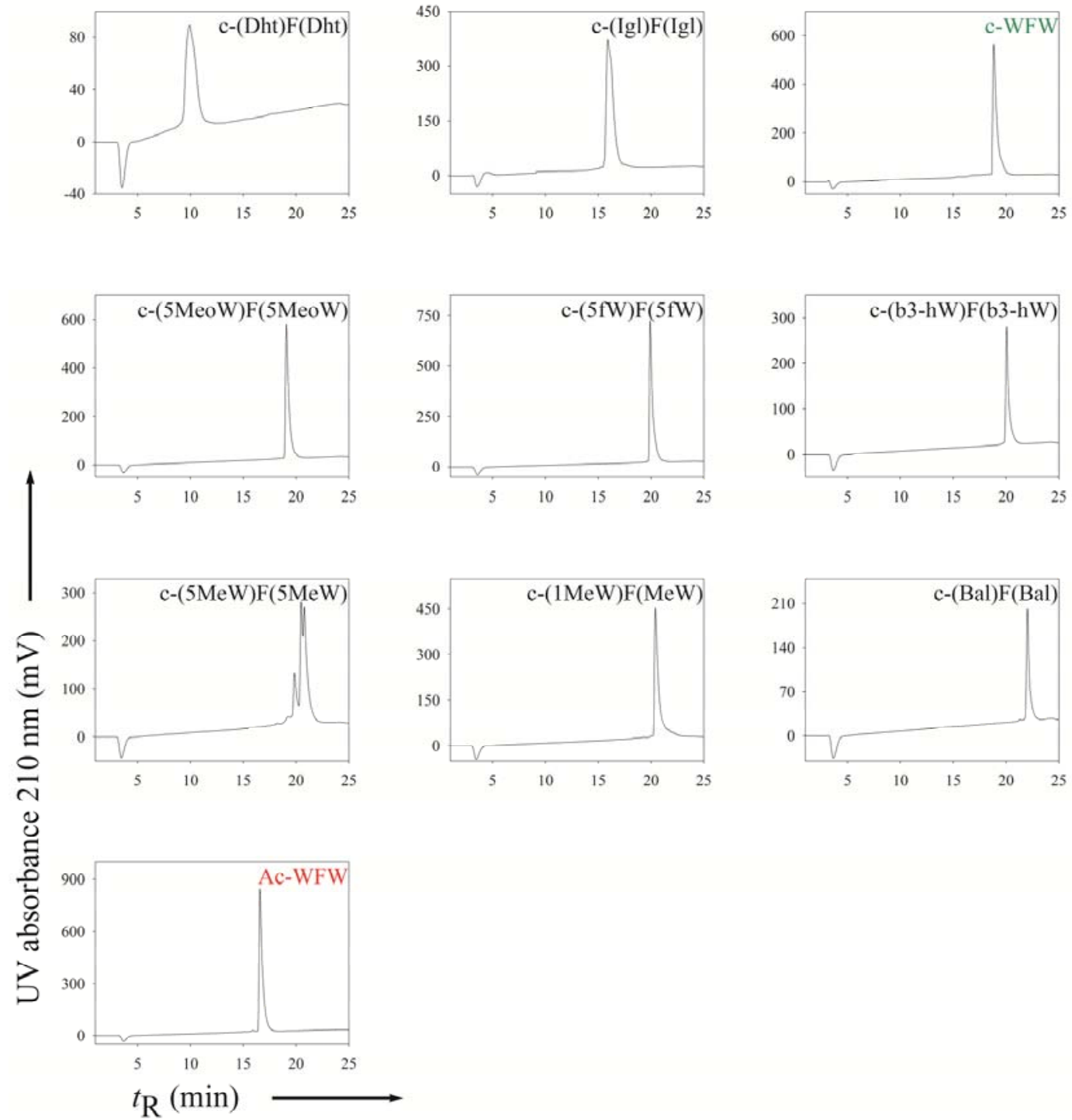

Fig.14. HPLC profile of c-WFW, W-substituted analogs, and the linear Ac-WFW. Except for the linear sequence, the panels were organized according to the increase in the $t_{\mathrm{R}}$-values of the cyclic peptides. The chromatogram for $\mathrm{c}-(5 \mathrm{MeW}) \mathrm{F}(5 \mathrm{MeW})$ clearly displays mixtures of diastereomers. 


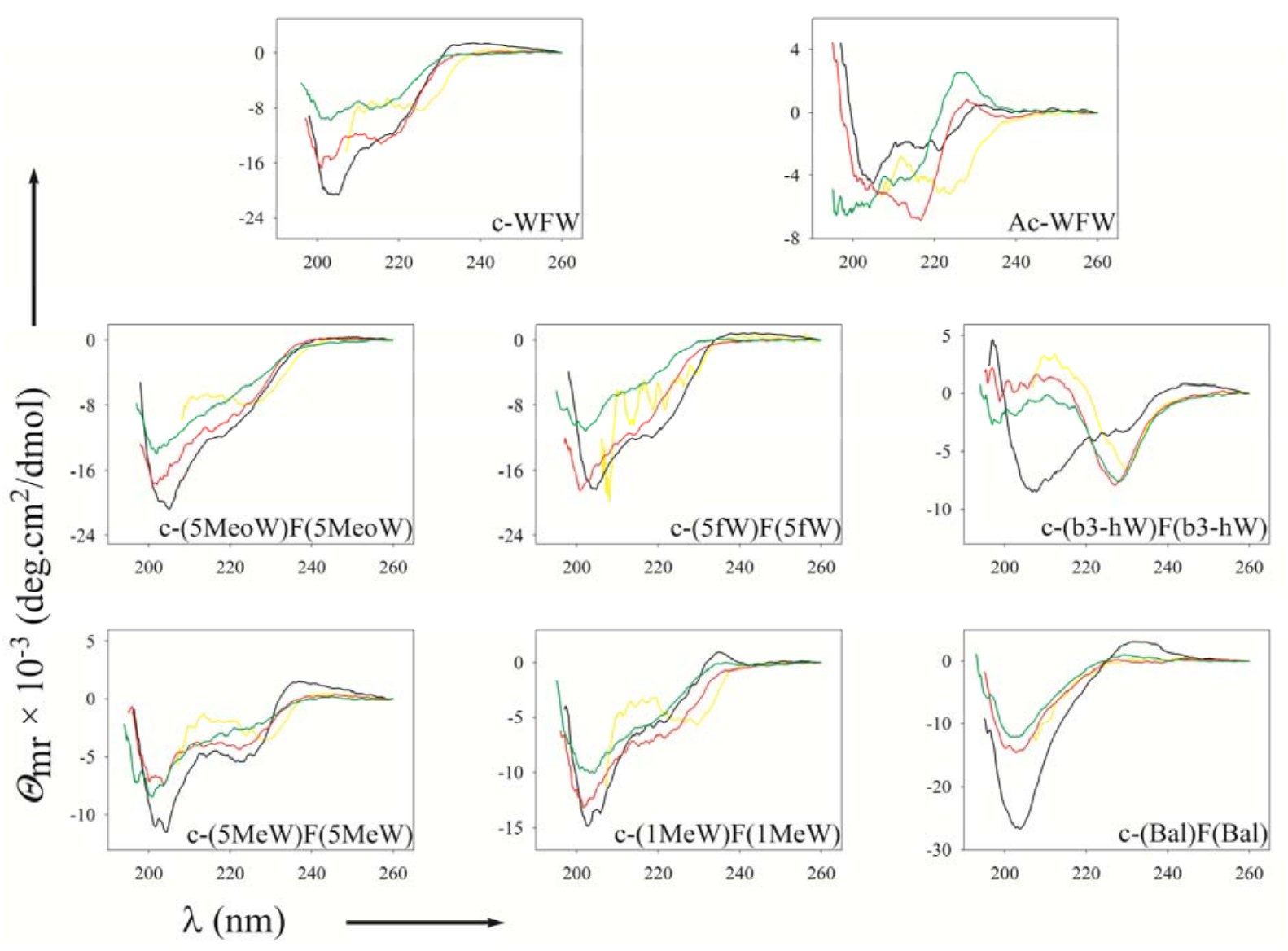

Fig. 15. Far-UV CD spectra of cylic peptides in phosphate buffer (green), 1:1 TFE/buffer [v/v] (red), SDS bound (black), and POPG SUVs lipid bound (yellow) $\left(T=20^{\circ} \mathrm{C}\right)$.

Ac-WFW reveals a positive band at $225 \mathrm{~nm}$ and decreasing ellipticity values down to $200 \mathrm{~nm}$ and below, which are characteristic of small random-coil peptides. In the presence of TFE, Ac-WFW showed spectral properties comparable to c-WFW though with different band intensities. Binding to POPG vesicles shifts the negative band from 220 to $\sim 225 \mathrm{~nm}$. The changes in the spectral characteristics of Ac-RW are comparable to those observed for c-RW which have been attributed to restrictions in the backbone structure and changes in the environment of the aromatic residues [53]. The increase in band intensity in the $200 \mathrm{~nm}$ region observed for SDS-bound c-WFW, in comparison to the solution structure, could also be associated with a reduction of flexibility in the cyclic backbone. The derived NMR structure of c-RW and Ac RW in micelle- and lipid-bound states [67,71] indicates that the amphipathic structures of the cyclic peptides were little modified with sequence modifications [73]. Thus, the CD spectra of c-WFW is assumed to reflect the structures derived from NMR measurements: a hydrophobic cluster of the aromatic residues in contact to the hydrophobic 
chains of SDS and POPG and the backbone and cationic side chains exposed to the negative charges of SDS and POPG. Introduction of $5 \mathrm{MeoW}, 5 \mathrm{fW}, 5 \mathrm{MeW}$ and $1 \mathrm{MeW}$ had little influence upon the spectral characteristics of the cycles. However, following introduction of Bal, the contribution of the aromatic side chain to the spectrum was lost. The pronounced band intensity of the SDS-bound peptide at lower wavelengths $(210 \mathrm{~nm})$, where the contribution of the backbone amid bonds predominates suggests that binding also reduces the number of backbone conformers of c-(Bal)F(Bal).

Introduction of b3-hW enlarges the ring size and is expected to enhance the backbone flexibility of the hexapeptide. The b3-hW-containing peptide shows a sharp negative band at $\sim 225-230 \mathrm{~nm}$, both in aqueous environment and when bound to POPG membranes (Fig. 15). This pronounced conformational change might be due to the disturption of the $\beta$-turn motifs in c-WFW [73] and induction of an amphipathic conformation different from that of c-WFW. Interestingly, in the SDS-bound state, spectral characeristics comparable to the other cyclic peptides, with a pronounced band in the $200 \mathrm{~nm}$ region, was observed for c-(b3-hW)F(b3$\mathrm{hW}$ ). This suggests that this peptide is also able to assume an amphipathic structure as suggested for the cyclic parent sequence and other analogs. Recent studies with analogs of Gramicidin S, with ring sizes ranging from 10 to 16 amino acid residues, confirmed the importance of amphipathicity induced by the $\beta$-turn/ $\beta$-sheet structure in interaction with membranes [128]. Disruption of the structure by increasing the size of the cyclic peptide weakened the peptides' interactions with POPC vesicles and reduced their hemolytic, antimicrobial, and antifungal activities.

\subsubsection{Antibacterial and hemolytic activities}

The antimicrobial activities of c-WFW, its analogs and the linear sequence (Ac-WFW) are summarized in Table 4. In general, the activity of the cyclic peptides was higher against B. subtilis than E. coli and correlated with the peptide hydrophobicity.

While the flexible Ac-WFW and hydrophilic peptides, i.e, c-(Dht)F(Dht) and c(Igl)F(Igl), showed MICs against B. subtilis in the range of $25-50 \mu \mathrm{M}$, the cyclic peptides, with $t_{\mathrm{R}}$-values ranging between $18.93 \mathrm{~min}$ and $22.03 \mathrm{~min}$, were highly active $(1.6 \mu \mathrm{M}<\mathrm{MIC}<6.3 \mu \mathrm{M})$. The reduction in activity of $\mathrm{c}-(\mathrm{b} 3-\mathrm{hW}) \mathrm{F}(\mathrm{b} 3-\mathrm{hW})$ by one dilution step compared to c-WFW correlates with an enhanced flexibility in the cyclic backbone. 
Table 4. Antimicrobial activities, and hemolytic activities of the peptides used in this study.

\begin{tabular}{|c|c|c|c|}
\hline \multirow[b]{2}{*}{ Peptide denotation } & \multicolumn{2}{|c|}{$\operatorname{MIC}(\mu \mathrm{M})^{*}$} & \multirow[b]{2}{*}{ Hemolysis for RBCs } \\
\hline & B. subtilis (DSM 347) & E. coli $($ DH $5 \alpha)$ & \\
\hline $\mathrm{c}-(\mathrm{Dht}) \mathrm{F}(\mathrm{Dht})$ & 50 & 200 & 1 \\
\hline c-(Igl)F(Igl) & 25 & 200 & 3 \\
\hline c-WFW & 3.1 & 3.1 & 6 \\
\hline c- $(5 \mathrm{MeoW}) \mathrm{F}(5 \mathrm{MeoW})$ & 3.1 & 12.5 & 1 \\
\hline$c-(5 \mathrm{fW}) \mathrm{F}(5 \mathrm{fW})$ & 1.6 & 3.1 & ND \\
\hline c-(b3-hW)F(b3-hW) & 6.3 & 50 & 1 \\
\hline $\mathrm{c}-(5 \mathrm{MeW}) \mathrm{F}(5 \mathrm{MeW})$ & 3.1 & 6.3 & 5 \\
\hline $\mathrm{c}-(1 \mathrm{MeW}) \mathrm{F}(1 \mathrm{MeW})$ & 3.1 & 6.3 & 27 \\
\hline $\mathrm{c}-(\mathrm{Bal}) \mathrm{F}(\mathrm{Bal})$ & 1.6 & 12.5 & 70 \\
\hline Ac-WFW & 50 & 400 & ND \\
\hline
\end{tabular}

${ }^{*}$ Values represent the means of three independent experiments performed in triplicate. Standard deviations after $17 \mathrm{~h}$ of cell incubation at $37^{\circ} \mathrm{C}$ were $<5 \%$ (Fig. 39).

†Values represent the percentage release of hemoglobin from human RBCs upon incubation with cyclic peptides at $c_{\mathrm{P}}=200 \mu \mathrm{M}$. Hemolytic activity was monitored by measuring the absorbance at $\lambda=540 \mathrm{~nm}$.

${ }^{*} \mathrm{ND}$, not determined.

The activity spectrum of the peptides against E. coli was more complex. The activity of Ac-WFW, which is very low $(\mathrm{MIC}=400 \mu \mathrm{M})$, increased $>130$-fold after cyclization. The MIC of c-WFW against E. coli was $3.1 \mu \mathrm{M}$ and the same for B. subtilis. Increasing the ring size of the cyclic peptide in $\mathrm{c}-(\mathrm{b} 3-\mathrm{hW}) \mathrm{F}(\mathrm{b} 3-\mathrm{hW})$ caused 16-fold reduction in anti-E. coli activity $(\mathrm{MIC}=50 \mu \mathrm{M})$. The least hydrophobic peptides, $\mathrm{c}-(\mathrm{Dht}) \mathrm{F}(\mathrm{Dht})$ and $\mathrm{c}-(\mathrm{Igl}) \mathrm{F}(\mathrm{Igl})$, showed little activity against $E$. coli $(\mathrm{MIC}=200 \mu \mathrm{M})$, which supports a significant role of hydrophobicity and the amphipathic nature of $\mathrm{W}$ residues upon antimicrobial effect. Interestingly, c-(5MeoW)F(5MeoW) and the most hydrophobic peptides, i.e., c-(Bal)F(Bal), were also much less active against the Gram-negative strain than c-WFW, an observation different to B. subtilis where the MIC values were reduced or conserved, respectively. The observation for the antimicrobial activities of $\mathrm{c}-(\mathrm{Bal}) \mathrm{F}(\mathrm{Bal})$ is in contrast to the results on the bactericidal activity of a 15-residue Bal-modified lactoferricin derivative, which exhibited higher activity than the parent peptide against $S$. aureus and E. coli $[123]$. c- $(5 \mathrm{fW}) \mathrm{F}(5 \mathrm{fW})$ had 
the same activity as c-WFW whereas c- $(5 \mathrm{MeW}) \mathrm{F}(5 \mathrm{MeW})$ and $\mathrm{c}-(1 \mathrm{MeW}) \mathrm{F}(1 \mathrm{MeW})$, two peptides with comparable high hydrophobicity, were less active against $E$. coli.

Except for the most hydrophobic peptides, c-(Bal)F(Bal) and c-(1MeW)F(1-MeW), causing $70 \%$ and $30 \%$ hemoglobin release from human RBCs repectively at $200 \mu \mathrm{M}$, all peptides showed no significant hemolytic activity (Table 4). The different susceptibilities of cells can be explained on the basis of peptide accumulation at the lipid matrices of the target membranes driven by electrostatic interactions.

\subsubsection{Cyclic peptide binding to lipid bilayers determined by ITC}

\subsubsection{Lipid bilayers as model of biological membranes}

The envelope of Gram-negative E. coli bacteria consists of an inner (cytoplasmic) membrane with a composition of $80 \%$ POPE, 15\% POPG, and 5\% cardiolipin [23], and a highly asymmetric outer membrane with LPS (>90\%) in the outer leaflet and POPE as the main components of the inner leaflet. To study peptide binding to lipid membranes, POPC, POPC/POPG (3/1 [mol/mol]), POPC/LA (12/1 [mol/mol]), and POPC mixed with two E. coli LPS chemotypes (POPC/Rd-LPS and POPC/s-LPS ratio=12/1) (Fig. 16), were chosen to mimic the charge properties of mammalian and Gram-negative cellular inner (cytoplasmic) and outer membranes [127].

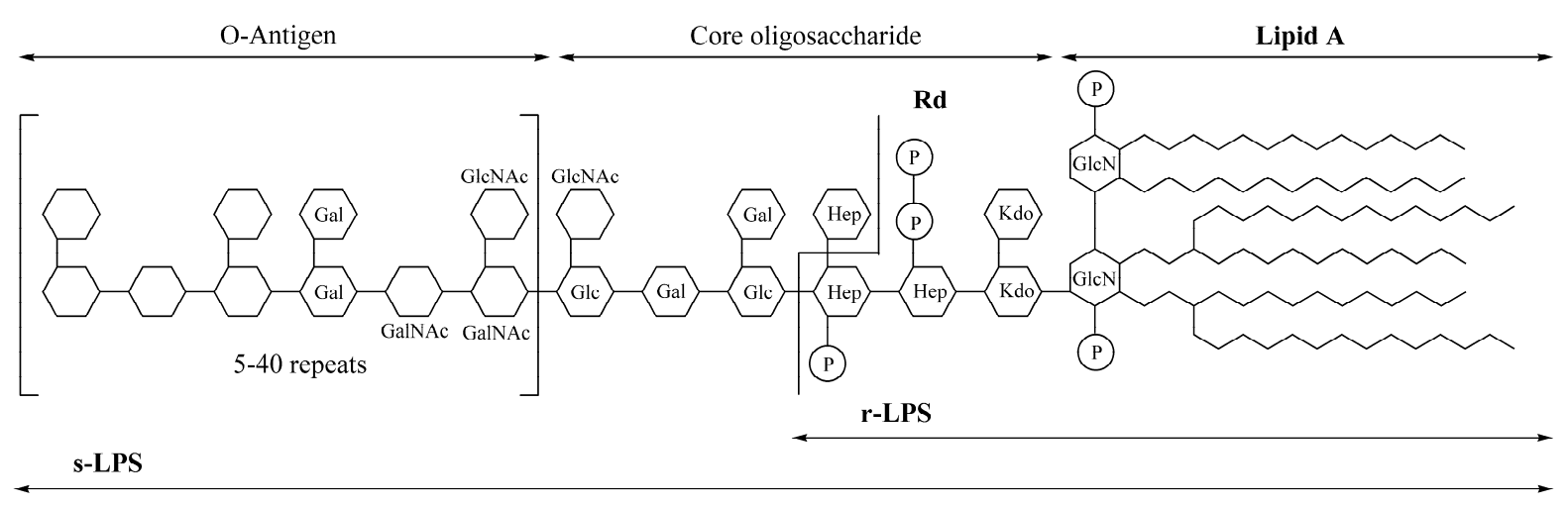

Fig. 16. Schematic structure of different LPS chemotypes from E. coli.

Due to POPE having a negative curvature strain, which might interfere in liposome formation, especially in the presence of natural lipids, such as LA and LPS [21], POPC was used as the zwitterionic phospholipid for the preparation of mixed vesicles. LA is the 
conserved part of LPS and has two divalent phosphate anions $\left(\left[-\mathrm{OPO}_{3}\right]^{-2}\right)$, and thus the ratio of negative charges of phosphate anions in POPC/LA (12/1 [mol/mol]) vesicles is the same as POPC/POPG (3/1 [mol/mol]). The main difference between the two LPS chemotypes comes from the composition of the polysaccharide part. The negatively charge mono $\left(\left[-\mathrm{OPO}_{3}-\right]^{-}\right)$ and divalent phosphate anions and carboxylate groups $\left(\left[-\mathrm{CO}_{2}\right]\right)$, attached at various positions to heptose moieties, are located at the inner core oligosaccharide part of LPS, resulting in the same number of negative charges for r-LPS and s-LPS. s-LPS has a long polysaccharide region of repeating oligosaccharide units (O-antigen region) attached to the core polysaccharide. In contrast, r-LPS belongs to deep rough mutants with the sugar moieties limited to the inner core oligosaccharide [28]. In this study, only the total negative charges of phosphates anions (nine charges) were considered for binding studies.

\subsubsection{Peptide accumulation as reflected by apparent binding}

\section{Influence of lipid composition upon binding}

Figs. 17 and 18 display typical ITC titration traces of small aliquots of POPC and POPC/POPG (3/1 [mol/mol]) SUV suspensions into the calorimeter cell containing the peptides at $37^{\circ} \mathrm{C}$. The surface underneath each signal represents the heat flow after an individual titration step. In general, the heat of binding of the cyclic peptides decreases with the number of injections because less and less peptide is available for binding. The signals finally approach the heat of dilution indicating that virtually all the peptide is bound to lipid vesicles. Comparable traces, but of enhanced signal intensity, were observed for peptide titration with POPC/POPG SUVs showing a much enhanced interaction of the cationic peptides with the negatively charged lipid system due to strong electrostatic interactions (Figs. 17, 18).

To investigate the role of LPS in peptide selectivity against $E$. coli, peptide binding to POPC bilayers containing LA, r-LPS or s-LPS at a molar ratio of 12/1 was studied. The ITC traces for peptide interaction with POPC/s-LPS (12/1 [mol/mol]) are shown as an example in Fig. 19. Fig. 20 demonstrates the binding isotherms for the lipid systems derived from the ITC traces, which gives $R_{\mathrm{b}}$ as function of $c_{\mathrm{P}, \mathrm{f}}$. Except for the most hydrophilic peptide, c(Dht)F(Dht), the binding curves for peptide interaction with the POPC containing LA, r-LPS, and mixed POPC/POPG bilayers were almost comparable (Fig. 20). 
r-LPS contains roughly nine negatively charged phosphate groups and thus peptide binding to POPC/r-LPS bilayers was expected to be higher than to POPC mixed with LA, which bears two phosphate groups. However, it was found that the increase in negative charge in r-LPS-doped bilayers compared to the POPC/LA system only slightly enhanced $R_{\mathrm{b}}$ (Fig. 20). In contrast, in the presence of s-LPS, peptide binding distinctly increased and the $R_{\mathrm{b}}$ values were doubled compared to r-LPS and LA with reduced size of the carbohydrate moiety (Fig. 20). This binding behavior correlates with reduced antimicrobial activity against Oantigen- and outer core-deficient LPS mutant E. coli strains, which was observed for RW-rich cyclic hexapeptides with three adjacent aromatic residues [70].
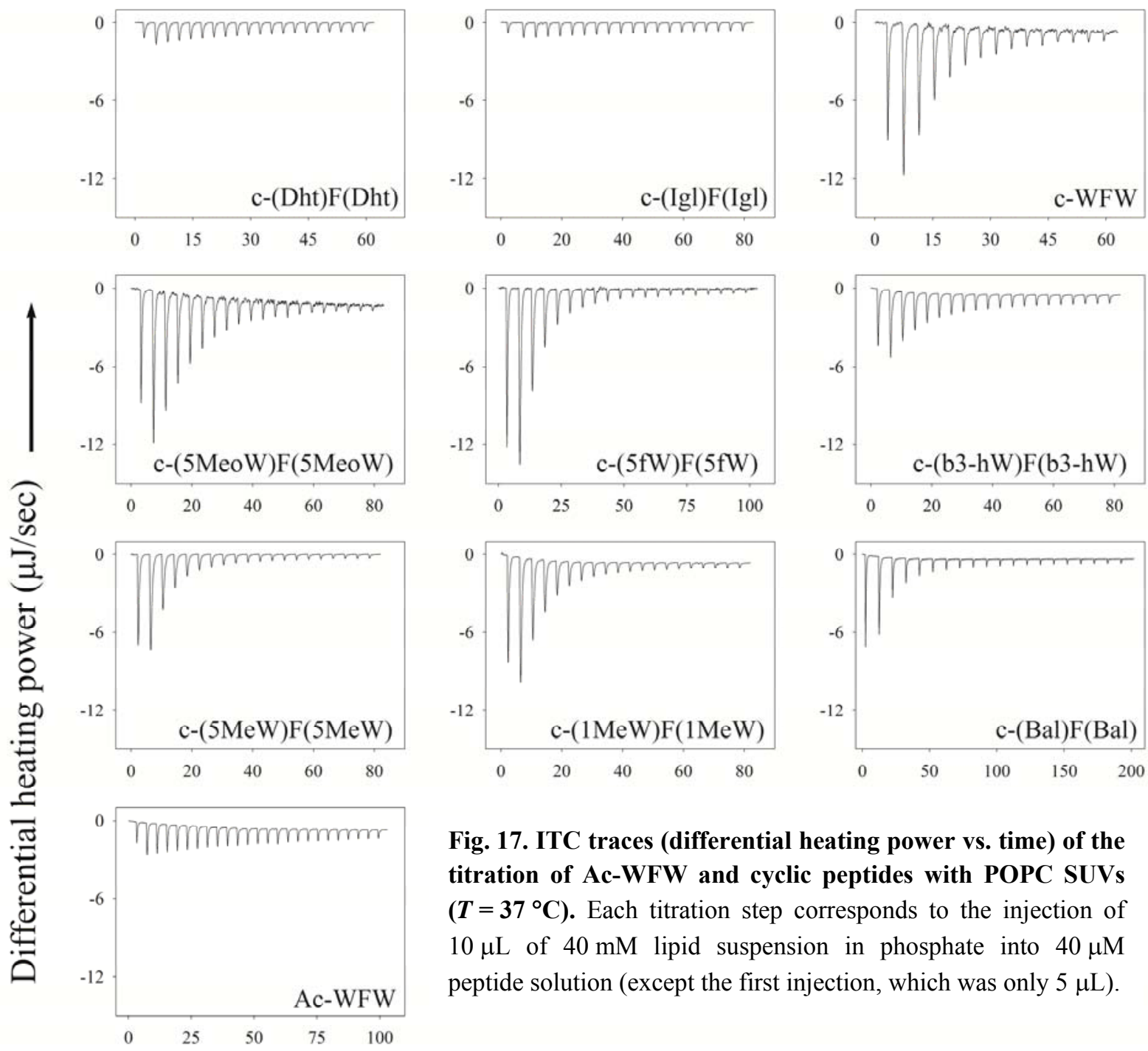

Fig. 17. ITC traces (differential heating power vs. time) of the titration of Ac-WFW and cyclic peptides with POPC SUVs $\left(\boldsymbol{T}=37^{\circ} \mathbf{C}\right)$. Each titration step corresponds to the injection of $10 \mu \mathrm{L}$ of $40 \mathrm{mM}$ lipid suspension in phosphate into $40 \mu \mathrm{M}$ peptide solution (except the first injection, which was only $5 \mu \mathrm{L}$ ).

Time (min) 
Role of sequence composition upon binding

Low binding of the linear and the two most hydrophilic cyclic peptides to POPC is reflected by $R_{\mathrm{b}}$ values $\left(\sim 1 \times 10^{-2} \mathrm{~mol} / \mathrm{mol}\right.$ at $c_{\mathrm{P}, \mathrm{f}}=30 \mu \mathrm{M}$; calculated according to the Eq. 4 shown in the experimental section) (Fig. 20). The $R_{\mathrm{b}}$ values (at $c_{\mathrm{P}, \mathrm{f}}=30 \mu \mathrm{M}$ ) follow the order: Ac-WFW $\approx \mathrm{c}-(\operatorname{Igl}) \mathrm{F}(\operatorname{Igl}) \approx \mathrm{c}-(\mathrm{Dht}) \mathrm{F}(\mathrm{Dht})<\mathrm{c}-(5 \mathrm{MeoW}) \mathrm{F}(5 \mathrm{MeoW}) \approx \mathrm{c}-(\mathrm{b} 3-\mathrm{hW}) \mathrm{F}(\mathrm{b} 3-\mathrm{hW})<$ $\mathrm{c}-\mathrm{WFW} \approx \mathrm{c}-(1 \mathrm{MeW}) \mathrm{F}(1 \mathrm{MeW})<\mathrm{c}(5 \mathrm{fW}) \mathrm{F}(5 \mathrm{fW}) \approx \mathrm{c}-(5 \mathrm{MeW}) \mathrm{F}(5 \mathrm{MeW})<\mathrm{c}-(\mathrm{Bal}) \mathrm{F}(\mathrm{Bal})$ (Fig. 20). The negative charge in POPC/POPG bilayers enhanced the $R_{\mathrm{b}}$, but also reduced differences in $R_{\mathrm{b}}$ between the individual peptides (Fig. 20).
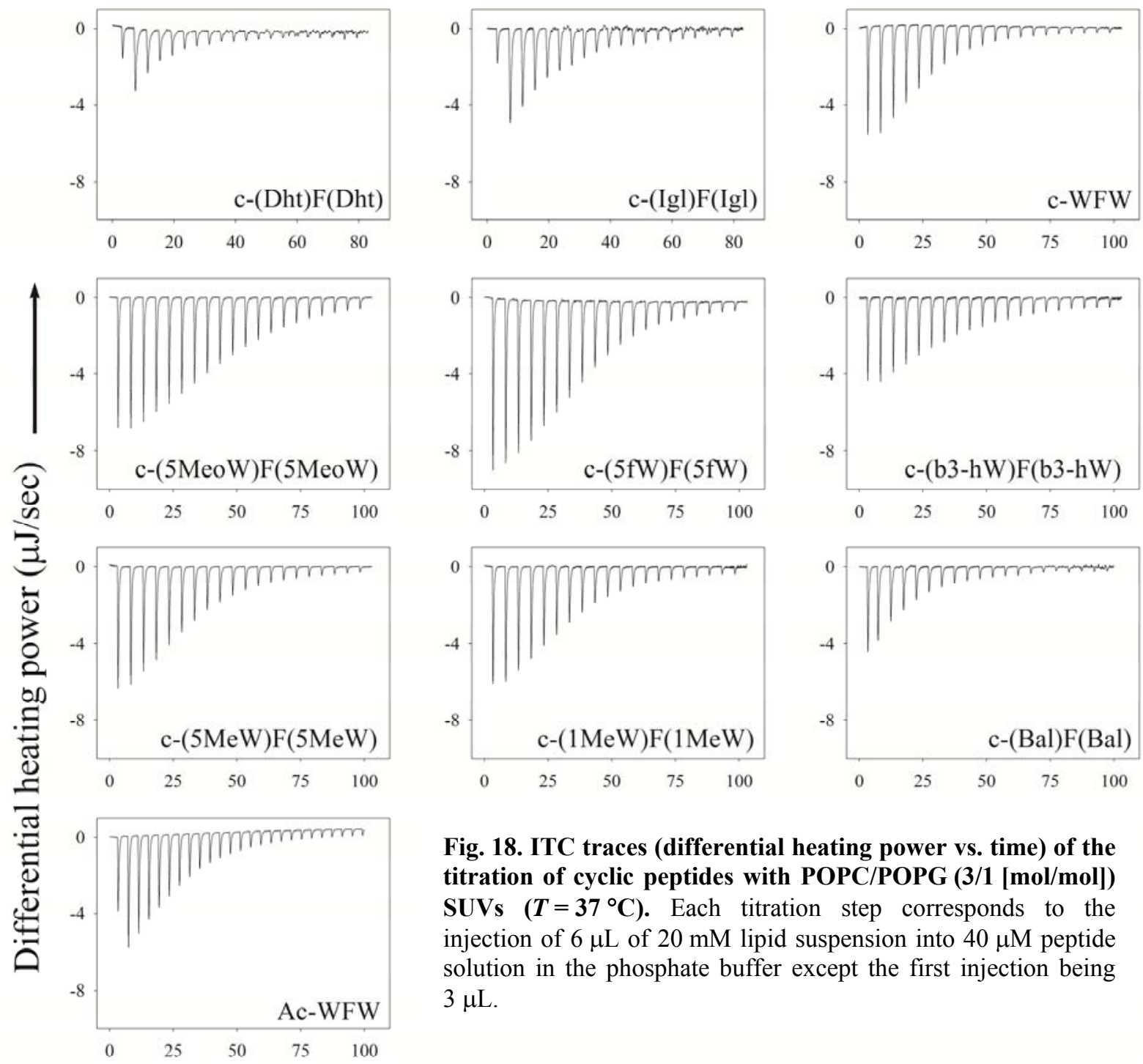

Fig. 18. ITC traces (differential heating power vs. time) of the titration of cyclic peptides with POPC/POPG (3/1 [mol/mol]) SUVs $\left(\boldsymbol{T}=\mathbf{3 7}{ }^{\circ} \mathbf{C}\right)$. Each titration step corresponds to the injection of $6 \mu \mathrm{L}$ of $20 \mathrm{mM}$ lipid suspension into $40 \mu \mathrm{M}$ peptide solution in the phosphate buffer except the first injection being $3 \mu \mathrm{L}$.

Time (min) 
With respect to the magnitude and sequence dependency of the thermodynamic parameters, the binding of the cyclic peptides to POPC/LA was comparable to that of POPC/POPG lipid system. Interestingly, for POPC containing r-LPS and s-LPS, peptide sequence-related differences were reduced (Fig. 20). An exception is Ac-WFW; its binding to liposomes containing LA, r-LPS and s-LPS was as low as to POPC and POPC/POPG SUVs.
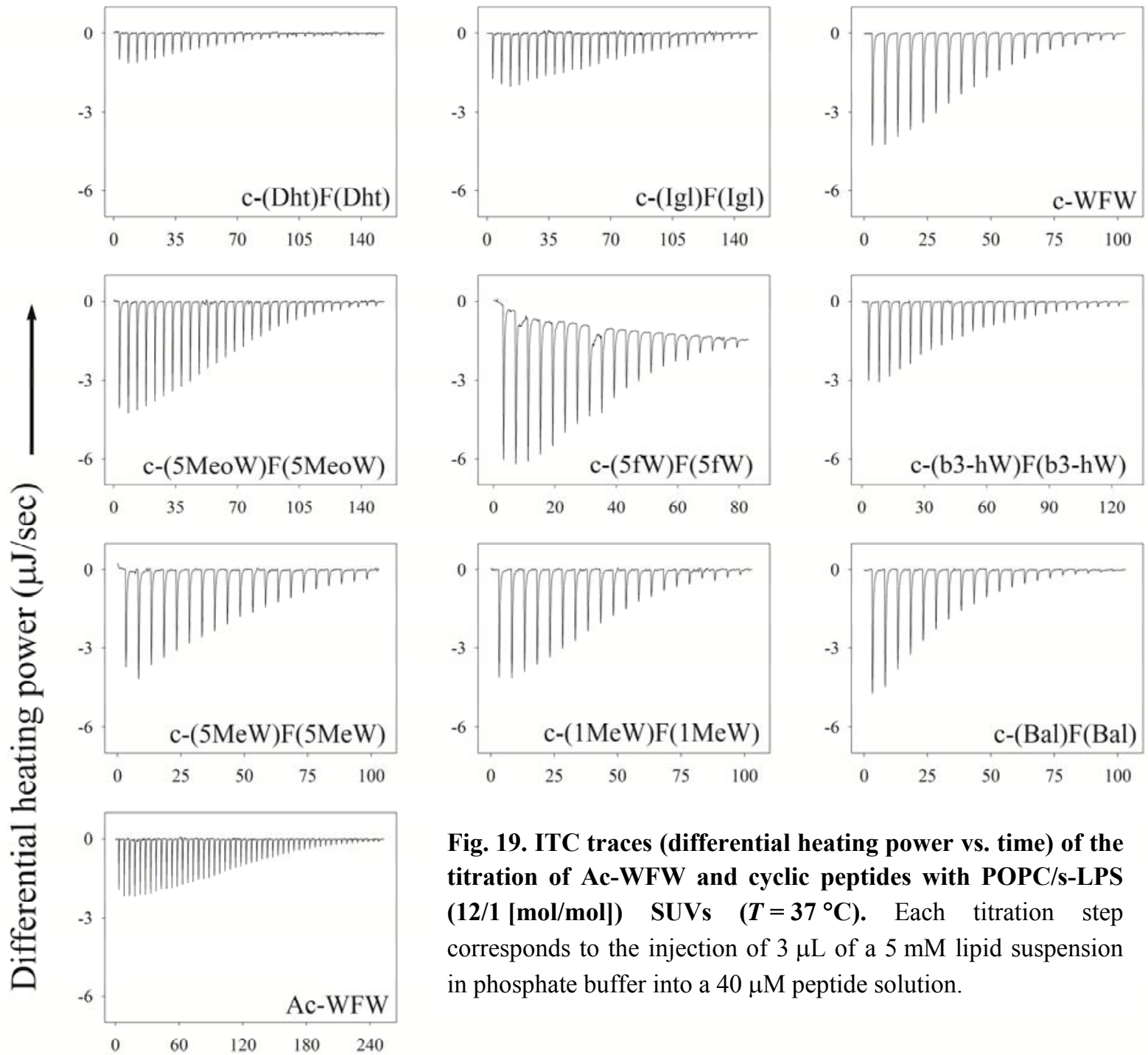

Fig. 19. ITC traces (differential heating power vs. time) of the titration of Ac-WFW and cyclic peptides with POPC/s-LPS $(\mathbf{1 2} / \mathbf{1}[\mathrm{mol} / \mathrm{mol}])$ SUVs $\quad\left(T=37^{\circ} \mathbf{C}\right)$. Each titration step corresponds to the injection of $3 \mu \mathrm{L}$ of a $5 \mathrm{mM}$ lipid suspension in phosphate buffer into a $40 \mu \mathrm{M}$ peptide solution.

Time (min)

These differences might be due to favorable contributions of the sugar moieties of LPS to peptide binding. In a recent study, the interactions between carbohydrates and aromatic groups have been described in terms of the hydrophobic effect, dispersion forces and carbohydrate- $\pi$ electron interaction [129]. Carbohydrates interact in a favorable manner with 
peptides and proteins via stacking involving aromatic side chains [129]. The $\pi$-electron distribution, surface area, and flexibility of the aromatic systems affect the magnitude of the interaction. In recent studies on a $\beta$-hairpin peptide containing a $\mathrm{W}$ residue, as well as a glucosyl or galactosyl analog of serine, strong intramolecular carbohydrate- $\pi$ electron interaction $(2.1-3.3 \mathrm{~kJ} / \mathrm{mol}$; stronger than $\pi-\pi$ or cation $-\pi$ interactions) were found to stabilize the peptide's secondary structure [129].
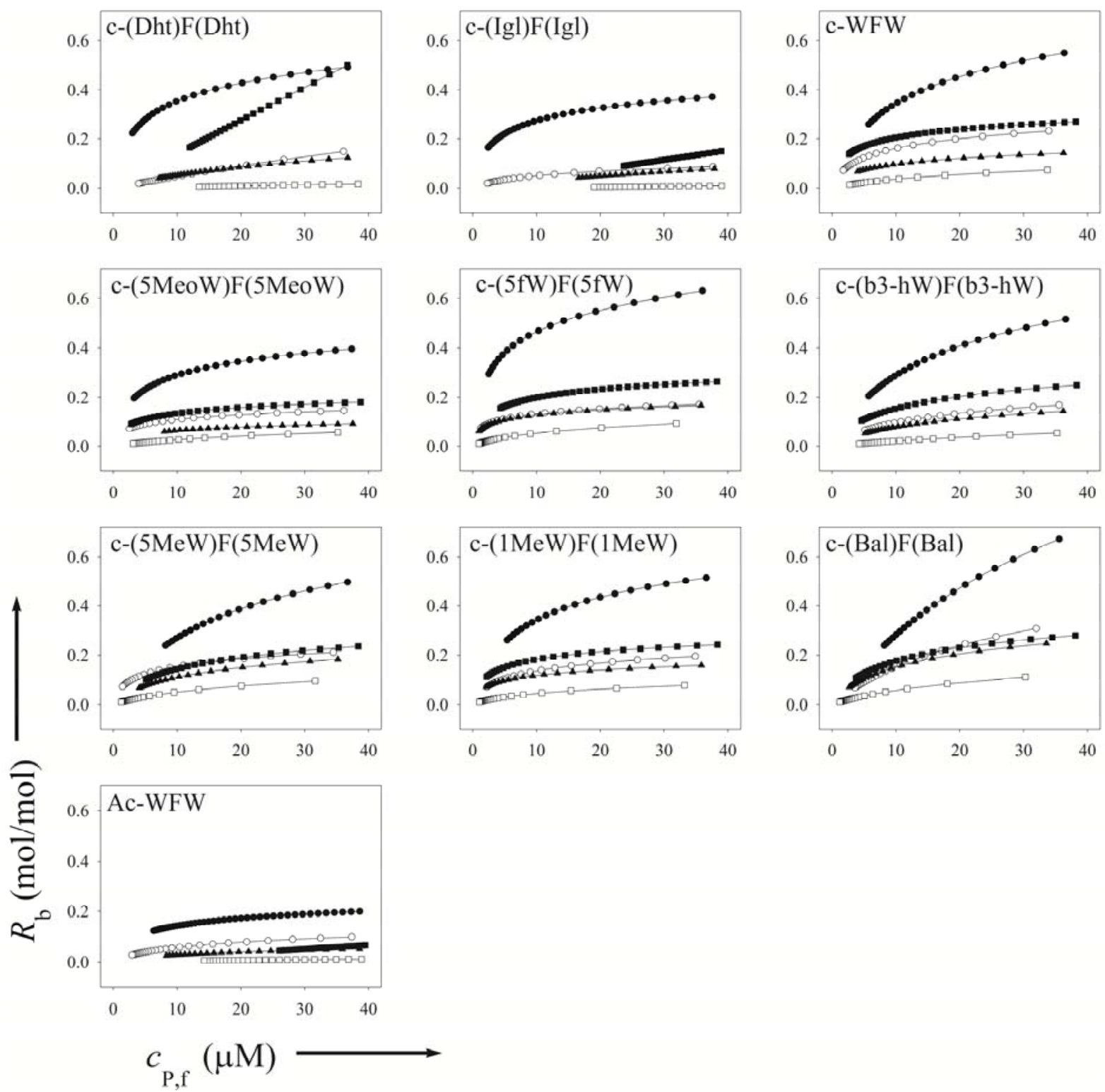

Fig. 20. Binding isotherms of cyclic and linear peptides for $(\square)$ POPC, $(\odot)$ POPC/POPG $(3 / 1$ [mol/mol]),

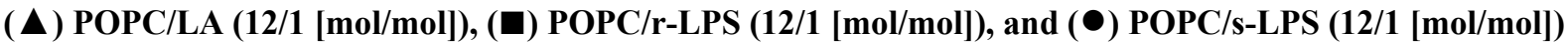
SUVs $\left(T=37^{\circ} \mathbf{C}\right)$. It is assumed that the cationic peptides cannot cross the bilayers and only $60 \%$ of the total lipid amount is accessible for binding. The data were calculated by combining a surface partitioning equilibrium with Gouy-Chapman theory. The fit parameters $\left(K_{0}, \Delta H^{\circ}\right.$, and $\left.z_{\mathrm{P}}\right)$ are listed in Tables 5 and 6. 


\subsubsection{Peptide partitioning in lipid bilayers}

\section{Influence of lipid composition upon binding}

Figs. 21 and 22, and Tables 5 and 6 show the $\Delta G^{\circ}$ and $K_{0}$ values of the individual peptides for binding to lipid bilayers. The best fits of binding data were obtained for $z_{\mathrm{P}}$ smaller than the nominal charge of peptides. Peptide partitioning ( $\Delta G^{\circ}$ and $K_{0}$ values) into POPC, POPC/POPG and POPC/LA did not differ. This indicates that the hydrophobic contribution to binding to these lipid systems is identical and independent upon interactions between the cationic $\mathrm{R}$ residues and the negatively charged lipid phosphate groups. However, in the presence of sugar moieties of the inner core and O-antigen of LPS, peptide partitionig increased. As shown in Fig. 22A, the negative values for $\Delta G^{\circ}$ are arranged in the following order: POPC/LA $<$ POPC/r-LPS $\ll$ POPC/s-LPS. The $K_{0}$ values for peptide binding to POPC/s-LPS bilayer were almost one order of magnitude higher than for binding to bilayers doped with O-antigen-deficient r-LPS and LA (Table 6). Based upon these observations, it can be concluded that hydrophobic peptide-LPS interaction is essential for an efficient transport across the bacterial outer membrane, but that LA does not act as a specific activity modulating binding site of the hexapeptides. This is in accordance with observations with lactoferricin peptides suggesting that the tight fatty acid packing in LA is not the primary site of interaction [130].
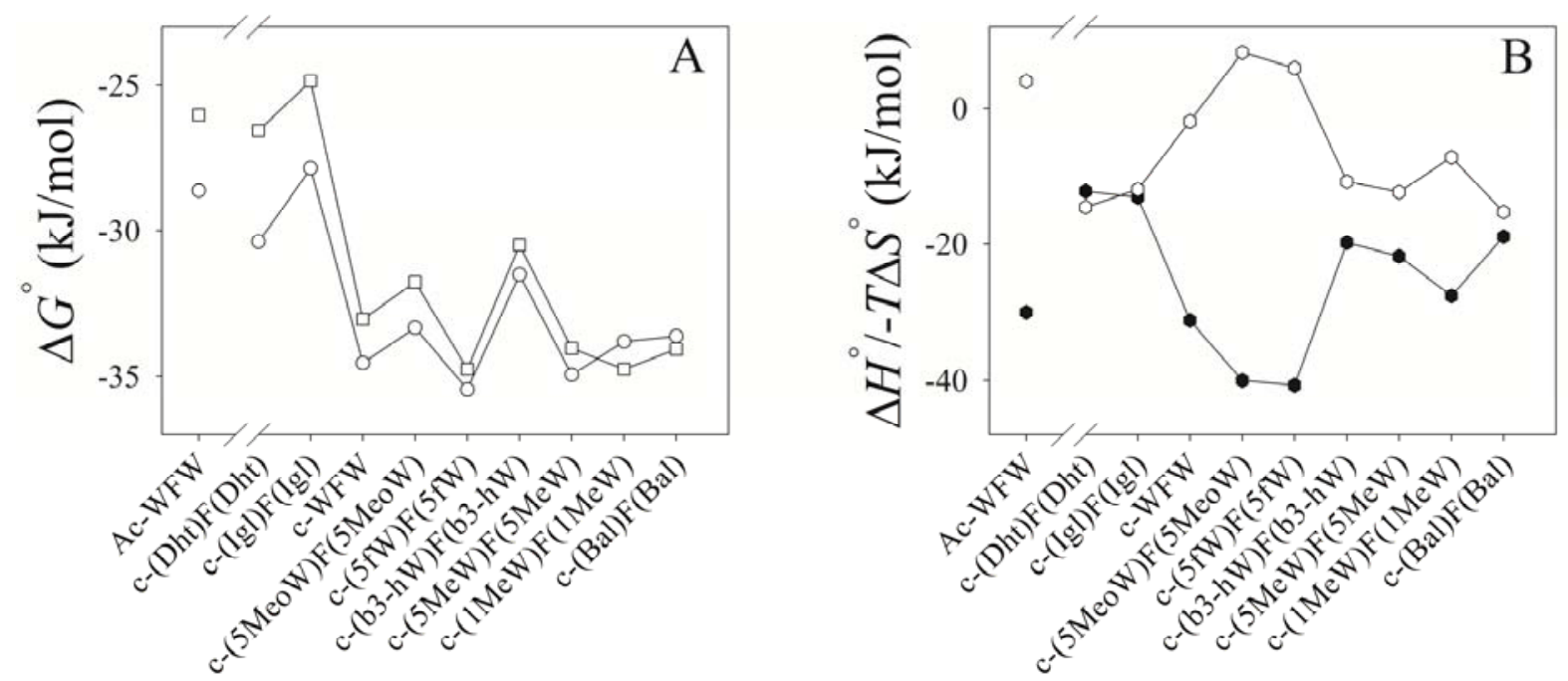

Fig. 21. Thermodynamic parameters of binding of Ac-WFW and the cyclic hexapeptides to lipid bilayers $\left(\boldsymbol{T}=37^{\circ} \mathbf{C}\right)$. (A) $\Delta G^{\circ}$ for binding to ( $\square$ ) POPC and (O) POPC/POPG (3/1 [mol/mol]) SUVs. (B) $\Delta H^{\circ}$ and $-T \Delta S^{\circ}$ as $(\bullet)$ and $(\bigcirc)$, respectively. 


\section{Role of sequence composition upon binding}

Binding to POPC followed the order: Ac-WFW $\approx \mathrm{c}-(\operatorname{Igl} 1) \mathrm{F}(\operatorname{Igl}) \approx \mathrm{c}-(\mathrm{Dht}) \mathrm{F}(\mathrm{Dht})<\mathrm{c}-$ $(5 \mathrm{MeoW}) \mathrm{F}(5 \mathrm{MeoW}) \approx \mathrm{c}-(\mathrm{b} 3-\mathrm{hW}) \mathrm{F}(\mathrm{b} 3-\mathrm{hW}) \approx \mathrm{c}-\mathrm{WFW}<\mathrm{c}-(1 \mathrm{MeW}) \mathrm{F}(1 \mathrm{MeW}) \approx$ $\mathrm{c}(5 \mathrm{fW}) \mathrm{F}(5 \mathrm{fW}) \approx \mathrm{c}-(5 \mathrm{MeW}) \mathrm{F}(5 \mathrm{MeW}) \approx \mathrm{c}-(\mathrm{Bal}) \mathrm{F}(\mathrm{Bal})$ (Table 5). The free energy of binding of Ac-WFW, c-(Igl)F(Igl) and c-(Dht)F(Dht) is low, while $\Delta G^{\circ}$ values for the more hydrophobic peptides $\left(t_{\mathrm{R}}>18 \mathrm{~min}\right)$ range between -31 and $-35 \mathrm{~kJ} / \mathrm{mol}$ and are almost identical. Among these, c-(b3-hW)F(b3-hW) shows lowest partitioning $\left(\Delta G^{\circ} \sim-31 \mathrm{~kJ} / \mathrm{mol}\right)$, indicating the role of conformational constraints of the cyclic peptides in binding. As shown in Table 5 and Fig. 21A, the contribution of $\Delta H^{\circ}$ and the entropy $\left(-T \Delta S^{\circ}\right)$ to lipid bilayer partitioning is highly variable. Both components of $\Delta G^{\circ}$ are comparable for binding of the highly hydrophilic c-(Dht)F(Dht) and c-(Igl)F(Igl), and the most hydrophobic c-(Bal)F(Bal) to POPC. The common feature of Dht, Igl, and Bal residues is a reduced dipole moment compared to W; however, unlike Igl and Bal, Dht is as amphipathic as W. The small enthalpic contribution to POPC/POPG bilayer binding for Dht-containing peptides is compensated by a more favorable entropic term (Table 5), which is in agreement with the classical hydrophobic effect [131]. This effect was observed for the antimicrobial peptide dicynthaurin as well [132]. The authors considered water and counterion release from the peptide and a sodium binding equilibrium at the lipid headgroups as the major driving forces for peptide-membrane interactions. The binding reaction of the other peptides including the linear Ac-WFW to both POPC and POPC/POPG systems is driven by enthalpy with $\Delta H^{\circ}$ values varying between about $\sim-40$ to $\sim-20 \mathrm{~kJ} / \mathrm{mol}$ (Table 5, Fig. 21). The enthalpy contribution is highest $(>-$ $30 \mathrm{~kJ} / \mathrm{mol})$ for c- $(5 \mathrm{fW}) \mathrm{F}(5 \mathrm{fW})$ and c- $(5 \mathrm{MeoW}) \mathrm{F}(5 \mathrm{MeoW})$ and followed by c-WFW and AcWFW. The pronounced $\Delta H^{\circ}$ of $\mathrm{c}-(5 \mathrm{MeoW}) \mathrm{F}(5 \mathrm{MeoW})$ and $\mathrm{c}-(5 \mathrm{fW}) \mathrm{F}(5 \mathrm{fW})$ correlates with a slightly enhanced peptide hydrophobicity and an enhanced hydrogen bonding tendency in comparison to the cyclic parent peptide (Tables 3,5 ). The high $\Delta H^{\circ}$ contribution is associated with a low positive and negative value of $T \Delta S^{\circ}$ (Fig. 21B). $\Delta H^{\circ}$ of c-(b3-hW)F(b3-hW), c$(5 \mathrm{MeW}) \mathrm{F}(5 \mathrm{MeW})$, and $\mathrm{c}-(1 \mathrm{MeW}) \mathrm{F}(1 \mathrm{MeW})$ binding ranges between $\sim-20$ and $-27 \mathrm{~kJ} / \mathrm{mol}$ and the contribution of entropy is about $6-12 \mathrm{~kJ} / \mathrm{mol}$. The common feature of these cyclic peptides is a mean hydrophobicity reflected by a $t_{\mathrm{R}}$ of about $20 \mathrm{~min}$ (Table 3 ). Except the Dht, Igl- and Bal-containing cyclic peptides, peptide binding to POPC and POPC/POPG lipid bilayers is in good agreement with the nonclassical hydrophobic effect as described for other CAPs $[55,133,134]$. 
These results demonstrate that low peptide hydrophobicity and conformational flexibility of the peptides reduced binding whereas the hydrogen bonding ability of the $\mathrm{W}$ residue and its dipole and quadrupole moments did not make any distinguished contribution to bilayer binding, as reflected by studies with c-(1MeW)F(1MeW), and c$(5 \mathrm{fW}) \mathrm{F}(5 \mathrm{fW}) / \mathrm{c}-(5 \mathrm{MeoW}) \mathrm{F}(5 \mathrm{MeoW})$, respectively (Fig. 21A, Tables 3 and 5). Studies with a $1 \mathrm{MeW}$-modified lactoferricin analog revealed enhanced membrane binding and showed $1 \mathrm{MeW}$ to be aligned at the membrane interface with an extent of motion similar to that of $\mathrm{W}$ [135]. Furthermore, the influence of dipole and quadrupole moments became apparent in intramolecular interactions between the $\pi$-electrons of the indole ring of $\mathrm{W}$ with the positively charged guanidino moiety of R in RW-rich peptides, which were suggested to stabilize the structure of CAPs and enhance membrane binding [136,137]. Because of the higher quadrupole moment (aromaticity) of the indole ring in c-(5MeoW)F(5MeoW) compared with $\mathrm{c}-(5 \mathrm{fW}) \mathrm{F}(5 \mathrm{fW})[124]$, a higher affinity of the former peptide for lipid bilayers was expected [136,137]. However, the opposite was observed (Fig. 21A and Table 5). This underlines the contribution of other driving forces, such as the dominant role of hydrophobicity for insertion of the RW-rich cyclic hexapeptides into a phospholipid membrane.
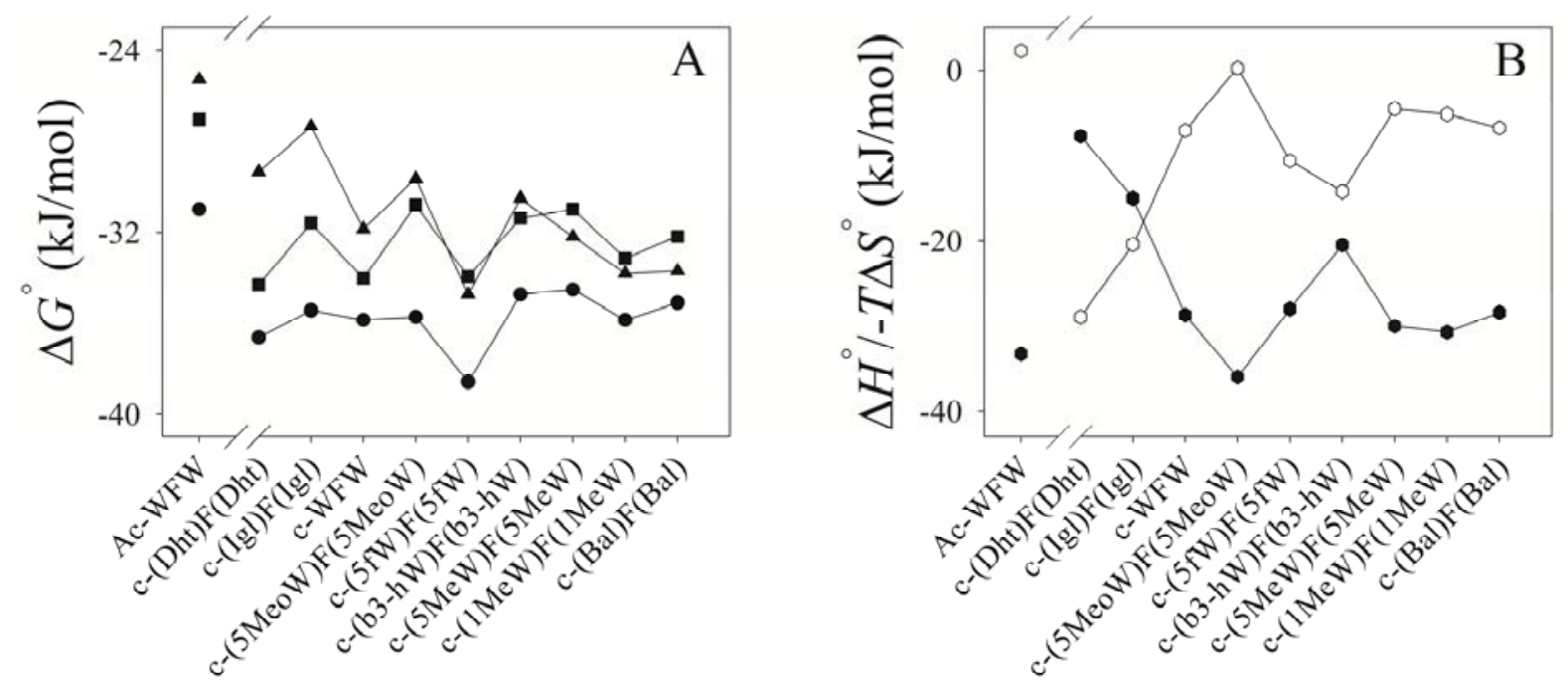

Fig. 22. Thermodynamic parameters of the binding of Ac-WFW and the cyclic hexapeptides to lipid bilayers doped with $\mathrm{LA}, \mathbf{r - L P S}$, and s-LPS $\left(\boldsymbol{T}=37^{\circ} \mathrm{C}\right)$. (A) $\Delta G^{\circ}$ for binding to ( $\Delta$ ) POPC/LA

(12/1 [mol/mol] $),(\boldsymbol{\square})$ POPC/r-LPS (12/1 [mol/mol]), and (•) POPC/s-LPS (12/1 [mol/mol]) SUVs. (B) $\Delta H^{\circ}$ and $-T \Delta S^{\circ}$ as $(\bullet)$ and $(\bullet)$, respectively. 
Table 5. Thermodynamic parameters for peptide binding to POPC and POPC/POPG $(3 / 1$ [mol/mol] $) \mathrm{SUVs}\left(T=37^{\circ} \mathrm{C}\right)$.

\begin{tabular}{|c|c|c|c|c|c|c|c|c|c|c|}
\hline \multirow{3}{*}{ Peptide ${ }^{*}$} & \multicolumn{10}{|c|}{ Lipid bilayers (SUVs) } \\
\hline & \multicolumn{5}{|c|}{ POPC $^{*}$} & \multicolumn{5}{|c|}{ POPC/POPG (3/1 [mol/mol] $)^{*}$} \\
\hline & $\begin{array}{c}\Delta H^{\circ} \\
(\mathrm{kJ} / \mathrm{mol})\end{array}$ & $\begin{array}{c}-T \Delta S^{\circ} \\
(\mathrm{kJ} / \mathrm{mol})\end{array}$ & $\begin{array}{c}\Delta G^{\circ} \\
(\mathrm{kJ} / \mathrm{mol})\end{array}$ & $K_{0}\left(\mathrm{M}^{-1}\right)$ & $z_{\mathrm{P}}^{\dagger}$ & $\begin{array}{c}\Delta H^{\circ} \\
(\mathrm{kJ} / \mathrm{mol})\end{array}$ & $\begin{array}{c}-T \Delta S^{\circ} \\
(\mathrm{kJ} / \mathrm{mol})\end{array}$ & $\begin{array}{c}\Delta G^{\circ} \\
(\mathrm{kJ} / \mathrm{mol})\end{array}$ & $K_{0}\left(\mathrm{M}^{-1}\right)$ & $z_{\mathrm{P}}^{\dagger}$ \\
\hline c-(Dht)F(Dht) & -12.1 & -14.5 & -26.6 & $5.4 \times 10^{2}$ & 1.0 & -11.4 & -19.0 & -30.4 & $2.4 \times 10^{3}$ & 0.5 \\
\hline c-(Igl)F(Igl) & -13.0 & -11.9 & -24.9 & $2.8 \times 10^{2}$ & 1.0 & -20.0 & -7.8 & -27.8 & $8.9 \times 10^{2}$ & 1.8 \\
\hline c-WFW & -31.2 & -1.8 & -33.0 & $6.7 \times 10^{3}$ & 1.3 & -23.5 & -11.0 & -34.5 & $1.2 \times 10^{4}$ & 1.2 \\
\hline c- $(5 \mathrm{MeoW}) \mathrm{F}(5 \mathrm{MeoW})$ & -40.0 & 8.2 & -31.8 & $4.1 \times 10^{3}$ & 1.3 & -37.6 & 4.3 & -33.3 & $7.5 \times 10^{3}$ & 1.8 \\
\hline$c-(5 \mathrm{fW}) \mathrm{F}(5 \mathrm{fW})$ & -40.7 & 6.0 & -34.7 & $1.3 \times 10^{4}$ & 1.4 & -41.6 & 6.2 & -35.4 & $1.7 \times 10^{4}$ & 1.8 \\
\hline c-(b3-hW)F(b3-hW) & -19.8 & -10.7 & -30.5 & $2.5 \times 10^{3}$ & 1.0 & -23.3 & -8.2 & -31.5 & $3.7 \times 10^{3}$ & 1.2 \\
\hline $\mathrm{c}-(5 \mathrm{MeW}) \mathrm{F}(5 \mathrm{MeW})$ & -21.8 & -12.2 & -34.0 & $9.9 \times 10^{3}$ & 1.2 & -25.9 & -9.0 & -34.9 & $1.4 \times 10^{4}$ & 1.4 \\
\hline $\mathrm{c}-(1 \mathrm{MeW}) \mathrm{F}(1 \mathrm{MeW})$ & -27.6 & -7.2 & -34.8 & $1.3 \times 10^{4}$ & 1.6 & -27.7 & -6.1 & -33.8 & $9.0 \times 10^{3}$ & 1.4 \\
\hline $\mathrm{c}-(\mathrm{Bal}) \mathrm{F}(\mathrm{Bal})$ & -18.9 & -15.2 & -34.1 & $1.0 \times 10^{4}$ & 1.0 & -16.4 & -17.2 & -33.6 & $8.4 \times 10^{3}$ & 0.7 \\
\hline Ac-WFW & -30.0 & 4.0 & -26.0 & $4.4 \times 10^{2}$ & 1.9 & -28.4 & -0.2 & -28.6 & $1.2 \times 10^{3}$ & 1.7 \\
\hline
\end{tabular}

${ }^{*}$ The peptide concentration was $40 \mu \mathrm{M}$, the concentration of POPC and POPC/POPG $(3 / 1 \mathrm{~mol} / \mathrm{mol})$ in the injection syringe was $40 \mathrm{mM}$ and $20 \mathrm{mM}$, respectively.

The effective charge number of the peptides corresponds to the best fits of the experimental data using the surface partition equilibrium in combination with Gouy-Chapman theory. 
Table 6. Thermodynamic parameters for peptide binding to POPC/LA (12/1 [mol/mol]), and POPC/r-LPS (12/1 [mol/mol]), and POPC/s-LPS $\left(12 / 1\right.$ [mol/mol]) SUVs $\left(T=37^{\circ} \mathrm{C}\right)$

\begin{tabular}{|c|c|c|c|c|c|c|c|c|c|c|c|c|c|c|c|}
\hline \multirow{3}{*}{ Peptide ${ }^{*}$} & \multicolumn{15}{|c|}{ Lipid bilayers (SUV) } \\
\hline & \multicolumn{5}{|c|}{ POPC/LA (12/1 [mol/mol]) } & \multicolumn{5}{|c|}{ POPC/r-LPS (12/1 [mol/mol] $)^{*}$} & \multicolumn{5}{|c|}{ POPC/s-LPS $(12 / 1[\mathrm{~mol} / \mathrm{mol}])^{*}$} \\
\hline & $\begin{array}{c}\Delta H^{\circ} \\
(\mathrm{kJ} / \mathrm{mol})\end{array}$ & $\begin{array}{c}-T \Delta S^{\circ} \\
(\mathrm{kJ} / \mathrm{mol})\end{array}$ & $\begin{array}{c}\Delta G^{\circ} \\
(\mathrm{kJ} / \mathrm{mol})\end{array}$ & $K_{0}\left(\mathrm{M}^{-1}\right)$ & $\frac{z_{\mathrm{P}}}{\mathrm{P}}$ & $\begin{array}{c}\Delta H^{\circ} \\
(\mathrm{kJ} / \mathrm{mol})\end{array}$ & $\begin{array}{c}-T \Delta S^{\circ} \\
(\mathrm{kJ} / \mathrm{mol})\end{array}$ & $\begin{array}{c}\Delta G^{\circ} \\
(\mathrm{kJ} / \mathrm{mol})\end{array}$ & $K_{0}\left(\mathrm{M}^{-1}\right)$ & $\frac{z_{\mathrm{P}}}{\mathrm{P}}$ & $\begin{array}{c}\Delta H^{\circ} \\
(\mathrm{kJ} / \mathrm{mol})\end{array}$ & $\begin{array}{c}-T \Delta S^{\circ} \\
(\mathrm{kJ} / \mathrm{mol})\end{array}$ & $\begin{array}{c}\Delta G^{\circ} \\
(\mathrm{kJ} / \mathrm{mol})\end{array}$ & $K_{0}\left(\mathrm{M}^{-1}\right)$ & $\frac{z_{\mathrm{P}}}{\mathrm{n}}$ \\
\hline $\mathrm{c}-(\mathrm{Dht}) \mathrm{F}(\mathrm{Dht})$ & -10.0 & -19.4 & -29.4 & $1.6 \times 10^{3}$ & 1.0 & -4.1 & -30.2 & -34.3 & $1.1 \times 10^{4}$ & 0.1 & -7.7 & -28.9 & -36.6 & $2.7 \times 10^{4}$ & 1.0 \\
\hline c-(Igl)F(Igl) & -9.30 & -18.0 & -27.3 & $7.3 \times 10^{2}$ & 1.0 & -11.2 & -20.4 & -31.6 & $3.8 \times 10^{3}$ & 0.0 & -15.0 & -20.4 & -35.4 & $1.7 \times 10^{4}$ & 1.2 \\
\hline c-WFW & -27.1 & -4.7 & -31.8 & $4.2 \times 10^{3}$ & 1.7 & -19.5 & -14.5 & -34.0 & $9.9 \times 10^{3}$ & 1.6 & -28.7 & -7.0 & -35.7 & $1.9 \times 10^{4}$ & 0.8 \\
\hline $\mathrm{c}-(5 \mathrm{MeoW}) \mathrm{F}(5 \mathrm{MeoW})$ & -40.4 & 10.8 & -29.6 & $1.8 \times 10^{3}$ & 2.2 & -30.0 & -0.8 & -30.8 & $2.8 \times 10^{3}$ & 1.9 & -36.0 & 0.3 & -35.7 & $1.9 \times 10^{4}$ & 1.2 \\
\hline$c-(5 f W) F(5 f W)$ & -33.7 & -1.1 & -34.8 & $1.3 \times 10^{4}$ & 1.8 & -26.7 & -7.0 & -33.7 & $8.7 \times 10^{3}$ & 1.6 & -28.0 & -10.6 & -38.6 & $5.8 \times 10^{4}$ & 0.9 \\
\hline $\mathrm{c}-(\mathrm{b} 3-\mathrm{hW}) \mathrm{F}(\mathrm{b} 3-\mathrm{hW})$ & -18.3 & -12.2 & -30.5 & $2.5 \times 10^{3}$ & 1.2 & -17.6 & -13.8 & -31.4 & $3.5 \times 10^{3}$ & 1.3 & -20.5 & -14.3 & -34.8 & $1.3 \times 10^{4}$ & 0.7 \\
\hline c-(5MeW)F(5MeW) & -20.2 & -12.0 & -32.2 & $4.8 \times 10^{3}$ & 1.2 & -25.0 & -6.0 & -31.0 & $3.0 \times 10^{3}$ & 1.3 & -30.0 & -4.5 & -34.5 & $1.2 \times 10^{4}$ & 0.7 \\
\hline$c-(1 \mathrm{MeW}) \mathrm{F}(1 \mathrm{MeW})$ & -22.6 & -11.2 & -33.8 & $9.1 \times 10^{3}$ & 1.8 & -23.5 & -9.7 & -33.2 & $7.0 \times 10^{3}$ & 1.6 & -30.7 & -5.2 & -35.9 & $2.0 \times 10^{4}$ & 0.9 \\
\hline $\mathrm{c}-(\mathrm{Bal}) \mathrm{F}(\mathrm{Bal})$ & -15.4 & -18.3 & -33.7 & $8.7 \times 10^{3}$ & 1.0 & -22.9 & -9.3 & -32.2 & $4.8 \times 10^{3}$ & 1.2 & -28.4 & -6.7 & -35.1 & $1.5 \times 10^{4}$ & 0.5 \\
\hline Ac-WFW & -29.4 & 5.3 & -24.1 & $2.1 \times 10^{2}$ & 2.3 & -30.0 & 3.0 & -27.0 & $6.5 \times 10^{2}$ & 0.5 & -33.3 & 2.3 & -31.0 & $3.0 \times 10^{3}$ & 1.7 \\
\hline
\end{tabular}

${ }^{*}$ The peptide concentration was $40 \mu \mathrm{M}$, for that of POPC/LA (12/1 [mol/mol]) and vesicles composed of LPS were $20 \mathrm{mM}$ and $5 \mathrm{mM}$, respectively. 
Binding of the cyclic sequences to LA systems was observed to correlate with peptide hydrophobicity: $\Delta G^{\circ}$ values gradually decreased from $\sim-28$ to $\sim-35 \mathrm{~kJ} / \mathrm{mol}$ (Fig. $22 \mathrm{~A}$ ). Interestingly, partitioning of $\mathrm{c}-(\mathrm{Dht}) \mathrm{F}(\mathrm{Dht})$ and $\mathrm{c}-(\operatorname{Igl}) \mathrm{F}(\mathrm{Igl})$ into POPC/LA became entropically driven (Table 6). The $\Delta G^{\circ}$ values for interaction with r-LPS containing bilayers scatter around $-32 \mathrm{~kJ} / \mathrm{mol}$ while they seem to increase with increasing $t_{\mathrm{R}}$ for POPC/s-LPS lipid bilayers. Compared to the POPC/LA system, r-LPS doped bilayers favored partitioning of the most hydrophilic peptides (Dht- and Igl-containing cycles). The interaction of the most hydrophobic, c-(Bal)F(Bal), with the three lipid systems is least differentiated, as is reflected by comparable $\Delta G^{\circ}$ and $K_{0}$ values (Fig. 22A, Table 6). Furthermore, the ring size has little effect on $\Delta G^{\circ}$.

Partitioning of hydrophilic c-(Dht)F(Dht) and c-(Igl)F(Igl) into the LPS-doped lipid vesicles was entropy-driven as reflected by the large positive values for $T \Delta S^{\circ}$, whereas binding of other cyclic peptides, as well as Ac-WFW, was dominated by enthalpy changes (Table 6). One exception is the binding of $\mathrm{c}-(\mathrm{Bal}) \mathrm{F}(\mathrm{Bal})$ to POPC/LA, which is characterized by comparable contributions of $\Delta H^{\circ}(-15.4 \mathrm{~kJ} / \mathrm{mol})$ and $-T \Delta S^{\circ}(-18.31 \mathrm{~kJ} / \mathrm{mol})$ to the free energy of binding. Comparable data were derived for $\mathrm{c}-(\mathrm{Bal}) \mathrm{F}(\mathrm{Bal})$ binding to mixed POPC/POPG bilayers. Another interesting observation is that Ac-WFW, the flexible b3-hWpeptide, and the two most hydrophilic cyclic peptides show little change in $\Delta H^{\circ}$ and $-T \Delta S^{\circ}$ values with variation in the LPS-moiety (Table 6). In contrast, the contribution of enthalpy to binding of the hydrophobic peptides increases whereas the entropic effect decreases.

Unlike the expectation of the differentiated activity pattern against E. coli [70], no dependency of the $\Delta G^{\circ}$ to s-LPS-doped bilayers was observed upon the composition of the cyclic peptide, the only exception was $\mathrm{c}-(5 \mathrm{fW}) \mathrm{F}(5 \mathrm{fW})$. The aromatic residue is characterized by a reduced quadrupole and enhanced dipole moment and an increased hydrogen bonding ability compared to $\mathrm{W}$ (Table 2). However, enhanced binding does not improve the activity (Table 4). The peptide is as active as the parent peptide c-WFW against E. coli.

\subsubsection{Effect of ionic strength upon c-WFW binding to r-LPS and s-LPS lipid systems}

To investigate whether the enhanced partitioning of the cyclic peptides into LPSdoped POPC bilayers is due to electrostatic interactions, titrations of c-WFW with POPC/r- 
LPS (12/1 [mol/mol]) and POPC/s-LPS (12/1 [mol/mol]) were performed at different NaF concentrations. The binding isotherms are shown in Fig. 23 and the thermodynamic parameters are presented in Table 7. The increasingly exothermic enthalpy change with enhanced ionic strength was compensated by an increasingly unfavorable entropic contribution.

As observed previously, binding was strongest to bilayers containing O-antigenpresenting s-LPS. For c-WFW interacting with POPC/r-LPS, only a slight influence of the ionic strength on $K_{0}$ was found. By contrast, peptide binding to POPC/s-LPS was slightly dependent upon ionic strength: $K_{0}$ decreased from $2.7 \times 10^{-4}$ to $1.6 \times 10^{-4} \mathrm{M}^{-1}$ upon increasing the salt concentration from 75-200 mM. The low salt dependency of c-WFW binding to POPC/r-LPS bilayers confirms a minor role of direct electrostatic interaction of the peptide with LPS inner core charges (Table 7, Fig. 23). This is related to a low antimicrobial activity observed for cyclic RW-peptides against E. coli mutant strains with outer core- and O-antigen deficient-LPS [70].

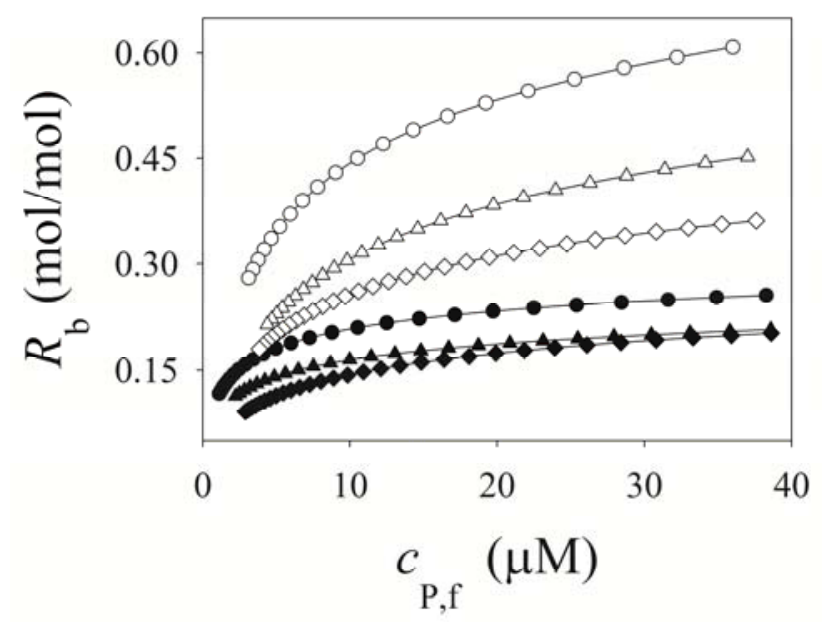

Fig. 23. Isotherms for c-WFW binding to r-LPS- and s-LPS- bearing POPC SUVs at different ionic strengths $\left(\boldsymbol{T}=37^{\circ} \mathbf{C}\right)$. The salt concentrations $\left(c_{\mathrm{NaF}}\right)$ were $(\bullet) 75 \mathrm{mM},(\boldsymbol{\Delta}) 125 \mathrm{mM},(\diamond) 200 \mathrm{mM}$ for POPC/rLPS (12/1 [mol/mol]) and $(\bigcirc) 75 \mathrm{mM},(\Delta) 125 \mathrm{mM},(\diamond) 200 \mathrm{mM}$ for POPC/s-LPS (12/1 [mol/mol]) lipid bilayers in $10 \mathrm{mM}$ phosphate buffer, $\mathrm{pH} 7.4$. 
Table 7. Salt dependency of the thermodynamic parameters for binding of c-WFW to POPC/r-LPS (12/1 [mol/mol]), and POPC/s-LPS (12/1 [mol/mol]) lipid bilayers in $10 \mathrm{mM}$ phosphate buffer, pH $7.4\left(T=37^{\circ} \mathrm{C}\right)$.

\begin{tabular}{lcccccc}
\hline & & \multicolumn{5}{c}{ Thermodynamic parameters } \\
\cline { 3 - 6 } Lipid bilayer SUV & $\begin{array}{c}c_{\mathrm{NaF}} \\
(\mathrm{mM})\end{array}$ & $\begin{array}{c}\Delta H \\
(\mathrm{~kJ} / \mathrm{mol})\end{array}$ & $\begin{array}{c}-T \Delta S \\
(\mathrm{~kJ} / \mathrm{mol})\end{array}$ & $\begin{array}{c}\Delta G \\
(\mathrm{~kJ} / \mathrm{mol})\end{array}$ & $K_{0}\left(\mathrm{M}^{-1}\right)$ & $Z_{\mathrm{c}-\mathrm{WFW}}$ \\
& 75 & -25.3 & -7.8 & -33.1 & $6.9 \times 10^{3}$ & 1.6 \\
POPC/r-LPS & 125 & -28.4 & -4.0 & -32.4 & $5.2 \times 10^{3}$ & 1.9 \\
& 200 & -31.0 & -0.7 & -31.7 & $4.0 \times 10^{3}$ & 1.8 \\
& & & & & \\
POPC/s-LPS & 75 & -27.6 & -9.0 & -36.6 & $2.7 \times 10^{4}$ & 0.8 \\
& 125 & -35.0 & -0.1 & -35.1 & $1.5 \times 10^{4}$ & 0.9 \\
& 200 & -41.0 & 5.7 & -35.3 & $1.6 \times 10^{4}$ & 1.2 \\
\hline
\end{tabular}

${ }^{*}$ The peptide and lipid concentrations were $40 \mu \mathrm{M}$ and $5 \mathrm{mM}$, respectively.

The high degree of peptide binding to POPC/s-LPS, compared to POPC/r-LPS, has to be associated with the presence of outer core and O-antigen oligosaccharides. The fact that the partitioning pattern of the cyclic peptides revealed little variation points to a dominating influence of electrostatic interactions upon binding (Figs. 22A and 23). Both r-LPS and s-LPS have the same distribution of negatively charged phosphate groups; however, unlike r-LPS, bilayer binding became more salt dependent for POPC/s-LPS (Fig. 23). The presence of the sugar moieties seems to favor the electrostatic component in binding. As a result of enhanced accumulation, peptide partitioning might increase.

\subsubsection{Heat capacity change on membrane partitioning of c-WFW}

A common feature of both classical and nonclassical hydrophobic effects is their strong temperature dependency, which is characterized by negative $\Delta C_{\mathrm{p}}{ }^{\circ}$ values [138]. To determine the heat capacity of peptide-lipid interactions, $\Delta C_{\mathrm{p}}{ }^{\circ}$, the partitioning of c-WFW into SUVs composed of POPC or POPC/POPG $(3 / 1 \mathrm{~mol} / \mathrm{mol})$ as a function of temperature was measured.

The results are summarized in Fig. 24 and Table 8 . The $\Delta H^{\circ}$ values vary almost linearly and become more exothermic with increasing temperature, as reflected by large negative $\Delta C_{\mathrm{p}}{ }^{\circ}$ values of $-182 \mathrm{~J} /(\mathrm{K} \mathrm{mol})$ and $-118 \mathrm{~J} /(\mathrm{K} \mathrm{mol})$ for POPC and POPC/POPG (3/1 [mol/mol]) respectively. This signature of the hydrophobic effect results from the release of ordered 
water molecules from hydrophobic surfaces upon partitioning of the peptide into the lipid bilayer [138]. Another contribution to $\Delta C_{\mathrm{p}}{ }^{\circ}$ may come from an increase in lipid acyl chain motion induced by membrane expansion on peptide binding [131]. These results are in contrast to large positive $\Delta C_{\mathrm{p}}{ }^{\circ}$ values found for membrane partitioning of magainins [139].

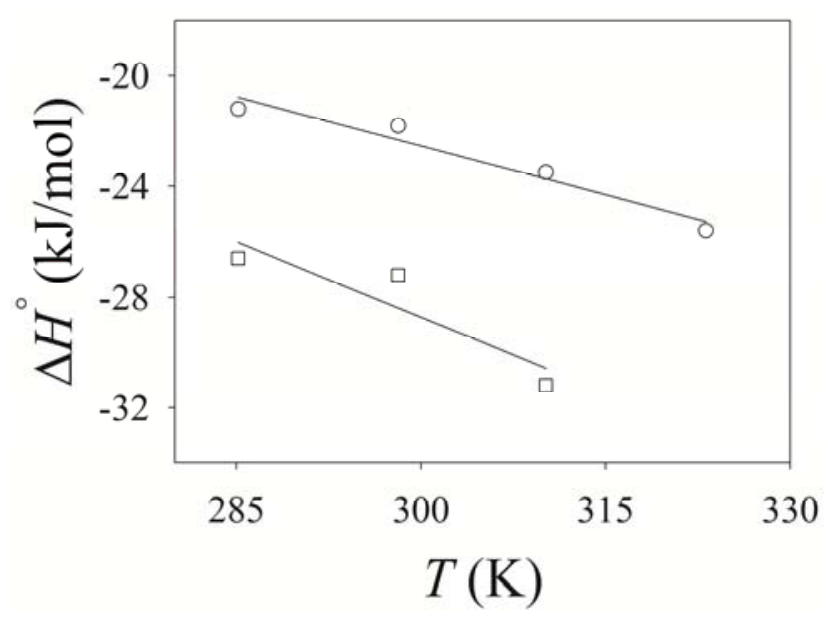

Fig. 24. Temperature dependency of the binding enthalpies of c-WFW to ( $\square$ ) POPC and (O) POPC/POPG (3/1 [mol/mol]) SUVs.

Table 8. Temperature dependency of the thermodynamic parameters of binding of c-WFW to POPC and POPC/POPG (3/1 [mol/mol]) lipid bilayers.

\begin{tabular}{lcccccc}
\hline \multirow{2}{*}{ Lipid vesicles } & Temp. & \multicolumn{5}{c}{ Thermodynamic parameters } \\
\cline { 3 - 6 } & $\left({ }^{\circ} \mathrm{C}\right)$ & $\begin{array}{c}\Delta{ }^{\circ} \\
(\mathrm{kJ} / \mathrm{mol})\end{array}$ & $\begin{array}{c}-T \Delta S \\
(\mathrm{~kJ} / \mathrm{mol})\end{array}$ & $\begin{array}{c}\Delta G^{\circ} \\
(\mathrm{kJ} / \mathrm{mol})\end{array}$ & $K_{0}\left(\mathrm{M}^{-1}\right)$ & $\Delta C_{\mathrm{p}}^{\circ}$ \\
\hline POPC (SUVs) & 12 & -26.6 & -7.6 & -34.2 & $3.4 \times 10^{4}$ & $(\mathrm{~J} / \mathrm{K} \mathrm{mol})^{*}$ \\
& 25 & -27.2 & -6.7 & -33.9 & $1.6 \times 10^{4}$ & -182.1 \\
& 37 & -31.2 & -1.8 & -33.0 & $6.7 \times 10^{3}$ & \\
POPC/POPG & 12 & -21.2 & -13.5 & -34.7 & $4.1 \times 10^{4}$ & \\
$($ SUVs) & 25 & -21.8 & -13.0 & -34.8 & $2.3 \times 10^{4}$ & -118.1 \\
& 37 & -23.5 & -11.0 & -34.5 & $1.2 \times 10^{4}$ & \\
& 50 & -25.6 & -9.2 & -34.8 & $7.8 \times 10^{3}$ &
\end{tabular}

${ }^{*}$ The values were determined by linear regression of the experimental values presented in Fig. 24 $\left(\Delta H^{\circ}\right.$ vs. $\left.T\right)$. 


\subsubsection{Summary}

Induction of conformational constraints in small RW-rich peptides by cyclization has been found to distinctly enhance antimicrobial activity, in particular against Gram-negative E. coli $[53,68]$. RW-rich clusters seem to be responsible for the selectivity increase as well as for the high affinity to lipid bilayers [53], and LPS moieties have been suggested to exert a strong activity-modulating effect [70].

In this study, W residues in c-WFW were replaced by various unnatural amino acids, such as Dht, Igl, 5MeoW, 5fW, b3-hW, 5MeW, 1MeW, and Bal (Fig. 13). This made possible a systematic investigation of aromatic clusters that affect peptide interactions with lipid systems mimicking the outer and inner membranes as well as of the biological activities against E. coli in comparison with Gram-positive B. subtilis and RBCs.

This study showed that:

i. Peptide hydrophobicity and backbone constraints are the crucial parameters for the biological activity (Hydrophilic and the linear and large cyclic sequences are least active) (Table 4).

ii. Compared to B. subtilis, the activity profile against the E. coli strain is much more differentiated (Table 4).

iii. E. coli is slightly less susceptible than B. subtilis to the cyclic peptides and the hemolytic activity of the cyclic peptides is low (Table 4).

iv. The activity profile against bacteria correlates with the profile of free energy of partitioning into phospholipid bilayers (Fig. 21 and Table 4). The negative charge in POPC/POPG bilayers enhances $K_{\text {app. }}$ but $K_{0}$ is independent upon the presence of the anionic lipid (Fig. 20 and Table 5).

v. Low partitioning into POPC and mixed POPC/POPG bilayers correlates with low hydrophobicity of the cyclic peptides, the large cycle containing $\beta$-amino acid, and the linear sequence (Fig. 21 and Table 5).

vi. Partitioning into POPC/LA bilayer is comparable to partitioning into POPC/POPG systems (Fig. 22 and Table 6). 
vii. Sugar moieties of r-LPS and s-LPS modify the partitioning behavior. Lipid interactions are strongest for POPC doped with s-LPS. The difference between the linear and cyclic peptides is conserved; however, partitioning does no longer depend on the structural properties of the cyclic sequences. The results clearly demonstrate a strong supporting role of the outer core and O-antigen in peptide binding to LPS rich bilayers (Fig. 22 and Table 6).

Membrane permeabilization by many cationic peptides depends upon both electrostatic accumulation by negatively charged membrane constituents and insertion into the bilayer, which finally results in a breakdown of the barrier function of the lipid matrix [44]. This idea is supported by the correlation of ITC binding data with hemolytic and antibacterial activities of c-WFW and its analogs. Accordingly, low peptide concentrations in the vicinity of neutral lipid bilayers are responsible for low hemolytic activities, whereas electrostatic attraction to negatively charged membranes favors partitioning into POPC/POPG bilayers and POPG-rich $(\sim 70 \mathrm{~mol} \%)$ B. subtilis membranes [23]. In addition to the effect of the outer membrane, the slightly reduced susceptibility of E. coli could be due to lower peptide accumulation at the inner target membrane, which contains only $15 \mathrm{~mol} \%$ negatively charged lipids [23]. However, the hydrophobic contributions to binding (as expressed by $K_{0}$; see Table 5) were identical. Peptide hydrophobicity and backbone constraints were found to be the crucial determinants of biological activity.

A balance between electrostatic and hydrophobic contributions to peptide-lipid interactions has been suggested to determine the positioning of RW-rich hexapeptides in the bilayer interface [68]. The preferential location of $\mathrm{W}$ residues at the membrane interface has been attributed to their aromaticity and ability to form hydrogen bonds with both water and polar lipid headgroup moieties [58,63,136,137,140,141]. In this study, hydrophobicity and conformational flexibility of RW-rich hexapeptides were identified as the crucial parameters which affect binding. This investigation confirmed the suggestion that peptide interactions with the cytoplasmic membrane determine the biological effect. Other modifications in the hydrophobic cluster of the cyclic hexapeptides have only a minor influence upon peptide interaction with biological systems and model membranes. 
Strong peptide interactions with the outer-membrane LPSs of E. coli influence the peptide transport across the outer wall and thus the accessibility at the target membrane. The affinities of the hexapeptides to POPC/LA and POPC/POPG bilayers, with identical negative surface charge densities, are comparable with respect to the magnitude and sequence dependency of the thermodynamic parameters. While interactions with the LA domain were not particularly strong, peptide partitioning was favored into POPC/r-LPS and even more pronounced in the presence of s-LPS. This behavior correlates with the reduced antimicrobial activity against O-antigen- and outer-core-deficient LPS mutant E. coli strains [70] and confirms the activity-modulating role of the E. coli outer wall. On the basis of these observations, it is concluded that hydrophobic peptide-LPS interactions are essential for an efficient transport across the bacterial outer membrane, but that LA does not act as a specific activity-modulating binding site for the hexapeptides. It seems that the O-antigen of LPS is essential for avid partitioning and likely decisive for efficient peptide transport across the E. coli outer wall. 


\subsection{Site-specific immobilization of CAPs}

In order to investigate the suitability of CAPs for the generation of antimicrobial surfaces, and to analyze parameters such as: the distance between the active sequences and the solid matrix; the density of peptide-loaded surface and the surface area available for peptide loading, which may influence the activities of tethered peptides upon bacterial cells and lipid bilayers; synthesis resins, i.e., TentaGel $\mathrm{S} \mathrm{NH}_{2}$, TentaGel $\mathrm{M} \mathrm{NH}_{2}$, TentaGel MB $\mathrm{NH}_{2}$, HypoGel $400 \mathrm{NH}_{2}$, and HypoGel $200 \mathrm{NH}_{2}$ were used as models of solid surfaces. The variability of resin beads in size, capacity and spacer length represent a set of critical parameters to be analyzed. The model KLAL peptide and the MAG 2-derived MK5E, two highly membrane active $\alpha$-helical CAPs, were used for this purpose. The model KLAL peptide has both antimicrobial and hemolytic activity [44], while MK5E is selectively active against bacteria [118]. KLAL peptide was suggested to act via a carpet-like mode of action [44] whereas MAG 2, the parent peptide of MK5E, was described to form toroidal pores on interaction with bacterial cells and model membranes [118].

The surface tethering of CAPs is known to reduce the flexibility of peptides and may limit the range of peptide penetration to bacteria cytoplasmic membrane. Due to different mechanisms being responsible for the antimicrobial effect of the peptides, site-specific tethering is expected to be used as a tool to get information on the mode of action of CAPs (Fig. 7). To examine this hypothesis, KLAL and MK5E peptides, as well as three natural CAPs (i.e., MEL, TP, and BUF), were tethered at $\mathrm{C}$ terminus, $\mathrm{N}$ terminus, and side chains via an $\varepsilon$-amino group of $\mathrm{K}$ residues. MEL, BUF, and TP form amphipathic structures at peptidelipid interfaces. MEL was suggested to act on bacterial cells through pore formation [8], whereas BUF targets intracellular processes after translocation across the cytoplasmic membrane [46]. TP has ambiguous mechanisms of action: membrane depolarization coupled to secondary intracellular targeting $[119,120]$.

The antimicrobial activities of tethered and soluble peptides were correlated to their lipid bilayers' permeabilizing activities, not only in order to identify critical parameters in desigining effective biocidal surfaces, but also to examine their applications in order to shed light on to the modes of action of CAPs. 


\subsubsection{Physical and chemical properties of PEGylated resins as model solid surfaces}

Synthesized resins, with PEG spacers of different length, were used to couple the peptides at different chain positions. PEG has been described to provide interfacial protective coating [142] and thus to improve the applicability (solubility and stability against enzymatic degradation) of proteins [143] and peptides [144].

TentaGel $\mathrm{S} \mathrm{NH}_{2}, \quad$ TentaGel $\mathrm{M} \mathrm{NH}_{2}$, TentaGel MB NH${ }_{2}, \quad$ HypoGel $400 \mathrm{NH}_{2}$, and HypoGel $200 \mathrm{NH}_{2}$ belong to the classes of divinyl benzene cross-linked polystyrene containing PEG grafts (Fig. 25). They are highly porous. The size of the pores for a TentaGel $\mathrm{S} \mathrm{NH}_{2}$ resin bead ranged between $0.1-0.2 \mu \mathrm{m}$, which is smaller than the size of a bacterium [145]. The PEG grafts have different spacer lengths and represent the majority of the mass of these polymers. Thus, the properties of these hybrid resin beads closely resemble those of PEG [146]. Furthermore, the reactive centers are located at the terminus of the glycol spacers. These properties provide the opportunities for synthesizing combinatorial libraries using organic solvents followed by bioassays in aqueous media [147,148]. These resins have various size distributions ranging from TentaGel $\mathrm{M} \mathrm{NH}_{2} \quad($ diameter $=10 \mu \mathrm{m})$ to TentaGel MB NH 2 (diameter $\sim 300 \mu \mathrm{m}$ ) (Table 9). Whereas TentaGel $\mathrm{S} \mathrm{NH}_{2}$ is characterized by a long spacer $(3 \mathrm{kDa})$ and has the lowest capacity, HypoGel $400 \mathrm{NH}_{2}$, and HypoGel $200 \mathrm{NH}_{2}$ have much shorter PEG spacers and comparably high capacities.

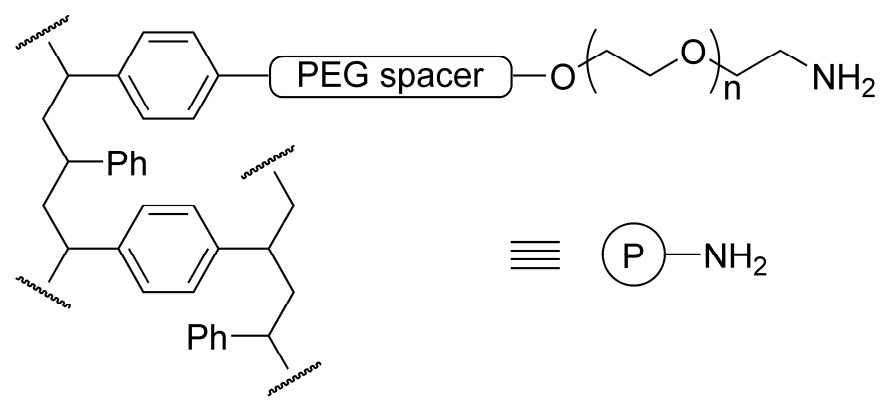

Fig. 25. Basic chemical structure of TentaGel $\mathrm{S} \mathrm{NH}_{2}$, TentaGel $\mathrm{M} \mathrm{NH}_{2}$, TentaGel MB, $\mathrm{HypoGel} 400 \mathrm{NH}_{2}$ and HypoGel $200 \mathbf{N H}_{2}$. P stands for the resin bearing PEG, and $\mathrm{n}$ represents the number of ethylene oxide units. 
Table 9. Physical and chemical characteristics of TentaGel S $\mathrm{NH}_{2}$, TentaGel $\mathrm{M} \mathrm{NH}_{2}$, TentaGel $\mathrm{MB} \mathrm{NH}_{2}$, HypoGel $400 \mathrm{NH}_{2}$, and HypoGel $200 \mathrm{NH}_{2}$.

\begin{tabular}{|c|c|c|c|c|c|c|}
\hline Resin & $\begin{array}{l}\text { Capacity } \\
(\mathrm{mmol} / \mathrm{g})\end{array}$ & $\begin{array}{l}\text { Diameter } \\
(\mu \mathrm{m})\end{array}$ & Beads/g* & $\begin{array}{l}\text { Capacity/Bead } \\
(\text { pmol })^{*}\end{array}$ & $\begin{array}{c}\text { MW of } \\
\text { spacer }(\mathrm{Da})\end{array}$ & $\begin{array}{l}\mathrm{n} \text { (ethylene } \\
\text { oxide units) }\end{array}$ \\
\hline TentaGel S NH & 0.32 & 130 & $8.87 \times 10^{5}$ & $280-330$ & 3000 & 75 \\
\hline TentaGel $\mathrm{M} \mathrm{NH}_{2}$ & 0.25 & 10 & $1.95 \times 10^{9}$ & 0.13 & $\mathrm{NA}^{\dagger}$ & NA \\
\hline TentaGel MB NH & 0.26 & $\sim 300$ & $6.40 \times 10^{4}$ & 4000 & NA & NA \\
\hline HypoGel $400 \mathrm{NH}_{2}$ & 0.69 & $110-150$ & NA & NA & 400 & 10 \\
\hline HypoGel $200 \mathrm{NH}_{2}$ & 0.92 & $110-150$ & NA & NA & 200 & 5 \\
\hline
\end{tabular}

${ }^{*}$ These data are taken from the ref. [145].

†NA, not available.

\subsubsection{Activity of surface tethered membrane-active CAPs - role of tethered peptide site}

\subsubsection{Characterization of KLAL and MK5E peptides by HPLC and CD}

N-terminally acetylated KLAL and MK5E peptides, as well as sequences bearing PEG 2 chains at the intended positions of immobilization, were prepared to assess the influence of immobilization related charge modification and introduction of the PEG moiety on the peptide structure and biological effect. Table 10 shows the PEGylated and acetylated KLAL and MK5E peptides, their helicity and the $t_{\mathrm{R}}$-HPLC values as a measure of hydrophobicity.

Introduction of the hydrophilic PEG 2 chain did not substantially influence the retention behavior. This might be due to the low molecular mass (163 Da) of PEG 2. In contrast, N-terminal acetylation caused reduction of positive peptide charge and this increase in hydrophobicity also enhanced the $t_{\mathrm{R}}$.

CD spectroscopic investigations of KLAL, MK5E and the acetylated and PEGylated analogs confirmed an unordered peptide conformation in phosphate buffer (Fig. 26). TFE induced $\alpha$-helical conformation, as reflected by negative ellipticities at $207 \mathrm{~nm}$ and $222 \mathrm{~nm}$ and a positive CD band below $200 \mathrm{~nm}$ (Fig. 26). Although, the helical content of MK5E and Ac-MK5E was quite similar $(\sim 50 \%)$, the helicity of the most hydrophobic Ac-KLAL was enhanced by more than $30 \%$ compared with KLAL (Table 10). PEGylation decreased the 
peptide helicity independent of the position of PEG introduction (Table 10). Steric hindrance might be responsible for this effect.

Table 10. Amino acid sequences, abbreviations, $t_{\mathrm{R}}$-RP-HPLC and helicity of peptides.

\begin{tabular}{|c|c|c|c|c|}
\hline \multirow[t]{2}{*}{ NO } & \multirow[t]{2}{*}{ Denotation } & \multirow[t]{2}{*}{ Peptide sequence } & \multirow[t]{2}{*}{$\begin{array}{c}t_{\mathrm{R}} \\
(\mathrm{min})\end{array}$} & $\begin{array}{c}\text { Calculated } \\
\text { helicity }\end{array}$ \\
\hline & & & & {$[\alpha] \%$} \\
\hline 1 & KLAL & KLALKLALKALKAALKLA-NH $_{2}$ & 20.6 & 52 \\
\hline 2 & Ac-KLAL & Ac-KLALKLALKALKAALKLA-NH ${ }_{2}$ & 24.0 & 68 \\
\hline 3 & PEG-KLAL ${ }^{*}$ & PEG-KLALKLALKALKAALKLA-NH ${ }_{2}$ & 21.9 & 44 \\
\hline 4 & KLAL-PEG & KLALKLALKALKAALKLA-PEG-NH ${ }_{2}$ & 20.3 & 43 \\
\hline 5 & Ac-PEG-KLAL & Ac-PEG-KLALKLALKALKAALKLA-NH ${ }_{2}$ & 23.7 & 51 \\
\hline 6 & Ac-KLAL-PEG & Ac-KLALKLALKALKAALKLA-PEG-NH ${ }_{2}$ & 23.8 & 43 \\
\hline 7 & Ac-KLAL5PEG & Ac-KLALK(PEG)LALKALKAALKLA-NH ${ }_{2}$ & 24.4 & 48 \\
\hline 8 & Ac-KLAL9PEG & Ac-KLALKLALK(PEG)ALKAALKLA-NH ${ }_{2}$ & 24.2 & 41 \\
\hline 9 & MK5E & GIGKFIHAVKKWGKTFIGEIAKS-NH ${ }_{2}$ & 18.7 & 50 \\
\hline 10 & Ac-MK5E & Ac-GIGKFIHAVKKWGKTFIGEIAKS-NH ${ }_{2}$ & 20.9 & 51 \\
\hline 11 & PEG-MK5E & PEG-GIGKFIHAVKKWGKTFIGEIAKS-NH ${ }_{2}$ & 19.4 & 29 \\
\hline 12 & MK5E-PEG & GIGKFIHAVKKWGKTFIGEIAKS-PEG-NH ${ }_{2}$ & 18.7 & 29 \\
\hline 13 & MK5E10PEG & GIGKFIHAVK(PEG)KWGKTFIGEIAKS-NH ${ }_{2}$ & 18.9 & $\mathrm{ND}^{\dagger}$ \\
\hline 14 & Ac-PEG-MK5E & Ac-PEG-GIGKFIHAVKKWGKTFIGEIAKS-NH ${ }_{2}$ & 20.7 & 30 \\
\hline 15 & Ac-MK5E-PEG & Ac-GIGKFIHAVKKWGKTFIGEIAKS-PEG-NH ${ }_{2}$ & 20.9 & 29 \\
\hline 16 & Ac-MK5E10PEG & Ac-GIGKFIHAVK(PEG)KWGKTFIGEIAKS-NH & 21.8 & ND \\
\hline
\end{tabular}

${ }^{*}$ PEG, bifunctional PEG 2 (2 ethylene oxide units).

${ }^{\dagger} \mathrm{ND}$, not determined.
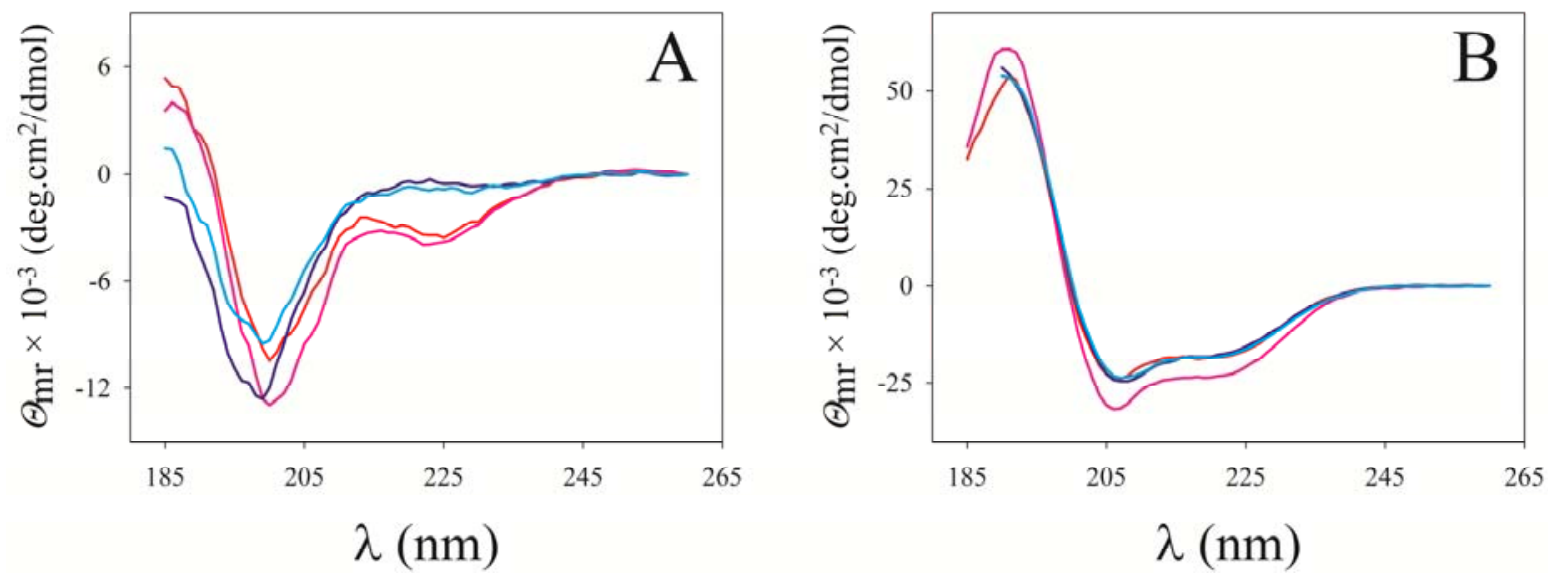

Fig. 26. CD spectra of model KLAL peptide and MK5E, and their acetylated analogs in (A) phosphate buffer and (B) TFE/buffer $(1 / 1[v / v])\left(T=25^{\circ} \mathrm{C}\right)$. The peptides are presented as KLAL (red), Ac-KLAL (pink), MK5E (blue), and Ac-MK5E (turquoise). 


\subsubsection{Preparation and characterization of tethered KLAL and MK5E peptides}

C-terminally immobilized KLAL and MK5E on TentaGel S NH 2 , HypoGel $200 \mathrm{NH}_{2}$, and HypoGel $400 \mathrm{NH}_{2}$ were prepared by standard SPPS using Fmoc-amino acids [149]. It is known from the literature [101] that the major sources of impurity in SPPS are deletion sequences and chain termination that might occur at each coupling step due to nonquantitative coupling reactions. Thus, the activities of C-terminally immobilized peptides might result not only from the right sequences, but also from minor contributions of deficient sequences. N terminus and side chain immobilization of KLAL and MK5E on TentaGel $\mathrm{S} \mathrm{NH}_{2}$ using the thioalkylation [150] and oxime-forming ligation strategies [151] were performed with HPLC-purified sequences (Fig. 27). Thus, the antimicrobial activities of these immobilized peptides result only from the correct sequences.

\section{A. MK5E}

$$
\text { (P)- } \mathrm{NH}_{2}+{ }_{\mathrm{DCM}}
$$

B. KLAL

$$
\text { (P) }-\mathrm{NH}_{2}+\text { (P) }_{\mathrm{DCM}}^{\mathrm{NH}}
$$

Fig. 27. Chemical strategies for side chain, $C$ terminus and/or $N$ terminus immobilization of CAPs. (A) Oxime-forming ligation, (B) Thioalkylation.

The formation of tethered peptides was confirmed after cleavage of the sequences immobilized on TentaGel S RAM resin (Fig. 28). TentaGel S RAM resin is similar in the 
chemical structure to TentaGel $\mathrm{S} \mathrm{NH}_{2}$ resin, but has a TFA cleavable linker. The molecular masses of the peptides coupled via the thioalkylation and oxime formation were $57 \mathrm{Da}$. and $69 \mathrm{Da}$. larger than those values for the Cys- and AOA-modified peptides, respectively (Fig. 29).
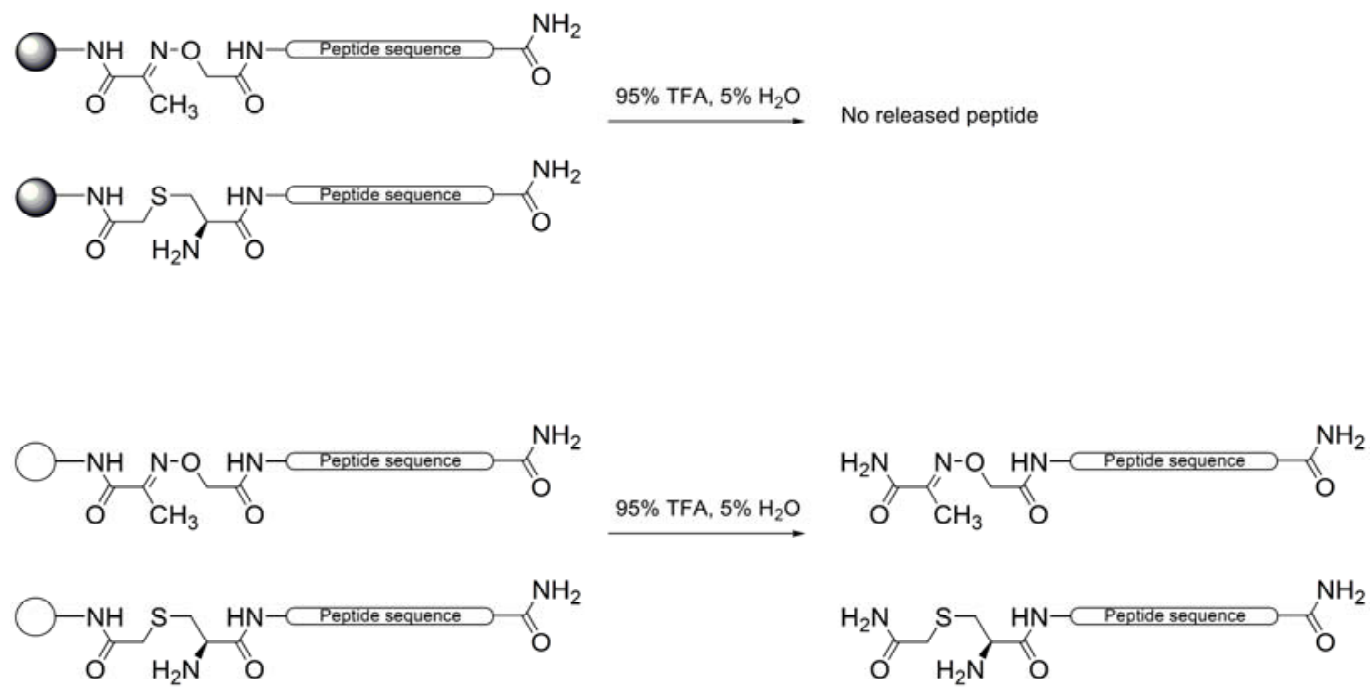

TentaGel $\mathrm{SNH}_{2} \bigcirc$ TentaGel S RAM

Fig. 28. The chemical strategy applied to confirm the formation of the tethered peptides. The tethered peptides are released from TentaGel S RAM after treatment with TFA and are characterized by analytical-HPLC and LC / ESI-TOF MS.
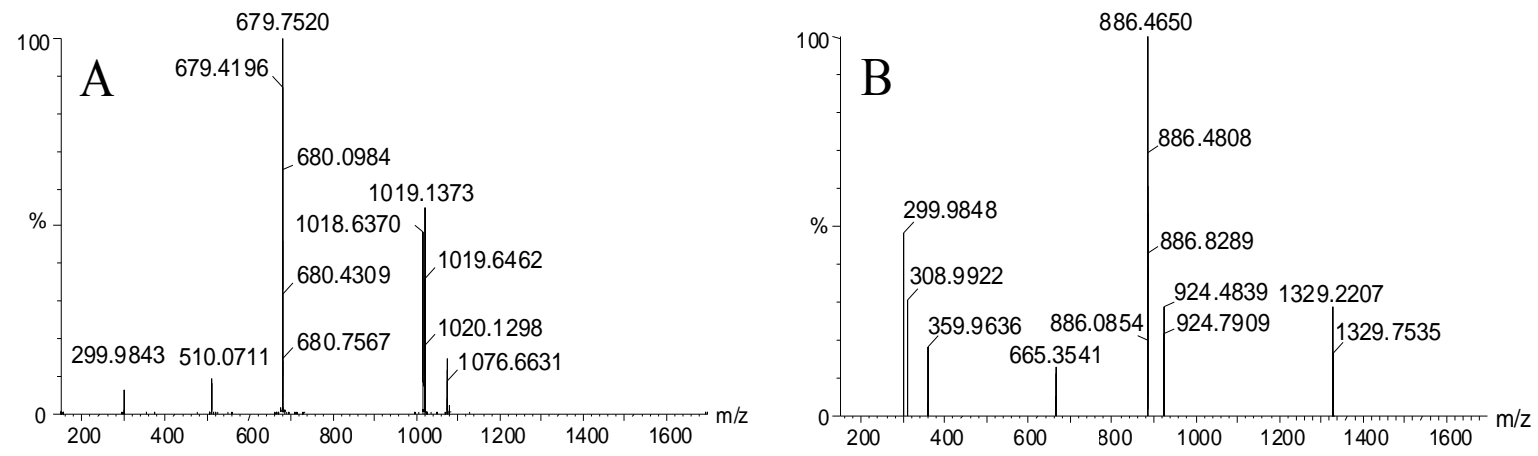

Fig. 29. LC-MS spectra of $N$ terminus tethered (A) KLAL and (B) MK5E. The ligation products result from the reaction between the N-terminally Cys- or AOA-modified KLAL and MK5E and TentaGel S RAM pretreated with $\mathrm{BrAcOH}$ and pyruvic acid, respectively. The signals represent the mass values for the thioalkylation and ligation products at various $\mathrm{m} / \mathrm{z}$. Mass differences in the peaks reflect TFA addition to the peptides during electrospray ionization. (TFA is used as an additive in the mobile phase for LC / ESI-TOF MS)
(A) $[\mathrm{M}+2 \mathrm{H}+\mathrm{TFA}]^{2+}=1076.66,[\mathrm{M}+2 \mathrm{H}]^{2+}=1018.64,[\mathrm{M}+3 \mathrm{H}]^{3+}=679.42,[\mathrm{M}+4 \mathrm{H}]^{4+}=510.07$.

(B) $[\mathrm{M}+2 \mathrm{H}]^{2+}=1329.22,[\mathrm{M}+3 \mathrm{H}+\mathrm{TFA}]^{3+}=924.48,[\mathrm{M}+3 \mathrm{H}]^{3+}=886.09,[\mathrm{M}+4 \mathrm{H}]^{4+}=665.35$. 
A comparison of the resin capacity and the density of immobilized peptides shows that about $1 / 3$ of the reactive groups of resins was occupied with C-terminally immobilized peptides (Tables 12,13). Furthermore, under the applied coupling conditions, the density of C-terminally TentaGel $\mathrm{S} \mathrm{NH}_{2}$-bound peptides $(0.099$ and $0.133 \mu \mathrm{mol} / \mathrm{mg}$ for $\mathrm{KLAL}$ and MK5E peptide respectively) was about three times higher than the density of the N-terminally and side chain-tethered sequences. This might be partially due to the different synthesis procedures and limited accessibility of the reactive functional groups. It has been reported that at most $15 \%$ of the total amount of functional groups of typical TentaGel beads are located on the surface of the bead [152]. Moreover, protein immobilization onto TentaGel was shown to be limited to the bead surface [153]. Whereas SPPS on the porous resin will result in a substantial amount of peptides, which might be not accessible for interaction with biological membranes, immobilization of the complete peptide sequences via thioalkylation and ligation strategies will be restricted to the surface of the beads. The enhanced capacity of the HypoGels (Table 9) leads to an enhanced (Table 13) but, compared to TentaGel $\mathrm{S} \mathrm{NH}_{2}$, the coupling efficiency slightly decreased as reflected by an increase in the ratio of resin capacity to peptide density.

\subsubsection{Biological activities of free and tethered KLAL and MK5E peptides}

\section{Antimicrobial activity of the free peptides}

All KLAL and MK5E peptides showed activity against B. subtilis and E. coli in the micromolar range (Table 11).

To model the loss of charge connected with immobilization via the N-terminal $\alpha$ amino group, acetylated and N-terminally free KLAL and MK5E sequences were compared. The activity of the KLAL peptides was highest against B. subtilis and independent of chemical modification with PEG $2(\mathrm{MIC} \approx 0.8 \mu \mathrm{M})$. As a consequence of charge reduction, the antibacterial activity of acetylated KLAL peptides against E. coli was 4-16 fold reduced compared with the parent sequence, whereas changes in the activity against $B$. subtilis were not observed. MK5E and Ac-MK5E were similarly active against $B$. subtilis (MIC $=1.6 \mu \mathrm{M})$, but acetylation reduced the anti-E. coli activity of the peptide. The loss of one cationic charge distinctly enhanced the hydrophobicity of the peptides as was reflected by an increase in $t_{\mathrm{R}^{-}}$ HPLC (Table 10). Likely, the $t_{R}$ value of Ac-KLAL was further enhanced by an increased amphipathicity, which is based on the enhanced helicity at interfaces as has been described for 
other peptides [154], and found here for Ac-KLAL as compared with KLAL under structure inducing solvent conditions.

Table 11. Antimicrobial and hemolytic activities of KLAL and MK5E peptides and their PEGylated analogs against $B$. subtilis and $E$. coli bacteria and RBCs.

\begin{tabular}{|c|c|c|c|c|}
\hline \multirow[b]{3}{*}{ NO } & \multirow{3}{*}{$\begin{array}{c}\text { Peptide } \\
\text { Denotation }\end{array}$} & \multicolumn{2}{|c|}{ Antimicrobial activity ${ }^{*}$} & \multirow{3}{*}{$\begin{array}{c}\text { Hemolytic activity } \\
\mathrm{EC}_{25}(\mu \mathrm{M}) \\
\text { Erythrocyte lysis }\end{array}$} \\
\hline & & \multicolumn{2}{|c|}{$\operatorname{MIC}(\mu \mathrm{M})^{\dagger}$} & \\
\hline & & B. subtilis (DSM 347) & E. coli (DH $5 \alpha)$ & \\
\hline 1 & KLAL & 0.8 & 1.6 & 13.1 \\
\hline 2 & Ac-KLAL & 0.8 & 12.5 & 9.1 \\
\hline 3 & PEG-KLAL & 0.8 & 3.1 & \\
\hline 4 & KLAL-PEG & 1.6 & 1.6 & \\
\hline 5 & Ac-PEG-KLAL & 0.8 & 12.5 & \\
\hline 6 & Ac-KLAL-PEG & 0.8 & 6.3 & \\
\hline 7 & Ac-KLAL5PEG & 0.8 & 25.0 & \\
\hline 8 & Ac-KLAL9PEG & 0.8 & 12.5 & \\
\hline 9 & MK5E & 1.6 & 0.8 & 334.0 \\
\hline 10 & Ac-MK5E & 1.6 & 3.1 & $>400.0$ \\
\hline 11 & PEG-MK5E & 1.6 & 1.6 & \\
\hline 12 & MK5E-PEG & 1.6 & 1.6 & \\
\hline 13 & MK5E10PEG & 1.6 & 1.6 & \\
\hline 14 & Ac-PEG-MK5E & 6.3 & 12.5 & \\
\hline 15 & Ac-MK5E-PEG & 6.3 & 6.3 & \\
\hline 16 & Ac-MK5E10PEG & 3.1 & 6.3 & \\
\hline
\end{tabular}

${ }^{*}$ The results are the mean of three independent experiments performed in triplicate with a standard deviation of less than $5 \%$ (Fig. 39).

${ }^{\dagger} \mathrm{MIC}$ values were determined after $17 \mathrm{~h}$ incubation at $37^{\circ} \mathrm{C} . \mathrm{MBC} \approx \mathrm{MIC}$.

Although the introduction of PEG 2 at different positions of both KLAL and MK5E caused the antimicrobial activities and the helicity of the N-terminally free and acetylated parent sequences to decease slightly (differences of one dilution step among the antimicrobial activities of PEGylated KLAL and MK5E peptides), changes in the activity spectrum were not observed (Tables 10,11). One might speculate that these small changes are due to the low molecular weight of the attached PEG 2 moiety. However, recently it has been reported that even coupling of much larger PEG units did not influence the basic mechanism of membrane permeabilization of amphipathic peptides $[155,156]$. Thus, modification of MG 2 with PEG 
$(5 \mathrm{kDa})$ resulted only in slightly reduced antimicrobial activity and did not change the interaction patterns with lipid bilayers [155]. Similar observations were made with $\beta$-sheet tachyplesin [156]. In contrast, the loss of the antimicrobial activity of PEG-nisin [144] could only be explained by the disturbance of the peculiar mechanism of action, which is based on selective lipid II binding and consecutive migration of the peptide's $\mathrm{C}$ terminus through the cell membrane.

These results show that the loss of the N-terminal charge may result in a drastic reduction of the antimicrobial activity, in particular against Gram-negative bacteria, whereas introduction of PEG chains at different chain positions might be expected to have little influence. Therefore, it is concluded that the conservation of the cationic charge with peptide immobilization is particularly important for maintaining the peptide activity against Gramnegative bacteria.

\section{Antimicrobial activity of the tethered peptides}

Peptides immobilized by the thioalkylation and ligation strategies inhibited the growth of both bacteria at similar MIC regardless of the position of immobilization (Table 12). Concentrations between $0.1-0.2 \mathrm{mM}$, and $0.6-0.8 \mathrm{mM}$ of KLAL peptides immobilized at the $\mathrm{N}$ terminus and side chains were required to inhibit bacterial growth and to act bactericidally against $B$. subtilis and E. coli, respectively (Table 12). The activity of randomly immobilized KLAL was comparable to other side chain-specific immobilized sequences.

The activity profile of TentaGel $\mathrm{S} \mathrm{NH}_{2}$-bound $\mathrm{MK} 5 \mathrm{E}$ peptides was found to be slightly different from KLAL (Table 12). The side chain and C-terminally immobilized MK5E sequences showed comparable activities, but a charged $\mathrm{N}$-terminal $\alpha$-amino group seems to be necessary for maximal bactericidal activity in particular againat E. coli, which diminish with either acetylation or N-terminal immobilization. The comparably high MIC values of C-terminally immobilized KLAL and MK5E are likely related to the fact that the majority of these sequences $(\sim 75 \%$; see ref. [152]) were tethered in the interior of the porous TentaGel $\mathrm{S} \mathrm{NH}_{2}$ and might not be accessible for membrane interaction [152,153]. Indeed, the small pore size of TentaGel $\mathrm{S} \mathrm{NH}_{2}$ [145] does not allow for bacterial entry and penetration. In all cases, the MBC values of the immobilized peptides were identical to the MIC. 
Table 12. The antimicrobial activities of KLAL and MK5E peptides immobilized on TentaGel $\mathrm{S} \mathrm{NH}_{2}$ resin against $B$. subtilis and $E$. coli along with the densities of resin-immobilized peptides and the MICs of the corresponding PEGylated free peptides.

Antimicrobial activity of immobilized peptides

\begin{tabular}{|c|c|c|c|c|c|c|}
\hline \multirow[t]{3}{*}{ Peptide } & \multirow{3}{*}{$\begin{array}{c}\text { Position of } \\
\text { immobilization }\end{array}$} & \multirow{3}{*}{$\begin{array}{c}\text { Density of } \\
\text { peptide } \\
(\mu \mathrm{mol} / \mathrm{mg})^{*}\end{array}$} & \multicolumn{4}{|c|}{$\mathrm{MIC}$} \\
\hline & & & \multicolumn{2}{|c|}{ B. subtilis (DSM 347) } & \multicolumn{2}{|c|}{ E. coli $(\mathrm{DH} 5 \alpha)$} \\
\hline & & & $\begin{array}{c}\text { Resin } \\
(\mathrm{mg} / \mathrm{ml})^{\dagger}\end{array}$ & $\begin{array}{c}\text { Immobilized } \\
(\mathrm{mM})^{\ddagger}\end{array}$ & $\begin{array}{c}\text { Resin } \\
(\mathrm{mg} / \mathrm{ml})^{\dagger}\end{array}$ & $\begin{array}{c}\text { Immobilized } \\
(\mathrm{mM})^{\ddagger}\end{array}$ \\
\hline \multirow[t]{6}{*}{ KLAL } & C terminus & 0.099 & 2 & 0.20 & 25 & 2.47 \\
\hline & $\mathrm{N}$ terminus & 0.028 & 5 & 0.14 & 25 & 0.70 \\
\hline & $\mathrm{K} 5^{\S}$ & 0.024 & 5 & 0.12 & 25 & 0.60 \\
\hline & K 9 & 0.028 & 2 & 0.06 & 25 & 0.70 \\
\hline & K 12 & 0.030 & 5 & 0.15 & 25 & 0.75 \\
\hline & Random & 0.031 & 5 & 0.15 & 25 & 0.77 \\
\hline Ac-KLAL & $\mathrm{C}$ terminus & 0.099 & 2 & 0.20 & 45 & 4.45 \\
\hline \multirow[t]{5}{*}{ MK5E } & $\mathrm{C}$ terminus & 0.133 & 5 & 0.67 & 5 & 0.67 \\
\hline & $\mathrm{N}$ terminus & 0.026 & 10 & 0.26 & 15 & 0.39 \\
\hline & K 4 & 0.039 & $\mathrm{ND}^{\uparrow}$ & ND & 5 & 0.19 \\
\hline & K 10 & 0.033 & 5 & 0.17 & 5 & 0.17 \\
\hline & K 14 & 0.025 & 5 & 0.13 & 5 & 0.13 \\
\hline Ac-MK5E & $\mathrm{C}$ terminus & 0.133 & 10 & 1.33 & 45 & 5.99 \\
\hline
\end{tabular}

${ }^{*}$ The amount of resin-immobilized peptides was determined from three independent experiments based on the absorption of the Fmoc-chromophore at $301 \mathrm{~nm}\left(\varepsilon=6000 \mathrm{M}^{-1} \mathrm{~cm}^{-1}\right)$. The standard deviations ranged between 2 and $10 \%$.

${ }^{\dagger}$ Each MIC of peptide-covered resin was determined in one experiment using a serial dilution of the peptideloaded resin. The values were confirmed in two independent experiments using the determined MIC and two resin concentrations below and above the MIC. No changes were found (Fig. 40).

*The MIC of the immobilized peptides was calculated on the basis of the concentration of peptide-covered resin causing growth inhibition and taking into consideration the density of the peptides on the resin beads. Based on the standard deviation of the surface density, variations in the MIC are less than $10 \%$.

${ }^{\S}$ The numbers give the chain position of immobilization. K stands for the lysine residue.

ॠND, not determined

Consequently, tethering conserved the activity spectra of the peptides at reduced concentrations. The resin-bound peptides were antimicrobial against E. coli and B. subtilis in the millimolar range compared to the results seen with micromolar concentrations of the free peptides. Moreover, insertion of either KLAL or MK5E into the membrane as a mode of action is supported by the fact that the activity is independent of the site of immobilization. As the immobilization at TentaGel $\mathrm{S} \mathrm{NH}_{2}$ was performed at the chain termini and the $\mathrm{K}$ residues 
in the polar face of peptide helices, the immobilized peptides are assumed to arrange their amphipathic helix in the membrane surface.

\section{Hemolytic activity of the free and tethered peptides}

KLAL peptides were active towards $\mathrm{RBCs}$ with $\mathrm{EC}_{25}$ values of about $10 \mu \mathrm{M}$ (Table 11). MK5E was not hemolytic up to concentrations of about $400 \mu \mathrm{M}$. TentaGel $\mathrm{S} \mathrm{NH}_{2}$ showed a concentration dependent hemolytic effect. Hemolysis was less than $10 \%$ up to about $80 \mathrm{mg} / \mathrm{ml}$, but rapidly increased at higher concentrations (Fig. 30). The activities of $40 \mathrm{mg}$ and $80 \mathrm{mg}$ TentaGel $\mathrm{S} \mathrm{NH}_{2}$-bound KLAL, Ac-KLAL, MK5E and Ac-MK5E were not distinguishable from the activity of the bare resin beads. This observation leads to the conclusion that at their MICs (amount of resin $<45 \mathrm{mg} / \mathrm{ml}$; Table 12) both immobilized KLAL and MK5E peptides are inactive towards RBCs.

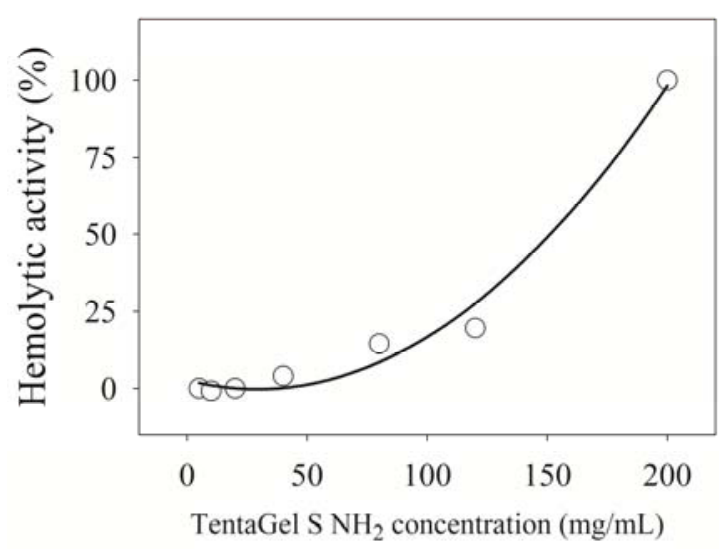

Fig. 30. The hemolytic activity of TentaGel $\mathrm{S} \mathrm{NH}_{2}$ resin beads.

\subsubsection{Bilayer permeabilizing activities of free and tethered KLAL and MK5E peptides}

The ability of peptides to permeabilize the lipid bilayer of liposomes and thus to induce the release of incorporated dye was measured in order to compare the membrane permeabilizing activity of free and tethered peptides. The measurements were to provide information about the peptide interaction with lipid matrices of variable composition as physical models of biological targets. Electrically neutral POPC LUVs and mixed vesicles, i.e, POPC/POPG (1/3 [mol/mol]) and POPC/POPG (3/1 [mol/mol] $)$ were employed in order 
to mimic the charge properties of the lipid matrix of RBCs, the membrane of Gram-positive and the inner membrane of Gram-negative bacteria respectively.

\section{The free peptides}

The $\mathrm{EC}_{50}$ values of initial calcein leakage (Fig. 31) showed that all acetylated and PEGylated peptides permeabilize highly negatively POPC/POPG (1/3 [mol/mol] $)$ LUVs in a narrow micromolar concentration range. With reduction of the negative bilayer charge, the peptide activity became more differentiated. The activity of all KLAL and Ac-KLAL peptides distinctly increased ( $\mathrm{EC}_{50}$ decrease) with reduction of anionic bilayer charge. In contrast, the activity of MK5E and Ac-MK5E was only slightly modified with variation in the lipid composition and the PEGylated peptides showed enhanced $\mathrm{EC}_{50}$ values with decreasing the POPG content of liposomes. This activity reduction was most obvious for Ac-MK5E, but little dependent upon the PEG position. Interestingly, the surface affinity and the permeabilizing effect upon lipid membranes correlated well with the antimicrobial activity profiles (Table 11, Fig. 31).

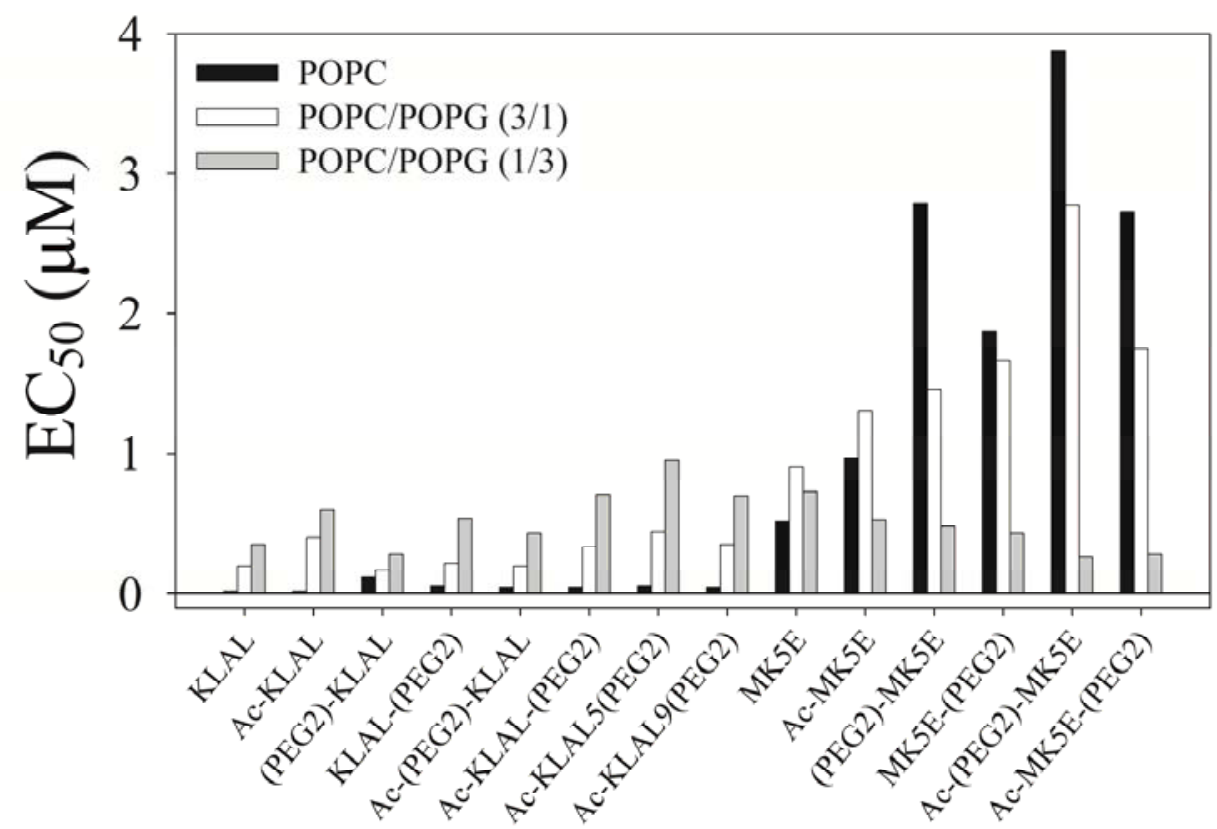

Fig. 31. The bilayer (LUVs) permeabilizing activity of KLAL and MK5E peptides. The vesicles are presented as POPC (black), POPC/POPG (3/1 [mol/mol]) (white), and POPC/POPG (1/3 mol/mol) (gray). $\mathrm{EC}_{25}$ was determined at $c_{\mathrm{L}}=25 \mu \mathrm{M}$ in buffer after $1 \mathrm{~min}$. 
The tethered peptides

The kinetics of the dye release from POPC, and mixed POPC/POPG LUVs induced by C-terminally TentaGel $\mathrm{S} \mathrm{NH}_{2}$-bound $\mathrm{KLAL}$ and $\mathrm{MK} 5 \mathrm{E}$ peptides is presented in Fig. 32. Although different in the magnitude, each of the resin-tethered peptides induced disruption of the bilayers in a dose-dependent manner. The activity profile of the bound peptides correlated well with the effects of the corresponding free peptides. Non-modified TentaGel $\mathrm{S} \mathrm{NH}_{2}$ was not bilayer active. These results suggest that $\mathrm{C}$-terminal immobilization via a large PEG chain conserved the bilayer permeabilizing ability of the free KLAL and MK5E peptides.

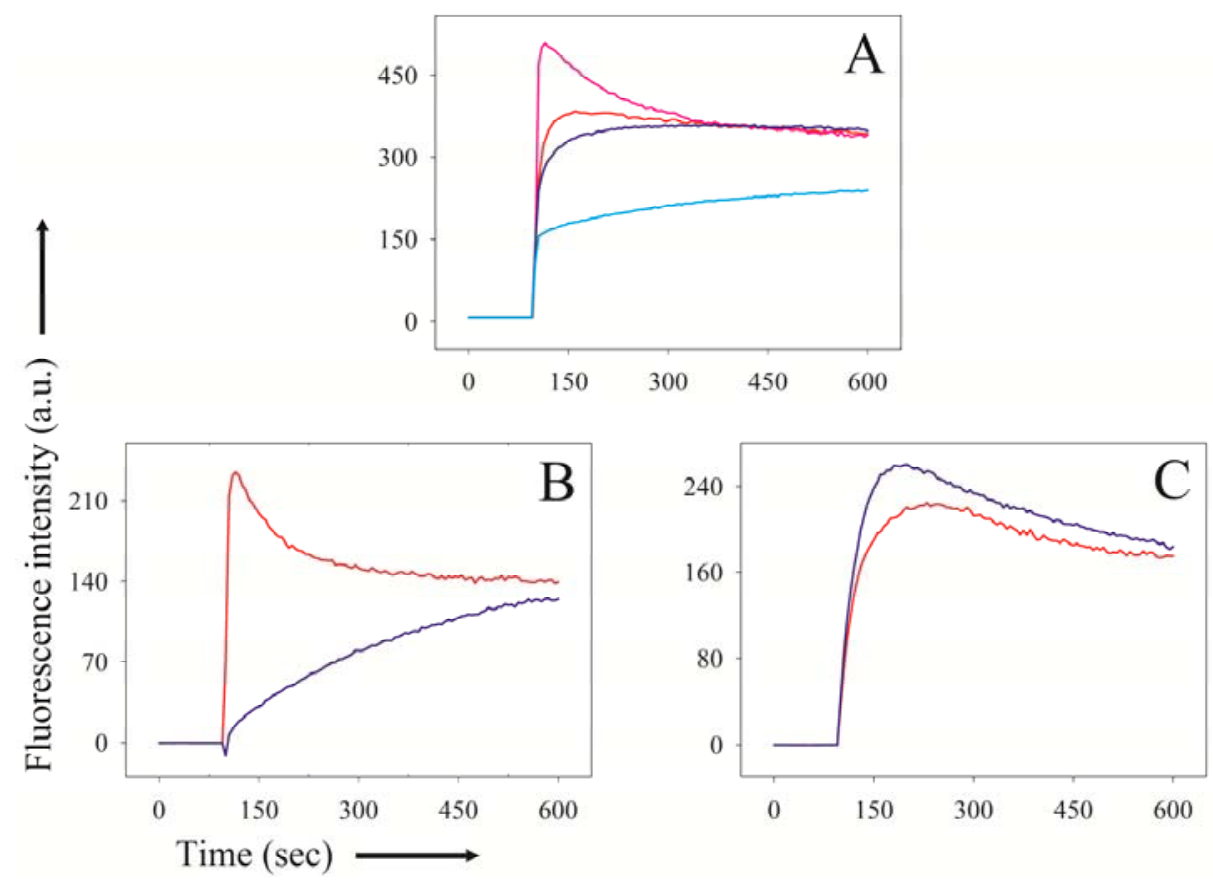

Fig. 32. Kinetics of dye release from (A) POPC, (B) POPC/POPG (3/1 [mol/mol]), and

(C) POPC/POPG (1/3 [mol/mol]) LUVs induced by tethered peptides. The tethered peptides are C-terminally immobilized at TentaGel $\mathrm{S} \mathrm{NH}_{2}$ and presented as KLAL (red), Ac-KLAL (pink), MK5E (blue), and Ac-

MK5E (turquoise). The final concentrations of tethered peptides are as follows: for POPC: KLAL (0.8 mM), AcKLAL (0.8 mM), MK5E (1.1 mM), and Ac-MK5E (1.1 mM); for POPC/POPG (3/1 [mol/mol]):

KLAL (1.6 mM), MK5E (2.1 mM); and for POPC/POPG (1/3 [mol/mol]): KLAL (0.8 mM), MK5E (1.1 mM).

The dye release was monitored as increase in the fluorescence intensity at $514 \mathrm{~nm}$ at $c_{\mathrm{L}}=25 \mu \mathrm{M}$. 


\subsubsection{Influence of physical characteristics of solid surfaces upon biocidal activity}

\subsubsection{Effect of spacer length}

Because the thickness of the cell envelope for E. coli and B. subtilis has been reported to be $46 \mathrm{~nm}$ and $45-55 \mathrm{~nm}$ respectively [157-159], the role of the spacer length upon the antimicrobial activities of KLAL and MK5E peptides C-terminally immobilized on TentaGel $\mathrm{S} \mathrm{NH}_{2}$, HypoGel $400 \mathrm{NH}_{2}$ and HypoGel $200 \mathrm{NH}_{2}$ was investigated. The data summarized in Tables 12 and 13 illustrate that peptide coupling via a long PEG spacer (TentaGel $\mathrm{S} \mathrm{NH}_{2}$ ) resulted in high antimicrobial activity against both strains whereas the PEG spacers of HypoGel $200 \mathrm{NH}_{2}$ and HypoGel $400 \mathrm{NH}_{2}$ are too short (Table 9) to span the highly negatively charged LPS-rich wall of Gram-negative and the peptidoglycan layer of Grampositive bacteria. The biocidal activities were as follows: TentaGel S NH $\mathrm{NH}_{2}>$ HypoGel $400 \mathrm{NH}_{2}>$ HypoGel $200 \mathrm{NH}_{2}$. Peptides attached via the long TentaGel $\mathrm{S} \mathrm{NH}_{2}$ spacer can interact with the cytoplasmic membrane, which is the target for antimicrobial peptides [1]. The observation suggests that a long spacer-related high flexibility of the immobilized peptide is of advantage for antimicrobial activity.

Table 13. Antimicrobial activities against $B$. subtilis and $E$. coli bacteria and peptide densities of $C$ terminally immobilized KLAL and MK5E peptides on HypoGel $400 \mathrm{NH}_{2}$, and HypoGel $200 \mathrm{NH}_{2}$.

\begin{tabular}{|c|c|c|c|c|c|}
\hline \multirow{3}{*}{ Peptide } & \multirow{3}{*}{$\begin{array}{l}\text { Density of peptide } \\
\qquad(\mu \mathrm{mol} / \mathrm{mg})\end{array}$} & \multicolumn{4}{|c|}{ Antimicrobial activity (HypoGel $400 \mathrm{NH}_{2} /$ HypoGel $200 \mathrm{NH}_{2}$ ) } \\
\hline & & \multicolumn{2}{|c|}{ B. subtilis (DSM 347) } & \multicolumn{2}{|c|}{ E. coli $(\mathrm{DH} 5 \alpha)$} \\
\hline & & $\begin{array}{l}\text { MIC Resin } \\
(\mathrm{mg} / \mathrm{ml})\end{array}$ & $\begin{array}{l}\text { MIC Peptide } \\
\text { (mM) }\end{array}$ & $\begin{array}{l}\text { MIC Resin } \\
(\mathrm{mg} / \mathrm{ml})\end{array}$ & $\begin{array}{l}\text { MIC Peptide } \\
\text { (mM) }\end{array}$ \\
\hline KLAL & $0.151 / 0.247$ & $10 / 15$ & $1.51 / 3.71$ & $55 / 70$ & $8.31 / 17.29$ \\
\hline Ac-KLAL & $0.151 / 0.247$ & $15 / 15$ & $2.27 / 3.71$ & $75 />80$ & $11.33 />19.76$ \\
\hline MK5E & $0.180 / 0.253$ & $10 / 15$ & $1.80 / 3.79$ & $15 / 10$ & $2.70 / 2.53$ \\
\hline Ac-MK5E & $0.180 / 0.253$ & $20 / 20$ & $3.60 / 5.06$ & $65 / 60$ & $11.70 / 15.18$ \\
\hline
\end{tabular}

\subsubsection{Surface density of tethered peptides}

The bacterial membrane possesses in the order of $10^{5}$ anionic charges [160]. Taking into consideration that a Gram-negative E. coli has an average surface area of $0.5 \times 2.0 \mu \mathrm{m}^{2}$, the membrane charge density is approximately $10^{13}$ charges $/ \mathrm{cm}^{2}$. The capacity of TentaGel $\mathrm{S} \mathrm{NH}_{2}$ 
is 280-330 pmol/bead (Table 9). Taking KLAL and MK5E peptides, the density of positive surface charges per TentaGel $\mathrm{S} \mathrm{NH}_{2}$ bead is much higher than the surface charge density of an E. coli bacterium, even if only one part of the total charge of the resin (at least $\sim 2 \times 10^{17}$ charges $/ \mathrm{cm}^{2}$ ) is considered. Therefore, the peptide density on the surface of TentaGel $\mathrm{S} \mathrm{NH}_{2}$ beads is sufficient to promote resin-cell interaction as demonstrated by the fact that higher loading of the HypoGels did not enhance the activity (Tables 12, 13). Moreover, the peptides loading on HypoGel $200 \mathrm{NH}_{2}$, which is about twice of the peptides density on HypoGel $400 \mathrm{NH}_{2}$ (Table 13), showed that increasing the peptide loading did not improve the biocidal activity if the flexibility of the immobilized peptide is limited by a short spacer. These results lead to the suggestion that with increased constraints induced by a reduced spacer length, the ability of peptides to bind to the bacterial membrane was conserved; however, the membrane permeabilization efficiency, e.g. the ability of the peptides to insert into the target membrane was reduced. Nevertheless, the antimicrobial activity of HypoGel-bound peptides suggests that interactions with the outer layer of bacteria provide a substantial contribution to the effect. For cationic biocidal polymers an exchange of structurally essential divalent cations in the bacterial membrane leading to the disturbance of the permeability barrier has been suggested [88,97,161-165]. The high cationic charge density of peptide-loaded HypoGel resin beads might have the same effect.

\subsubsection{Effect of particle size}

To investigate the effect of the surface area of the peptide-coated solid matrix upon biological activity, the model KLAL peptide was immobilized on resin beads of different size: TentaGel MB NH 2 and TentaGel $\mathrm{M} \mathrm{NH}_{2}$ (Table 9). The surface area of TentaGel $\mathrm{M} \mathrm{NH}_{2}$ is closer to the size of a bacterium $(\sim 0.5 \times 2.0 \mu \mathrm{m}$; along the short and long axes of the ellipsoidal body) than that of TentaGel $\mathrm{MB} \mathrm{NH}_{2}$. However, both resin beads have an identical overall loading capacity $(0.2-0.3 \mathrm{mmol} / \mathrm{g})$. Taking the diameters of spherical beads and the number of beads in $1 \mathrm{~g}$ resin (Table 9), the surface area of TentaGel $\mathrm{M} \mathrm{NH}_{2}$ is calculated to be almost 35 times larger than that of TentaGel $\mathrm{MB} \mathrm{NH}_{2}$.

The density of C-terminally immobilized KLAL on TentaGel $\mathrm{MB} \mathrm{NH}_{2}$ and TentaGel $\mathrm{M} \mathrm{NH}_{2}$ was 0.167 and $0.102 \mu \mathrm{mol} / \mathrm{mg}$, respectively (Table 14). Inverse to the density, KLAL immobilized on TentaGel $\mathrm{M} \mathrm{NH}_{2}$ was more active than the TentaGel $\mathrm{MB} \mathrm{NH}_{2}$-tethered peptide against Gram-positive and Gram-negative bacteria 
(Table 14). According to the suggested mode of action, the peptide accumulates onto the membrane of bacteria until it reaches a threshold concentration followed by lysis of the membrane in a carpet-like mode [44]. The results obtained with tethered KLAL on microspheres and macrobeads suggest that the small micospheres allow a higher local peptide concentration on the bacterial membrane due to the decreased constraint induced by the small size of the resin beads. This leads to higher antimicrobial activities for TentaGel $\mathrm{M} \mathrm{NH}_{2}-$ bound KLAL in comparison with the tethered peptide on TentaGel $\mathrm{MB} \mathrm{NH}_{2}$ beads. Moreover, the kinetics of dye release from LUVs show that TentaGel $\mathrm{M} \mathrm{NH}_{2}$-bound $\mathrm{KLAL}$ at $\mathrm{C}_{\mathrm{KLAL}}=0.26 \mathrm{mM}$ is more active than TentaGel $\mathrm{MB} \mathrm{NH}_{2}$-bound $\mathrm{KLAL}$ at $\mathrm{C}_{\mathrm{KLAL}}=0.42 \mathrm{mM}$ (Fig. 33).

Table 14. Antimicrobial activities against $B$. subtilis and $E$. coli bacteria and peptide densities of $\mathrm{C}$ terminus tethered model KLAL peptide on TentaGel $\mathrm{M} \mathrm{NH}_{2}$ (microsphere) and TentaGel MB $\mathrm{NH}_{2}$ (macrobead).

\begin{tabular}{|c|c|c|c|c|c|}
\hline \multirow{3}{*}{ Bead } & \multirow{3}{*}{$\begin{array}{c}\text { Density of } \\
\text { peptide } \\
(\mu \mathrm{mol} / \mathrm{mg})\end{array}$} & \multicolumn{4}{|c|}{$\mathrm{MIC}$} \\
\hline & & \multicolumn{2}{|c|}{ B. subtilis (DSM 347) } & \multicolumn{2}{|c|}{ E. coli $(\mathrm{DH} 5 \alpha)$} \\
\hline & & $\begin{array}{c}\text { Bead } \\
(\mathrm{mg} / \mathrm{ml})\end{array}$ & $\begin{array}{c}\text { Immobilized } \\
\text { peptides } \\
(\mathrm{mM})\end{array}$ & $\begin{array}{c}\text { Bead } \\
(\mathrm{mg} / \mathrm{ml})\end{array}$ & $\begin{array}{c}\text { Immobilized } \\
\text { peptides } \\
(\mathrm{mM})\end{array}$ \\
\hline TentaGel $\mathrm{M} \mathrm{NH}_{2}$ & 0.102 & 2 & 0.20 & 25 & 2.55 \\
\hline TentaGel MB NH${ }_{2}$ & 0.167 & 6 & 1.00 & 36 & 6.01 \\
\hline
\end{tabular}

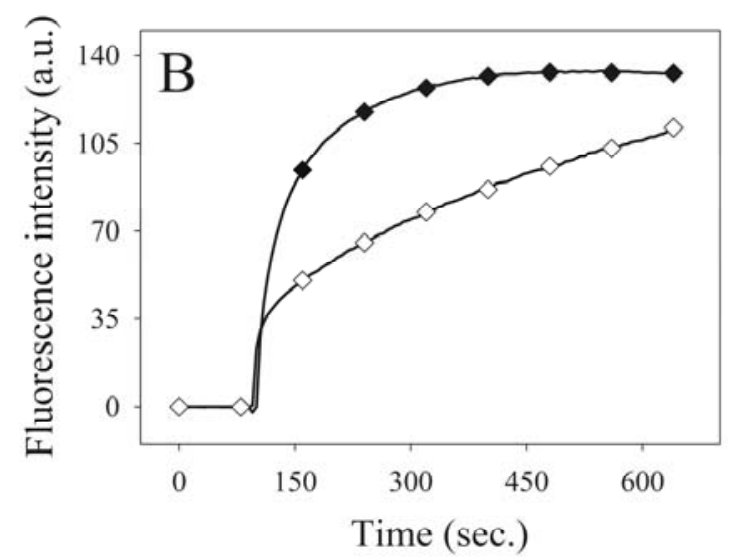

Fig. 33. Kinetics of dye release from POPC/POPG (3/1 [mol/mol]) LUVs induced by TentaGel M NH2- and TentaGel MB $\mathbf{N H}_{2}$-tethered KLAL. Dye release was monitored as increase in the fluorescence intensity at $514 \mathrm{~nm}$ at $c_{\mathrm{L}}=25 \mu \mathrm{M}$. The concentrations of immobilized KLAL on $(\diamond)$ TentaGel $\mathrm{M} \mathrm{NH}_{2}$ and $(\diamond)$ TentaGel $\mathrm{MB} \mathrm{NH}_{2}$ are $0.26 \mathrm{mM}$ and $0.42 \mathrm{mM}$, respectively. 
Taken together, these results suggest that enlargement of the surface area available for peptide tethering may lead to enhanced peptide aggregation onto the bacteria membranes and thus, enhanced the antibacterial activity of CAPs with a membrane-lytic mode of action.

\subsubsection{Peptide-tethering as a strategy to investigate the mode of action of CAPs}

\subsubsection{Characterization of MEL, BUF, and TP peptides}

MEL (26 amino acids) shows antibacterial and hemolytic activity. It has five basic residues with two $\alpha$-helical segments, which have been connected together with a helixbreaking $\mathrm{P}$ residue. Basic and hydrophobic residues are located mainly at the $\mathrm{C}$ termius and $\mathrm{N}$ terminus, respectively (Table 15 ). The hinge allows the $\mathrm{N}$ terminus and $\mathrm{C}$ terminus helices to localize independently upon interaction with the bacteria membrane. The hydrophobic flexible "GIG" hinge sequence at the $\mathrm{N}$ terminus has been proposed to be important for insertion into the lipid bilayer [10]. Membrane insertion and association of the peptides into ion-permeable pores, as proven by discrete conductivity levels, has been suggested to lead to permeabilization of the bacteria cell membrane by toroidal pore formation (see Fig. 7) [166].

BUF (21 amino acids) is selectively active against bacteria. It is highly basic with charged residues (+7 including one $\mathrm{H}$ residue) dispersed throughout the sequence (Table 15). BUF is not membrane active and the peptide appears to target intracellular nucleic acids after translocation across lipid bilayers without significant permeabilizing activity [167]. A hinge induced by a $\mathrm{P}$ residue within the sequence was found to be responsible for translocation across the cell membranes [46].

TP (13 amino acids) is a cathelicidin-derived CAP, which is rich in $\mathrm{R}, \mathrm{W}$, and P residues (Table 15) [168] with membrane permeabilizing activity as well as the ability to translocate across the cytoplasmic membrane [119]. The peptide has four R residues localized at the peptide termini with three $\mathrm{W}$ residues in the center of the sequence. The presence of two $\mathrm{P}$ residues induces a unique amphipathic $\beta$-turn structure in interaction with detergent micelles [64]. 
Table 15. Amino acid sequences, antimicrobial activities, calculated and observed molecular masses, and $t_{R}-R P-H P L C$ of the peptides.

\begin{tabular}{|c|c|c|c|c|c|c|c|}
\hline \multirow[b]{3}{*}{ NO } & \multirow[b]{3}{*}{ Peptide denotation } & \multirow[b]{3}{*}{ Amino acid sequence } & \multirow{2}{*}{\multicolumn{2}{|c|}{$\begin{array}{l}\text { Molecular mass } \\
{[\mathrm{M}+3 \mathrm{H}]^{+3} \text { (Da.) }}\end{array}$}} & \multirow[b]{3}{*}{$t_{\mathrm{R}}(\min )$} & \multirow{2}{*}{\multicolumn{2}{|c|}{$\operatorname{MIC}(\mu \mathrm{M})^{*}$}} \\
\hline & & & & & & & \\
\hline & & & Observed & Calculated & & $\begin{array}{c}\text { B subtilis } \\
\text { (DSM 347) }\end{array}$ & $\begin{array}{c}\text { E. coli } \\
\text { (DH 5a) }\end{array}$ \\
\hline 1 & MEL & GIGAVLKVLTTGLPALISWIKRKRQQ-NH ${ }_{2}$ & 949.50 & 949.26 & 23.2 & 1.6 & 12.5 \\
\hline 2 & MEL-AOA & GIGAVLKVLTTGLPALISWIKRKRQQK(AOA)- $\mathrm{NH}_{2}$ & 1016.26 & 1016.29 & 22.5 & 0.8 & 12.5 \\
\hline 3 & AOA-MEL & AOA-GIGAVLKVLTTGLPALISWIKRKRQQ-NH ${ }_{2}$ & 973.86 & 973.59 & 23.4 & 1.6 & 50.0 \\
\hline 4 & BUF & TRSSRAGLQFPVGRVHRLLRK-NH ${ }_{2}$ & 811.74 & 811.82 & 12.9 & 25.0 & 6.3 \\
\hline 5 & BUF-AOA & TRSSRAGLQFPVGRVHRLLRKK(AOA)- $\mathrm{NH}_{2}$ & 878.83 & 878.85 & 12.8 & 25.0 & 25.0 \\
\hline 6 & AOA-BUF & AOA-TRSSRAGLQFPVGRVHRLLRK-NH ${ }_{2}$ & 836.45 & 836.16 & 12.9 & 50.0 & 25.0 \\
\hline 7 & $\mathrm{TP}$ & VRRFPWWWPFLRR-NH ${ }_{2}$ & 634.70 & 634.36 & 21.1 & 1.6 & 6.3 \\
\hline 8 & TP-AOA & VRRFPWWWPFLRRK(AOA)- $\mathrm{NH}_{2}$ & 701.73 & 701.39 & 18.0 & 1.6 & 6.3 \\
\hline 9 & AOA-TP & AOA-VRRFPWWWPFLRR-NH ${ }_{2}$ & 659.03 & 658.70 & 17.9 & 0.8 & 12.5 \\
\hline
\end{tabular}

${ }^{*}$ Values represent the means of the results of three independent experiments performed in triplicate, with standard deviations of less than $5 \%$ after $17 \mathrm{~h}$ of incubation at $37^{\circ} \mathrm{C}$ (Fig. 39). 
The peptide sequences, the AOA-modified analogs and the $t_{\mathrm{R}}$-HPLC values are presented in Table 15. AOA modification influenced the peptide hydrophobicity. Whereas, modification of MEL at the $C$ terminus resulted in a more hydrophilic peptide $\left(t_{R}=22.5 \mathrm{~min}\right.$ compared with $t_{\mathrm{R}}=23.2 \mathrm{~min}$ for the parent peptide), no difference in the $t_{\mathrm{R}}$ values was seen between MEL and AOA-MEL (Table 15). In contrast, AOA modification at peptide termini had no effect upon the $t_{\mathrm{R}}$ values for both BUF and TP. However, TP-AOA and AOA-TP were more hydrophilic than TP (Table 15).

\subsubsection{Characterization of tethered MEL, BUF, and TP peptides}

MEL, BUF, and TP were immobilized at the $\mathrm{C}$ terminus and $\mathrm{N}$ terminus on TentaGel $\mathrm{S} \mathrm{NH}_{2}$ resin beads using the oxime-forming ligation strategy (Fig. 27). HPLCpurified AOA-modified peptides were used. Linkage of peptides at the $\mathrm{N}$ terminus results in reduction of one positive charge compared with the C-terminally modified counterparts. The tethering was confirmed by the immobilization of the peptides on TentaGel S RAM as described before (Fig. 34). The derived molecular masses of the immobilized MEL, BUF, and TP correspond to the theoretical values.

The density of MEL and TP tethered at the $\mathrm{C}$ terminus and $\mathrm{N}$ terminus on TentaGel $\mathrm{S} \mathrm{NH}_{2}$ was almost identical $(\sim 0.02 \mu \mathrm{mol} / \mathrm{mg}$ for MEL, $\sim 0.15 \mu \mathrm{mol} / \mathrm{mg}$ for TP) whereas for BUF, the density of tethered peptide at $\mathrm{N}$ terminus was higher (Table 16).

\subsubsection{Biological activities of free and tethered peptides}

\section{Antimicrobial activity of free peptides}

The peptides showed antimicrobial activities at micromolar concentrations (Table 15). MEL and TP peptides are more active against B. subtilis than E. coli with the MIC ranging between $0.8-1.6 \mu \mathrm{M}$. Whereas the peptide activity against B. subtilis follows the order $\mathrm{MEL} \approx \mathrm{TP}>>\mathrm{BUF}$, the compounds showed comparable MIC values against E. coli (between $6.3-12.5 \mu \mathrm{M}$ ). The influence of AOA-modification is low upon anti-B. subtilis activity. However, a 4-fold reduction in the antimicrobial activities of AOA-MEL, BUFAOA and AOA-BUF against E. coli compared with the corresponding parent peptides was found. 

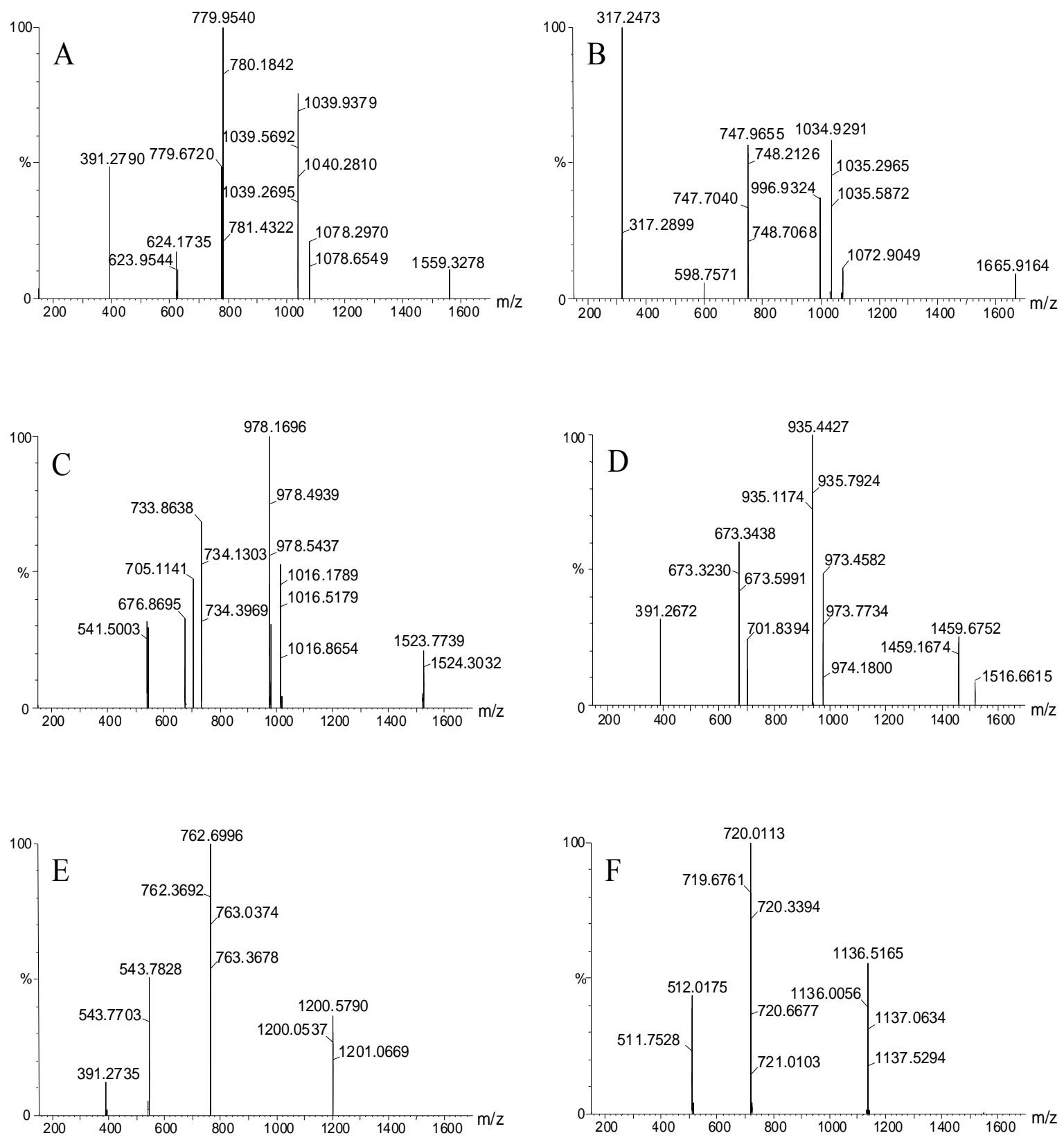

Fig. 34. LC-MS spectra of tethered (A) MEL-AOA, (B) AOA-MEL, (C) BUF-AOA, (D) AOA-BUF,

(E) TP-AOA, and (F) AOA-TP. The ligation products result from the reaction between the AOA-modified peptides and TentaGel S RAM pretreated with pyruvic acid. (A) $[\mathrm{M}+2 \mathrm{H}]^{2+}=1559.33$,

$[\mathrm{M}+3 \mathrm{H}+\mathrm{TFA}]^{3+}=1078.30,[\mathrm{M}+3 \mathrm{H}]^{3+}=1039.57,[\mathrm{M}+4 \mathrm{H}]^{4+}=779.67,[\mathrm{M}+5 \mathrm{H}]^{5+}=623.95$.

(B) $[\mathrm{M}+2 \mathrm{H}+3 \mathrm{TFA}]^{2+}=1665.92,[\mathrm{M}+3 \mathrm{H}+2 \mathrm{TFA}]^{3+}=1072.90,[\mathrm{M}+3 \mathrm{H}+\mathrm{TFA}]^{3+}=1034.93,[\mathrm{M}+3 \mathrm{H}]^{3+}=996.93$, $[\mathrm{M}+4 \mathrm{H}]^{4+}=747.70,[\mathrm{M}+5 \mathrm{H}]^{5+}=598.76 .(\mathrm{C})[\mathrm{M}+2 \mathrm{H}+3 \mathrm{TFA}]^{2+}=1523.77,[\mathrm{M}+3 \mathrm{H}+3 \mathrm{TFA}]^{3+}=1016.18$, $[\mathrm{M}+3 \mathrm{H}+2 \mathrm{TFA}]^{3+}=978.17,[\mathrm{M}+4 \mathrm{H}+2 \mathrm{TFA}]^{4+}=733.86,[\mathrm{M}+4 \mathrm{H}+\mathrm{TFA}]^{4+}=705.11,[\mathrm{M}+4 \mathrm{H}]^{4+}=676.87$, $[\mathrm{M}+5 \mathrm{H}]^{5+}=541.50$. (D) $[\mathrm{M}+2 \mathrm{H}+4 \mathrm{TFA}]^{2+}=1516.66,[\mathrm{M}+2 \mathrm{H}+3 \mathrm{TFA}]^{2+}=1459.17,[\mathrm{M}+3 \mathrm{H}+3 \mathrm{TFA}]^{3+}=973.46$, $[\mathrm{M}+3 \mathrm{H}+2 \mathrm{TFA}]^{3+}=935.12,[\mathrm{M}+4 \mathrm{H}+2 \mathrm{TFA}]^{4+}=701.84,[\mathrm{M}+4 \mathrm{H}+\mathrm{TFA}]^{4+}=673.32$

(E) $[\mathrm{M}+2 \mathrm{H}+2 \mathrm{TFA}]^{2+}=1200.05,[\mathrm{M}+3 \mathrm{H}+\mathrm{TFA}]^{3+}=762.37,[\mathrm{M}+4 \mathrm{H}]^{4+}=543.77$.

(F) $[\mathrm{M}+2 \mathrm{H}+2 \mathrm{TFA}]^{2+}=1136.01,[\mathrm{M}+3 \mathrm{H}+\mathrm{TFA}]^{3+}=719.68,[\mathrm{M}+4 \mathrm{H}]^{4+}=511.75$. 
Inner and outer membrane-permeabilizing activities of MEL, BUF, and TP peptides

To further analyze the membrane activity of MEL, BUF, TP and their AOA-modified analogs, we examined the effect of the peptides on the integrity of the inner and outer membrane of E. coli (strain ML-35p). The results are summarized in Fig. 35. Membraneactive KLAL peptide was used as the positive control. The peptide concentration was around the MIC values for E. coli (strain DH $5 \alpha$ ).

Outer membrane permeabilization
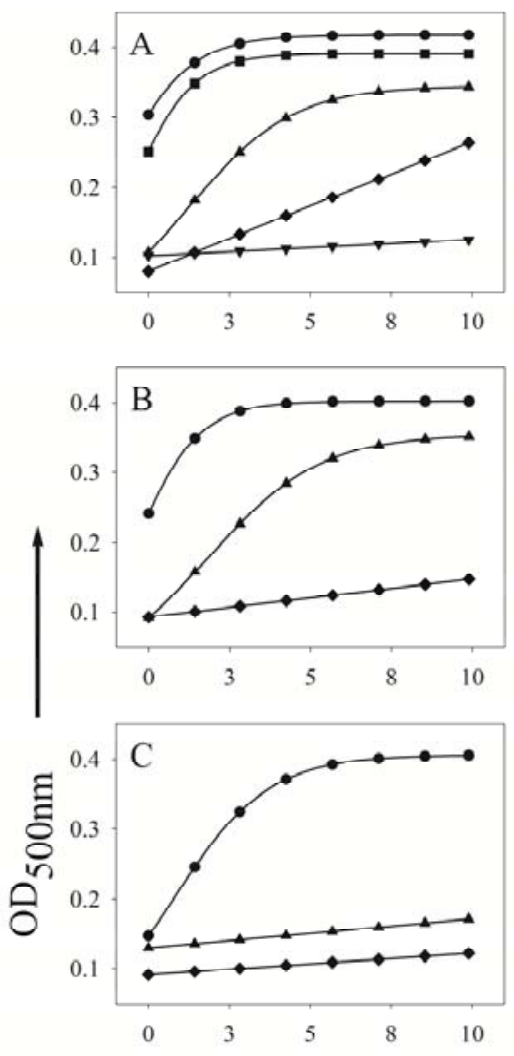

Time ( $\mathrm{min})$
Inner membrane permeabilization
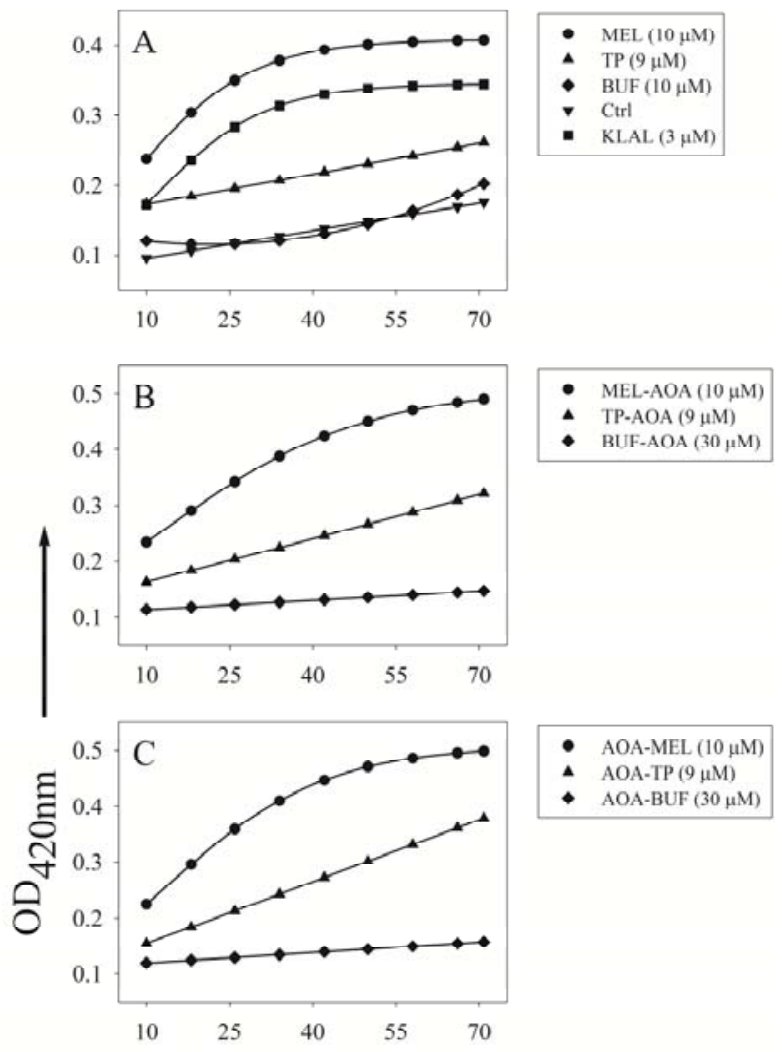

Time $(\mathrm{min})$

Fig. 35. Kinetics of permeabilization of inner and outer membranes of $E$. coli (strain ML-35p) induced by MEL, BUF, TP and their AOA-modified analogs. The inner and outer membrane permeabilizing activities result from the cleavage of ONPG and NCF, respectively. The panels indicate (A) intact, (B) $\mathrm{C}$ terminus AOAmodified, and (C) $\mathrm{N}$ terminus AOA-modified peptides. The peptide concentration was in the range of the MICs values for $E$. coli (DH $5 \alpha)$ growth.

KLAL and the MEL peptides permeabilize the outer membrane of E. coli in a few minutes at concentrations of $3 \mu \mathrm{M}$ and $10 \mu \mathrm{M}$, respectively. This is followed by a fast permeabilization of the inner membrane confirming the high membrane-lytic activity of the peptides. Compared with MEL, the TP peptides could permeabilize the membranes at a 
concentration of $9 \mu \mathrm{M}$; however, the kinetics of inner membrane permeabilization are slow (time period of $\sim 1 \mathrm{~h}$ ).

BUF and its AOA-modified analogs do not show significant permeabilizing activities at concentrations of $10 \mu \mathrm{M}$ and $30 \mu \mathrm{M}$ respectively, the activity patterns were comparable to the buffer control. The good antimicrobial activity (Table 15), but inability to permeabilize the bacterial membranes, is consistant with a membrane-independent mechanism of action as previous studies have suggested $[46,167,169]$.

\section{Antimicrobial activity of tethered peptides}

Table 16 summarizes the biological activities of MEL, BUF, and TP immobilized on TentaGel $\mathrm{S} \mathrm{NH}_{2}$ against B. subtilis and E. coli. The activity profiles of bound MEL and TP against B. subtilis and E. coli are comparable to those of the free peptides. Both tethered peptides were more active against B. subtilis than E. coli. However, MIC values for the Cterminally tethered MEL against B. subtilis and E. coli $(0.06 \mathrm{mM}$ and $0.60 \mathrm{mM}$, respectively) are much lower than the MICs of the N-terminally tethered MEL (up to a factor 5). This position-dependent activity indicates that the $\mathrm{N}$ terminus of MEL should be presented for optimal interaction with bacteria cell membrane and supports the suggested mode of MEL action: Insertion of the peptide's hydrophobic N-terminal domain into the membrane while the charged $\mathrm{C}$ terminus is located in the membrane surface. A similar membrane localization has been suggested for the highly antimicrobial and hemolytic cupiennin 1 peptide [170], which has a structural similarity to MEL [166]. The polar C terminus modulates the peptide accumulation at negatively charged cell surfaces via electrostatic interactions [171]. The hydrophobic $\mathrm{N}$ terminus inserts into the hydrophobic core of the lipid membrane and acts as a driving force for pore formation and membrane disruption. Membrane insertion of both peptides results in formation of an ion-conducting pathway.

No differences in the activities of TP immobilized at the $\mathrm{C}$ terminus or $\mathrm{N}$ terminus exist against $B$. subtilis $(\mathrm{MIC}=0.74 \mathrm{mM})$ or E. coli $(\mathrm{MIC}=2.94 \mathrm{mM})$. With TP insertion into the membrane, the three consecutive $\mathrm{W}$ residues form a large hydrophobic domain and the charged termini remain exposed to the surface [120]. Lipid displacement and pore formation are the consequences. Tethering of the peptide at both termini has obviously little influence upon membrane localization and organization, thus excluding a mechanism, which is related to deep penetration or translocation across the membrane. 
Table 16. The antimicrobial activities of MEL, and BUF tethered on TentaGel $\mathrm{S} \mathrm{NH}_{2}$ beads against $B$. subtilis and $E$. coli and densities of the tethered peptides.

\begin{tabular}{|c|c|c|c|c|c|c|}
\hline \multirow{3}{*}{$\begin{array}{c}\text { Peptide } \\
\text { denotation }\end{array}$} & \multirow{3}{*}{$\begin{array}{c}\text { Position of } \\
\text { immobilization }\end{array}$} & \multirow{3}{*}{$\begin{array}{c}\text { Density of } \\
\text { peptide } \\
(\mu \mathrm{mol} / \mathrm{mg})\end{array}$} & \multicolumn{4}{|c|}{$\mathrm{MIC}$} \\
\hline & & & \multicolumn{2}{|c|}{ B. subtilis (DSM 347) } & \multicolumn{2}{|c|}{ E. coli $(\mathrm{DH} 5 \alpha)$} \\
\hline & & & $\begin{array}{c}\text { Bead } \\
(\mathrm{mg} / \mathrm{ml})\end{array}$ & $\begin{array}{c}\text { Immobilized } \\
\text { peptides } \\
(\mathrm{mM})\end{array}$ & $\begin{array}{c}\text { Bead } \\
(\mathrm{mg} / \mathrm{ml})\end{array}$ & $\begin{array}{c}\text { Immobilized } \\
\text { peptides } \\
(\mathrm{mM})\end{array}$ \\
\hline \multirow[t]{2}{*}{ MEL } & $\mathrm{C}$ terminus & 0.020 & 3 & 0.06 & 30 & 0.60 \\
\hline & $\mathrm{N}$ terminus & 0.022 & 15 & 0.33 & $>60$ & $>1.32$ \\
\hline \multirow[t]{2}{*}{ BUF } & $\mathrm{C}$ terminus & 0.067 & ND & ND & $>28$ & $>1.88$ \\
\hline & $\mathrm{N}$ terminus & 0.099 & ND & ND & $>24$ & $>2.38$ \\
\hline \multirow[t]{2}{*}{$\mathrm{TP}$} & $\mathrm{C}$ terminus & 0.147 & 5 & 0.74 & 20 & 2.94 \\
\hline & $\mathrm{N}$ terminus & $0.147^{*}$ & 5 & 0.74 & 20 & 2.94 \\
\hline
\end{tabular}

${ }^{*}$ Because of the absence of any free amino group in the case of the $\mathrm{N}$ terminus tethered TP, the density of the peptide was taken as identical as the value for the $\mathrm{C}$ terminus tethered TP for the data analysis.

So far, no convincing results were obtained for immobilized BUF (Table 16). Because BUF has interacellular targets [46,167,169], it has to translocate across the bacterial membrane. It is expected that immobilization excludes the peptide from the cytoplasm and thus abolishes the biological effect (studies will be continued). For nisin, Joshi et al. showed that the covalent immobilization results in the loss of antimicrobial activity [105]. Nisin belongs to the group of lantibiotics [172] and targets the lipid II, which is located on the cytoplasmic side. The authors immobilized thiolated nisin on poly[ethylene oxide]poly[propylene oxide]-poly[ethylene oxide] triblocks via formation of a disulfide bridge, but the peptide was active against bacteria only after reduction of the disulfide bridge, which means after peptide release. The peptide had to be free for migration of its $\mathrm{C}$ terminus across the cell membrane and the formation of nisin-lipid II complexes [173].

\subsubsection{Bilayer permeabilizing activities of free and tethered MEL, BUF, and TP peptides}

The bilayer-permeabilizing activities of the peptides against negatively charged POPC/POPG (3/1 [mol/mol]) LUVs mimicking the charge properties of the lipid matrix of the inner membrane of Gram-negative bacteria (Fig. 36) correlate well with the activity profile derived for peptide-induced inner membrane permeabilization (Fig. 35). The activity of the peptides decreases according to the following order: MEL peptides $>$ TP peptides $>>$ BUF peptides. As MEL, TP and BUF showed comparable 
antimicrobial activity against E. coli (Table 15), the results suggest different bactericidal modes of action for the peptides. Unlike the channel-forming MEL, Yang et al. suggested that the effect of TP is due to depolarization of the bacterial cell membrane, coupled to targeting intracellular components [119]. In contrast, the BUF peptides showed no permeabilizing activity even at the concentration of $400 \mu \mathrm{M}$, which is consistent with the results of Kobayashi et al. [167,169] and the idea of the peptide translocation across the cytoplasmic membrane to reach intracellular targets.

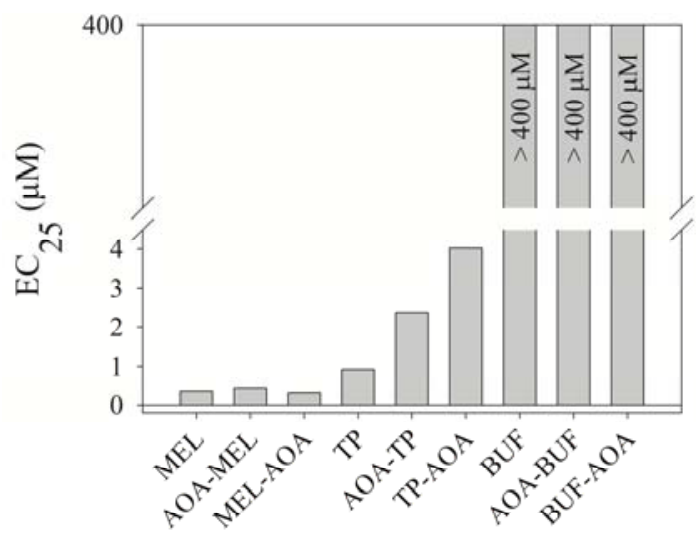

Fig. 36. The bilayer permeabilizing activity of MEL, BUF, TP and their $\mathrm{C}$ terminus and $\mathrm{N}$ terminus AOAmodified analogs. $\mathrm{EC}_{25}$ was determined at $c_{\mathrm{L}}=25 \mu \mathrm{M}$ in buffer after $1 \mathrm{~min}$.

MEL, TP and BUF immobilized at the $\mathrm{C}$ terminus and $\mathrm{N}$ terminus confirmed the activity pattern (Fig. 37). BUF and TP are both inactive and the kinetics of peptide induced bilayer permeabilization is slow at about $1 \mathrm{mM}$ concentration. In contrast to the free peptides, tethered BUF peptides cause higher fluorescence intensity compared to the tethered TP peptides. Considering the density of loaded peptides (Table 16), this might be due to the light scattering induced by higher amount of resin used for BUF peptides (Fig. 37). On the other hand, C-terminally tethered MEL induced dye release more efficiently than the peptide bound at the $\mathrm{N}$ terminus at much lower concentration $(0.1 \mathrm{mM})$. The dependency of activity upon the site of MEL immobilization again underlines the role of the hydrophobic $\mathrm{N}$ terminus domain for membrane insertion. 


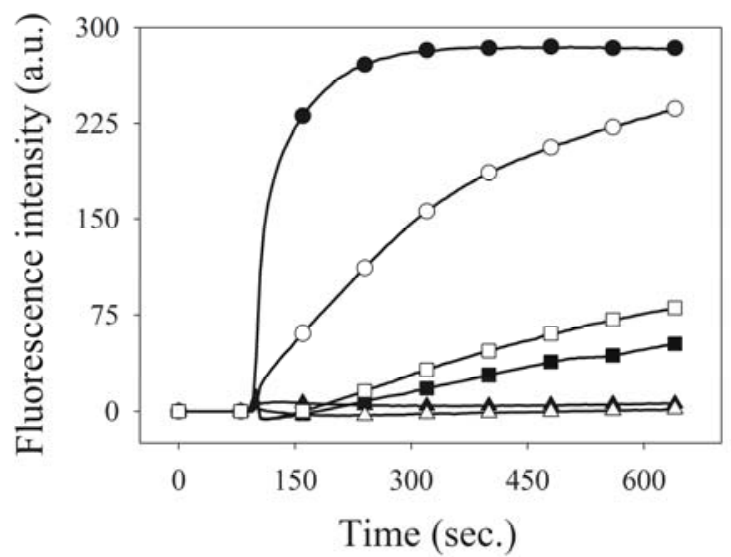

Fig. 37. Kinetics of dye release from POPC/POPG (3/1 [mol/mol]) LUVs induced by TentaGel-tethered MEL, BUF, and TP immobilized at $\mathbf{C}$ terminus and $\mathbf{N}$ terminus. Dye release was monitored as an increase in the fluorescence intensity at $514 \mathrm{~nm}$ at $c_{\mathrm{L}}=25 \mu \mathrm{M}$. The concentration of C-terminally immobilized peptides are

(•) MEL: $0.10 \mathrm{mM}$, (ם) BUF: $1.34 \mathrm{mM}$, and ( $\boldsymbol{\Delta}$ ) TP: $1.47 \mathrm{mM}$, and for those of N-terminally immobilized peptides are (O) MEL: $0.11 \mathrm{mM},(\square) \mathrm{BUF}: 1.98 \mathrm{mM}$, and $(\triangle) \mathrm{TP}: 1.47 \mathrm{mM}$.

In summary, the distribution of the hydrophobic and charged amino acid residues within a peptide sequence is an important issue, which has to be taken into account for preparation of tethered peptides. Because the free hydrophobic region within a peptide sequence has to insert into the cell membranes in order to disturb their integrity, this domain should always be far away from the site of immobilization. Whereas, for peptides, such as KLAL and MK5E with almost identical distribution of positively charged amino acid residues along the sequenece, and TP with its charges at the sequence termini, the activities of the immobilized sequences are not position dependent (Tables 12 and 16), MEL should be tetherd specifically at $\mathrm{C}$ terminus for maximal activity. Moreover, not all CAPs may be active against bacteria when they are tethered. The primary support comes from the resin bead-tethered BUF, which causes neither cell death nor permeabilization of lipid bilayers.

\subsubsection{Summary}

Contact-active cationic antimicrobial surfaces have been proposed to exert their bactericidal effect by penetrating the bacterial cell wall if their biologically active site is far enough away from the surface of the solid matrix (Fig. 38). Autolysis, initiated by the exchange of membrane stabilizing cations, has been suggested as the mode of action $[88,97,161-165]$. Because of the toxicity of these surfaces to human cells, in recent years 
increasing attention has been focused upon surfaces covered with CAPs. Among the various methods of immobilization of CAPs, covalent attachment offers several advantages such as long-term stability and lower toxicity of the biomolecules compared to their incorporation into release-based systems [101]. However, the application of the appropriate chemistry for peptide tethering on materials, which induces little modification of the peptide structural parameters, such as conformation, charge, hydrophobicity and amphipathicity is of particular importance [16].

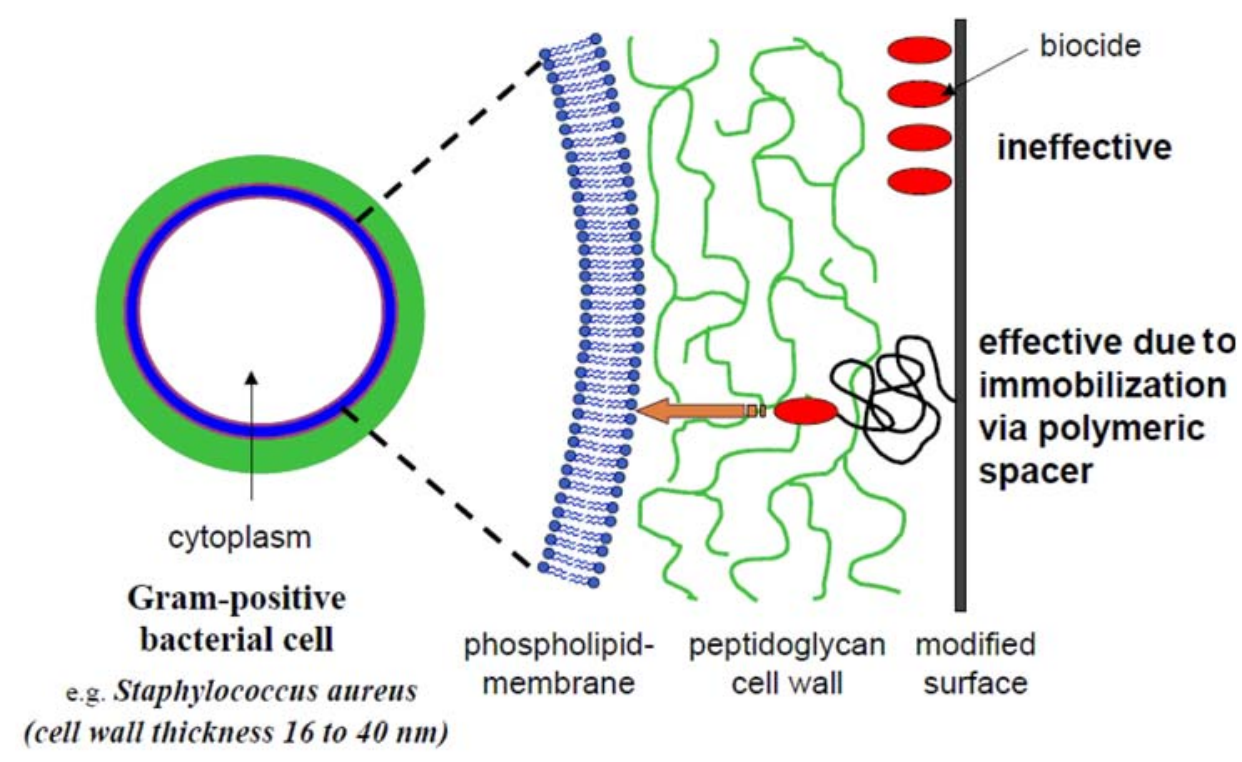

Fig. 38. Scheme of antimicrobial action of immobilized biocides via a polymeric spacer.

Chemical strategies including SPPS, thioalkylation and oxime-forming ligation were used in order to link CAPs with different activity spectra and modes of action at the $\mathrm{C}$ terminus, $\mathrm{N}$ terminus, and side chains on PEGylated resin beads as model solid surfaces (Fig. 27). The CAPs include membrane-active peptides, such as model KLAL peptide [44], MG 2-derived MK5E [118], MEL [8], BUF [46,167,169], and TP [119,120,168].

Reasonable antimicrobial activity of surface-bound peptides requires the optimization of the coupling parameters such as the length of the spacer, the surface area of solid matrices, and the amount of target-accessible peptide. Studies with the tethered membrane active peptides, e.g., KLAL, and MK5E, on TentaGel $\mathrm{S} \mathrm{NH}_{2}$ resin (the resin, which is characterized with the PEG spacers $(3 \mathrm{kDa})$ (Table 9) long enough to span the thickness of bacteria cell 
membrane) demonstrated that tethering conserved the activity spectrum of the peptides at reduced concentrations (Table 12). The antimicrobial activity distinctly decreased with reduction of the spacer length and even an increase in the loading capacity of the resin, e.g., HypoGel $200 \mathrm{NH}_{2}$, was not sufficient to compensate for the spacer length-related activity decrease (Tables 12,16). Furthermore, an increase in surface area of the solid matrices for peptide tethering improved the antimicrobial activity. The analyzed parameters are relevant for the establishment of a more general approach to obtain efficient biocidal solid matrices loaded with CAPs.

Furthermore, the studies demonstrate that immobilization can be used as a powerful tool to gain insight into the modes of peptide interaction with biological and model membranes. Differences in the activity of $\mathrm{N}$ - and C-terminally tethered MEL confirmed the important role of the MEL $\mathrm{N}$ terminus for insertion and peptide orientation within the lipid matrix to form pores, whereas the independency of KLAL activity upon the site of immobilization confirmed an orientation of the helix parallel to the lipid bilayer and a carpetlike mode of action. Hopefully, ongoing studies on immobilized BUF would enable us to distinguish between the peptides with a membrane-perturbing mode of action and those with intracellular targets. 


\section{Summary}

CAPs are components of the innate immune system of mammalians and play an important role in the defense of all organisms, including plants, against invading pathogens. Their mode of action, based on interaction with the cell membrane and their properties, such as rapid action and a low tendency to stimulate the bacterial resistance have been considered as a promising basis for the development of a new class of antibiotics, particularly for topical application. In recent years, much effort has been focused upon modifying such peptides with respect to antimicrobial activity. However, only identification of the structural motifs and optimization of peptide interactions with the different classes of pathogens, such as Grampositive or Gram-negative bacteria will provide the basis for the development of highly selective antimicrobial compounds. Furthermore, increasing efforts have been focused upon the development of antimicrobial surfaces, which inhibit the growth of bacterial adhesion and subsequent biofilm formation.

\subsection{W-substituted c-WFW analogs}

In the first part of this work, it was planned to identify interaction moieties on the cellular level and the driving forces responsible for the pronounced activity increase in RWrich hexapeptides after induction of conformational constraints by peptide cyclization, using systematic modification of the hydrophobic cluster. For this, a small library of peptides based upon the sequence of cyclo-RRRWFW was prepared, in which W residues were replaced by unnatural analogs such as Dht, Igl, 5MeoW, $5 \mathrm{fW}, 5 \mathrm{MeW}, 1 \mathrm{MeW}$, Bal and the $\beta$-amino acid b3-hW with altered hydrophobicity, dipole and quadrupole moments, ability of hydrogen bonding, amphipathicity and flexibility of the cyclic peptide. This made allowed for the undertaking of a systematic investigation of aromatic clusters that affect peptide interactions with lipid systems mimicking the outer and inner membranes, as well as of the biological activities of peptides against E. coli, in comparison with Gram-positive B. subtilis and red blood cells.

To understand the effect of the peptides upon both bacteria and eukaryotic cell membranes in detail, the peptides' interactions with lipid bilayers, i.e., POPC, POPC/POPG $(3 / 1[\mathrm{~mol} / \mathrm{mol}])$ as models of the target membrane and POPC/LA $(12 / 1[\mathrm{~mol} / \mathrm{mol}])$, POPC/rLPS (12/1 [mol/mol]), and POPC/s-LPS (12/1 [mol/mol]), as models of the outer membrane of Gram-negative bacteria were studied by isothermal titration calorimetry. Thermodynamic 
parameters for peptide-lipid interaction were determined using a surface partitioning equilibrium model and correcting for electrostatic effects by the Gouy-Chapman theory and the results were correlated with the biological data.

The study showed that peptide activity against erythrocytes and bacteria can be explained on the basis of peptide accumulation at the lipid matrices of the target membranes driven by electrostatic interactions and subsequent membrane partitioning determined by hydrophobic interactions. Peptide hydrophobicity and backbone constraints are the crucial determinants of biological activity. Other modifications in the hydrophobic cluster of the cyclic hexapeptides have minor influence upon peptide interaction with biological systems and model membranes.

The different susceptibilities of E. coli and B. subtilis can be explained by differences in the negative surface charge of the plasma membranes. Strong peptide interactions with the outer-membrane LPSs of E. coli probably influence the peptide transport across the outer wall, and thus are responsible for high activities of cycles. The activity of the peptides against B. subtilis increased with enhanced hydrophobicity. In contrast, any alterations in hydrophobicity, amphipathicity of the indole ring, and backbone flexibility modulated the antimicrobial activity against $E$. coli in a more complex way.

The accumulation of the individual peptides to different lipid systems was found to be determined by electrostatic and hydrophobic interactions and followed the order: POPC/sLPS $>>$ POPC $/ r-L P S ~>$ POPC $/$ POPG $=$ POPC/LA $>$ POPC. The hydrophobic contribution to binding to POPC and mixed POPC/POPG bilayers was comparable. Low hydrophobicity and conformational flexibility of the peptides reduced partitioning into the layers. The peptide binding was largely enthalpy-driven, which is in agreement with the nonclassical hydrophobic effect.

In the presence of r-LPS and s-LPS the modulating role of hydrophobicity in partitioning of the different cyclic peptides decreased while no influence was found upon the low affinity of the highly flexible linear parent peptide. For lipid systems with incorporated rLPS or s-LPS, the different cyclic peptides showed comparable binding affinities. However, the $K_{0}$ values for interaction with POPC/s-LPS systems were almost by one order of magnitude larger than for binding to POPC/r-LPS bilayers which uncovers the significant role 
of the O-antigen and outer core oligosaccharides of LPS for more specific interactions of the cylic peptides.

The reason why distinct differences in hydrogen bonding ability, dipole moment, and aromaticity of the $\mathrm{W}$ residues are not reflected in the thermodynamic characteristics of the peptide interactions with LPS-containing lipid bilayers remains to be elucidated.

\subsection{Site-specific immobilization of CAPs}

In the second part of this work, the influence of immobilization upon the activity profile of CAPs was analyzed. This study was to analyze a number of coupling parameters with respect to the use of peptides in the generation of biocidal surfaces. Resin beads bearing PEG spacers of different lengths and various size distributions (between 10-300 $\mu \mathrm{m}$ ) were covered by linkage of an amphipathic model KLAL peptide, a magainin 2-amide-derived MK5E, melittin, buforin 2, and the RW-rich tritrpticin. The peptides were characterized by different modes of action. Standard SPPS, thioalkylation and oxime-forming ligation strategies were used to immobilize the peptides at $\mathrm{C}$ terminus and $\mathrm{N}$ terminus and via different side chain positions. The influence of resin bead parameters, such as spacer length, spacer density, and surface area available for peptide attachment were studied by the investigation of antimicrobial and bilayer permeabilizng activities of the peptides covered surfaces. Additionally, covalent immobilization of the CAPs to an insoluble solid material in combination with activity studies was developed as an alternative approach to elucidate the mode of action of the peptides.

The antimicrobial peptides KLAL and MK5E were suitable for the production of antibacterial surfaces. The tethered peptides also act via permeabilization of the cell membrane. The free peptides showed antimicrobial activities against B. subtilis and E. coli at micromolar concentrations. Immobilization on resins reduced the antimicrobial activity spectra of the free peptides to millimolar concentrations. The activity profile against Gram negative and Gram positive bacteria and red blood cells remained constant.

The length of spacer between the solid surface and active sequences is a critical parameter for peptide activity. The peptide activities decrease with reduction of the spacer length independent of amount of loaded peptide on solid surface. Furthermore, enhancement 
of surface area available for peptide attachment increases the biocidal activity of tethered peptides.

Depending upon the mechanism of action of peptides, the coupling position affects the peptide activity. An appropriate coupling position has to be selected depending upon the orientation of the peptides in the membrane. Supports come from the biological and lipid bilayers permeabilizing activities of tethered KLAL with a "carpet-like" mode of action as compared with MEL, which forms pores through the peptide N-terminal insertion and association. Whereas the activities of tethered KLAL is independent of coupling position, Nterminal immobilization of MEL leads to the loss of the activities compared with the Cterminally tethered peptide.

Based upon the relation between peptide activity, their positioning and association within the membrane, peptide tethering should make it possible to gain insight into the mechanisms of peptides action according to the "carpet-like mode" or pore formation via the "barrel stave" or "toroidal model". 


\section{Zusammenfassung}

Kationische antimikrobielle Peptide sind Bestandteil des angeborenen Immunsystems von Säugetieren und spielen eine wichtige Rolle bei der Verteidigung aller Organismen gegen Krankheitserreger. Ihre Wirkungsweise über die Permeabilisierung der Zellmembran und ihre rasche Wirkung bei nur geringer Stimulation einer bakteriellen Resistenzentwicklung bilden eine vielversprechende Grundlage für die Entwicklung peptidischer Antibiotika, insbesondere für topische Anwendungen. In den letzten Jahren wurde vielfach versucht, Peptide im Hinblick auf ihre antimikrobielle Aktivität zu optimieren. Um selektive antimikrobielle Verbindungen zu entwickeln, müssen die Strukturmotive identifiziert werden, die für die Wechselwirkung der Peptide mit verschiedenen Klassen von Pathogenen, wie z. B. Grampositiven oder Gram-negativen Bakterien, entscheidend sind. Darüber hinaus werden große Anstrengungen unternommen, um antimikrobielle Oberflächen $\mathrm{zu}$ entwickeln, die die bakterielle Adhäsion an Oberflächen und die dadurch ermöglichte Biofilmbildung hemmen sollen.

\subsection{W-substituierten c-WFW Analoga}

Im ersten Teil dieser Arbeit sollten sowohl die Interaktionsgruppen auf der Ebene von Zellmembranen als auch die Triebkräfte identifiziert werden, die für den ausgeprägten Aktivitätsanstieg bei Zyklisierung RW-reicher Hexapeptide verantwortlich sind. Für die systematische Modifizierung des hydrophoben Clusters der Peptide, wurde eine kleine Bibliothek von cyclo-RRRWFW-abgeleiteten Sequenzen synthetisiert, in denen W-Reste durch unnatürliche Analoga wie Dht, Igl, 5MeoW, 5fW, 5MeW, $1 \mathrm{MeW}$, Bal und die $\beta$ Aminosäure, b3-hW ersetzt wurden, was in einer Änderung der physiko-chemischen Eigenschaften, wie z. B. Hydrophobizität, Dipol- und Quadrupol-Moment, Fähigkeit zur Wasserstoffbrückenbildung, Amphipathie, und Flexibilität resultierte. Dies machte systematische Untersuchungen der aromatischen Clustern in Wechselwirkungen mit Membran-modellierenden Lipidsystemen möglich und erlaubte einen Vergleich der biologischen Aktivität der Peptide gegenüber Gram-negativen E.coli, Gram-positiven B. subtilis und roten Blutzellen.

Um die Wirkung der Peptide auf bakterielle und eukaryotische Zellmembranen im Detail zu verstehen, wurde die Bindung der Peptide an verschiedene Lipid-Doppelschichten, nämlich POPC und POPC/POPG (3/1 [mol/mol]) als Modelle biologischer Targetmembranen 
und POPC/LA $\quad(12 / 1[\mathrm{~mol} / \mathrm{mol}]), \quad$ POPC/r-LPS $(12 / 1[\mathrm{~mol} / \mathrm{mol}])$ und POPC/s-LPS (12/1 [mol/mol]) als Modelle der äußeren Membran von Gram-negativen Bakterien, durch isothermale Titrationskalorimetrie untersucht. Thermodynamische Parameter der LipidPeptid-Interaktionen wurden mittels eines Verteilungs-Modells bestimmt und bezüglich elektrostatischer Effekte nach der Gouy-Chapman Theorie korrigiert. Diese Ergebnisse wurden mit den biologischen Daten korreliert.

Die Ergebnisse zeigten, dass die Peptidaktivität gegenüber Erythrocyten und Bakterien durch die Peptidakkumulation, die durch elektrostatische Wechselwirkungen bestimmt ist sowie nachfolgende Verteilung in das hydrophobe Innere der Lipidmatrix erklärt werden kann. Die Peptidhydrophobizität und konformationelle Beschränkungen im Ring sind entscheidende Faktoren für die biologische Aktivität. Andere Modifikationen in den hydrophoben Clustern der Hexapeptide haben nur geringen Einfluß auf die Peptidwirkung gegenüber Zellen und auf Modelmembranen.

Die unterschiedliche Empfindlichkeit von E. coli und B. subtilis Bakterien lässt sich auf Grundlage der unterschiedlichen Ladung der Plasmamembranen verstehen. Die Aktivität der Peptide gegen B. subtilis stieg mit erhöhter Hydrophobizität. Im Gegensatz dazu beeinflußt jede Änderung der Hydrophobizität, Amphipathie des Indolring und Flexibilität im Rückgrat die antimikrobielle Aktivität gegen E. coli in einer komplexeren Art und Weise. Starke Interaktionen der Peptide mit dem O-Antigen und Resten der äußeren Region von LPS in der äußeren Membran Gram-negativer E. coli sind wahrscheinlich für den effizienten Peptidtransport durch die äußere Barriere und damit die hohe Aktivität der Zyklen verantwortich.

Die Akkumulation der Peptide an unterschiedliche Lipid-Bilayern wird durch elektrostatische und hydrophobe Wechselwirkungen bestimmt und folgt der Reihenfolge: POPC/s-LPS $>>$ POPC/r-LPS $>$ POPC/POPG $=$ POPC/LA $>$ POPC. Der hydrophobe Beitrag zur Bindung an POPC und gemischte POPC/POPG Doppelschichten war vergleichbar. Geringe Hydrophobizität und konformationelle Flexibilität der Peptide reduziert die Verteilung in die Lipidschichten. Die Peptidbindung ist weitgehend Enthalpie-getrieben was dem nichtklassischen hydrophoben Effekt entspricht.

In Anwesenheit von LA, r-LPS und s-LPS sinkt die modulierende Rolle der Hydrophobizität bei der Verteilung der verschiedenen zyklischen Peptide, wobei kein Einfluß 
auf die geringe Affinität des hochflexiblen linearen Ausgangspeptids gefunden wurde. Für Lipid-Systeme mit r-LPS oder s-LPS, zeigten die verschiedenen zyklischen Peptide vergleichbare Bindungsaffinitäten. Allerdings waren die hydrophoben Verteilungskoeffizienten für die Interaktion mit POPC/s-LPS-Systeme fast eine Größenordnung höher als für die Bindung an POPC/r-LPS-Doppelschichten. Das unterstreicht die bedeutende Rolle des O-Antigens und der Oligosaccharide im äußeren Kern des LPS als spezifischer Wechselwirkungspartner der zyklischen Peptide.

Der Grund dafür, dass sich deutliche Unterschiede der Peptide in der Fähigkeit, Wasserstoffbrückenbindungen zu bilden, im Dipol-Moment und in der Aromatizität nicht in den thermodynamischen Eigenschaften ihren Interaktionen mit LPS-enthaltende LipidDoppelschichten widerspiegeln, bleibt noch aufgeklärt werden.

\subsection{Ortsspezifische Immobilisierung von CAPs}

Im zweiten Teil dieser Arbeit wurde der Einfluss einer Immobilisierung kationischer antimikrobieller Peptide auf ihr Wirkprofil analysiert. Mit dieser Arbeit sollte ein Beitrag geleistet werden, um Peptide für die Entwicklung antimikrobieller Materialien einsetzen zu können. Dazu wurden Harze verschiedener Korngrößenverteilungen (zwischen 10-300 mm) und mit PEG-Spacern unterschiedlicher Längen mit dem linearen amphipatischen Modellpeptide KLAL, einem von Magainin 2-amide abgeleitetem MK5E-Peptid sowie den Peptiden Melittin, Buforin 2 und dem W-reichen Tritrptizin beladen. Die Peptide zeichnen sich durch unterschiedliche Wirkungsmechanismen aus. Die Peptide wurden mit Hilfe verschiedener Synthesestrategien: Standard Festphasen-Peptidsynthese, Thioalkylierung und Oxim-forming Ligation, über ihren C-terminus, N-terminus oder verschiedene Seitenkettenpositionen immobilisiert. Der Einfluss der Harzparameter, wie Länge und Dichte der Spacer oder der für die Peptidanbindung zur Verfügung stehenden Oberfläche sowie die Rolle der Peptidposition zur Immobilisierung wurde analysiert durch eine Bestimmung der antimikrobiellen und membranpermeabilisierenden Aktivität der beladenen Harze. Darüber hinaus wurde die Peptidimmobiliseirung an Syntheseharz als ein alternativer Ansatz zur Untersuchung der Wirkungsweise der Peptide eingesetzt.

Die antimikrobiellen Peptide KLAL und MK5E sind zur Herstellung antibakterieller Oberflächen geeignet. Sie wirken auch im immobilisierten Zustand durch Permeabilisierung der Zellmembran. Die untersuchten freien Peptide zeigten antimikrobielle Aktivitäten gegen 
B. subtilis und E. coli im mikromolaren Konzentrationen. Immobilisierung am Harz reduziert die Peptidaktivität auf millimolare Konzentrationen. Das Aktivitätsprofil gegenüber Gram negativen, Gram positiven Bakterien und roten Blutzellen bleibt jedoch erhalten.

Die Abstand zwischen der festen Oberfläche und der aktiven Sequenzen ist ein kritischer Parameter für die Peptid-Aktivität. Die Peptidwirksamkeit verringert sich mit Abnahme der Spacerlänge, unabhängig von der Menge der Peptids auf der Oberfläche. Andererseits, führt die Vergrößerung der verfügbaren Fläche für die Peptidkopplung zur einer Verbessrung der bioziden Wrikung.

In Abhängigkeit vom Wirkungsmechanismus, beeinflusst die Kopplungsposition im Peptid die Aktivität entscheidend. Eine geeignete Kopplungsposition ist in Abhängigkeit von der Orientierung der Peptide in der Membran zu wählen. So ist die Aktivität von KLAL, für das eine Lokalisation in der Membranoberfläche und ein "Carpet-like" Wirkungsmodus vorgeschagen wird, im immobilisierten Zusand weitgehend unabhängig von der Kopplungsposition. Für Mellitin, das in Lipidschichten Poren bildet durch Insertion des Nterminus und Assoziation, muß N-terminale Immobilisierung zum Aktivitätsverlust führen.

Dieser Zusammenhang sollte es möglich machen Peptidimmobilisierung als Methode zu entwickeln, um Aussagen zu den Modellen der Peptidwirkung zu gewinnen, die durch unterschiedliche Positionierung und Assoziation der Peptide in der Membrane charakterisiert sind. 


\section{Experimental section}

\subsection{Materials: Chemicals and reagents}

TentaGel $\mathrm{S} \mathrm{NH}_{2}, \quad$ TentaGel $\mathrm{M} \mathrm{NH}_{2}, \quad$ TentaGel MB NH $2, \quad$ TentaGel S RAM, HypoGel $400 \mathrm{NH}_{2}$, HypoGel $200 \mathrm{NH}_{2}$, and ClTrt-Cl resins were purchased from Rapp Polymere GmbH, Germany. The Fmoc-N-protected amino acids were obtained from GL Biochem (Shanghai) LtdS, China. The side chain protecting groups were as follows: Arg (Pbf), Asn (Trt), Asp (t-Bu), Cys (Trt), Gln (Trt), Glu (t-Bu), Gly (Boc), His (Trt), Lys (Boc), Pro (Boc), Ser (t-Bu), Thr (t-Bu), Trp (Boc), and Tyr (t-Bu). We used FmocDht(Boc)-OH and Fmoc-Igl-OH (both Advanced ChemTech/ThuraMed, U.S.A.), Fmoc-Bal$\mathrm{OH}$ and N- $\beta$-Fmoc-b3-hW-OH (both Sigma-Aldrich GmbH, Germany), Fmoc-5Metrp-OH and Fmoc-5Meotrp-OH (both AnaSpec Inc., U.S.A.), Fmoc-1Metrp-OH (BACHEM, Switzerland), Fmoc-5Ftrp-OH (Iris Biotech GmbH, Germany), Fmoc-Lys(Dde)-OH and Fmoc-PEG 2-OH [Fmoc-NH-PEG-COOH (9 atoms)] (both Novabiochem, Germany), BocAOA-OH and pyruvic acid (both Fluka, Germany) from the noted provider. Fmoc-Cl, and activating reagents, such as $\mathrm{HOBt}$ and HBTU were obtained from Iris Biotech $\mathrm{GmbH}$. Thioanisole, EDT, TIPS, GnHCl, and calcein were provided from Fluka, NCF from Oxoid (U.K.), and phenol from Honeywell Riedel-de Haen, Germany. 1-PrOH, TBP, ampicillin, and ONPG were from Sigma-Aldrich GmbH. The culture tubes (reagent and centrifuge tube), $5 \mathrm{~mL} ; 75 \times 12 \mathrm{~mm}$; PS were from SARSTEDT AG \& Co, Germany. LB, LB-agar, s-LPS (source: E. coli K-235), Rd-LPS (source: E. coli F583 (r-LPS)), and diphosphoryl LA (source: E. coli F583 (Rd mutant)) were obtained from Sigma-Aldrich GmbH. The lipids POPC and POPG were purchased from Avanti Polar Lipids, U.S.A. TRIS, and other chemicals were from Fluka, Acros Organics (Belgium), or Merck (Germany).

\subsection{Methods}

\subsubsection{Synthesis of peptides}

\subsubsection{Synthesis of linear peptides (automated synthesis)}

The linear peptides were synthesized automatically by SPPS using a standard Fmoc/t$\mathrm{Bu}$ protocol [149]. Syntheses were carried out on TentaGel S RAM resin $(0.26 \mathrm{mmol} / \mathrm{g})$ using 5 equiv. Fmoc-protected amino acids and 4.9 equiv. HBTU as a coupling reagent in the 
presence of 10 equiv. DIEA in DMF. Double couplings for 20 min were allowed. $\mathrm{N}$ terminus deblocking was carried out twice with $20 \%$ piperidine in DMF for $5 \mathrm{~min}$. Washes were made with DMF. Acetylation was carried out twice and for $10 \mathrm{~min}$ using $\mathrm{Ac}_{2} \mathrm{O} / \mathrm{DIEA} / \mathrm{DMF}(0.5 / 1 / 3.5 \mathrm{v} / \mathrm{v} / \mathrm{v})$. For acetylation of the PEGylated peptides the same methodology was used. The strategy of SPPS was also used to introduce PEG 2. For side chain PEGylation of K residues, Fmoc-Lys(Dde)-OH was used instead of Fmoc-Lys(Boc)$\mathrm{OH}$. The Dde side chain was removed by exposure to $2 \%$ hydrazine in DMF twice for 5 and 10 min. After washing, PEG 2 was coupled to the free amino group using HBTU activation. Final cleavage from the resin and deprotection of the side chain functionalities were achieved by exposure to a mixture of 5\% phenol, 2\% TIPS, and 5\% water in TFA for $2 \mathrm{~h}$. After cleavage of the protecting groups, peptides were precipitated by addition of cold diethyl ether.

\subsubsection{Synthesis of cyclic peptides (manuel synthesis)}

The peptide acids, as precursors for the preparation of cyclic peptides, were synthesized manually by SPPS using the standard Fmoc/t-Bu protocol. Syntheses were carried out on ClTrt-Cl resin ( $1.03 \mathrm{mmol} / \mathrm{g})$ using Fmoc-protected amino acids. Before the synthesis, the resin was placed in a reaction vessel equipped with a porous frit and swollen in DCM for $30 \mathrm{~min}$ followed by filtration of the solvent under vacuum. The peptides were synthesized according to the sequence $\operatorname{RRRXX}(\mathrm{X}=\mathrm{W}$ and other unnatural amino acids). To couple the first amino acid, i.e, Fmoc-Trp(Boc)-OH or the unnatural amino acids, 1 equiv. of the protected amino acid and 1 equiv. of DIEA were dissolved in DCM and added to the resin. The mixture was agitated on a shaker for $2 \mathrm{~h}$. Afterwards, the vessel was drained and subjected to a mixture of DCM, methanol, and DIEA (8/2/1 [v/v/v]) twice for 10 min to block any unreacted chloro- functional groups on resin. The resin was washed again with DCM five times for $1 \mathrm{~min}$ and drained under vacuum. The final loading of the coupled amino acid was quantified by UV absorption of the released Fmoc chromophor at $301 \mathrm{~nm}$. The resin was then washed with 20\% piperidine in DMF twice for 5 min to deblock the Fmoc group and washed again with DMF five times. The synthesis was continued to the end by utilizing the HBTU activation, i.e., 3 equiv. amino acids, 3 equiv. HBTU and 6 equiv. DIEA in respect to the capacity of the resin in DMF. Double couplings for $20 \mathrm{~min}$ were allowed and washes were conducted with DMF. Final cleavage from the resin and deprotection of the side chain functionalities were achieved by exposure to a mixture of 5\% phenol in TFA for $2 \mathrm{~h}$. In the case of sequences with $\mathrm{W}$-analogs, in which the indole moiety is unprotected, the 
reagent $\mathrm{K}$ (TFA/thioanisole/water/phenol/EDT [82.5/5/5/5/2.5 v/v]) was applied as the cleavage cocktail. After cleavage, the peptides were precipitated by addition of cold diethyl ether. The crude peptides were dissolved in a mixture of water/ACN $(1 / 1[\mathrm{v} / \mathrm{v}])$ and the resulting solution was lyophilized. The head-to-tail cyclization of the crude linear peptides was performed by the use of HAPyU and DIEA in DMF under dilute condition as described before [53].

\subsubsection{HPLC purification of crude peptides}

The crude peptides were dissolved in a mixture of water/ACN $(1 / 1 \mathrm{v} / \mathrm{v})$ and purified by RP-HPLC on a Shimadzu LC-10A system (Japan) using a PolyEncap C-18 column $(250 \times 20 \mathrm{~mm}, 10.0 \mu \mathrm{m}, 300 \AA)$ (Bischoff Analysentechnik, Germany) operating at $220 \mathrm{~nm}$ and $10 \mathrm{~mL} / \mathrm{min}$ to produce final products that were more than $95 \%$ pure. The sample concentration was $5 \mathrm{mg}$ of peptide $/ \mathrm{mL}$ in water/ACN $(1 / 1 \mathrm{v} / \mathrm{v})$. The mobile phase A was $0.1 \%$ TFA in water, and phase B was $0.1 \%$ TFA in $80 \% \mathrm{ACN}-20 \%$ water (v/v) using a linear gradient 5 to $95 \% \mathrm{~B}$ in $40 \mathrm{~min}$. The compounds were further characterized either by ESI-MS in the positive ionization mode using an ACQUITY UPLC system with LCT Premier mass spectrometer (Waters Corporation, U.S.A.) or by MALDI-MS (MADLI II, U.K.) to confirm the right molecular mass.

\subsubsection{Characterization of peptides based upon $t_{\mathrm{R}}$-HPLC.}

Measurement of the $t_{\mathrm{R}}$ value of CAPs using RP-HPLC is a convenient method to compare peptide hydrophobicity. This method is based on the ability of the hydrophobic residues in a peptide to interact with the hydrophobic surface of the HPLC reversed stationary phase. Thus, the differences due to increases in hydrophobicity are reflected in the retention time $t_{\mathrm{R}}$.

Chromatographic characterization was performed on a Jasco analytical HPLC system (Jasco, Japan) with a diode array detector operating at $220 \mathrm{~nm}$. Runs were carried out using a PolyEncap C-18 column $(250 \times 4.0 \mathrm{~mm}, \quad 5.0 \mu \mathrm{m}, 300 \AA) \quad$ (Bischoff Analysentechnik) operating at $220 \mathrm{~nm}$ and $1 \mathrm{~mL} / \mathrm{min}$. The sample concentration was $1 \mathrm{mg}$ of peptide $/ \mathrm{mL}$ in eluent A. The mobile phase A was $0.1 \%$ TFA in water, and phase B was $0.1 \%$ TFA in $80 \% \mathrm{ACN}-20 \%$ water $(\mathrm{v} / \mathrm{v})$. The $t_{\mathrm{R}}$ of the peptides was determined using a linear gradient of 5 to $95 \%$ phase B over $40 \mathrm{~min}$ at room temperature. 


\subsubsection{Immobilization of CAPs}

\subsubsection{SPPS: C terminus immobilization}

C-terminally immobilized model KLAL peptide and MK5E were prepared by the use of automated peptide synthesis as described above except that: TentaGel $\mathrm{S} \mathrm{NH}_{2}$, HypoGel $200 \mathrm{NH}_{2}$, HypoGel $400 \mathrm{NH}_{2}$, TentaGel MB NH , and TentaGel M NH 2 were used for the synthesis. The immobilized peptides were deprotected by TFA cleavage as mentioned above. The resins were then washed several times with diethyl ether, DCM, DMF, 5\% DIEA in DCM, and DCM. Afterwards, the peptide-loaded resins were dried under vacuum and stored at $4{ }^{\circ} \mathrm{C}$.

\subsubsection{Thioalkylation: $N$ terminus and side chain immobilization of KLAL}

An additional $\mathrm{C}$ residue was introduced at the $\mathrm{N}$ terminus or an $\varepsilon$-amino group of the $\mathrm{K}$ residues of the peptides. BrAcOH (Fluka, Germany) was introduced at the aminofunctionalized resin using its anhydride, which was prepared in situ by mixing $\mathrm{BrAcOH}$ (3 equiv.), DIC (3 equiv.) and HOBt (3 equiv.) in DCM for $2 \mathrm{~h}$. After washing and drying the resins overnight under vacuum, the Cys-modified peptides $[\sim 15 \mathrm{mM}$ in DMF/1-PrOH (1/4 v/v), TBP (3 equiv.), DIEA (6 equiv.)] were added to the BrAcOHmodified resins and incubated by vortexing overnight at room temperature. The peptidebearing resins were washed with DMF, followed by DCM and then dried under vacuum and stored at $4{ }^{\circ} \mathrm{C}$ (Fig. 27).

\subsubsection{Oxime-forming ligation: $\mathrm{N}$ terminus and side chain immobilization of MK5E, MEL, BUF, and TP}

AOA was introduced at the $\mathrm{C}$ terminus, $\mathrm{N}$ terminus or an $\varepsilon$-amino group of $\mathrm{K}$ residues. For the $\mathrm{C}$ terminus immobilization of the peptides, we introduced an extra $\mathrm{K}$ residue at the first position of the $\mathrm{C}$ terminus of the sequences. Fmoc-Lys(Dde)-OH was used for this purpose. To overcome the problem of over-acetylation of nitrogen atoms in the - NH-O- moiety, which would lead to AOA(AOA)-peptides during the synthesis of an aminooxy-peptide for chemical ligation [174], the aminooxy-peptides were prepared by using 3 equiv. DIC, 3 equiv. HOBt as coupling reagents and 3 equiv. AOA in DCM for $1 \mathrm{~h}$. The ketone-containing resin was prepared as followed: Three equiv. of pyruvic acid were added to 
the reaction vessel containing TentaGel $\mathrm{S} \mathrm{NH}_{2}, 3$ equiv. DIC and 3 equiv. HOBt in an appropriate amount of DCM. After $2 \mathrm{~h}$, the reaction was followed with the Kaiser test. Finally, the resin was washed several times with DMF and DCM and subsequently dried under vacuum overnight for further use. Peptides modified with AOA $(\sim 15 \mathrm{mM}$ in acetate buffer, $6 \mathrm{M} \mathrm{GnHCl}$, $\mathrm{pH} 4.6$ ) were added to the dry ketone-functionalized resin and allowed to react at room temperature overnight. After washing with DMF followed by DCM, the resins were dried under vacuum and stored at $4{ }^{\circ} \mathrm{C}$ (Fig. 27).

\subsubsection{Characterization of tethered peptides using UV-absorption of the Fmoc-chromophore}

The density of immobilized peptides was determined by measuring the absorption of the cleaved Fmoc-chromophore upon treatment of the peptide-loaded resins with $20 \%$ piperidine in DMF. The resin-bound peptides were exposed to a 5-fold excess of Fmoc-Cl, and DIEA in DCM (calculated on the basis resin capacity and the number of available amino groups in the sequence of the individual peptide). After $1 \mathrm{~h}$, the resin was washed in DCM and subjected to $20 \%$ piperidine in DMF for 20 min. Afterwards an aliquot of the supernatant was added to a cuvette containing piperidine and the absorption was measured at $301 \mathrm{~nm}\left(\varepsilon=6000 \mathrm{M}^{-1} . \mathrm{cm}^{-1}\right)$ using a Lambda 9 spectrophotometer (PerkingElmer, Germany).

\subsubsection{Antimicrobial activity}

Antibacterial activities were assessed against Gram-negative E. coli (strain DH $5 \alpha$ ) and Gram-positive B. subtilis (strain DSM 347).

\subsubsection{Bacterial culture preparation and determination of MIC and MBC}

Bacteria were grown at $37^{\circ} \mathrm{C}$, shaking at $180 \mathrm{rpm}$, in LB to the mid-log phase as determined by the optical density $\left(\mathrm{OD}_{600}\right.$ of $\left.0.4-0.5\right)$. The bioassays with resin-bound and free peptides were carried out in culture tubes and 96-well microtiter plates respectively (Figs. 39, 40). 


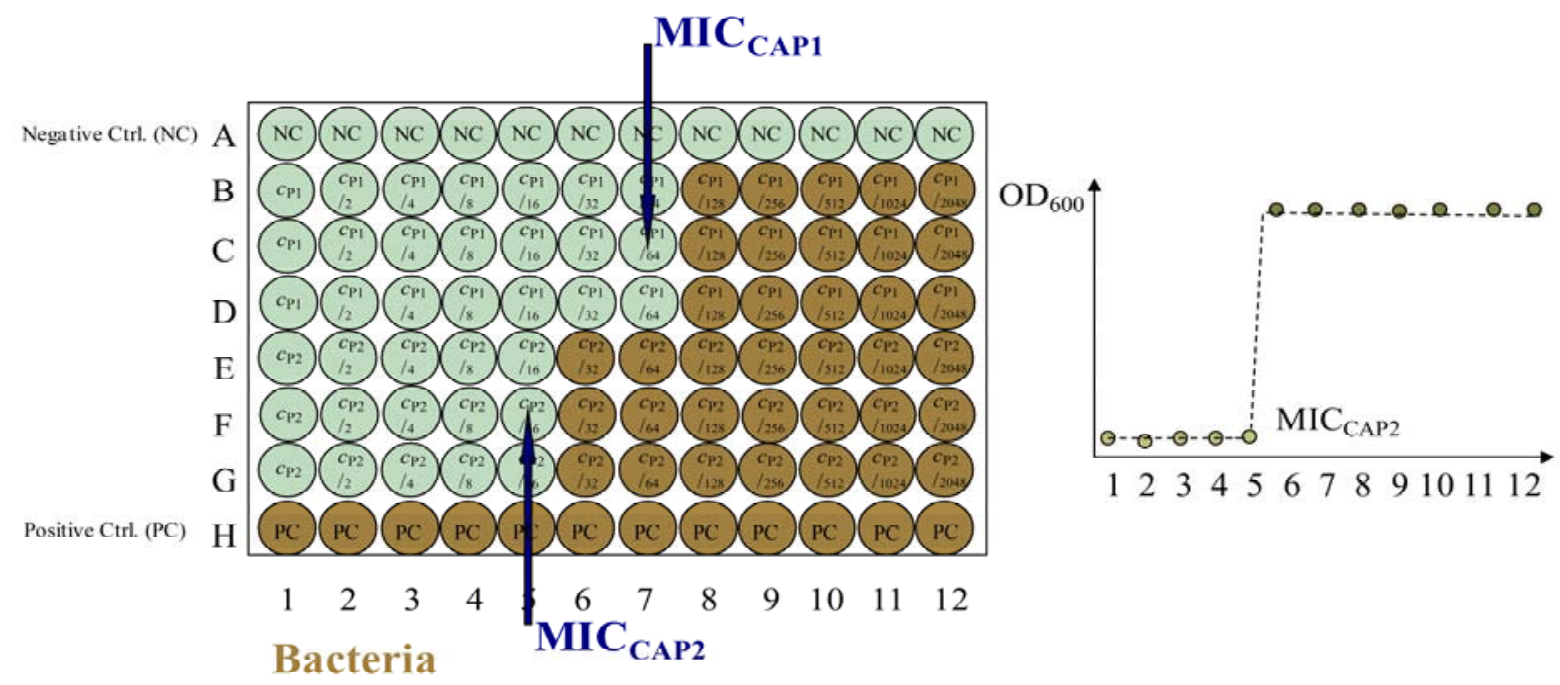

Fig. 39. Determination of MIC of bacterial growth of free peptides using microtiter plate method. MIC values represent the means of three independent experiments performed in triplicate.
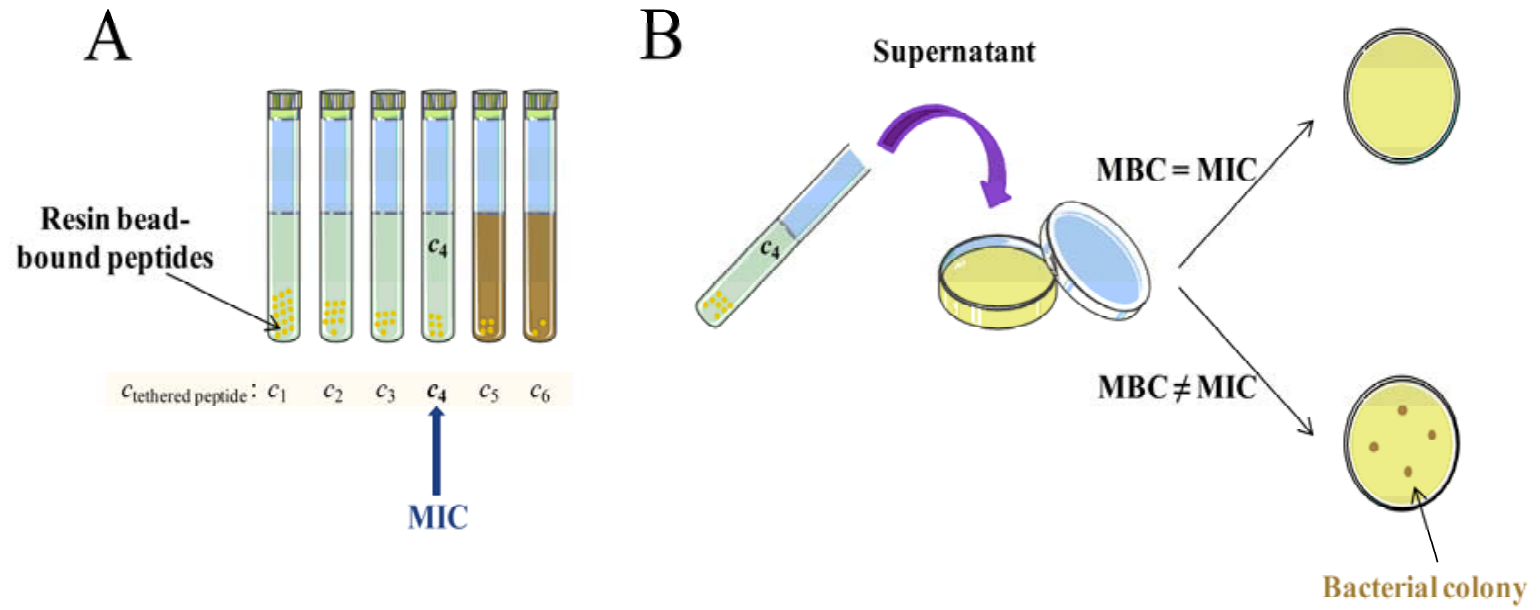

Fig. 40. (A) Determination of MIC of bacterial growth of tethered peptides. (B) Determination of MBC on an LB-agar plate. Each MIC of peptide-covered resin was determined in one experiment using a serial dilution of the peptide-loaded resin. The values were confirmed in two independent experiments using the determined MIC and two resin concentrations below and above the MIC.

Appropriate amounts of peptide-bearing resin were added to the culture tubes containing $1 \mathrm{~mL}$ of LB medium. An aliquot of the cell suspension was then added resulting in a cell concentration of $\sim 1.6 \times 10^{6}$ cells $/ \mathrm{mL}$. Non-modified resins were used as a control. Depending upon the cell line, the tested concentrations ranged between 0.5 and $80 \mathrm{mg} / \mathrm{mL}$. For free peptides, $150 \mu \mathrm{L}$ of the bacterial suspension was added to $50 \mu \mathrm{L}$ of the culture 
medium containing the peptides at various concentrations. The final cell concentration was $\sim 1.6 \times 10^{6}$ cells $/ \mathrm{mL}$. The final concentrations of peptides ranged from 100 to $0.05 \mu \mathrm{M}$ in 2-fold dilutions. Cultures without peptides were used as control. The microtiter plates were incubated at $37^{\circ} \mathrm{C}$ with shaking $(180 \mathrm{rpm})$. After $17 \mathrm{~h}$, the absorbance was read at $600 \mathrm{~nm}$ (Safire Microplate Reader, Tecan, Germany). The MIC was determined as the lowest peptide concentration at which no bacterial growth was observed. To evaluate the antimicrobial activity of the immobilized peptides, test tubes were shaken horizontally in order to enhance the probability of cell-resin contact. This procedure provided reproducible values. After $17 \mathrm{~h}$ the MICs of immobilized peptides (mM) were determined on the basis of the determined resin-related MIC values $(\mathrm{mg} / \mathrm{mL})$ taking into consideration the amount of immobilized peptide $(\mu \mathrm{mol})$ per mg resin. To determine the $\mathrm{MBC}$, an aliquot $(200 \mu \mathrm{L})$ from the wells with peptide concentrations $\geq$ MIC was spread on an LB-agar plate. After incubation at $37^{\circ} \mathrm{C}$ for $24 \mathrm{~h}$, the number of colonies was counted. The MBC was defined as the lowest peptide concentration at which no colonies were detected (Fig. 40B). The experiments were performed in triplicates.

\subsubsection{Hemolytic activity}

The hemolytic activity of the peptides was determined using human RBCs (CharitéUniversitätsmedizin, Germany). Prior to the assay, the erythrocytes were washed several times in buffer $(10 \mathrm{mM}$ TRIS, $150 \mathrm{mM} \mathrm{NaCl}, \mathrm{pH} 7.4) .100 \mu \mathrm{L}$ cell suspension $\left(2.5 \times 10^{9}\right.$ cells $\left./ \mathrm{mL}\right)$, varying amounts of the peptide stock solution (concentration usually $10^{-3}$ and $10^{-4} \mathrm{M}$ in TRIS buffer) and buffer were pipetted into Eppendorf tubes to give a final volume of $1 \mathrm{~mL}$. For determination of the resin, appropriate amounts of non-modified TentaGel $\mathrm{S} \mathrm{NH}_{2}$ were added to $100 \mu \mathrm{L}$ cell suspensions and $900 \mu \mathrm{L}$ buffer. Afterwards, the suspensions containing $2.5 \times 10^{8}$ cells $/ \mathrm{mL}$ were incubated for $30 \mathrm{~min}$, with gentle shaking, in an Eppendorf thermomixer. After cooling in ice water and centrifugation at $2000 \times g$ and $4{ }^{\circ} \mathrm{C}$ for $5 \mathrm{~min}, 200 \mu \mathrm{L}$ of the supernatant was mixed with $2300 \mu \mathrm{L}$ of $0.5 \% \mathrm{NH}_{4} \mathrm{OH}$, and the $\mathrm{OD}_{540}$ was determined at $540 \mathrm{~nm}$. Zero hemolysis (blank) and 100\% hemolysis (control) were determined with cell suspensions incubated in buffer or $0.5 \% \mathrm{NH}_{4} \mathrm{OH}$, respectively. 


\subsubsection{Inner and outer membrane permeabilizing activities of MEL, BUF and TP and their AOA-modified analogs}

Most CAPs act via permeabilization of the bacterial cell membrane. In order to assess the permeabilizing activity of the peptides in vitro, Lehrer et al. developed a protocol, which allows the study of the Gram-negative bacterial inner and outer membrane permeabilizing activity of CAPs [175].

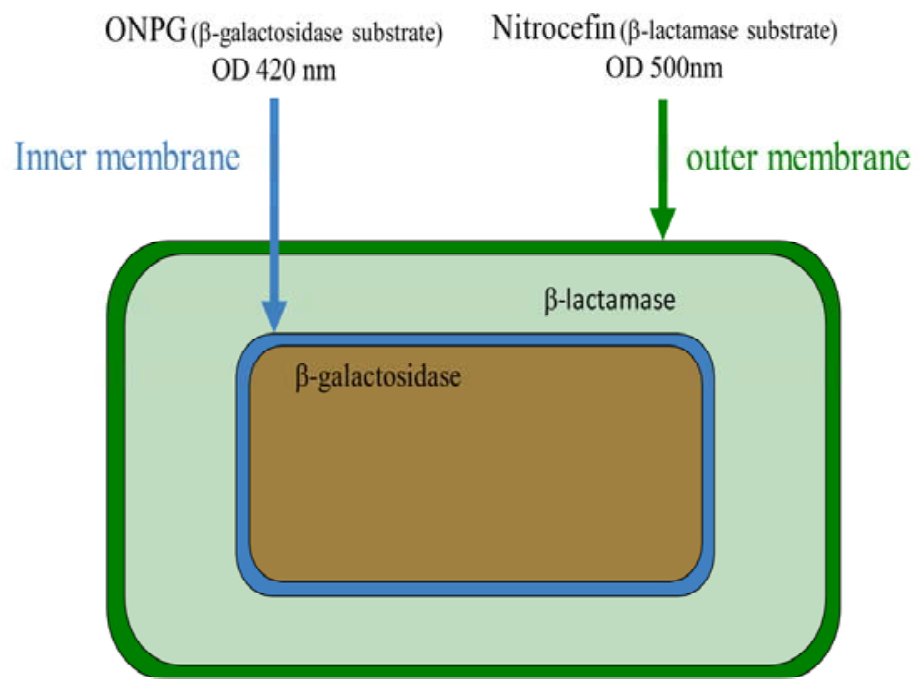

Fig. 41. Schematic representation of the assay used for determination of the $E$. coli inner and outer membrane permeabilizing activity of CAPs.

To perform this assay, the E. coli (strain ML-35p) was used. The cells are characterized by a lack of lactose permease. The strain expresses periplasmic $\beta$-lactamase and cytoplasmic $\beta$-galactosidase. Due to the lack of lactose permease, NCF ( $\beta$-lactamase substrate) and ONPG ( $\beta$-Galactosidase substrate) are blocked from being transported across the outer and inner membrane of the bacterial cell respectively. However, as the result of peptide-induced outer membrane permeabilization, $\beta$-lactamase can cleave $\mathrm{NCF}$, which is detected by a color change from yellow to red. The inner membrane permeabilization allows ONPG to reach the cytoplasm, where $\beta$-galactosidase metabolizes its substrate, which can be followed by a color change from colorless to yellow (Fig. 41).

The inner and outer membrane permeabilizating activities of MEL, BUF and TP and the AOA-modified peptides against E. coli (strain ML-35p) were determined in 96-well 
microtiter plates. The bacterial culture was grown in LB medium containing $100 \mu \mathrm{g} / \mathrm{mL}$ ampicillin until an $\mathrm{OD}_{600}$ of 0.3 was reached; cells were then rinsed twice and resuspended in HEPES buffer to an $\mathrm{OD}_{600}$ of 0.3. The microtiter wells were filled up with $50 \mu \mathrm{L}$ of the dissolved peptides at individual concentrations close to the bacteria MIC. To assay inner membrane permeabilization, $50 \mu \mathrm{L}$ of ONPG stock solution $(300 \mu \mathrm{g} / \mathrm{mL})$ was added to the microtiter wells and for monitoring the outer membrane permeabilization, $50 \mu \mathrm{L}$ of NCF stock solution $(60 \mu \mathrm{g} / \mathrm{mL})$ was pipetted into the wells. Finally, $50 \mu \mathrm{L}$ cell suspension $\left(\mathrm{OD}_{600}\right.$ of 0.3$)$ was added to the wells and the absorbance was measured. The wells without peptides served as controls. The inner and outer membrane permeabilizations were monitored spectrophotometrically over a time period up to $\sim 1 \mathrm{~h}$ at $\lambda$ of $420 \mathrm{~nm}$ and $500 \mathrm{~nm}$, respectively.

\subsubsection{Vesicle preparation}

\subsubsection{SUVs}

The final concentrations of lipids for ITC experiments were $40 \mathrm{mM}$ for POPC, $20 \mathrm{mM}$ for POPC mixed with POPG or LA and $5 \mathrm{mM}$ for POPC mixed with r-LPS and s-LPS.

\section{Synthetic lipids}

To make SUVs of different lipid mixtures, the dried lipid films, as prepared above, were hydrated in pyrogen-free phosphate buffer $\left(10 \mathrm{mM} \mathrm{NaH} \mathrm{PO}_{4} / \mathrm{Na}_{2} \mathrm{HPO}_{4}, 154 \mathrm{mM} \mathrm{NaF}\right.$, $\mathrm{pH}$ 7.4). The lipid concentration was calculated gravimetrically on the basis of amount of the dried lipids used for the preparation of vesicles. The suspensions were vortexed for $5 \mathrm{~min}$ and ultrasonicated in an ice/water bath using an ultrasonicator (Labsonic L, B. Braun Biotech, Germany; and Sonopuls HD 2070, Bandelin electronic, Germany) with clamp for $20 \mathrm{~min}$. The size of the vesciles was determined by DLS on an N4 Plus particle sizer (Beckman Coulter, U.S.A.) equipped with a $10-\mathrm{mW}$ helium/neon laser with $\lambda=632.8 \mathrm{~nm}$ at a scattering angle of $90^{\circ}$. The mean diameter for SUVs was $\sim 30 \mathrm{~nm}$.

\section{Natural lipids}

For the preparation of the POPC/LA (12/1 [mol/mol]) lipid film, dried LA (molecular mass $=1792 \mathrm{Da}$. $)$ was firstly dissolved in a volume of chloroform/methanol $(2 / 1[\mathrm{v} / \mathrm{v}])$ to give a concentration of $2.5 \mathrm{mg} / \mathrm{ml}$. A certain volume of the dissolved LA was added to a $10 \mathrm{~mL}$ 
round-bottomed glass tube prefilled with a specific amount of dried POPC lipid film to reach the exact molar ratio of POPC/LA. Afterwards, the solvent was removed by rotary evaporation, followed by the use of a high vacuum overnight in order to dry the uniform lipid film.

To make the POPC/LPS (12/1 [mol/mol]) lipid film, we employed a protocol called "dry method" [176]. According to this protocol, a certain amount of dry LPS was weighed and added into a $10 \mathrm{~mL}$ round-bottomed glass tube, prefilled with specific amount of dried POPC lipid film, such that the molar ratio of POPC/LPS reaches 12/1. Based on the structure of LPS shown in Fig. 16, we assumed that Rd-LPS and s-LPS have molecular masses of approximately 2.5 and $10 \mathrm{kDa}$., respectively. Because LPS is a heterogenous molecule and has the tendency to aggregate in varying sizes, the exact value for the molecular mass of LPS cannot be determined [177]. The assumed molecular masses for Rd-LPS and s-LPS used in these studies fit well with the masses reported for Rd-LPS from Salmonella Minnesota and sLPS from E. coli (strain O8:K127) [177]. However; considering the overall heterogeneity, it has been reported that the molecular mass for s-LPS from E. coli K-235 varies between 10-80 kDa. [178]. The dried POPC/LPS lipid was then suspended in pyrogen-free water (Milli-Q, Element System, Millipore, France) and extensively vortexed. It was then heated up to $60{ }^{\circ} \mathrm{C}$ followed by sonication in a bath sonicator for $10 \mathrm{~min}$. The suspension was vortexed again and the cycle repeated twice. This turbid mixture was next lyophilized and made ready for further application. This protocol leads to the maximum amount of LPS incorporated into POPC phospholipid membrane [179]. To prevent any contamination of the POPC/LPS vesicles, no further attempt was done to separate non-incorporated LPS.

\subsubsection{LUVs}

Appropriate amounts of POPC alone, and its mixture with POPG at molar ratios of 3:1 and 1:3, were prepared. The lipids films were perepared, as described above, for the synthetic lipids. The lipid films were dried overnight under high vacuum and then suspended by vortex mixing in calcein buffer solution at a self-quenching concentration ( $80 \mathrm{mM}$ calcein, 10 mM TRIS, $0.1 \mathrm{mM}$ EDTA, pH 7.4). Liposome size was reduced by extrusion (Avestin Inc., Canada) 35 times through two stacked $100 \mathrm{~nm}$ pore size polycarbonate filters. Untrapped calcein was removed from the LUVs by gel filtration on a Sephadex G50medium column (eluent: buffer containing $10 \mathrm{mM}$ TRIS, $154 \mathrm{mM} \mathrm{NaCl}, 0.1 \mathrm{mM}$ EDTA, 
pH 7.4). A plastic syringe ( $5 \mathrm{~mL}$ volume, plugged with a filter pad) mounted in a centrifugation tube was filled with hydrated Sephadex G-50 gel. After spinning at $2000 \times g$ for $5 \mathrm{~min}$, the gel column had dried and could be parted from the sides of the syringe. $500 \mu \mathrm{L}$ of the vesicle suspension was dropped onto the gel bed and the liposomes were eluted by centrifugation at $2000 \times g$ for $5 \mathrm{~min}$. The collected liposomes were diluted 1:1 with buffer containing salt and finally the lipid concentration was determined by phosphorus analysis $[44,118]$.

\subsubsection{Lipid bilayer permeabizing activities}

In the dye release assay, aliquots of the LUV suspensions, loaded with calcein at selfquenching concentration were injected into cuvettes containing the dissolved peptides or stirred suspensions of TentaGel $\mathrm{S} \mathrm{NH}_{2}$-bound CAPs at different concentrations in buffer (10 mM TRIS, $154 \mathrm{mM} \mathrm{NaCl}, 0.1 \mathrm{mM}$ EDTA, $\mathrm{pH}$ 7.4). The lipid concentration was $25 \mu \mathrm{M}$ in a total volume of $2 \mathrm{~mL}$. The peptide-induced calcein release was monitored fluorimetrically by measuring the time dependent decrease in self-quenching ( $\lambda_{\text {excitation }}=490 \mathrm{~nm}$, $\lambda_{\text {emission }}=514 \mathrm{~nm}$ ) at room temperature using a LS 50B spectrofluorimeter (Perkin-Elmer, Germany) (Fig. 42). The fluorescence intensity corresponding to $100 \%$ release was determined by addition of $100 \mu \mathrm{L}$ of a $10 \%$ Triton X-100 solution. $\mathrm{EC}_{50} \mathrm{~s}$ (or $\mathrm{EC}_{25} \mathrm{~s}$ ) were derived from dose response curves giving the fluorescence intensity after $1 \mathrm{~min}$.
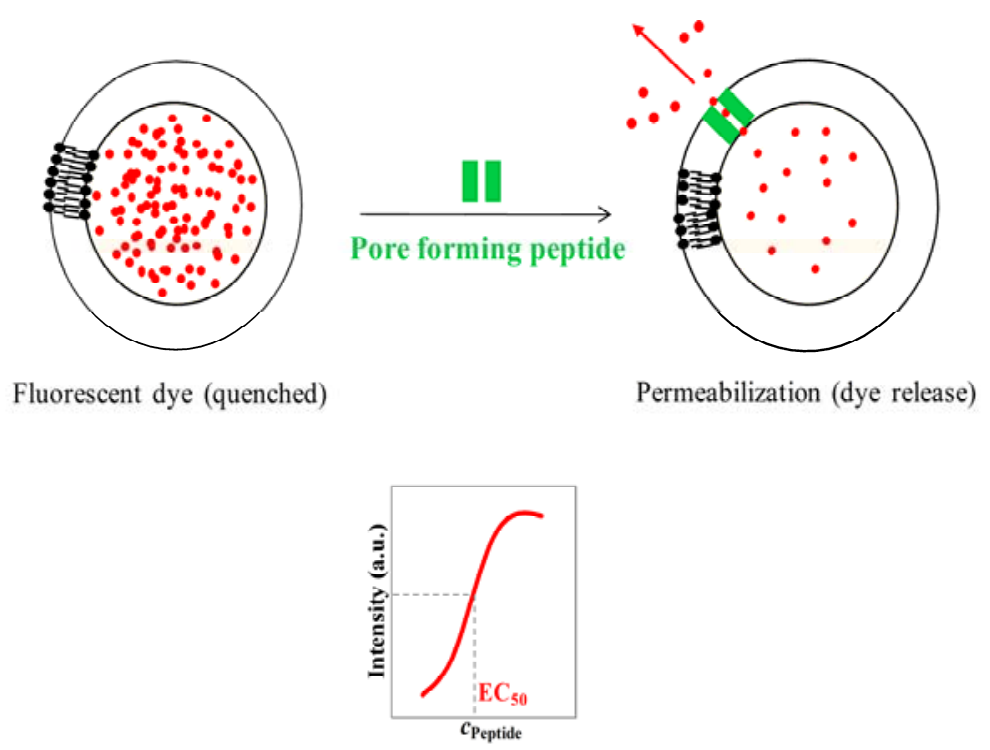

Dose response curve

Fig. 42. Schematic representation of CAPs-induced relase of liposome-loaded dye (calcein) measured by fluorescence. 


\subsubsection{Isothermal titration calorimetry}

ITC is a useful technique to study chemical reactions quantitatively and describe them thermodynamically. Each reaction is connected with an enthalpy change $\left(\Delta H^{\circ}\right)$, which means that heat is either released into (exothermic) or taken in from (endothermic) the surroundings. This universal property is independent of molecule size and so that all chemical and biochemical reactions can be studied [180]. This includes the formation of complexes between proteins, DNA, lipids or low molecular weight biomolecules, which are mostly based on non-covalent bonds. A particular example is the interaction between peptides $(\mathrm{P})$ and lipid (L) bilayers mimicking bacterial membranes [181]. The complex formation (L.P) can be described by the simple equilibrium shown below:

$\mathrm{L}+\mathrm{P} \rightleftharpoons \mathrm{L} . \mathrm{P}$

This equilibrium is defined by a binding constant $(K)$ as given by:

$$
K=\frac{[\mathrm{L} \cdot \mathrm{P}]}{[\mathrm{L}][\mathrm{P}]}
$$

In Fig. 43, the operation of an isothermal titration calorimeter is schematically shown. It consists of a reference and a sample cell. The temperature difference between two cells can be very precisely measured. The ITC syringe is filled with a solution of the interaction partner L (liposomes) and a solution of binding partner P (peptide) is present in the sample cell. The reference cell is filled with buffer. It serves as the reference for the temperature change, which takes place in the sample cell. Both cells have a higher temperature than the carefully thermostated environment (hold isothermal) and are supplied with controlled and measurable heating to keep the temperature constant. Each injection from the syringe leads to the formation of the L.P complex and this process is accompanied by heat absorption/release from/to the sample cell. The calorimeter responds to the endothermic or exothermic reaction with a corresponding increase or decrease of the electrical heating power to keep the temperature in the sample cell constant. These responses appear as differential heating power, as shown e.g. for heat release in the upper part of Fig. 43B. By integrating the area under each signal, the free-set quantity of heat versus the increasing ratio of $\mathrm{L}$ and $\mathrm{P}$ is obtained (lower part of Fig. 43B). By adjusting the theoretical curve to these data, $K$ is obtained. 

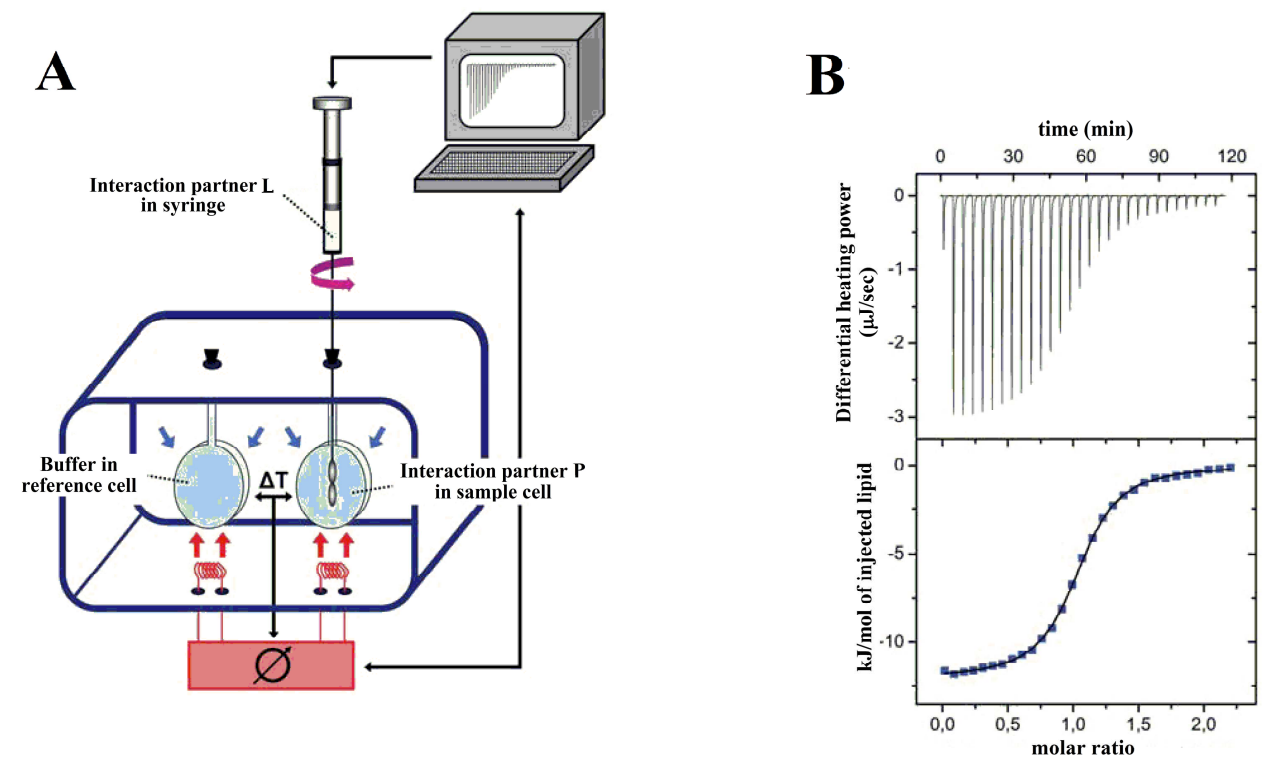

Fig. 43.(A) Scheme of an isothermal titration calorimeter, and (B) a typical ITC experiment. The red and blue arrows (shown left) represent the exactly equilibrated heat flow from the electric heater (red) to the reference and the sample cell and from there to the cooler surroundings (blue). The smallest changes in temperature $(\Delta T)$ between the two cells are detected and compensated by changing the heating power. In the right panel, the change in heating power for each injection into the sample cell is presented as a trace of negative peaks, which become smaller by increasing the number of injection because less substance is available for binding.

ITC can provide the comprehensive thermodynamic characterization of binding of antimicrobial peptides to different lipid vesicles [181]. The thermodynamic parameters in terms of $\Delta H^{\circ}, \Delta S^{\circ}$, and $\Delta G^{\circ}$ are useful to understand the mechanism of action of CAPs and their selectivity towards different lipid membranes.

\subsubsection{Theory and description of surface partitioning equilibrium model}

The interaction between a peptide and a lipid membrane surface can be described by a two-step model. The interaction is initiated by electrostatic contributions resulting in surface accumulation. This is followed by hydrophobic interactions causing peptide insertion [181]. In order to describe the peptide-lipid binding, a surface partitioning equilibrium model was used to fit all ITC experimental data and draw the thermodynamic parameters [182,183].

Based on this model, a non-ideal mixing was assumed in both the aqueous solution and the bilayer phase in order to describe the peptide partitioning into the lipid surface adequately (see ref. 182, and 183). Peptide binding from the bulk aqueous solution to the lipid bilayer, so-called $K_{\text {app. }}$, includes both hydrophobic and electrostatic contributions for peptidelipid interaction and is defined as: 


$$
K_{\text {app. }}=\frac{R_{\mathrm{b}}}{c_{\mathrm{P}, \mathrm{f}}}
$$

where $R_{\mathrm{b}}$ is:

$$
R_{\mathrm{b}}=\frac{c_{\mathrm{P}, \mathrm{b}}}{\gamma c_{\mathrm{L}}}
$$

$\gamma$ was taken as 0.6 for membrane-impermeant peptides interacting with SUVs [181]. $R_{\mathrm{b}}$ was assumed to be given by:

$$
R_{\mathrm{b}}=K_{0} c_{\mathrm{P}, \mathrm{i}}=K_{0} c_{\mathrm{P}, \mathrm{f}} \exp \left(\frac{-z_{\mathrm{e}} e \Delta \varphi}{k T}\right)
$$

where $e, k$, and $T$ are the elementary charge $\left(1.602 \times 10^{-9} \mathrm{C}\right)$, the Boltzmann constant, and the absolute temperature, respectively. According to the Gouy-Chapman theory, $\Delta \varphi$ is related to the membrane surface charge density, as described by Seelig and Keller et al (Eq.4) [181-183].

$$
\sigma^{2}=2000 \varepsilon_{0} \varepsilon_{\mathrm{r}} R T \sum_{i} c_{\mathrm{i}}\left[\exp \left(-z_{\mathrm{i}} F_{0} \Delta \varphi / R T\right)-1\right]
$$

where $z_{\mathrm{i}}$ is the valence of $\mathrm{ith}$ species, and $c_{\mathrm{i}}$ is the concentration of the $\mathrm{i}^{\text {th }}$ dissociated electrolyte in the solution. $\sigma$ is obtained according to the theoretical calculation described by Seelig [184], which is corrected for the effect of counterion binding due to the association of $\mathrm{Na}^{+}$with the POPG headgroups as given by:

$$
\sigma=\frac{z_{\mathrm{P}} e R_{\mathrm{b}}}{\left(A_{\mathrm{L}}+R_{\mathrm{b}} A_{\mathrm{P}}\right)\left(1+K_{\mathrm{Na}} c_{\mathrm{Na}} \exp \left(F_{0} \Delta \varphi / R T\right)\right)}
$$

where $A_{\mathrm{L}}$ is $68 \mathrm{~nm}^{2}$ and $A_{\mathrm{P}}$ is assumed zero when the peptide adsorbs superficially. $K_{\mathrm{Na}+}$ is the binding constant of the sodium to the negatively charged lipid headgroup $\left(0.6 \mathrm{M}^{-1}\right)$ with a concentration of $c_{\mathrm{Na}+}$.

In an ITC experiment, the normalized heat produced or consumed on peptide-lipid interactions $(Q)$ is given by (see ref. 182 for details):

$$
Q=V_{\text {cell }}\left(c_{\mathrm{P}, \mathrm{b}}-\left(1-\frac{\Delta V_{\text {cell }}}{V_{\text {cell }}}\right) c_{\mathrm{P}, \mathrm{b}}-\frac{\Delta V_{\text {cell }}}{V_{\text {cell }}} c_{\mathrm{P}, \mathrm{s}}\right) \frac{\Delta H^{\mathrm{o}}}{\Delta n_{\mathrm{L}}}+Q_{\text {dil. }}
$$


where $\Delta H^{\circ}$ stands for the molar transfer enthalpy of the peptide from the aqueous into the bilayer phase, and $Q_{\text {dil }}$, for the heat of dilution normalized with respect to the molar amount of lipid injected, $\Delta n_{\mathrm{L}} \cdot \dot{c}_{\mathrm{P}, \mathrm{b}}$ and $c_{\mathrm{P}, \mathrm{b}}$ are considered as the equilibrium concentrations of bound peptide before and after an injection of volume $\Delta V_{\text {cell }}$, respectively, and $c_{\mathrm{P}, \mathrm{s}}$ that in the syringe.

On the basis of this model, we fitted the ITC data to obtain $K_{0}, \Delta H^{\circ}$, and $z_{\mathrm{e}}$ for each peptide. The $\Delta G^{\circ}$ was then taken as:

$\Delta G^{\circ}=-R T \ln \left(55.5 \mathrm{M} K_{0}\right)$

where $55.5 \mathrm{M}$ is the molar concentration of water in the aqueous phase [185]. Finally, the entropic contribution to membrane partitioning, $-T \Delta S^{\circ}$, was calculated from the GibbsHelmholtz equation as

$$
-T \Delta S^{\circ}=\Delta G^{\circ}-\Delta H^{\circ}
$$

\subsubsection{Instrument setup and measurement}

High-sensitivity ITC was performed on a VP-ITC (GE Healthcare, Sweden). All experiments were run at $37^{\circ} \mathrm{C}$ to study peptide binding to POPC doped with LA and LPSs above the gel-to-liquid-crystalline phase transition temperature. At lower temperatures, the binding process is endothermic [186]. To determine peptide-lipid interactions, a $40 \mu \mathrm{M}$ peptide solution in the calorimeter cell was titrated with an SUV suspension ranging from 5 to $40 \mathrm{mM}$. All peptide solutions were degassed before ITC experiments. In a typical experiment, 3-10 $\mu \mathrm{L}$ aliquots of the SUV suspension were titrated into the peptide solution during each injection and the content of the sample cell was stirred continuously at $310 \mathrm{rpm}$. Because of a small loss of titrant during the mounting of the syringe and the equilibration stage preceding the actual titration, the first injection volume was usually set to $3-5 \mu \mathrm{L}$. The first injection peak was excluded during data analysis. Time spacings of 5 min were long enough to allow the ITC signal to return to the baseline value. The measured heat of binding decreased with consecutive lipid injections because less free peptide was available. Control experiments, injecting lipid vesicles into buffer without peptide, showed that the heats of dilution were small and constant. 


\subsubsection{ITC data analysis and curve fitting}

The raw ITC data were collected based on the program supplied by the manufacturer. Baseline correction, peak integration and its adjustment for data acquisition and analysis were conducted as described by the manufacturer. Nonlinear least-squares data fitting was performed in an Excel (Microsoft, U.S.A.) spreadsheet using the Solver add-in (Frontline Systems, U.S.A.) [187].

\subsubsection{CD spectroscopy}

CD spectroscopy is a technique by which conformational properties of peptides can be quickly measured in solution. $\mathrm{CD}$ occurs due to the difference in absorption of left or right circularly polarized light in the UV-VIS wavelength range (100-1000 nm) by optically active chromophores. In addition to inherent chiral absorbing systems, achiral chromophores also show a CD when they are disturbed by the dissymmetric field of an optically active group. In the absence of aromatic amino acid residues, only the peptide backbone contributes significantly in the far UV region. Thus, the CD spectra of peptides are determined by transition dipole moments of the amide groups, which are influenced by the chiral $\mathrm{C}^{\alpha}$-atoms. Absorption occurs mainly in the range between 180-240 nm: $\pi-\pi^{*}$ transitions $(\lambda<200 \mathrm{~nm})$ and $n-\pi^{*}$ transitions $(\lambda=\sim 218 \mathrm{~nm})$ with less intensity. The superposition of contributions from aromatic residues in the 220 to $240 \mathrm{~nm}$ region influences the spectral characteristics. The induction of a secondary structure confers a structural asymmetry upon peptide sequences, which is reflected by characteristic CD patterns. There are three main classes of secondary structures: the $\alpha$-helix, the $\beta$-sheet, and the random coil. The $\alpha$-helix produces the most distinctive CD spectrum: a very strong positive band near $192 \mathrm{~nm}$, which corresponds to $\pi-\pi_{\perp}^{*}$ transitions and two negative maxima of approximately equal intensity near $222 \mathrm{~nm}$ $\left(\mathrm{n}-\pi^{*}\right)$ and $208 \mathrm{~nm}\left(\pi-\pi^{*}\right)$. The $\beta$-sheet exhibits a single negative band near $217 \mathrm{~nm}$, representing $n-\pi^{*}$. The random coil exhibits a strong negative band at $197 \mathrm{~nm}\left(\pi-\pi^{*} \|\right)$ and a small positive band in the $220 \mathrm{~nm}\left(\mathrm{n}-\pi^{*}\right)$ region. In the spectra of complex proteins, the contributions of the individual structures superimpose. The spectra provide less information about the conformation of certain parts of the molecule, but rather provide an integrated picture of a peptide's structure. The value of the method is in the sensitivity of the CD signal with respect to structural changes induced by variations in the peptide concentration, $\mathrm{pH}$, change in temperature, solvent polarity or ionic additives [188]. However, based upon the 
helicity of an ideal helix, or the correlation of CD spectra of proteins and their known crystal structure, also the content of helix or amount of other structures of peptides and proteins of interest can be calculated. However, these methods are only slightly suitable for small peptides because small sequences form poor helices and the data evaluation is based on the analysis of proteins with secondary and tertiary structures [189]. In general, the CD spectrum of a peptide represents the $\Theta_{\mathrm{mr}}$ versus $\lambda$.

\subsubsection{1 c-WFW and $W$-subtituted analogs}

Stock solutions of cyclic peptides $(2.5 \mathrm{mM})$ were prepared by dissolving the samples in buffer $(10 \mathrm{mM}$ phosphate buffer, $154 \mathrm{mM} \mathrm{NaF}, \mathrm{pH} 7.4)$. CD measurements were performed in far-UV $(190-260 \mathrm{~nm})$ and near-UV $(240-340 \mathrm{~nm})$ regions. The measurements were conducted in phosphate buffer, buffer/TFE $(1 / 1[\mathrm{v} / \mathrm{v}])$, buffer/GnHCl $(1 / 1[\mathrm{v} / \mathrm{v}])$, SDSand POPG-bound peptides at the desired tempretaure. Thus, an aliquot of the peptide stock solution was diluted with: (i) the phosphate buffer, (ii) TFE, (iii) $8 \mathrm{M} \mathrm{GnHCl,} \mathrm{(iv)}$ $50 \mathrm{mM}$ suspension of SDS and (v) $20 \mathrm{mM}$ suspension of POPG SUVs in the same buffer to achieve the desired peptide $(100 \mu \mathrm{M}), \mathrm{GnHCl}(4 \mathrm{M}), \operatorname{SDS}(25 \mathrm{mM})$, and POPG $(10 \mathrm{mM})$ concentrations. Measurements were carried out on a Jasco J-720 spectropolarimeter (Jasco, Japan) at either $20^{\circ} \mathrm{C}$ or $80{ }^{\circ} \mathrm{C}$. To increase the signal/noise ratio, 35 scans were accumulated. Peptide spectra were corrected by subtracting spectra of the corresponding buffer or peptidefree lipid suspensions. The presented spectra give $\Theta_{\mathrm{mr}}$.

\subsubsection{Model KLAL peptide, MK5E, and the PEGylated analogs}

$200 \mu \mathrm{M}$ stock peptide solutions were prepared by dissolving the samples in buffer (10 mM phosphate buffer, $154 \mathrm{mM} \mathrm{NaF}, \mathrm{pH} 7.4)$. The solutions were mixed 1/1 (v/v) with TFE to get the desired peptide concentration $(50 \mu \mathrm{M})$ and solvent composition. CD measurements were carried out on a J-720 spectropolarimeter over a $\lambda=185-260 \mathrm{~nm}$ at room temperature. Twenty $\mathrm{CD}$ scans were accumulated for each sample. The helicity was determined from $\Theta_{m r}$ at $222 \mathrm{~nm}$ according to the relation $\left[\Theta_{m r}\right]_{222}=-30300[\alpha]-2340$ with $[\alpha]$ being the amount of helix [190]. 


\section{References}

[1] Zasloff, M. 2002. Antimicrobial peptides of multicellular organisms. Nature. 415:389-395.

[2] Hancock, R. E. W., and H. G. Sahl. 2006. Antimicrobial and host-defense peptides as new anti-infective therapeutic strategies. Nat. Biotechnol. 24:1551-1557.

[3] Dathe, M. 2000. Antibacterial and Hemolytic Activity of Amphipathic Helical Peptides, pp. 1-26. In G. Zimmer (Ed.), Membrane Structure in Disease and Drug Therapy. Marcel Dekker, Inc., New York.

[4] Brogden, K. A. 2005. Antimicrobial peptides: pore formers or metabolic inhibitors in bacteria? Nat. Rev. Microbiol. 3:238-250.

[5] Boman, H. G., B. Agerberth, and A. Boman. 1993. Mechanisms of action on Escherichia coli of cecropin P1 and PR-39, two antibacterial peptides from pig intestine. Infect. Immun. 61:2978-2984.

[6] Helmerhorst, E. J., I. M. Reijnders, W. van 't Hof, E. C. Veerman, and A. V. N. Amerongen. 1999. A critical comparison of the hemolytic and fungicidal activities of cationic antimicrobial peptides. FEBS Lett. 449:105-110.

[7] Leite, J. R., G. D. Brand, L. P. Silva, S. A. Kückelhaus, W. R. Bento, A. L. Araújo, G. R. Martins, A. M. Lazzari, and C. Bloch Jr. 2008. Dermaseptins from Phyllomedusa oreades and Phyllomedusa distincta: Secondary structure, antimicrobial activity, and mammalian cell toxicity. Comp. Biochem. Physiol. A Mol. Integr. Physiol . 151:336-343.

[8] Raghuraman, H., and A. Chattopadhyay. 2007. Melittin: a membrane-active peptide with diverse functions. Biosci. Rep. 27:189-223.

[9] Epand, R. M., and H. J. Vogel. 1999. Diversity of antimicrobial peptides and their mechanisms of action. Biochim. Biophys. Acta. 1462:11-28.

[10] Sitaram, N., and R. Nagaraj. 1999. Interaction of antimicrobial peptides with biological and model membranes: structural and charge requirements for activity. Biochim. Biophys. Acta. 1462:29-54.

[11] Jenssen, H., P. Hamill, and R. E. W. Hancock. 2006. Peptide antimicrobial agents. Clin. Microbiol. Rev. 19:491-511.

[12] Hancock, R. E. W. 1997. Peptide antibiotics. Lancet. 349:418-422. 
[13] Gennaro, R., B. Skerlavaj, and D. Romeo. 1989. Purification, composition, and activity of two bactenecins, antibacterial peptides of bovine neutrophils. Infect. Immun. 57:3142-3146.

[14] Agerberth, B., J. Y. Lee, T. Bergman, M. Carlquist, H. G. Boman, V. Mutt, and H. Jornvall. 1991. Amino acid sequence of PR-39. Isolation from pig intestine of a new member of the family of proline-arginine-rich antibacterial peptides. Eur. J. Biochem. 202:849-854.

[15] Oppenheim, F. G., $\quad$ T. Xu, $\quad$ F. M. McMillian, $\quad$ S. M. Levitz, $\quad$ R. D. Diamond, G. D. Offner, and R. F. Troxler. 1988. Histatins, a novel family of histidine-rich proteins in human parotid secretion. Isolation, characterization, primary structure, and fungistatic effects on Candida albicans. J. Biol. Chem. 263:7472-7477.

[16] Dathe, M., and T. Wieprecht. 1999. Structural features of helical antimicrobial peptides: their potential to modulate activity on model membranes and biological cells. Biochim. Biophys. Acta. 1462:71-87.

[17] Dathe, M., M. Schümann, T. Wieprecht, A. Winkler, M. Beyermann, E. Krause, K. Matsuzaki, O. Murase, and M. Bienert. 1996. Peptide helicity and membrane surface charge modulate the balance of electrostatic and hydrophobic interactions with lipid bilayers and biological membranes. Biochemistry. 35:12612-12622.

[18] Dathe, M., T. Wieprecht, H. Nikolenko, L. Handel, W. L. Maloy, D. L. MacDonald, M. Beyermann, and M. Bienert. 1997. Hydrophobicity, hydrophobic moment and angle subtended by charged residues modulate antibacterial and haemolytic activity of amphipathic helical peptides. FEBS Lett. 403:208-212.

[19] Wieprecht, T., M. Dathe, M. Beyermann, E. Krause, W. L. Maloy, D. L. MacDonald, and M. Bienert. 1997. Peptide hydrophobicity controls the activity and selectivity of magainin 2 amide in interaction with membranes. Biochemistry. 36:6124-6132.

[20] Wieprecht, T., M. Dathe, R. M. Epand, M. Beyermann, E. Krause, W. L. Maloy, D. L. MacDonald, and M. Bienert. 1997. Influence of the angle subtended by the positively charged helix face on the membrane activity of amphipathic, antibacterial peptides. Biochemistry. 36:12869-12880.

[21] Calderón, C. B., B. P. Sabundayo. 2007. Antimicrobial classifications: drugs for bugs. pp.7-52. In R. Schwalbe, L. Steele-Moore, and A. C. Goodwin (Eds.), 
Antimicrobial susceptibility testing protocols. CRC Press. Taylor \& Frances group, Florida.

[22] Lonher, K. 2001. The role of membrane lipid composition in cell targeting of antimicrobial peptides. pp. 149-165. In K. Lonher (Ed.), Development of novel antimicrobial agents: emerging strategies. Horizon Scientific Press, Norfolk.

[23] Epand, R. M., and R. F. Epand. 2009. Domains in bacterial membranes and the action of antimicrobial agents. Mol. Biosyst. 5:580-587.

[24] Iwamoto, K., T. Hayakawa, M. Murate, A. Makino, K. Ito, T. Fujisawa, and T. Kobayashi. 2007. Curvature-dependent recognition of ethanolamine phospholipids by duramycin and cinnamycin. Biophys. J. 93:1608-1619.

[25] Verkleij, A. J., R. F. Zwaal, B. Roelofsen, P. Comfurius, D. Kastelijn, and L. L. van Deenen. 1973. The asymmetric distribution of phospholipids in the human red cell membrane. A combined study using phospholipases and freeze-etch electron microscopy. Biochim. Biophys. Acta. 323:178-193.

[26] Allende, D. and T. J. McIntosh. 2003. Lipopolysaccharides in bacterial membranes act like cholesterol in eukaryotic plasma membranes in providing protection against melittin-induced bilayer lysis. Biochemistry. 42:1101-1108.

[27] Downey, J. S., J. Han. 1998. Cellular activation mechanisms in septic shock. Front. Biosci. 3:d468-d76.

[28] Raetz, C. R. H. 1990. Biochemistry of endotoxins. Annu. Rev. Biochem. 59:129-170.

[29] Cardoso, P. G., G. C. Macedo, V. Azevedo, and S. C. Oliveira. 2006. Brucella spp noncanonical LPS: structure, biosynthesis, and interaction with host immune system. Microb. Cell Fact. 5:13.

[30] Rietschel, E. T., L. Brade, B. Lindner, and U. Zahringer. 1992. Molecular biochemistry of lipopolysaccharides. pp. 3-42. In D. C. Morrison, and J. L. Ryan (Eds.), Bacterial endotoxic lipopolysaccharides. CRC Press, Florida.

[31] Coughlin, R. T., S. Tonsager, and E. J. McGroarty. 1983. Quantitation of metal cations bound to membranes and extracted lipopolysaccharide of Escherichia coli. Biochemistry. 22:2002-2007.

[32] Andrä, J., M. H. J. Koch, R. Bartels, and K. Brandenburg. 2004. Biophysical characterization of endotoxin inactivation by NK-2, an antimicrobial peptide derived from mammalian NK-lysin. Antimicrob. Agents Chemother. 48:1593-1599. 
[33] Oren, Z., and Y. Shai. 1998. Mode of action of linear amphipathic $\alpha$-helical antimicrobial peptides. Biopolymers. 47:451-463.

[34] Jelinek, R., and S. Kolusheva. 2005. Membrane interactions of host-defense peptides studied in model systems. Curr. Protein Pept. Sci. 6:103-114.

[35] Vogel, H. 1987. Comparison of the conformation and orientation of alamethicin and melittin in lipid membranes. Biochemistry. 26:4562-4572.

[36] Breed, J., P. C. Biggin, I. D. Kerr, O. S. Smart, M. S. Sansom. 1997. Alamethicin channels: modeling via restrained molecular dynamics simulations. Biochim. Biophys. Acta. 1325:235-249.

[37] He, K., S. J. Ludtke, H. W. Huang, and D. L. Worcester. 1995. Antimicrobial peptide pores in membranes detected by neutron in-plane scattering. Biochemistry. 34:1561415618.

[38] Spaar, A., C. Münster, and T. Salditt. 2004. Conformation of peptides in lipid membranes studied by X-ray grazing incidence scattering. Biophys. J. 87:396-407.

[39] Ludtke, S. J., K. He, Y. Wu, H. W. Huang. 1994. Cooperative membrane insertion of magainin correlated with its cytolytic activity. Biochim. Biophys. Acta. 1190:181-184.

[40] Hallock, K. J., D.-K. Lee, and A. Ramamoorthy. 2003. MSI-78, an analog of the magainin antimicrobial peptides, disrupts lipid bilayer structure via positive curvature strain. Biophys. J. 84:3052-3060.

[41] Matsuzaki, K., O. Murase, N. Fujii, and K. Miyajima. 1996. An antimicrobial peptide, magainin 2, induced rapid flip-flop of phospholipids coupled with pore formation and peptide translocation. Biochemistry. 35:11361-11368.

[42] Matsuzaki, K. 1998. Magainins as paradigm for the mode of action of pore forming polypeptides. Biochim. Biophys. Acta. 1376:391-400.

[43] Ludtke, S. J., K. He, W. T. Heller, T. A. Harroun, L. Yang, H. W. Huang. 1996. Membrane pores induced by magainin. Biochemistry. 35:13723-13728.

[44] Dathe, M., J. Meyer, M. Beyermann, B. Maul, C. Hoischen, and M. Bienert. 2002. General aspects of peptide selectivity towards lipid bilayers and cell membranes studied by variation of the structural parameters of amphipathic helical model peptides. Biochim. Biophys. Acta. 1558:171-186.

[45] Gennaro, R., M. Zanetti, M. Benincasa, E. Podda, and M. Miani M. 2002. Pro-rich antimicrobial peptides from animals: structure, biological functions and mechanism of action. Curr. Pharm. Des. 8:763-778. 
[46] Park, C. B., K.-S. Yi, K. Matsuzaki, M. S. Kim, and S. C. Kim. 2000. Structureactivity analysis of buforin II, a histone $\mathrm{H} 2 \mathrm{~A}$-derived antimicrobial peptide: The proline hinge is responsible for the cell-penetrating ability of buforin II. Proc. Natl. Acad. Sci. U.S.A. 97:8245-8250.

[47] Kavanagh, K., and S. Dowd. 2004. Histatins: antimicrobial peptides with therapeutic potential. J. Pharm. Pharmacol. 56:285-289.

[48] Falla, T. J., D. N. Karunaratne, and R. E. W. Hancock. 1996. Mode of action of the antimicrobial peptide indolicidin. J. Biol. Chem. 271:19298-19303.

[49] Arouri, A., M. Dathe, and A. Blume. 2009. Peptide induced demixing in PG/PE lipid mixtures: a mechanism for the specificity of antimicrobial peptides towards bacterial membranes? Biochim. Biophys. Acta. 1788:650-659.

[50] Wang, G., X. Li, Z. Wang. 2009. APD2: The updated antimicrobial peptide database and its application in peptide design. Nucleic Acids Res. 37:D933-D937.

[51] Otvos, L., Jr. 2002. The short proline-rich antibacterial peptide family. Cell. Mol. Life Sci. 59:1138-1150.

[52] Strøm, M. B., B. E. Haug, M. L. Skar, W. Stensen, T. Stiberg, and J. S. Svendsen. 2003. The pharmacophore of short cationic antibacterial peptides. J. Med. Chem. 46:1567-1570.

[53] Dathe, M., H. Nikolenko, J. Klose, and M. Bienert. 2004. Cyclization increases the antimicrobial activity and selectivity of arginine- and tryptophan-containing hexapeptides. Biochemistry. 43:9140-9150.

[54] Hilpert, K., R. Volkmer-Engert, T. Walter, and R. E. W. Hancock. 2005. Highthroughput generation of small antibacterial peptides with improved activity. Nat. Biotechnol. 23:1008-1012.

[55] Svenson, J., B.-O Brandsdal, W. Stensen, and J. S. Svendsen. 2007. Albumin binding of short cationic antimicrobial micropeptides and its influence on the in vitro bactericidal effect. J. Med. Chem. 50:3334-3339.

[56] van 't Hof, W., E. C. Veerman, E. J. Helmerhorst, and A. V. Amerongen. 2001. Antimicrobial peptides: properties and applicability. Biol. Chem. 382:597-619.

[57] Jelokhani-Niaraki, M., $\quad$ E. J. Prenner, $\quad$ C. M. Kay, R. N. McElhaney, and R. S. Hodges. 2002. Conformation and interaction of the cyclic cationic antimicrobial peptides in lipid bilayers. J. Pept. Res. 60:23-36. 
[58] Schibli, D. J., R. F. Epand, H. J. Vogel, and R. M. Epand. 2002. Tryptophan-rich antimicrobial peptides: comparative properties and membrane interactions. Biochem. Cell Biol. 80:667-677.

[59] Staubitz, P., A. Peschel, W. F. Nieuwenhuizen, M. Otto, F. Götz, G. Jung, and R. W. Jack. 2001. Structure-function relationships in the tryptophan-rich, antimicrobial peptide indolicidin. J. Pept. Sci. 7:552-564.

[60] Nagpal, S., V. Gupta, K. J. Kaur, and D. M. Salunke. 1999. Structure-function analysis of tritrypticin, an antibacterial peptide of innate immune origin. J. Biol. Chem. 274:23296-23304.

[61] Wei, S. Y., J. M. Wu, Y. Y. Kuo, H. L. Chen, B. S. Yip, S. R. Tzeng, and J.W. Cheng. 2006. Solution structure of a novel tryptophan-rich peptide with bidirectional antimicrobial activity. J. Bacteriol. 188:328-334.

[62] Blondelle, S. E., and R. A. Houghten. 1996. Novel antimicrobial compounds identified using synthetic combinatorial library technology. Trends Biotechnol. 14:6065.

[63] Yau, W.-M., W. C. Wimley, K. Gawrisch, and S. H. White. 1998. The preference of tryptophan for membrane interfaces. Biochemistry. 37:14713-14718.

[64] Chan, D. I., E. J. Prenner, and H. J. Vogel. 2006. Tryptophan- and arginine-rich antimicrobial peptides: structures and mechanisms of action. Biochim. Biophys. Acta. 1758:1184-1202.

[65] Muhle, S. A., and J. P. Tam. 2001. Design of Gram-negative selective antimicrobial peptides. Biochemistry. 40:5777-5785.

[66] Elass-Rochard, E., A. Roseanu, D. Legrand, M. Trif, V. Salmon, C. Motas, J. Montreuil, and G. Spik. 1995. lactoferrin-lipopolysaccharide interaction: involvement of the 28-34 loop region of human lactoferrin in the high-affinity binding to Escherichia coli 055B5 lipopolysaccharide. Biochem. J. 312:839-845.

[67] Jing, W., H. N. Hunter, J. Hagel, and H. J. Vogel. 2003. The structure of the antimicrobial peptide Ac-RRWWRF-NH $\mathrm{NH}_{2}$ bound to micelles and its interactions with phospholipid bilayers. J. Pept. Res. 61:219-229.

[68] Wessolowski, A., M. Bienert, and M. Dathe. 2004. Antimicrobial activity of arginineand tryptophan-rich hexapeptides: the effects of aromatic clusters, D-amino acid substitution and cyclization. J. Pept. Res. 64:159-169. 
[69] Pritz, S., M. Pätzel, G. Szeimies, M. Dathe, and M. Bienert. 2007. Synthesis of a chiral amino acid with bicyclo[1.1.1]pentane moiety and its incorporation into linear and cyclic antimicrobial peptides. Org. Biomol. Chem. 5:1789-1794.

[70] Junkes, C., A. Wessolowski, S. Farnaud, R. W. Evans, L. Good, M. Bienert, and M. Dathe. 2008. The interaction of arginine- and tryptophan-rich cyclic hexapeptides with Escherichia coli membranes. J. Pept. Sci. 14:535-543.

[71] Appelt, C., A. Wessolowski, J. A. Soderhall, M. Dathe, and P. Schmieder. 2005. Structure of the antimicrobial, cationic hexapeptide cyclo(RRWWRF) and its analogs in solution and bound to detergent micelles. ChemBioChem 6:1654-1662.

[72] Appelt, C., F. Eisenmenger, R. Kühne, P. Schmieder, and J. A. Söderhäll. 2005. Interaction of the antimicrobial peptide cyclo(RRWWRF) with membranes by molecular dynamics simulations. Biophys. J. 89:2296-2306.

[73] Appelt, C., A. Wessolowski, M. Dathe, and P. Schmieder. 2008. Structures of cyclic, antimicrobial peptides in a membrane-mimicking environment define requirements for activity. J. Pept. Sci. 14:524-527.

[74] Appelt, C., A. K. Schrey, J. A. Söderhäll, and P. Schmieder. 2007. Design of antimicrobial compounds based on peptide structures. Bioorg. Med. Chem. Lett. 17:2334-2337.

[75] Costerton, J. W., P. S. Stewart, and E. P. Greenberg. 1999. Bacterial biofilms: a common cause of persistent infections. Science. 284:1318-1322.

[76] Samaranayake, L. P., and A. N. B. Ellepola. 2000. Studying Candida albicans adhesion, pp. 527-540. In Y. H. An, and R. J. Friedman (Eds.), Handbook of bacterial adhesion: Principles, methods and applications, Humana Press Inc., New Jersey.

[77] Lawrence, J. R., D. R. Korber, B. D. Hoyle, J. W. Costerton, and D. E. Caldwell. 1991. Optical sectioning of microbial biofilms. J. Bacteriol. 173:6558-6567.

[78] An, Y. H., and R. J. Friedman. 1996. Prevention of sepsis in total joint arthroplasty. J. Hosp. Infect. 33:93-108.

[79] Nickel, J. C., I. Ruseska, J. B. Wright, and J. W. Costerton. 1985. Tobramycin resistance of Pseudomonas aeruginosa cells growing as a biofilm on urinary catheter material. Antimicrob. Agents Chemother. 27:619-624.

[80] Davies, D. Understanding biofilm resistance to antibacterial agents. 2003. Nat. Rev. Drug Discov. 2:114-122. 
[81] Harris, L. G., S. Tosatti, M. Wieland, M. Textor, and R. G. Richards. 2004. Staphylococcusaureus adhesion to titanium oxide surfaces coated with nonfunctionalized and peptide-functionalized poly(L-lysine)-graftedpoly(ethylene glycol) copolymers. Biomaterials. 25:4135-4148.

[82] Jansen, B., and W. Kohnen. 1995. Prevention of biofilm formation by polymer modification. J. Ind. Microbiol. Biotechnol. 15:391-396.

[83] Kwok, C. S., C. Wan, S. Hendricks, J. D. Bryers, T. A. Horbett, and B. D. Ratner. 1999. Design of infection-resistant antibiotic-releasing polymers: I. Fabrication and formulation. J. Control. Release. 62:289-299.

[84] Schierholz, J. M., H. Steinhauser, A. F. E. Rump, R. Berkels, and G. Pulverer. 1997. Controlled release of antibiotics from biomedical polyurethanes: morphological and structural features. Biomaterials. 18:839-844.

[85] Fuchs, A. D., and J. C. Tiller. 2006. Contact-active antimicrobial coatings derived from aqueous suspensions. Angew. Chem. Int. Ed. Engl. 45:6759-6762.

[86] Mowery, B. P., S. E. Lee, D. A. Kissounko, R. F. Epand, R. M. Epand, B. Weisblum, S. S. Stahl, and S. H. Gellman. 2007. Mimicry of antimicrobial host-defense peptides by random copolymers. J. Am. Chem. Soc. 129:15474-15476.

[87] Tashiro, T. 2001. Antibacterial and bacterium adsorbing macromolecules. Macromol. Mater. Eng. 286:63-87.

[88] Endo, Y., T. Tani, M. Kodama. 1987. Antimicrobial activity of tertiary amine covalently bonded to a polystyrene fiber. Appl. Environ. Microbiol. 53:2050-2055.

[89] Flemming, R. G., C. C. Capelli, S. L. Cooper, and R. A. Proctor. 2000. Bacterial colonization of functionalized polyurethanes. Biomaterials. 21:273-281.

[90] Gelman, M. A., B. Weisblum, D. M. Lynn, and S. H. Gellman. 2004. Biocidal activity of polystyrenes that are cationic by virtue of protonation. Org. Lett. 6:557560.

[91] Gottenbos, B., H. C. van der Mei, F. Klatter, P. Nieuwenhuis, and H. J. Busscher. 2002. In vitro and in vivo antimicrobial activity of covalently coupled quaternary ammonium silane coatings on silicone rubber. Biomaterials. 23:1417-1423.

[92] Kenawy, E.-R., F. I. Abdel-Hay, A. A. El-Magd, Y. Mahmoud. 2006. Biologically active polymers: VII. Synthesis and antimicrobial activity of some crosslinked 
copolymers with quaternary ammonium and phosphonium groups. React. Funct. Polym. 66:419-429.

[93] Lee, S. B., ～R. R. Koepsel， S. W. Morley， K. Matyjaszewski， Y. Sun， and A. J. Russell. 2004. Permanent, nonleaching antibacterial surfaces. 1. synthesis by atom transfer radical polymerization. Biomacromolecules. 5:877-882.

[94] Ilker, M. F., K. Nüsslein, G. N. Tew, and E. B. Coughlin. 2004. Tuning the hemolytic and antibacterial activities of amphiphilic polynorbornene derivatives. J. Am. Chem. Soc. 126:15870-15875.

[95] Kuroda, K., and W. F. DeGrado. 2005. Amphiphilic polymethacrylate derivatives as antimicrobial agents. J. Am. Chem. Soc. 127:4128-4129.

[96] Isquith, A. J., E. A. Abbott, and P. A. Walters. 1972. Surface bounded antimicrobial activity of an organosilicon quaternary ammonium chloride. Appl. Microbiol. 2:859-863.

[97] Tiller, J. C., C. J. Liao, K. Lewis, and A. M. Klibanov. 2001. Designing surfaces that kill bacteria on contact. Proc. Natl. Acad. Sci. U.S.A. 98:5981-5985.

[98] Nagamune, H., T. Maeda, K. Ohkura, K. Yamamoto, M. Nakajima, and H. Kourai. 2000. Evaluation of the cytotoxic effects of bis-quaternary ammonium antimicrobial reagents on human cells. Toxicol. In Vitro. 14:139-147.

[99] Aumsuwan, N., S. Heinhorst, and M. W. Urban. 2007. The effectiveness of antibiotic activity of penicillin attached to expanded poly(tetrafluoroethylene) (ePTFE) surfaces: a quantitative assessment. Biomacromolecules. 8:3525-3530.

[100] Aumsuwan, N., R. C. Danyus, S. Heinhorst, and M. W. Urban. 2008. Attachment of ampicillin to expanded poly(tetrafluoroethylene): surface reactions leading to inhibition of microbial growth. Biomacromolecules. 9:1712-1718.

[101] Haynie, S. L., G. A. Crum, and B. A. Doele. 1995. Antimicrobial activities of amphiphilic peptides covalently bonded to a water-insoluble resin. Antimicrob. Agents Chemother. 39:301-307.

[102] Glinel, K., A. M. Jonas, T. Jouenne, J. Leprince, L. Galas, and W. T. S. Huck. 2009. Antibacterial and antifouling polymer brushes incorporating antimicrobial peptide. Bioconjug. Chem. 20:71-77. 
[103] Humblot, V., J. F. Yala, P. Thebault, K. Boukerma, A. Héquet, J.-M. Berjeaud, and C.-M. Pradier. 2009. The antibacterial activity of Magainin I immobilized onto mixed thiols self-assembled monolayers. Biomaterials. 30:3503-3512.

[104] Loose, C., W. S. O'Shaughnessy, L. Ferreira, A. Zumbuehl, R. Langer, and G. Stephanopoulos. Nov. 2007. Medical devices and coatings with non-leaching antimicrobial peptides. U.S. Patent Application 20070254006.

[105] Joshi, P. R., J. McGuire, and J. A. Neff. 2009. Synthesis and antibacterial activity of nisin-containing block copolymers. J. Biomed. Mater. Res. B Appl. Biomater. 91B:128-134.

[106] Hilpert, K., M. Elliott, H. Jenssen, J. Kindrachuk, C. D. Fjell, J. Körner, D. F. H. Winkler, L. L. Weaver, P. Henklein, A. S. Ulrich, S. H. Y. Chiang, S. W. Farmer, N. Pante, R. Volkmer, and R. E. W. Hancock. 2009. Screening and characterization of surface-tethered cationic peptides for antimicrobial activity. Chem. Biol. 16:58-69.

[107] Steven, M. D., and J. H. Hotchkiss. 2007. Covalent immobilization of an antimicrobial peptide on poly(ethylene) film. J. Appl. Polym. Sci. 110:2665-2670.

[108] Cho, W.-M., B. P. Joshi, H. Cho, and K.-H Lee. 2007. Design and synthesis of novel antibacterial peptide-resin conjugates. Bioorg. Med. Chem. Lett. 17:5772-5776.

[109] Eby, D. M., K. E. Farrington, and G. R. Johnson. 2008. Synthesis of bioinorganic antimicrobial peptide nanoparticles with potential therapeutic properties. Biomacromolecules. 9:2487-2494.

[110] Wach, J.-Y., S. Bonazzi, and K. Gademann. 2008. Antimicrobial Surfaces through Natural Product Hybrids. Angew. Chem. Int. Ed. Engl. 47:7123-7126.

[111] Gabriel, M., K. Nazmi, E. C. Veerman, A. V. N. Amerongen, and A. Zentner. 2006. Preparation of LL-37-grafted titanium surfaces with bactericidal activity. Bioconj. Chem. 17:548-550.

[112] Statz, A. R., J. P. Park, N. P. Chongsiriwatana, A. E. Barron, and P. B. Messersmith. 2008. Surface-immobilized antimicrobial peptoids. Biofouling. 24:439-448.

[113] Becker, M. L., J. Liu, and K. L. Wooley. 2005. Functionalized micellar assemblies prepared via block copolymers synthesized by living free radical polymerizationupon peptide-loaded resins. Biomacromolecules. 6:220-228. 
[114] Overhage, J., A. Campisano, M. Bains, E. C. W. Torfs, B. H. A. Rehm, and R. E. W. Hancock. 2008. The human host defence peptide LL-37 prevents bacterial biofilm formation. Infect. Immun. 76:4176-4182.

[115] Beckloff, N., D. Laube, T. Castro, D. Furgang, S. Park, D. Perlin, D. Clements, H. Tang, R. W. Scott, G. N. Tew, and G. Diamond. 2007. Activity of an antimicrobial peptide mimetic against planktonic and biofilm cultures of oral pathogens. Antimicrob. Agents Chemother. 51:4125-4132.

[116] Appendini, P., and J. H. Hotchkiss. 2001. Surface modification of poly(styrene) by the attachment of an antimicrobial peptide. J. Appl. Polym. Sci. 81:609-616.

[117] Kadurugamuwa, J. L., A. J. Clarke, and T. J. Beveridge. 1993. Surface action of gentamicin on Pseudomonas aeruginosa. J. Bacteriol. 175:5798-5805.

[118] Dathe, M., H. Nikolenko, J. Meyer, M. Beyermann, and M. Bienert. 2001. Optimization of the antimicrobial activity of magainin peptides by modification of charge. FEBS Lett. 501:146-150.

[119] Yang, S.-T., S. Y. Shin, K. S. Hahm, and J. I. Kim. 2006. Different modes in antibiotic action of tritrpticin analogs, cathelicidin-derived Trp-rich and Pro/Arg-rich peptides. Biochim. Biophys. Acta. 1758:1580-1586.

[120] Salay, L. C., J. Procopio, E. Oliveira, C. R. Nakaie, and S. Schreier. 2004. Ion channel like activity of the antimicrobial peptide tritrpticin in planar lipid bilayers. FEBS Lett. 565:171-175.

[121] Deber, C. M., L.-P. Liu, C. Wang, N. K. Goto, and R. A. F. Reithmeier. 2002. The hydrophobicity threshold for peptide insertion into membranes, pp. 465-479. In Current topics in membranes, lipid-peptide interactions. S. A. Simon and T. J. McIntosh (Eds.) Academic press, Elsevier science imprint, California.

[122] McClellan, A. L. 1963. Tables of experimental dipole moments, pp. 280-325. W. H. Freeman and Company, San Francisco.

[123] Strøm, M. B., B. E. Haug, Ø. Rekdal, M. L. Skar, W. Stensen, and J. S. Svendsen. 2002. Important structural features of 15-residue lactoferricin derivatives and methods for improvement of antimicrobial activity. Biochem. Cell Biol. 80:65-74.

[124] Schweizer, S., and J. Reed. 2008. Effect of variation of the strength of the aromatic interactions of tryptophan on the cooperative structural refolding behavior of a peptide from HIV 1. Biophys. J. 95:3381-3390. 
[125] Lehrman, S. R., J. L. Tuls, and M. Lund. 1990. Peptide alpha-helicity in aqueous trifluoroethanol: correlations with predicted alpha-helicity and the secondary structure of the corresponding regions of bovine growth hormone. Biochemistry. 29:5590-5596.

[126] Rozek, A., C. L. Friedrich, and R. E. W. Hancock. 2000. Structure of the bovine antimicrobial peptide indolicidin bound to dodecylphosphocholine and sodium dodecyl sulfate micelles, Biochemistry. 39:15765-15774.

[127] Lohner, K., and F. Prossnigg. 2009. Biological activity and structural aspects of PGLa interaction with membrane mimetic systems. Biochim. Biophys. Acta. 1788:1656-1666.

[128] Jelokhani-Niaraki, M., L. H. Kondejewski, L. C. Wheaton, and R. S. Hodges. 2009. Effect of ring size on conformation and biological activity of cyclic cationic antimicrobial peptides. J. Med. Chem. 52:2090-2097.

[129] Laughrey, Z. R., S. E. Kiehna, A. J. Riemen, and M. L. Waters. 2008. Carbohydrate- $\pi$ interactions: what are they worth? J. Am. Chem. Soc. 130:14625-14633.

[130] Farnaud, S., C. Spiller, L. C. Moriarty, A. Patel, V. Gant, E. W. Odell, and R. W. Evans. 2004. Interactions of lactoferricin-derived peptides with LPS and antimicrobial activity. FEMS Microbiol. Lett. 233:193-199.

[131] Seelig, J., and P. Ganz. 1991. Nonclassical hydrophobic effect in membrane binding equilibria. Biochemistry. 30:9354-9359.

[132] Shaoying, W., M. Majerowicz, A. Waring, and F. Bringezu. 2007. Dicynthaurin (ala) monomer interaction with phospholipid bilayers studied by fluorescence leakage and isothermal titration calorimetry. J. Phys. Chem. B. 111:6280-6287.

[133] Andrushchenko, V. V., M. H. Aarabi, L. T. Nguyen, E. J. Prenner, and H. J. Vogel. 2008. Thermodynamics of the interactions of tryptophan-rich cathelicidin antimicrobial peptides with model and natural membranes. Biochim. Biophys. Acta. 1778:1004-1014.

[134] Wieprecht, T., O. Apostolov, M. Beyermann, and J. Seelig. 2000. Membrane binding and pore formation of the antibacterial peptide PGLa: thermodynamic and mechanistic aspects. Biochemistry. 39:442-452. 
[135] Greathouse, D., V. Vostrikov, N. Mcclellan, J. Chipollini, J. Lay, R. Liyanage, and T. Ladd. 2008. Lipid interactions of acylated tryptophan-methylated lactoferricin peptides by solid-state NMR. J. Pept. Sci. 14:1103-1110.

[136] Khandelia, H., and Y. N. Kaznessis. 2007. Cation- $\pi$ interactions stabilize the structure of the antimicrobial peptide indolicidin near membranes: molecular dynamics simulations. J. Phys. Chem. B. 111:242-250.

[137] Jing, W., A. R. Demcoe, and H. J. Vogel. 2003. Conformation of a bactericidal domain of puroindoline a: structure and mechanism of action of a 13-residue antimicrobial peptide. J. Bacteriol. 185:4938-4947.

[138] Privalov, P. L., and S. J. Gill. 1988. Stability of protein structure and hydrophobic interaction. Adv. Protein Chem. 39:191-234.

[139] Wieprecht, T., M. Beyermann, and J. Seelig. 1999. Binding of antibacterial magainin peptides to electrically neutral membranes: thermodynamics and structure. Biochemistry. 38:10377-10387.

[140] Aliste, M. P., J. L. MacCallum, and D. P. Tieleman. 2003. Molecular dynamics simulations of pentapeptides at interfaces: salt bridge and cation- $\pi$ interactions. Biochemistry. 42:8976-8987.

[141] Petersen, F. N., M. Ø. Jensen, and C. H. Nielsen. 2005. Interfacial tryptophan residues: a role for the cation- $\pi$ effect? Biophys. J. 89:3985-3996.

[142] Holmberg, K., K. Bergstrom, and M. B. Stark. 1992. Immobilization of proteins via PEG chains, pp. 303-324. In J. M. Harris (Ed.), Poly(ethylene glycol) chemistry: biotechnical and biomedical applications. Plenum Press, New York.

[143] Veronese, F. M., and G. Pasut. 2005. PEGylation, successful approach to drug delivery. Drug Discov. Today. 10:1451-1458.

[144] Guiotto, A., M. Pozzobon, M. Canevari, R. Manganelli, M. Scarin, and F. M. Veronese. 2003. PEGylation of the antimicrobial peptide nisin A: problems and perspectives. Il Farmaco. 58:45-50.

[145] Rapp, W. E. 1997. Macro beads as microreactors: new solid-phase synthesis methodology, pp. 65-93. In S. R. Wilson, and A. W. Czarnik (Eds.), Combinatorial chemistry: synthesis and application. Wiley \& Sons, Inc., New York. 
[146] Quarrell, R., T. D. W. Claridge, G. W. Weaver, and G. Lowe. 1995. Structure and properties of TentaGel resin beads: Implications for combinatorial library chemistry. Molecular Diversity. 1:223-232.

[147] Liang, R., J. Loebach, N. Horan, M. Ge, C. Thompson, L. Yan, and D. Kahne. 1997. Polyvalent binding to carbohydrates immobilized on an insoluble resin. Proc. Natl. Acad. Sci. U.S.A. 94:10554-10559.

[148] Tu, J., Z. Yu, and Y.-H. Chu. 1998. Combinatorial search for diagnostic agents: Lyme antibody H9724 as an example. Clin. Chem. 44:232-238.

[149] Beyermann, M., and M. Bienert. 1992. Synthesis of difficult peptide sequences: a comparison of Fmoc- and Boc-technique. Tetrahedron Lett. 33:3745-3748.

[150] Takahashi, M., K. Nokihara, and H. Mihara. 2003. Construction of a proteindetection system using a loop peptide library with a fluorescence label. Chem. Biol. 10:53-60.

[151] Kochendoerfer, G. G. 2005. Site-specific polymer modification of therapeutic proteins. Curr. Opin. Chem. Biol. 9:555-560.

[152] Vágner, J., G. Barany, K. S. Lam, V. Krchanky, N. F. Sepetov, J. A. Ostrem, P. Strops, and M. Lebl. 1996. Enzyme-mediated spatial segregation on individual polymeric support beads: Application to generation and screening of encoded combinatorial libraries. Proc. Natl. Acad. Sci. U.S.A. 93:8194-8199.

[153] Bayer, E., and W. Rapp. 1992. Polystyrene-immobilized PEG Chains: Dynamics and application in peptide synthesis, immunology, and chromatography, pp. 325-345. In J. M. Harris (Ed.), Poly(ethylene glycol) chemistry: biotechnical and biomedical applications. Plenum Press, New York.

[154] Chakrabartty, A., A. J. Doig, and R. L. Baldwin. 1993. Helix capping propensities in peptides parallel those in proteins. Proc. Natl. Acad. Sci. U.S.A. 90:11332-11336.

[155] Imura, Y., M. Nishida, and K. Matsuzaki. 2007. Action mechanism of PEGylated magainin 2 analog peptide. Biochim. Biophys. Acta. 1768:2578-2585.

[156] Imura, Y., M. Nishida, Y. Ogawa, Y. Takakura, and K. Matsuzaki. 2007. Action mechanism of tachyplesin I and effects of PEGylation. Biochim. Biophys. Acta. 1768:1160-1169. 
[157] Matias, V. R. F., A. Al-Amoudi, J. Dubochet, and T. J. Beveridge. 2003. CryoTransmission Electron Microscopy of Frozen-Hydrated Sections of Escherichia coli and Pseudomonas aeruginosa. J. Bacteriol. 185:6112-6118.

[158] Matias, V. R. F., and T. Beveridge. 2005. Cryo-electron microscopy reveals native polymeric cell wall structure in Bacillus subtilis 168 and the existence of a periplasmic space. Mol. Microbiol. 56:240-251.

[159] Meroueh, S. O., K. Z. Bencze, D. Hesek, M. Lee, J. F. Fisher, T. L. Stemmler, and S. Mobashery. 2006. Three-dimensional structure of the bacterial cell wall peptidoglycan. Proc. Natl. Acad. Sci. U.S.A. 103:4404-4409.

[160] Poortinga, A. T., R. Bos, W. Norde, and H. J. Busscher. 2002. Electric double layer interactions in bacterial adhesion to surfaces. Surface Sci. Rep. 47:1-32.

[161] Hu, F. X., K. G. Neoh, L. Cen, and E. T. Kang. 2005. Antibacterial and antifungal efficacy of surface functionalized polymeric beads in repeated applications. Biotech. Bioeng. 89:474-484.

[162] Lin, J., J. C. Tiller, S. B. Lee, K. Lewis, and A. M. Klibanov. 2002. Insights into bactericidal action of surface-attached poly(vinyl- $N$-hexylpyridinium) chains. Biotechnol. Lett. 24:801-805.

[163] Lin, J., S. Qiu, K. Lewis, and A. M. Klibanov. 2003. Mechanism of bactericidal and fungicidal activities of textiles covalently modified with alkylated polyethylenimine. Biotechnol. Bioeng. 83:168-172.

[164] Milović, N. M., J. Wang, K. Lewis, and A. M. Klibanov. 2005. Immobilized Nalkylated polyethylenimine avidly kills bacteria by rupturing cell membranes with no resistance developed. Biotechnol. Bioeng. 90:715-722.

[165] Murata, H., R. R. Koepsel, K. Matyjaszewski, and A. J. Russell. 2007. Permanent, non-leaching antibacterial surfaces-2: How high density cationic surfaces kill bacterial cells. Biomaterials. 28:4870-4879.

[166] Yang, L., T. A. Harroun, T. M. Weiss, L. Ding, and H. W. Huang. 2001. Barrelstave model or toroidal model? A case study on melittin pores. Biophys. J. 81:1475-1485.

[167] Kobayashi, S., A. Chikushi, S. Tougu, Y. Imura, M. Nishida, Y. Yano, and K. Matsuzaki. 2004. Membrane translocation mechanism of the antimicrobial peptide buforin 2. Biochemistry. 43:15610-15616. 
[168] Lawyer, C., S. Pai, M. Watabe, P. Borgia, T. Mashimo, L. Eagleton, and K. Watabe. 1996. Antimicrobial activity of a 13 amino acid tryptophan-rich peptide derived from a putative porcine precursor protein of a novel family of antibacterial peptides. FEBS Lett. 390:95-98.

[169] Kobayashi, S., K. Takeshima, C. B. Park, S. C. Kim, and K. Matsuzaki. 2000. Interactions of the novel antimicrobial peptide buforin 2 with lipid bilayers: proline as a translocation promoting factor. Biochemistry. 39:8648-8654.

[170] Kuhn-Nentwiga, L., M. Dathe, A. Walz, J. Schaller, and W. Nentwig. 2002. Cupiennin $1 \mathrm{~d}^{*}$ : the cytolytic activity depends on the hydrophobic $\mathrm{N}$-terminus and is modulated by the polar C-terminus. FEBS Lett. 527:193-198.

[171] Pukala, T. L., M. P. Boland, J. D. Gehman, L. Kuhn-Nentwig, F. Separovic, and J. H. Bowie. 2007. Solution structure and interaction of cupiennin 1a, a spider venom peptide, with phospholipid bilayers. Biochemistry. 46:3576-3585.

[172] Breukink, E., and B. de Kruijff. 2006. Lipid II as a target for antibiotics. Nat. Rev. Drug Discov. 5:321-332.

[173] Wiedemann, I., E. Breukink, C. van Kraaij, O. P. Kuipers, G. Bierbaum, B. de Kruijff, and H. G. Sahl. 2001. Specific binding of nisin to the peptidoglycan precursor lipid II combines pore formation and inhibition of cell wall biosynthesis for potent antibiotic activity. J. Biol. Chem. 276:1772-1779.

[174] Decostaire, I. P., D. Lelièvre, H. Zhang, and A. F. Delmas. 2006. Controlling the outcome of overacylation of N-protected aminooxyacetic acid during the synthesis of an aminooxy-peptide for chemical ligation. Tetrahedron Lett. 47:7057-7060.

[175] Lehrer, R. I., A. Barton, and T. Ganz. 1988. Concurrent assessment of inner and outer membrane permeabilization and bacteriolysis in E. coli by multiple-wavelength spectrophotometry. J. Immunol. Methods. 108:153-158.

[176] Dijkstra, J., J. L. Ryan, and F. C. Szoka. 1988. A procedure for the efficient incorporation of wild-type lipopolysaccharide into liposomes for use in immunological studies. J. Immunol. Methods. 114:197-205.

[177] Brandenburg, K., M. D. Arraiza, G. Lehwark-Ivetot, I. Moriyon, and U. Zähringer. 2002. The interaction of rough and smooth form lipopolysaccharides with polymyxins as studied by titration calorimetry. Thermochim. Acta. 394:53-61. 
[178] McIntire, F. C., H. W. Sievert, G. H. Barlow, R. A. Finley, and A. Y. Lee. 1967. Chemical, physical, and biological properties of a lipopolysaccharide from Escherichia coli K-235. Biochemistry. 6:2363-2372.

[179] Bennett-Guerrero, E., T. J. McIntosh, G. R. Barclay, D. S. Snyder, R. J. Gibbs, M. G. Mythen, and I. R. Poxton. 2000. Preparation and preclinical evaluation of a novel liposomal complete-core lipopolysaccharide Vaccine. Infect. Immun. 68:62026208 .

[180] Holdgate, G. A., and W. H. Ward. 2005. Measurements of binding thermodynamics in drug discovery. Drug Discov. Today. 10:1543-1550.

[181] Seelig, J. 1997. Titration calorimetry of lipid-peptide interactions. Biochim. Biophys. Acta. 1331:103-116.

[182] Keller, S., H. Heerklotz, and A. Blume. 2006. Monitoring lipid membrane translocatlon of sodium dodecyl sulfate by isothermal titration calorimetry. J. Am. Chem. Soc. 128:1279-1286.

[183] Keller, S., M. Böthe, M. Bienert, M. Dathe, and A. Blume. 2007. A simple fluorescence-spectroscopic membrane translocation assay. ChemBioChem 8:546-552.

[184] Beschiaschvili, G., and J. Seelig. 1990. Peptide binding to lipid bilayers. Binding isotherms and .zeta.-potential of a cyclic somatostatin analog. Biochemistry. 29:10995-11000.

[185] Cantor, C. R., and P. R. Schimmel. 1980. Biophysical chemistry. Part I. The conformation of biological macromolecules. Chapter 5. W. H. Freeman and Company, San Francisco.

[186] Brandenburg, K., A. David, J. Howe, M. H. Koch, J. Andrä, and P. Garidel. 2005. Temperature dependence of the binding of endotoxins to the polycationic peptides polymyxin B and its nonapeptide. Biophys. J. 88:1845-1858.

[187] Kemmer, G., S. Keller. 2010. Nonlinear least-squares data fitting in Excel spreadsheets. Nat. Protoc. 5:267-281.

[188] Fasman, G. D. 1996. Circular Dichroism and the Conformational Analysis of Biomolecules. Plenum Press, New York.

[189] Juban, M. M., M. M. Javadpour, and M. D. Barkley. 1997. Circular dichroism studies of secondary structure of peptides. Methods Mol. Biol. 78:73-78. 
[190] Chen, Y.-H., J. T. Yang, and H. M. Martinez. 1972. Determination of the secondary structures of proteins by circular dichroism and optical rotatory dispersion. Biochemistry. 11:4120-4131. 


\section{Appendix}

\subsection{Curriculum vitae}

For reasons of data protection, the curriculum vita is not included in the online version.

\subsection{Publications and scientific conference contributions}

\subsubsection{Original publications}

Articles in journals

- Bagheri, M., M. Beyermann, and M. Dathe. 2010. Membrane-active peptides: tethering on solid surfaces to get information on the mode of action. Eur. Biophys. J. In Press.

- Bagheri, M., S. Keller, and M. Dathe. 2010. Interaction of W-substituted analogs of cyclo-RRRWFW with bacterial lipopolysaccharides: The role of the aromatic cluster in antimicrobial activity. Antimicrob. Agents Chemother. In press.

- Junkes, C., R. Harvey, K. D. Bruce, R. Dölling, M. Bagheri, and M. Dathe. 2010. Cyclic antimicrobial R-, W-rich peptides: structure and membrane composition determine the mechanism of action. Eur. Biophys. J. In Press.

- Bagheri, M. 2010. Synthesis and thermodynamic characterization of small cyclic antimicrobial arginine and tryptophan-rich peptides with selectivity for Gram-negative bacteria, Vol. 618. p. 87-109. In A. Giuliani and A. C. Rinaldi (eds.), Antimicrobial peptides: methods and protocols, methods in molecular biology. Humana press, New York.

- Bagheri, M., M. Beyermann, and M. Dathe. 2009. Immobilization reduces the activity of surface-bound cationic antimicrobial peptides with no influence upon the activity spectrum. Antimicrob. Agents Chemother. 53:1132-1141.

- Bagheri, M., N. Azizi, and M. R. Saidi. 2005. An intriguing effect of lithium perchlorate dispersed on silica gel in the bromination of aromatic compounds by $\mathrm{N}$ bromosuccinimide. Can. J. Chem. 83:146-149.

- Matloubi-Moghaddam, F., H. Zali-Boeini, M. Bagheri, P. Rüedi, A. Linden. 2005. Highly efficient and versatile one-pot synthesis of new thiophenelyidene compounds. J. Sulfur Chem. 26:245-250. 
Published contributions to academic conferences

- Bagheri, M., S. Keller, and M. Dathe. 2010. Interactions of W-substituted cycloRRRWFW analogs with lipid membranes studied by isothermal titration calorimetry. Proceedings of the $12^{\text {th }}$ Iberian peptide meeting at Lisbon, University of Lisbon. February 2010, pp. 50-50 (in Portugal).

- Bagheri, M., M. Beyermann, and M. Dathe. 2008. Surface-bound cationic antimicrobial peptides: the effect of immobilization upon the activity spectrum and the mode of action. Proceedings of the $30^{\text {th }}$ European Peptide Symposium (Peptides 2008) at Helsinki, ONGREX / Blue \& White Conferences Oy. September 2008, pp. 208-209 (in Finland).

\subsubsection{Scientific conference contributions}

- "The role of tryptophan in activity and E. coli selectivity of cyclic hexapeptides" Poster at the $455^{\text {th }}$ WE-Heraeus-Seminar on Biophysics of Membrane-Active Peptides. Physikzentrum Bad Honnef, Bad Honnef, Germany, April $11^{\text {th }}-$ April $14^{\text {th }}$, 2010.

- “Interactions of W-substituted cyclo-RRRWFW analogs with lipid membranes studied by isothermal titration calorimetry" Oral Presentation at $\mathbf{1 2}^{\text {th }}$ Iberian peptide meeting. The Faculty of Medicine, University of Lisbon, Lisbon, Portugal, $10^{\text {th }}-12^{\text {th }}$ February 2010.

- “Surface-bound cationic antimicrobial peptides: The effect of immobilization upon the activity spectrum and the mode of action" Oral Presentation at $30^{\text {th }}$ European Peptide Symposium (30EPS)-Young Investigators Mini Symposium. ONGREX/Blue \& White Conferences Oy, Helsinki, Finland, August $31^{\text {st }}$-September $5^{\text {th }}, 2008$.

- "Polymer-bound Magainin-derived MK5E and KLAL; The effect of spacer length on the antimicrobial activities” Poster at the $6^{\text {th }}$ Gordon Research Conferences (GRC) on Antimicrobial Peptides. Il Ciocco, Lucca (Barga), Italy, April $29^{\text {th }}-$ May $4^{\text {th }}, 2007$. 